ORNL-4870

UC-25 - Materials

for Period Ending June 30, 1973

J. H Frye, Jr., Director *

J. E. Cunningham, Associate Director

Section Heads

G. M. Adamson, Jr.

C. J. McHargue

P. Patriarca

J. R. Weir, Jr. ${ }^{\dagger}$

Compiled and Edited by Sigfred Peterson

-Retired June 30, 1973, present address, University of Alabama.

$\dagger_{\text {Now Division Director. }}$

\title{
OCTOBER 1973
}

NOTICE

This report was prepared as an account of work sponsored by the United States Government. Neither the United States nor the United States Atomic Energy Commission, nor any of their employees, nor any of their contractors, subcontractors, or their employees, makes any warrenty, express or implied, or essumes any legal tiability or responsibility for the accuracy, completenoss or usefulnés of any information, apparatua, preteness or process disclosed, or represents that its use product or process disciosed, or represents
would not infringe privately owned rights.
-

$\div$

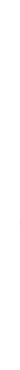
OAK RIDGE NATIONAL LABORATORY
Oak Ridge, Tennessee 37830
operated by
UNION CARBIDE CORPORATION
for the
U.S. ATOMIC ENERGY COMMISSION


Reports previously issued in this series are as follows:

ORNL-28

ORNL-69

ORNL-407

ORNL-511

ORNL-583

ORNL-754

ORNL-827

ORNL-910

ORNL-987

ORNL-1033

ORNL-1108

ORNL-1161

ORNL-1267

ORNL-1302

ORNL-1366

ORNL-1437

ORNL-1503

ORNL-1551

ORNL-1625

ORNL-1727

ORNL-1875

ORNL-1911

ORNL-1988

ORNL-2080

ORNL-2217

ORNL-2422

ORNL-2632

ORNL-2839

ORNL-2988

ORNL-3160

ORNL-3313

ORNL-3470

ORNL-3670

ORNL-3870

ORNL-3970

ORNL-4170

ORNL-4370

ORNL-4470

ORNL-4570

ORNL-4770

ORNL-4820
Period Ending March 1, 1948

Period Ending May 31, 1948

Period Ending July 31, 1949

Period Ending October 31, 1949

Period Ending January 31, 1950

Period Ending April 30, 1950

Period Ending July 31, 1950

Period Ending October 31, 1950

Period Ending January 31, 1951

Period Ending April 30, 1951

Period Ending July 31, 1951

Period Ending October 31, 1951

Period Ending January 31, 1952

Period Ending April 30, 1952

Period Ending July 31, 1952

Period Ending October 31, 1952

Period Ending January 31, 1953

Period Ending April 10, 1953

Period Ending October 10, 1953

Period Ending April 10, 1954

Period Ending October 10, 1954

Period Ending April 10, 1955

Period Ending October 10, 1955

Period Ending April 10, 1956

Period Ending October 10, 1956

Period Ending October 10, 1957

Period Ending October 10, 1958

Period Ending September 1, 1959

Period Ending July 1, 1960

Period Ending May 31, 1961

Period Ending May 31, 1962

Period Ending May 31, 1963

Period Ending June 30, 1964

Period Ending June 30, 1965

Period Ending June 30, 1966

Period Ending June 30, 1967

Period Ending June 30, 1968

Period Ending June 30, 1969

Period Ending June 30, 1970

Period Ending June 30, 1971

Period Ending June 30, 1972 


\section{Contents}

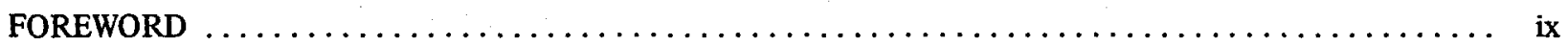

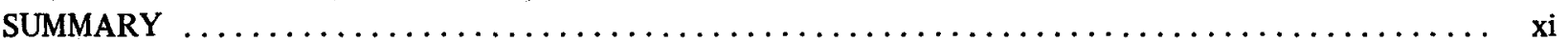

PART I. FUNDAMENTAL PROGRAMS

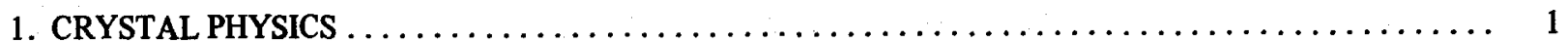

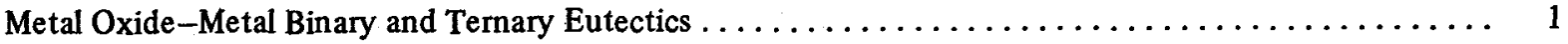

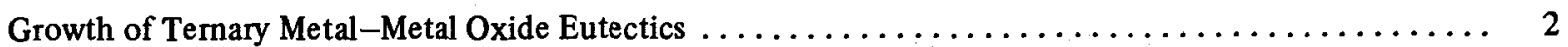

Eutectic Solidification in Binary and Ternary Metal-Metal Oxide Systems $\ldots \ldots \ldots \ldots \ldots \ldots \ldots \ldots$

Crystal Growth of Oxides by Czochralski and Edge-Defined Film-Fed Methods $\ldots \ldots \ldots \ldots \ldots \ldots \ldots$ 2

Bridgman Stockbarger Growth of Single-Crystal $\mathrm{BaF}_{2}$ and $\mathrm{BaF}_{2}$ Doped with 1 at. $\% \mathrm{La} \ldots \ldots \ldots \ldots \ldots 2$

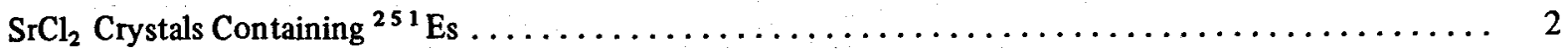

Electron Paramagnetic Resonance of ${ }^{249} \mathrm{Bk}^{4+}$ in $\mathrm{ThO}_{2}$ Single Crystals .................... 3

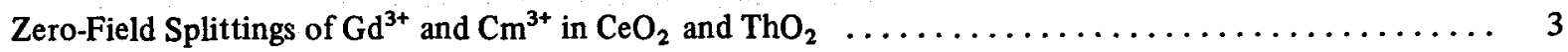

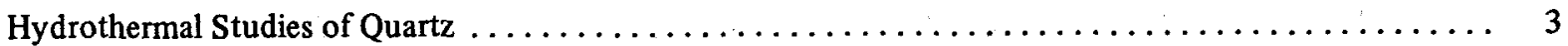

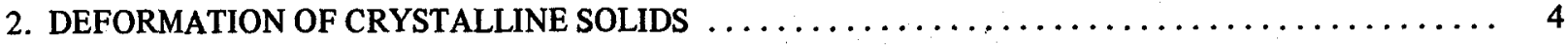

The Nature of the Limitations of Second-Law Determinations of Solution Thermodynamics ........ 4

A Computer Program for the Reduction of Diffuse X-Ray Data from Solid Solutions $\ldots \ldots \ldots \ldots \ldots \ldots 4$

Fracture Mechanism in Precipitation-Hardened BCC Alloys $\ldots \ldots \ldots \ldots \ldots \ldots \ldots \ldots \ldots \ldots \ldots, 4$

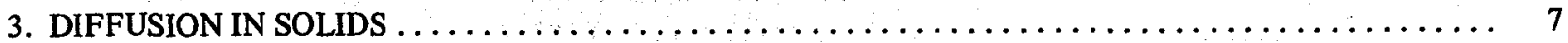

Relevance of Tracer Diffusion Experiments to Problems in Nuclear Systems $\ldots \ldots \ldots \ldots \ldots \ldots \ldots \ldots$. 7

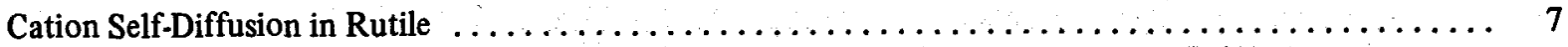

Effect of Dislocations on Self-Diffusion of Uranium in $\mathrm{UO}_{2}$ Single Crystals $\ldots \ldots \ldots \ldots \ldots \ldots \ldots \ldots .7$

Diffusion Under High Pressures $\ldots \ldots \ldots \ldots \ldots \ldots \ldots \ldots \ldots \ldots \ldots \ldots \ldots \ldots \ldots \ldots \ldots \ldots \ldots$

Tracer Self-Diffusion in $\mathrm{Fe}-17 \mathrm{wt} \% \mathrm{Cr}-12 \mathrm{wt} \% \mathrm{Ni}$ Austenitic Alloy $\ldots \ldots \ldots \ldots \ldots \ldots \ldots \ldots \ldots \quad 8$

The Volume Diffusion of Carbon in $\mathrm{Fe}-17 \mathrm{wt} \% \mathrm{Cr}-12 \mathrm{wt} \%$ Ni Austenitic Alloy $\ldots \ldots \ldots \ldots \ldots \ldots .8$

Thermotransport of Cadmium and Thallium in Sodium and Potassium Chlorides . . . . . . . . . . . 9

Binary Intrinsic Diffusion and Interdiffusion in Vanadium-Titanium Solid Solutions $\ldots \ldots \ldots \ldots \ldots .9$

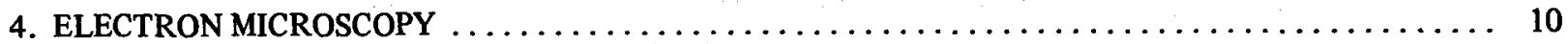

Radiation-Induced Strengthening and Embrittlement in Aluminum $\ldots \ldots \ldots \ldots \ldots \ldots \ldots \ldots \ldots$ 
Reply to "Comments on 'On the Question of Void Formation in Neutron Irradiated Zirconium' " . . . . 10

Effect of Silicon on Void Formation in Aluminum $\ldots \ldots \ldots \ldots \ldots \ldots \ldots \ldots \ldots \ldots \ldots \ldots \ldots \ldots$

Effects of Solute Interstitial Elements on Swelling of Stainless Steel $\ldots \ldots \ldots \ldots \ldots \ldots \ldots \ldots \ldots \ldots 11$

A High-Voltage Electron Microscope Study of the Effects of Preinjected Helium on

Electron Damage in Aluminum $\ldots \ldots \ldots \ldots \ldots \ldots \ldots \ldots \ldots \ldots \ldots \ldots \ldots \ldots, 11$

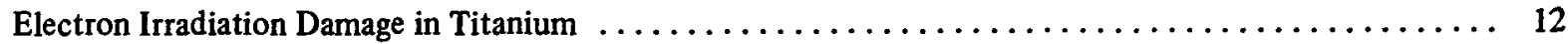

Effect of Purity on Loop Formation in Aluminum and Nickel $\ldots \ldots \ldots \ldots \ldots \ldots \ldots \ldots \ldots \ldots \ldots \ldots$

Defect Structure of Neutron-Irradiated Boron Carbide $\ldots \ldots \ldots \ldots \ldots \ldots \ldots \ldots \ldots \ldots \ldots \ldots \ldots \ldots \ldots \ldots$

Nucleation of Voids in Solids Containing Excess Vacancies, Interstitials, and Helium Atoms . . . . . . 12

Reply to Comment on Some Calculations of Vacancy Characteristics in Substitutional Alloys ........ 13

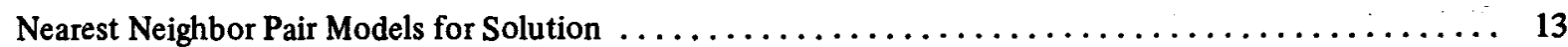

Reply to Comments on "The Energy Stored in Polycrystalline Copper Deformed at Room

Temperature" - More Details of the Single-Step Isoperibol Deformation Calorimeter . . . . . . . . 13

The Efficiency of Energy Storage During Plastic Deformation of Metals $\ldots \ldots \ldots \ldots \ldots \ldots \ldots \ldots \ldots$

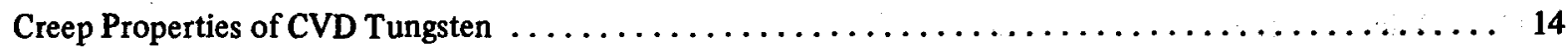

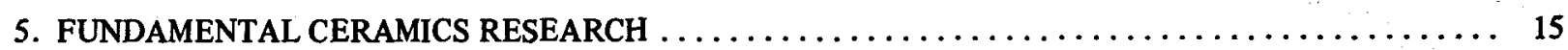

Observation of Lattice and Grain Boundary Dislocations in $\mathrm{UO}_{2}$ Deformed at High Temperatures $\ldots \ldots \ldots 15$

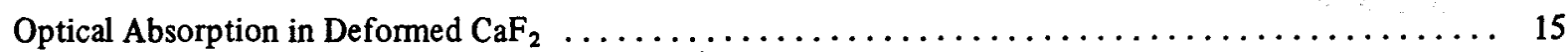

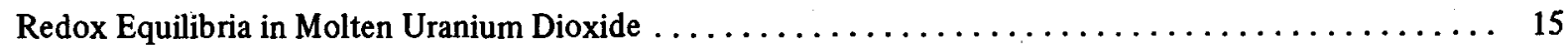

Synthesis, Structure, and Properties of Titanium(II) Tetrachloroaluminate $\ldots \ldots \ldots \ldots \ldots \ldots \ldots \ldots$

Electronic Absorption Spectra of Platinum(II) Centers in Liquid Alkali Metal Chlorides $\ldots \ldots \ldots \ldots \ldots 16$

6. FUNDAMENTAL PHYSICAL METALLURGY $\ldots \ldots \ldots \ldots \ldots \ldots \ldots \ldots \ldots \ldots \ldots \ldots \ldots \ldots$

Phase Transformations in U-Nb-Zr and U-Ti Alloys $\ldots \ldots \ldots \ldots \ldots \ldots \ldots \ldots \ldots \ldots \ldots \ldots \ldots \ldots$

Texture Inhomogeneities in Cold-Rolled Niobium $\ldots \ldots \ldots \ldots \ldots \ldots \ldots \ldots \ldots \ldots \ldots \ldots \ldots \ldots$

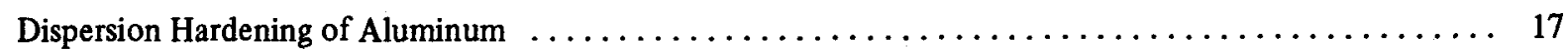

Structural Effects on Radiation Damage $\ldots \ldots \ldots \ldots \ldots \ldots \ldots \ldots \ldots \ldots \ldots \ldots \ldots \ldots \ldots \ldots \ldots \ldots$

7. PHYSICAL PROPERTY RESEARCH $\ldots \ldots \ldots \ldots \ldots \ldots \ldots \ldots \ldots \ldots \ldots \ldots \ldots \ldots \ldots$

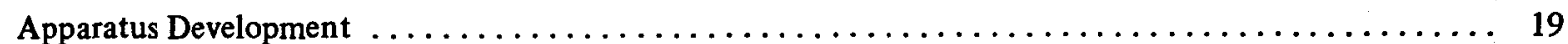

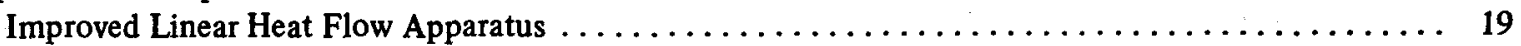

Electrical Resistivity Measurements . . . . . . . . . . . . . . . . . . . . . . . . . . 19

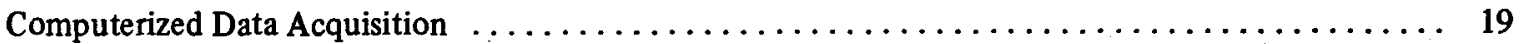

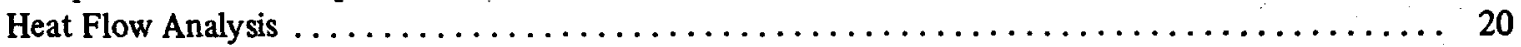

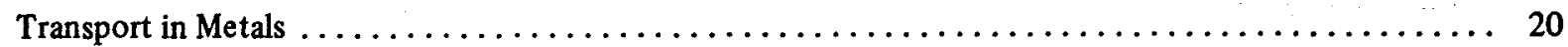

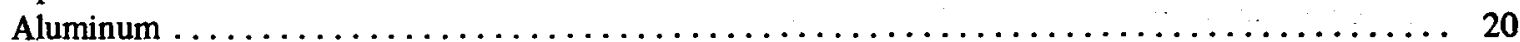

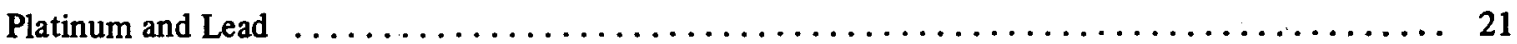

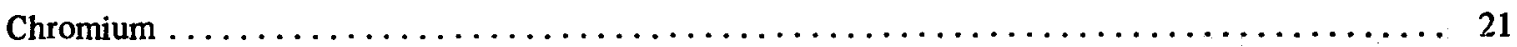

Lattice Heat Transport in Alkali Halides $\ldots \ldots \ldots \ldots \ldots \ldots \ldots \ldots \ldots \ldots \ldots \ldots \ldots \ldots \ldots \ldots \ldots \ldots \ldots \ldots$

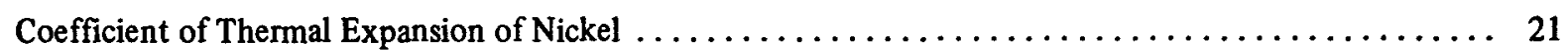

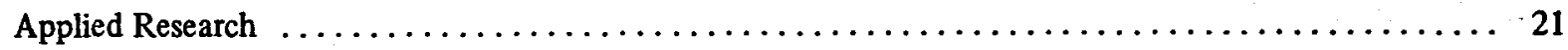

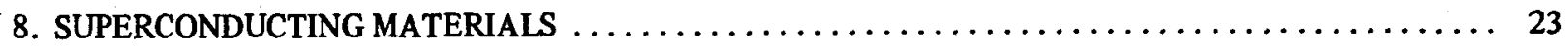

Measurement of Critical Bulk and Surface Current Densities in Type II Superconductors

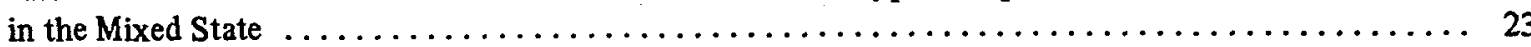


Effects of Interstitial Oxygen on the Superconductivity of Niobium $\ldots \ldots \ldots \ldots \ldots \ldots \ldots \ldots \ldots \ldots$

Annealing, Long-Range Order, and Superconducting Transition Temperature in

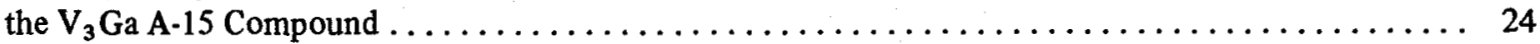

A Low-Temperature X-Ray Investigation of Technetium and the Tc-Mo A-15 Compound . ......... 24

Critical Current Densities in Sputter-Deposited Nb-Al-Ge $\ldots \ldots \ldots \ldots \ldots \ldots \ldots \ldots \ldots \ldots \ldots .24$

Thermodynamic Properties of Zirconium-Cadmium and Certain Other Solid Solutions .......... 24

Superconducting Materials Technology for Power Transmission $\ldots \ldots \ldots \ldots \ldots \ldots \ldots \ldots \ldots \ldots \ldots$

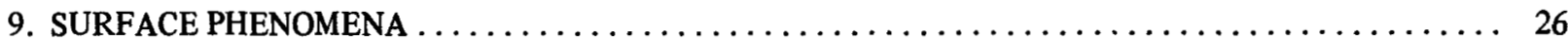

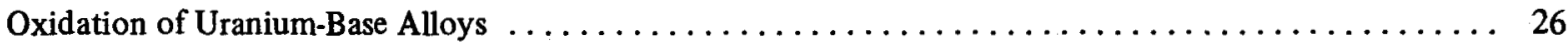

The Mechanical Properties of Two Uranium Alloys and Their Role in the

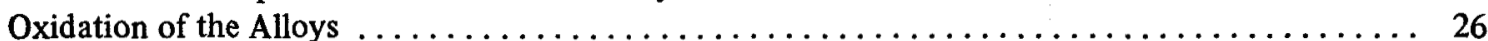

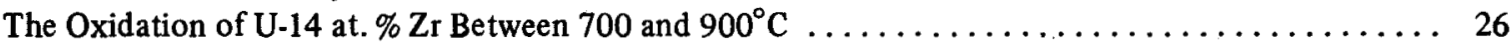

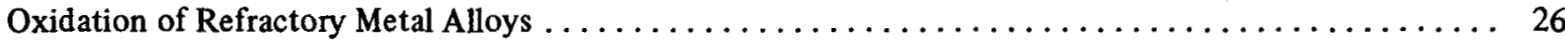

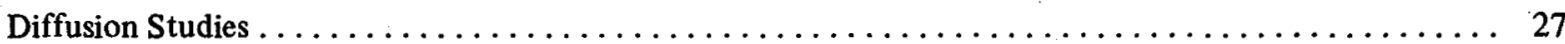

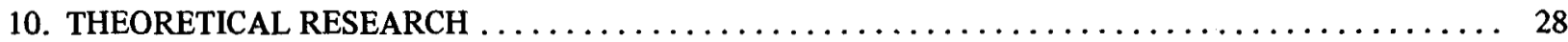

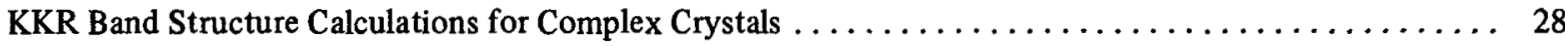

Density of States Expressed as Continued Fraction of Matrices;

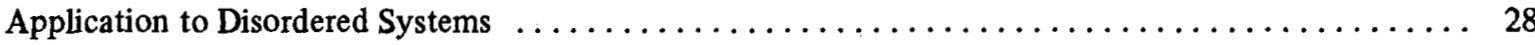

Self-Consistent Cluster Theories of Disordered Alloys $\ldots \ldots \ldots \ldots \ldots \ldots \ldots \ldots \ldots \ldots \ldots \ldots \ldots \ldots \ldots \ldots \ldots$

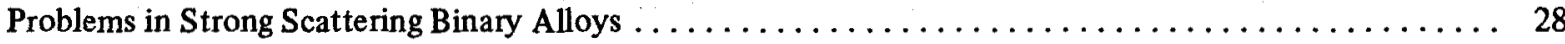

Charged Impurity Drift and Dispersion in Discrete Media ........................ 29

Auger Catalog Calculated Transition Energies Listed by Energy and Element $\ldots \ldots \ldots \ldots \ldots \ldots \ldots \ldots$

Diffusion of Vacancies Near Faulted Dislocation Loops in Aluminum $\ldots \ldots \ldots \ldots \ldots \ldots \ldots \ldots \ldots$

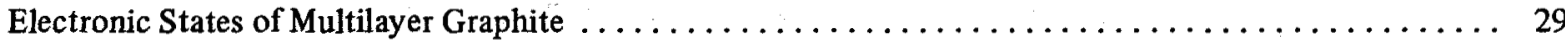

Observation of High-Energy Excited States in Graphite $\ldots \ldots \ldots \ldots \ldots \ldots \ldots \ldots \ldots \ldots \ldots \ldots$

A Combined Korringa-Kohn-Rostoker-Discrete Variational Method for the

Electronic Structure of Crystals and Molecules with General Potentials .................. 30

A Combined Multiple-Scattering-Discrete-Variational Method for the Molecular Cluster Problem . . .... 30

Effects of Thermoelastic Properties on Void Formation in Hexagonal Metals . . . . . . . . . . . . . 30

Equilibrium Shape of a Prismatic Dislocation Loop $\ldots \ldots \ldots \ldots \ldots \ldots \ldots \ldots \ldots \ldots \ldots \ldots \ldots$

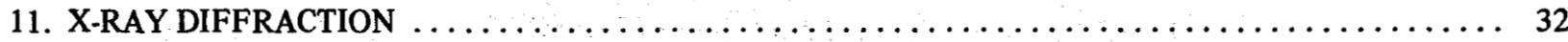

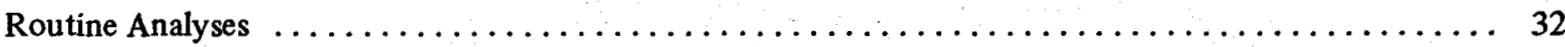

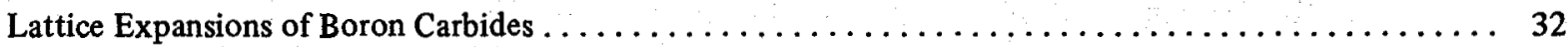

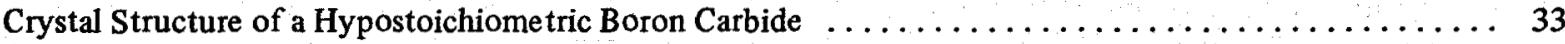

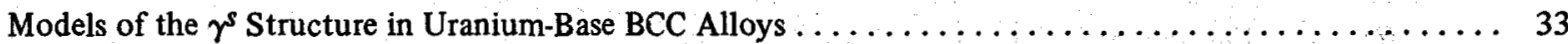

The Short-Range Structure of Titanium and Zirconium BCC Solid Solutions $\ldots \ldots \ldots \ldots \ldots \ldots \ldots \ldots$

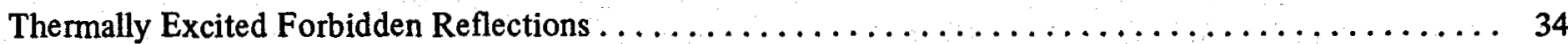

Structural and Dynamical Properties of Neutron-Irradiated Quartz and Noncrystalline $\mathrm{SiO}_{2} \ldots \ldots \ldots .34$

Optimization of the Kratky Small-Angle X-Ray Scattering Collimation System Parameters . . . . . . . 35

Inelastic Resonance Emission of X Rays: Anomalous Scattering Associated with

Anomalous Dispersion $\ldots \ldots \ldots \ldots \ldots \ldots \ldots \ldots \ldots \ldots \ldots \ldots \ldots \ldots \ldots \ldots \ldots \ldots \ldots \ldots \ldots \ldots, 35$ 
Strengthening and Fracture of Ta, Nb, Mo, and W Binary Solid Solutions with Short-Range Order . . ... 35

Development of High-Sensitivity X-Ray Fluorescence for Analysis of Trace Elements $\ldots \ldots \ldots \ldots \ldots .36$

Short-Range Order with Large Atomic Displacements in Niobium-Vanadium Alloys $\ldots \ldots \ldots \ldots \ldots \ldots 36$

PART II. SPACE POWER TECHNOLOGY

12. HIGH-TEMPERATURE ALLOYS FOR ISOTOPIC HEAT SOURCES $\ldots \ldots \ldots \ldots \ldots \ldots \ldots \ldots \ldots$

Development of Iridium-Base Alloys $\ldots \ldots \ldots \ldots \ldots \ldots \ldots \ldots \ldots \ldots \ldots \ldots \ldots \ldots \ldots \ldots \ldots \ldots \ldots \ldots \ldots \ldots$

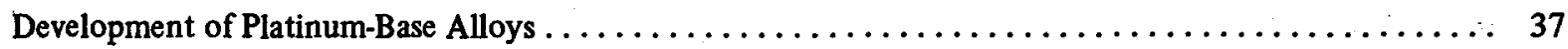

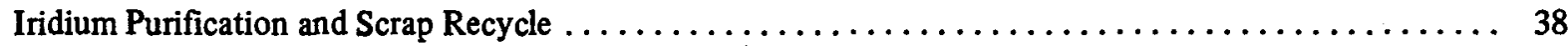

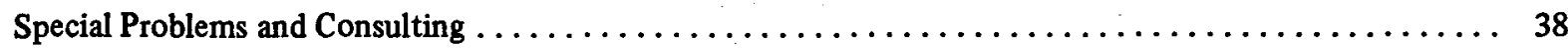

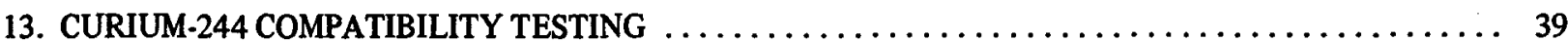

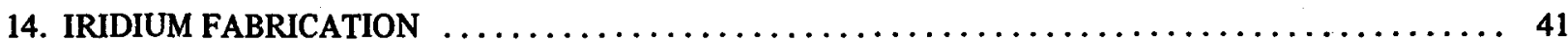

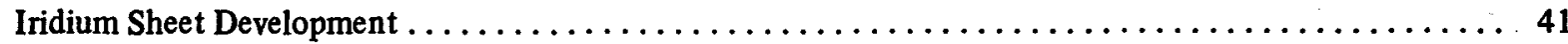

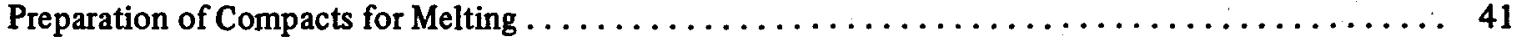

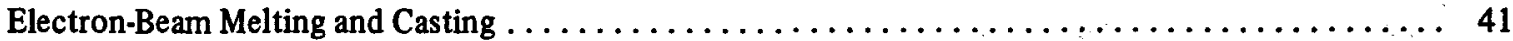

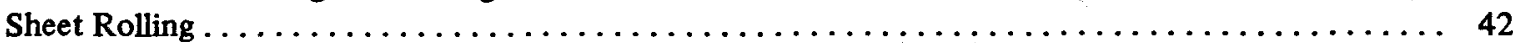

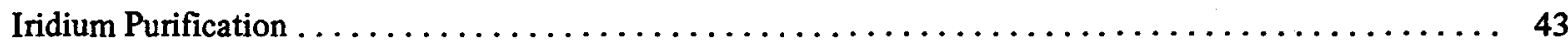

15. PHYSICAL METALLURGY OF HEAT SOURCE CONTAINMENT MATERIALS $\ldots \ldots \ldots \ldots \ldots \ldots .45$

Structure and Mechanical Properties of Internally Oxidized Ta-8\% W-2\% Hf (T-111) Alloy ........ 45

Low-Pressure Oxidation and Tensile Properties of Oxygen-Contaminated T-11 $\ldots \ldots \ldots \ldots \ldots \ldots 45$

Mechanical Properties and Interstitial Contamination in a Molybdenum-Base Alloy, TZM . ........ 46

Effects of Exposure to Oxygen and Graphite on the Physical and Mechanical Properties

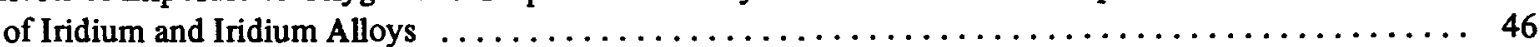

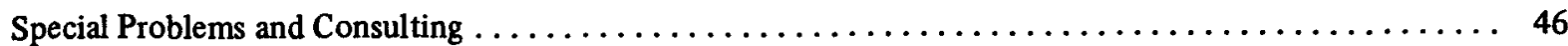

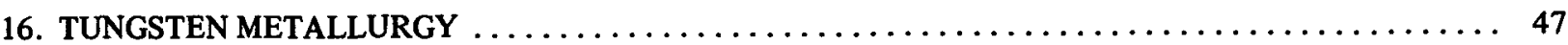

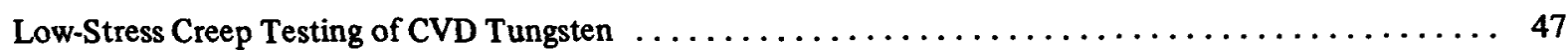

Effect of Carburization on the Creep Properties of Tungsten $\ldots \ldots \ldots \ldots \ldots \ldots \ldots \ldots \ldots \ldots \ldots 47$

Effect of Fast-Neutron Irradiation on the Properties of Tungsten Alloys $\ldots \ldots \ldots \ldots \ldots \ldots \ldots \ldots .47$

PART III. REACTOR DEVELOPMENT SUPPORT

17. GAS-COOLED REACTOR PROGRAM $\ldots \ldots \ldots \ldots \ldots \ldots \ldots \ldots \ldots \ldots \ldots \ldots \ldots \ldots \ldots \ldots$

Coated Particles from Ion Exchange Resins $\ldots \ldots \ldots \ldots \ldots \ldots \ldots \ldots \ldots \ldots \ldots \ldots \ldots \ldots \ldots, 49$

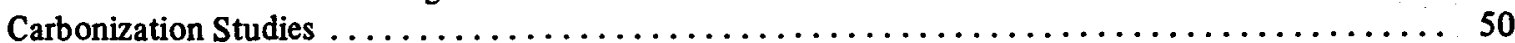

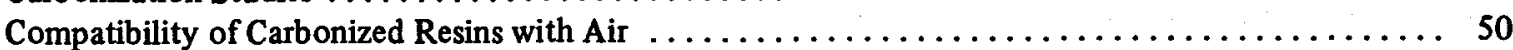

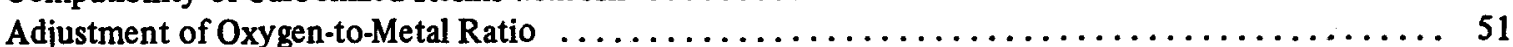

Fuel Element Fabrication Studies for HTGR Fuels $\ldots \ldots \ldots \ldots \ldots \ldots \ldots \ldots \ldots \ldots \ldots \ldots \ldots, 51$

Thermal Conductivity of Bonded HTGR Fuel Materials $\ldots \ldots \ldots \ldots \ldots \ldots \ldots \ldots \ldots \ldots \ldots \ldots \ldots \ldots \ldots$

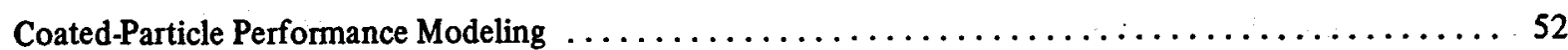

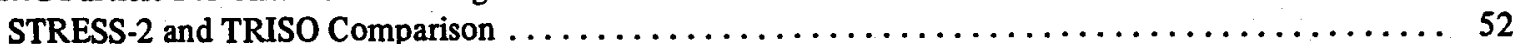

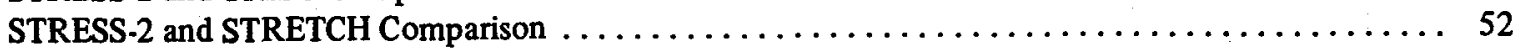


Irradiation Testing of HTGR Fuels and Fuel Elements $\ldots \ldots \ldots \ldots \ldots \ldots \ldots \ldots \ldots \ldots \ldots \ldots \ldots$

Performance of BISO-Coated $\mathrm{ThO}_{2}$ Particles in HFIR Experiments $\ldots \ldots \ldots \ldots \ldots \ldots \ldots \ldots \ldots$

Effects of Neutron Irradiation on Loose and Bonded Inert

Particles Coated with Pyrolytic Carbon and Silicon Carbide ................... 55

The HT-8 Capsule Irradiation Test of Resin-Derived HTGR Fuels

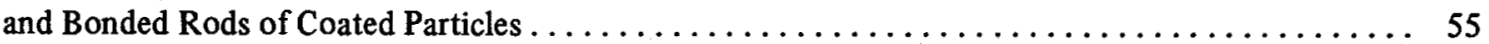

Irradiation Performance of HTGR Fuel Rod Specimens Bonded

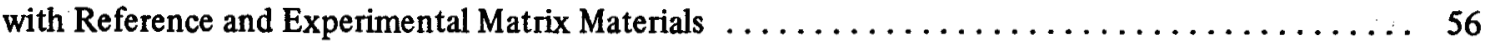

Gas-Cooled Fast Breeder Reactor Fuel Element Development $\ldots \ldots \ldots \ldots \ldots \ldots \ldots \ldots \ldots \ldots 7$

18. HEAVY SECTION STEEL TECHNOLOGY $\ldots \ldots \ldots \ldots \ldots \ldots \ldots \ldots \ldots \ldots \ldots \ldots \ldots \ldots$

Characterization of HSST Intermediate Test Vessels $\ldots \ldots \ldots \ldots \ldots \ldots \ldots \ldots \ldots \ldots \ldots \ldots \ldots \ldots$

Radiation Strengthening and Embrittlement in Heavy Section Steel Plates and Welds $\ldots \ldots \ldots \ldots \ldots 60$

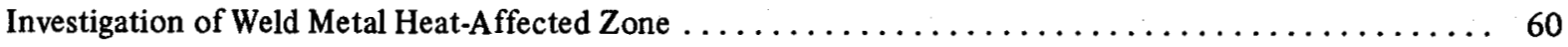

Fractography Study of Failure in Intermediate Test Vessel $V \cdot 1 \ldots \ldots \ldots \ldots \ldots \ldots \ldots \ldots \ldots \ldots$

19. MILITARY REACTOR FUEL ELEMENT PROCUREMENT ASSISTANCE $\ldots \ldots \ldots \ldots \ldots \ldots \ldots \ldots$

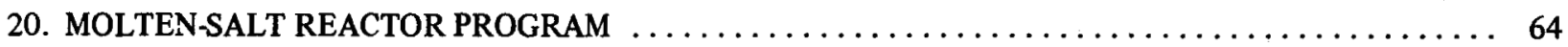

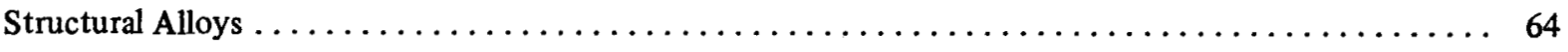

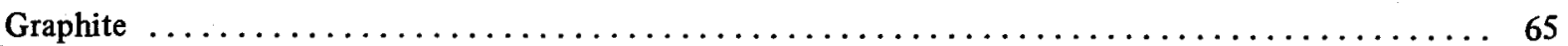

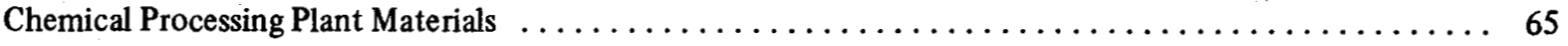

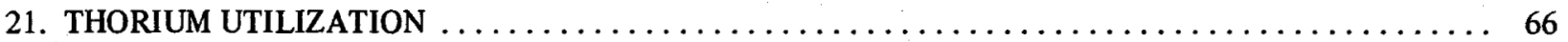

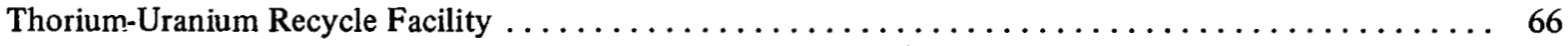

Feasibility Study for Increasing Capacity in the Refabrication Pilot Plant $\ldots \ldots \ldots \ldots \ldots \ldots \ldots .66$

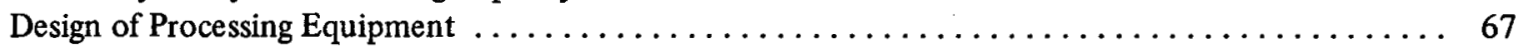

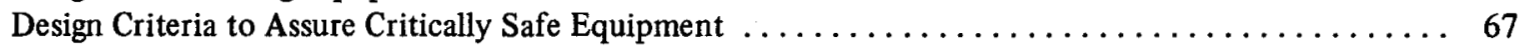

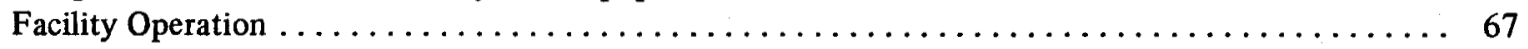

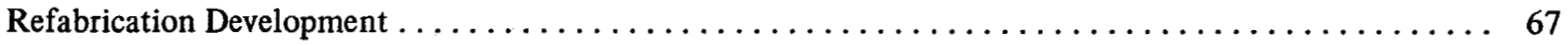

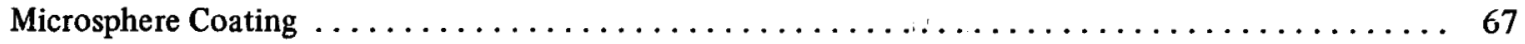

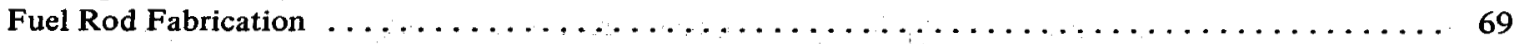

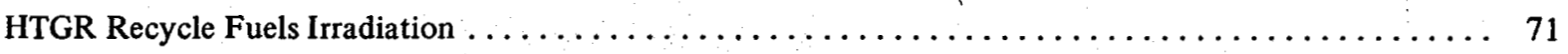

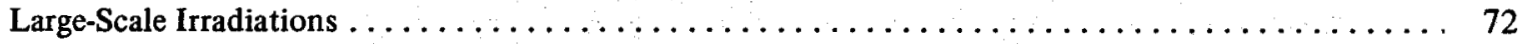

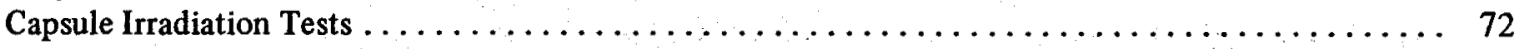

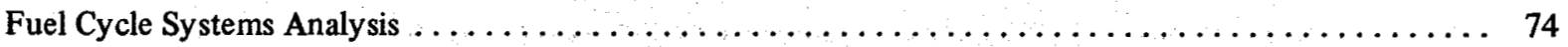

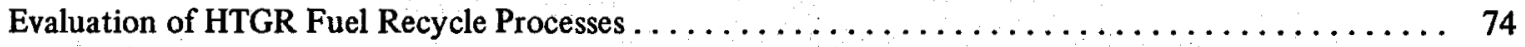

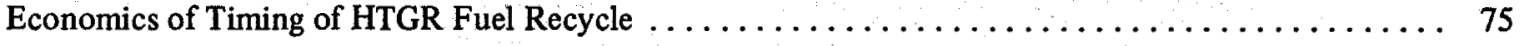

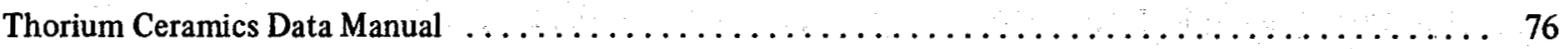

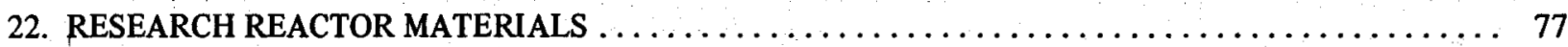

Postirradiation Examination and Testing of the $\mathrm{ORR}_{\mathrm{F}}$ Tray $\ldots \ldots \ldots \ldots \ldots \ldots \ldots \ldots \ldots \ldots \ldots \ldots$

Bowing of an Oak Ridge Research Reactor Component $\ldots \ldots \ldots \ldots \ldots \ldots \ldots \ldots \ldots \ldots \ldots \ldots \ldots 77$

Examination of the Irradiated 6061 Aluminum HFIR Target Holder $\ldots \ldots \ldots \ldots \ldots \ldots \ldots \ldots \ldots \ldots, 78$

Assembly of Experiments for the Aluminum Surveillance Program $\ldots \ldots \ldots \ldots \ldots \ldots \ldots \ldots \ldots \ldots$

Creep Properties of Irradiated Aluminum Alloys from the HFIR Surveillance Program $\ldots \ldots \ldots \ldots \ldots 78$

Swelling and Mechanical Properties of Aluminum Alloys Irradiated to High Fluences $\ldots \ldots \ldots \ldots \ldots$ 
HFIR Fuel Element Production Assistance $\ldots \ldots \ldots \ldots \ldots \ldots \ldots \ldots \ldots \ldots \ldots \ldots \ldots \ldots \ldots \ldots$

Postirradiation Examination of HFIR Fuel Elements 100-I and $100-0 \ldots \ldots \ldots \ldots \ldots \ldots \ldots \ldots \ldots .80$

PART IV. THERMONUCLEAR AND TRANSURANIUM RESEARCH

23. CONTROLLED THERMONUCLEAR RESEARCH $\ldots \ldots \ldots \ldots \ldots \ldots \ldots \ldots \ldots \ldots \ldots \ldots \ldots . .81$

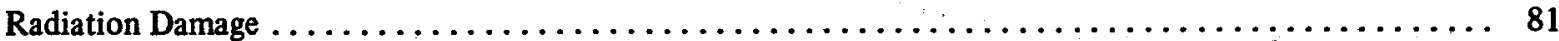

Neutron Irradiation of Body-Centered Cubic Materials $\ldots \ldots \ldots \ldots \ldots \ldots \ldots \ldots \ldots \ldots \ldots \ldots$

The Tensile Properties of Fast-Reactor Neutron-Irradiated BCC Metals and Alloys .......... 81

The Effect of Injected Helium on the Creep Properties of $\mathrm{Nb}-1 \% \mathrm{Zr} \ldots \ldots \ldots \ldots \ldots \ldots \ldots, 81$

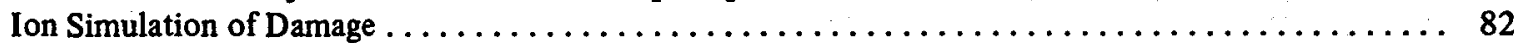

Irradiation-Induced Swelling in Aluminum, Nickel, and Vanadium $\ldots \ldots \ldots \ldots \ldots \ldots \ldots, 82$

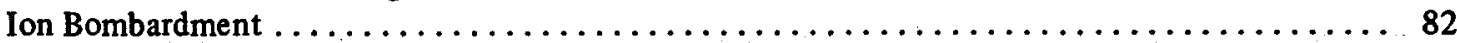

Chemical Compatibility of Potential Blanket and First Wall Materials . . . . . . . . . . . . . . 83

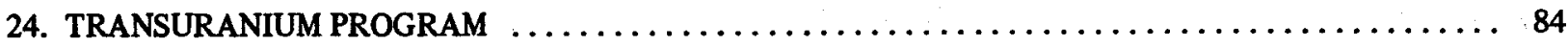

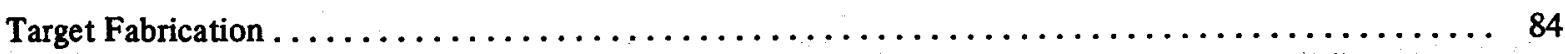

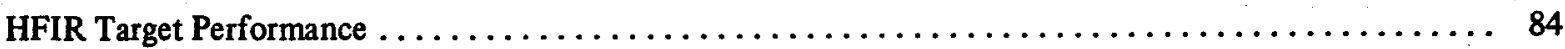

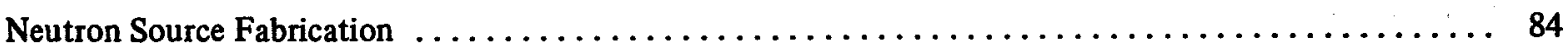

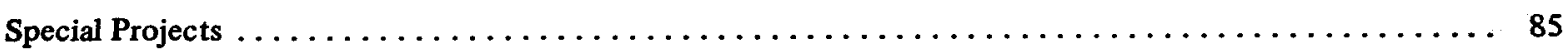

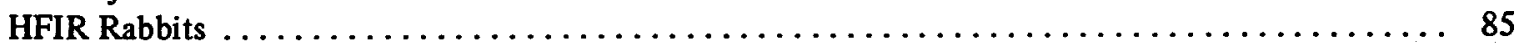

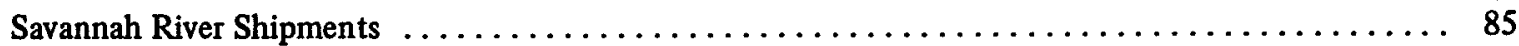

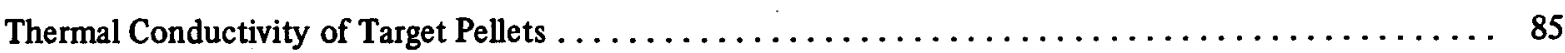

Thermal Conductivity and DC Electrical Resistivity Measurements .................. 85

Nondestructive Testing for Thermal Conductivity $\ldots \ldots \ldots \ldots \ldots \ldots \ldots \ldots \ldots \ldots \ldots \ldots \ldots$

\section{PART V. OTHER PROGRAM ACTIVITIES}

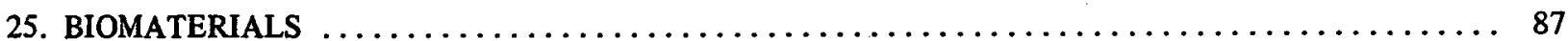

Examination of Failed Prostheses from the Human Body $\ldots \ldots \ldots \ldots \ldots \ldots \ldots \ldots \ldots \ldots \ldots .87$

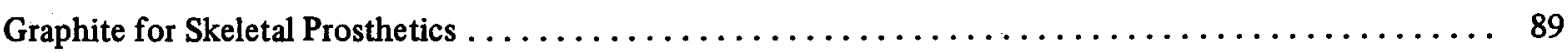

26. GRAPHITE FABRICATION STUDIES FOR NAVAL ORDNANCE LABORATORY $\ldots \ldots \ldots \ldots \ldots 91$

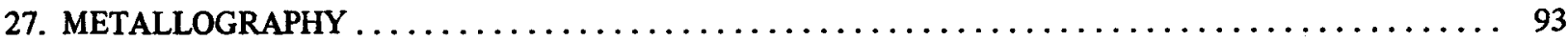

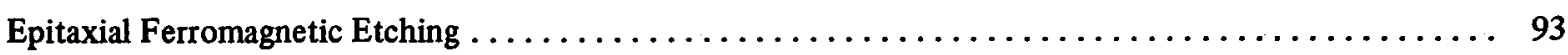

Correlation of Metallography and Radiography to Show Defects in Weld Structures $\ldots \ldots \ldots \ldots \ldots .95$

Examination of Tungsten-Rhenium Thermocouple Wires $\ldots \ldots \ldots \ldots \ldots \ldots \ldots \ldots \ldots \ldots \ldots$

28. AUGER ELECTRON SPECTROSCOPY $\ldots \ldots \ldots \ldots \ldots \ldots \ldots \ldots \ldots \ldots \ldots \ldots \ldots \ldots \ldots \ldots \ldots$

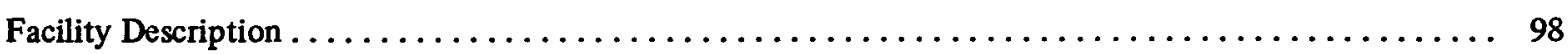

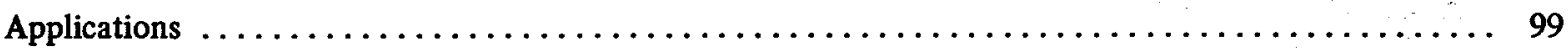

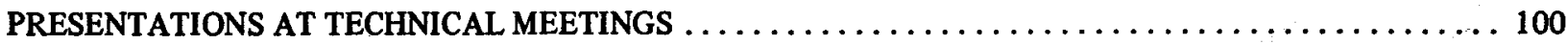
81

1

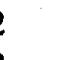

\section{3} a 4 4

.

85

5

85

86




\section{Foreword}

After serving as the Director of the Metals and Ceramics Division for the past 25 years, John H Frye, Jr., retired on July 1, 1973. He intends to remain active by part-time teaching at the University of Alabama this fall. His new address is: Department of Chemical and Metallurgical Engineering, College of Engineering, University of Alabama, P.O. Box 1968, University, Alabama 35486.

We are pleased to announce the appointment of James $R$. Weir, Jr., as the Division Director. Jim has been an active member of the Division staff for the past 18 years and was a recipient of the USAEC Ernest Orlando Lawrence Award in 1973. The award was given in recognition of his important contributions in the field of structural materials for reactor construction, particularly in advancing our understanding of mechanical behavior, irradiation embrittlement, and swelling observed in these engineering materials.

During the first half of this reporting period a new TID-4500 category, UC-79, Liquid Metal Fast Breeder Reactors, was established by AEC for the dissemination of formal reports issued by LMFBR Program participants. For this reason the research under this program is not included here, but is reported in the Fuels and Materials Program quarterly progress reports. 


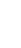

4

- 


\section{Summary}

\section{PART I. FUNDAMENTAL PROGRAMS}

\section{Crystal Physics}

A search for metal oxide-metal coupled eutectic systems led to the discovery of seven binaries and six ternaries. For the ternary $\mathrm{Cr}_{2} \mathrm{O}_{3} \cdot \mathrm{ZrO}_{2}-\mathrm{W}$ system, the continuous phase is $\mathrm{Cr}_{2} \mathrm{O}_{3}$, with $\mathrm{ZrO}_{2}$ and $\mathrm{W}$ appearing predominantly as rods. Tungsten fibers as small as 0.2 $\mu \mathrm{m}$ in diameter at a density of about $10^{8}$ fibers $/ \mathrm{cm}^{2}$ were produced. We assembled an apparatus capable of growing crystals by the standard Czochralski technique and by a new method called edge-defined film-fed growth. Single-crystal boules of ackermanite were pulled (Czochralski) up to $0.8 \mathrm{~cm}$ in diameter by $3 \mathrm{~cm}$ long and are here reported for the first time. Crystals of $\mathrm{BaF}_{2}$ undoped and doped with 1 at. \% $\mathrm{La}$ were grown by the Bridgman-Stockbarger method. Single crystals of $\mathrm{SrCl}_{2} 4 \mathrm{~mm}$ on a side were grown doped with ${ }^{251}$ Es in a Bridgman system. Quartz crystals were grown large enough to cut $1-\mathrm{cm}^{2}$ wafers for direct measurements of electronic oscillator quality and the temperature dependence of the oscillator frequency.

\section{Deformation of Crystalline Solids}

We are currently investigating the nature of solid solutions as derived from diffuse $x$-ray scattering and the structures and properties that result from the precipitation within such solutions. The thermodynamics of liquid and solid metallic solutions is also of concern.

\section{Diffusion in Solids}

Cation self-diffusion measurements in rutile $\left(\mathrm{TiO}_{2}\right)$ disclosed that at least two kinds of atomic jumps must occur. The influence of dislocations on uranium diffusion in $\mathrm{UO}_{2}$ is being determined experimentally. $\mathrm{A}$ comprehensive examination of tracer diffusion $\left({ }^{59} \mathrm{Fe}\right.$, ${ }^{51} \mathrm{Cr},{ }^{63} \mathrm{Ni},{ }^{14} \mathrm{C}$ ) in $\mathrm{Fe}-17 \% \mathrm{Cr}-12 \% \mathrm{Ni}$ has been completed. Investigations of the thermotransport of cadmium and thallium in $\mathrm{NaCl}$ and $\mathrm{KCl}$, respectively, have yielded heats of transport for both systems. Binary chemical diffusion studies for the vanadium-titanium system have begun.

\section{Electron Microscopy}

A major part of our effort is devoted to a study of the microstructure and mechanical properties of irradiated materials. Characteristics of the damage structure introduced into several metals and alloys by elevatedtemperature neutron irradiation are described and in several cases related to mechanical properties. In such dissimilar materials as commercially pure aluminum and the precipitation-hardened 6061 aluminum alloy, irradiation hardening results from precipitates containing transmutation-produced silicon and from the associated dislocation structure; voids play only a minor role. In stainless steel solute interstitial elements rather than the major alloying additions are responsible for the swelling resistance, but these are shown to precipitate from solution during irradiation. Irradiations in the highvoltage electron microscope, where details of the microstructure can be observed continuously, confirm the strong dependence of the damage structure on small quantities of impurities. The microstructure of neutronirradiated boron carbide, which has a high cross section for the production of helium, contains disklike cavities, but unlike the voids found in irradiated metals these contain gas at pressure much greater than equilibrium. A formal treatment is given for the nucleation of voids in solids containing excess vacancies, interstitials, and helium atoms, and some characteristics of vacancies in substitutional alloys and of solid solutions are described.

Some details are given of calorimetry for measuring the storage of energy in metals during plastic deformation. The creep properties of chemically vapor deposited tungsten are analyzed and rationalized in terms of the fluorine content of the materials. 


\section{Fundamental Ceramics Research}

The substructures produced in the grains and grain boundaries of polycrystalline $\mathrm{UO}_{2}$ deformed to low strains have been observed by transmission electron microscopy. Anisotropic optical absorption bands were observed in calcium fluoride single crystals that had been deformed in compression along a $\langle 111\rangle$ axis. Studies of the redox equilibria of molten $\mathrm{UO}_{2 \pm x}$ were continued.

\section{Fundamental Physical Metallurgy}

Phase transformations in uranium alloys are being studied by means of dilatometry, $x$-ray diffraction, and optical microscopy. The cause of texture inhomogeneity in cold-rolled niobium is being sought. The relationship between the nature of the precipitated state and the alloy's electrical properties, strength, and radiation damage resistance is under investigation in aluminum alloys.

\section{Physical Property Research}

The accuracy of several physical property measurements was improved by equipment modifications and detailed heat flow analyses. The computerized data acquisition system was improved and interfaced with a thermal expansion apparatus and a thermal diffusivity apparatus. Data on aluminum shows the electronic thermal conductivity to have a shallow minimum and the energy of formation of vacancies to be $0.633 \mathrm{eV}$. Thermal conductivity measurements on polycrystalline $\mathrm{RbI}$ yielded corrections for infrared transmission in single crystals of $\mathrm{Rbl}, \mathrm{RbCl}$, and $\mathrm{RbBr}$.

\section{Superconducting Materials}

Our method of calculating critical current density from ac susceptibility measurements was improved by including the surface shielding term and developing a graphical procedure that also provides a check for consistency of the data with the model. The effect of interstitial oxygen on the superconductivity of niobium was studied with calorimetric, magnetic, and resistive measuring techniques. The influence of low-temperature annealing on the superconducting transition temperature and long-range chemical order was investigated in the $\mathrm{V}_{3} \mathrm{Ga} \mathrm{A}-15$ compound. The structural stability of technetium and the Tc-40 at. \% Mo A-15 compound was studied at temperatures from 4.2 to $298 \mathrm{~K}$ by $\mathrm{x}$-ray diffraction. Critical current densities were measured on sputter-deposited $\mathrm{Nb}_{3} \mathrm{Al}_{0.75} \mathrm{Ge}_{0.25}$ ribbons in magnetic fields up to $100 \mathrm{kOe}$. Thermodynamic properties of $\mathrm{Zr}$-rich $\mathrm{Zr}$-Cd alloys were determined. A study of the influence of material parameters on ac losses in superconductors for potential power transmission application was initiated.

\section{Surface Phenomena}

This research is aimed at understanding the influence of stress on the oxidation of metals and alloys. Our investigations include studies of uranium- and tantalumbase alloys. Work with the uranium alloys has emphasized the importance of the mechanical properties of the oxide scale and the substrate alloy in the oxidation process. Measurements of the creep rates of a pair of uranium alloys and of the stress levels existing in their oxide scales showed that the changes an alloying element produces in the mechanical properties of oxide scale or metal can play a critical role in altering the oxidation behavior of a metal.

Studies of the oxidation of several tantalum alloys were continued. We showed that the radical grain boundary embrittlement suffered by Ta-W alloys is related to grain size and is retarded by hafnium additions. We also participated in a multilaboratory investigation of the distribution of impurities in anodic oxide films on tantalum.

\section{Theoretical Research}

The anisotropic elasticity theory of dislocations was used to calculate the shape of large prismatic dislocation loops in various crystal structures. A study of point defect interactions with prismatic dislocation loops has not only explained the unusual shrinking of faulted vacancy loops in aluminum but also is useful for understanding the radiation-induced void growth in such metals. Possible effects of anisotropic thermal expansion coefficients and elastic constants on radiation-induced void growth in highly anisotropic hexagonal metals such as zirconium were studied. This work on voids is useful for understanding high-temperature radiation damage.

Our original discrete variational method band theory calculations on graphite were used by the Surface Physics Group of the European Space Research Organization to demonstrate the feasibility of a new cross modulation spectroscopic technique for studying the density of final states from secondary electron emission. At that group's request we extended these calculations and found good agreement with its experiments to $50 \mathrm{eV}$ above the Fermi energy in graphite.

We are programming our formula for KKR band theory calculations in complex lattices and also a 
formula for finding the electronic states in a cluster of muffin-tin potentials. Combining our discrete variational method with these programs leads to a computationally efficient scheme that allows us to treat a wide range of physical problems better than other investigators.

We extended the theory of electronic states in disordered systems beyond the level of the coherent potential approximation by developing the selfconsistent boundary site approximation, which works well in the short mean free path regime, where the CPA is inadequate. The analytic properties of the average Green's function may suffer damage when one attempts to go beyond the CPA. We developed a continued fraction technique for calculating the density of states of a three-dimensional disordered system.

We have published an extensive table of Auger transition energies, which has proved to be very useful for practitioners in Auger spectroscopy.

We have extended the theory of diffusion to treat diffusion in discrete media and treated a problem in the oxidation of surfaces.

\section{X-Ray Diffraction}

A new kind of inelastic $x$-ray scattering process was found and identified with the anomalous dispersion correction to coherent atomic scattering factors. Diffuse X-ray scattering data from Ta-Mo, Ta-W, Nb-Mo, $\mathrm{Nb}-\mathrm{W}, \mathrm{Ta}-\mathrm{Nb}$, and Mo-W alloys was analyzed and correlated with mechanical properties.

Investigations of models of short-range structures in omega-forming alloys have been expanded to include faulted omega, untransformed regions, and variations in the distribution of omega regions. Application of the short-range structure concept to certain uranium alloys gave a successful model whose predicted x-ray scattering is in reasonable agreement with observed data.

Thermal expansions of the rhombohedral lattices of two boron carbides were measured from 12 to $940^{\circ} \mathrm{C}$. A structural analysis of one of these (a boron-rich material) is under way. A method for predicting thermally excited Bragg maxima from certain simple crystals was found. Extinction rules for these spacegroup-forbidden reflections are derived.

Small-angle $x$-ray scattering from neutron-irradiated $\mathrm{SiO}_{2}$ is reported. General optimization procedures for experimentally variable parameters governing operation of the Kratky small-angle $x$-ray scattering camera have been developed. Short-range order with large atomic displacements was found in niobium-vanadium alloys.

\section{PART II. SPACE POWER TECHNOLOGY}

\author{
12. High-Temperature Alloys \\ for Isotopic Heat Sources
}

Iridium alloys containing up to 2 at. $\% \mathrm{Ru}, \mathrm{Re}, \mathrm{W}$, $\mathrm{Nb}$, and $\mathrm{Hf}$ have been studied in an effort to develop high-melting, high-strength, oxidation-resistant materials for space power applications to $1400^{\circ} \mathrm{C}$. These alloying additions significantly raise the recrystallization temperature and high-temperature tensile properties, including toughness, with little or no impairment in oxidation resistance.

Recently developed platinum alloys containing 26 to $30 \% \mathrm{Rh}$ and $8 \% \mathrm{~W}$ continue to show good fabricability and strength; however, scale-up efforts have encountered some variability in fabrication behavior and mechanical properties, possibly resulting from difficulties in compositional control.

A method for purifying and/or recycling iridium scrap involving high-temperature oxidation was developed. After acid treatments and hydrogen reduction to the metal, a powder assaying $99.98 \%$ Ir is produced. A variety of short-term tasks and consulting services were provided to SNS in connection with the Multi-Hundred Watt Thermoelectric Generator Project.

\section{Curium-244 Compatibility Testing}

A program to identify materials that are compatible with ${ }^{244} \mathrm{Cm}_{2} \mathrm{O}_{3}$ for applications from 900 to $1400^{\circ} \mathrm{C}$ was initiated. Examination of nickel- and cobalt-base test capsules exposed to ${ }^{244} \mathrm{Cm}_{2} \mathrm{O}_{3}$ at $750^{\circ} \mathrm{C}$ for 1000 and $10,000 \mathrm{hr}$ revealed that all materials were compatible under the test conditions.

\section{Iridium Fabrication}

Procedures were developed for melting and fabricating high-quality iridium and $\mathrm{Ir}-0.3 \% \mathrm{~W}$ alloy sheet for subsequent hydroforming at Mound Laboratory. Cleaning and sintering techniques were developed to lower impurity content of starting powders and prepare them for electron-beam melting. The electron-beam dropcasting technique was used to produce $1 \cdot 1 \mathrm{~b}$ ingots routinely. Rolling studies determined that ingot break. down temperatures of 1100 to $1200^{\circ} \mathrm{C}$ were required using molybdenum frames and cover plates. Warm rolling and intermediate stress-relief temperatures of pure iridium were very dependent on the trace impurity content. This sensitivity was overcome by alloying with $0.3 \% \mathrm{~W}$. In a demonstration of production capability, 
90 acceptable hydroforming blanks were produced in a 20-working-day period.

An iridium purification process utilizing volatilization by high-temperature oxidation followed by reduction in hydrogen was demonstrated on a pilot scale. Materials containing up to $3 \%$ total impurities were upgraded to 99.98\% Ir by this technique. The form of the input scrap produced a 15 -fold difference in oxidation rate. Approximately $7 \mathrm{~kg}$ of impure iridium has been processed.

\section{Physical Metallurgy of Heat-Source Containment Materials}

Thermodynamic calculations based on lattice parameter measurements indicate that the oxygen solubility in T-111 is only about $72 \mathrm{ppm}$ at $1700^{\circ} \mathrm{C}$. Beyond the solubility limit, oxygen reacts with hafnium to form fine, coherent hafnium-oxygen zones, which coarsen upon annealing and eventually precipitate as $\mathrm{HfO}_{2}$ particles. In the as-oxidized condition, T-111 loses all ductility at $800 \mathrm{ppm} \mathrm{O}$. Aging at $1700^{\circ} \mathrm{C}$ increases this to $4200 \mathrm{ppm} \mathrm{O}$. The tolerance of T-111 for oxygen, as measured by ductility, doubled on increasing the contaminating temperature from 825 to $1000^{\circ} \mathrm{C}$ and increased by an additional order of magnitude at $1200^{\circ} \mathrm{C}$. In similar tests, TZM lost its ductility at 300 to $500 \mathrm{ppm} 0$. As with T-111, the ductility could be restored by high-temperature heat treatment. Iridium and iridium alloys were exposed to low-pressure oxygen and/or graphite at $1300^{\circ} \mathrm{C}$ to simulate radioisotope thermoelectric generator environments. Mechanical property tests showed these materials to be compatible in these environments. A variety of short-term tasks and consulting services were provided to SNS in connection with the Pioneer and Viking projects.

\section{Tungsten Metallurgy}

The creep properties of CVD tungsten depend on the fluorine impurity content of the material. At $1650^{\circ} \mathrm{C}$ and stresses above 2000 psi, material with about 20 ppm $F$ is significantly stronger than that with low fluorine in tests to $3000 \mathrm{hr}$. In tests to $10,000 \mathrm{hr}$ at 1000 psi low-fluorine material is stronger. The creep strength of tungsten in a carburizing atmosphere depends on the formation of a crack-free carbide layer. The physical properties of tungsten and tungstenrhenium alloys irradiated at high temperature in a fast-neutron flux were partially evaluated.

\section{PART III. REACTOR DEVELOPMENT SUPPORT}

\section{Gas-Cooled Reactor Program}

Our primary objective is to develop and improve the coated-particle fuels currently specified for large hightemperature gas-cooled reactors (HTGR's). We prepared and characterized coated particles and bonded fuel rods and tested them to high fast-neutron fluence and burnup. Fissile particles derived from uranium-loaded ion exchange resins were shown to be a viable alternative to the carbide or mixed-oxide fissile particles presently specified. Performance of BISO-coated $\mathrm{ThO}_{3}$ particles with reference design coatings was more than adequate, and the behavior of particles with less conservatively designed coatings could be correlated with a performance model. Fuel rod specimens prepared by slug-injection bonding with coal-tar pitch containing natural flake graphite performed well when irradiated to the design HTGR fast-neutron fluence of 8 $\times 10^{21}$ neutrons $/ \mathrm{cm}^{2}$. However, examination of polished sections revealed a potential problem in the directional migration of $\mathrm{ThO}_{2}$ kernels at the higher temperatures. Fuel rod specimens prepared by molding or extrusion have lower fuel loadings and improved physical properties, and such rods performed very well when irradiated to the same fluence and heat ratings.

Our program also contributes to the development of fuel elements for a gas-cooled fast breeder reactor (GCFBR). We participated in postirradiation examination of a manifolded-vented fuel pin successfully irradiated to an exposure of $53,000 \mathrm{MWd} /$ ton and assisted with operation of the second such test of a vented element (GB-10).

\section{Heavy Section Steel Technology}

Tensile properties, toughness, and crack propagation were studied for representative sections of intermediatesize pressure vessels and pipe. An extensive study of neutron-induced changes in impact and tensile properties of thick plate and weldments was completed and reported. A thorough search found no evidence of cracking in submerged-arc welds in 6-in.-thick forgings and plates. In an intentionally flawed pressure vessel pressurized to destruction, the longitudinal split showed ductile tearing near the initial flaw, changing to a cleavage mode of fracture. 


\section{Military Reactor Fuel Element Procurement Assistance}

Technical assistance was provided for procurement of the Type II fuel element assemblies for the Army MH-1A reactor, including evaluation of fabricators and review of numerous documents.

\section{Molten-Salt Reactor Program}

Experience with the MSRE showed that Hastelloy N was embrittled by thermal neutrons and formed shallow intergranular cracks likely due to the fission product $\mathrm{Te}$. The addition of $2 \% \mathrm{Ti}$ seems like a suitable solution to both problems. Graphite with suitable dimensional stability in a fast neutron fluence has been produced by two vendors and in experimental quantities at ORNL. Pyrolytic carbon coatings on graphite to prevent ${ }^{135} \mathrm{Xe}$ absorption were produced and shown to remain impermeable to high neutron fluences. Molybdenum, graphite, and T-111 (Ta-8\% W-2\% Hf) are candidate materials for use in a chemical processing plant in contact with $\mathrm{Bi}$ and fuel salt. A test facility constructed of Mo was designed and partially fabricated before this program was terminated.

\section{Thorium Utilization}

The objective of the Thorium Utilization Program is to demonstrate economic processes and techniques for the $\mathrm{Th}^{2{ }^{23}} \mathrm{U}$ fuel cycle for the High-Temperature Gas-Cooled Reactor. Fabrication processes and equipment are being developed to handle the highly radioactive recycle fuel, and the fuel materials of interest are being tested under irradiation. The ultimate objective is to demonstrate economic fuel recycle techniques for the HTGR fuel in a pilot scale facility, the ThoriumUranium Recycle Facility at ORNL. The demonstration is now scheduled to start in TURF in 1980. The TURF was maintained in a state of operational readiness. An estimate of the maximum production capacity of the Refabrication Pilot Plant indicated that it could be increased to about $100 \mathrm{~kg}$ of heavy metal/day for sustained operation, an amount which could support an HTGR economy in excess of $9000 \mathrm{MW}(\mathrm{e})$. Design of processing equipment for TURF was limited to the updating of process flowsheets; definition of basic performance, design, and development requirements for equipment required in the microsphere coating; design of a portion of the equipment required for the fuel rod fabrication system; and determining the effect of criticality of ${ }^{233} \mathrm{U}$ on the design of process equipment.
The coating equipment and process development effort was focused on obtaining adequate engineering information to allow design and operation of a remote system. Process development emphasized the buffer coating process; statistically designed experiments defined the parameters of the product in terms of the process control variables.

A new electronic particle size analyzer, which shows promise of very rapid determination of particle diameter, was developed. Preliminary work indicates that the mean particle size for a batch of $500-\mu$ m-diam particles reproduces to closer than $1 \mu \mathrm{m}$.

An automatic fuel stick machine, based on the slug injection process and having a capacity of approximately 4000 fuel rods per day, was placed in operation. The effect of temperature, pressure, particle size, pitch type, and filler type and amount on the intrusion rate of matrix into a bed of particles was determined. In addition, methods for carbonizing and annealing a suitable matrix for fuel rods for the HTGR were investigated. Laboratory-scale experiments established the feasibility of in-block carbonization.

Other investigations concerned methods to determine filler distribution, fission-gas release due to surface contamination and broken particles, fuel distribution within and between rods, and the amount of fuel in a given rod or a batch of rods.

The irradiation of the recycle test elements in the Peach Bottom Reactor continued, and we tested fuels in the HFIR in capsules sponsored by the HTGR Base Program. Two of the recycle test elements in Peach Bottom have been removed for examination and for use in head-end processing studies. Fuel performance has been excellent, as would be expected at the low exposures that these fuels have seen thus far in the program. Fuel rods from the ETR capsule, which were subjected to severe temperatures and temperature gradients due to the unintentional inversion of the capsule during the last irradiation cycle, were severely damaged. Fuel rods that operated at normal temperatures and temperature gradients throughout the test were either fragmented or partially debonded, but no particle failures were observed in these rods. Amoeba effect was observed in all particle types but was most severe in $\mathrm{UO}_{2}$ and mixed-oxide particles.

In our economic evaluation of various fuel recycle processing options, we have prepared computer programs to determine overall material balances and to estimate process capital costs. In addition, a study indicated that the optimum time to begin commercial reprocessing is 1984 to 1985 . 


\section{Research Reactor Materials}

Aluminum-base materials and components used in the Oak Ridge Research Reactor and the High Flux Isotope Reactor are being studied to determine the effects of neutron irradiation on dimensional stability and mechanical integrity. These effects are summarized.

We continued to assist the manufacturer of HFIR fuel elements. The fuel plate rejection rate for this year was 3.63\%. Burned $\mathrm{U}_{3} \mathrm{O}_{8}$ is being qualified, and unclad 6061 aluminum appears to be an acceptable replacement for alclad 6061 aluminum for frame and cover plates.

The examination of fuel elements $100-\mathrm{I}$ and $100-0$ is completed. Burned $\mathrm{U}_{3} \mathrm{O}_{8}$ will perform as well as or better than the present reference fuel, high-fired $\mathrm{U}_{3} \mathrm{O}_{8}$.

\section{PART IV. THERMONUCLEAR AND TRANSURANIUM RESEARCH}

\section{Controlled Thermonuclear Research}

Tensile mechanical properties were obtained for samples of niobium, molybdenum, tantalum, and several of their alloys that had been irradiated in EBR-II at temperatures of 390 to $1140^{\circ} \mathrm{C}$ to neutron fluences of 1.5 to $1.6 \times 10^{22}$ neutrons $/ \mathrm{cm}^{2}(>0.1 \mathrm{MeV})$. The effects of helium, injected with the ORIC, on the mechanical properties of $\mathrm{Nb}-1 \% \mathrm{Zr}$ were determined. Creep tests were conducted at 1000,1200 , and $1400^{\circ} \mathrm{C}$ and the results compared with undoped specimens.

The variation of swelling with temperature was determined for pure aluminum, nickel, and vanadium irradiated in the ORR to 0.5 to $1.2 \times 10^{21}$ neutrons/ $\mathrm{cm}^{2}(>0.1 \mathrm{MeV})$. These data form the basis for determining the temperature shift due to dose rate for ion bombardment experiments.

An irradiation chamber was built for the ORNL 6-MV Van de Graaff, and ion sources were developed for self-ion and transmutation product irradiation.

Corrosion data were reviewed to define the scope and nature of compatibility problems involving the first-wall metal and the lithium blanket.

\section{Transuranium Program}

A total of 33 targets containing $244 \mathrm{Cm}$ were fabricated for irradiation in the HFIR, and 25 of these have been inserted within the HFIR core. During the year, 22 target elements were removed from the HFIR, and burnups ranged from 36.8 to $73.7 \%$ FIMA and fluences from 4.33 to $12.38 \times 10^{22}$ neutrons $/ \mathrm{cm}^{2}(<0.41 \mathrm{eV})$ and 1.24 to $3.27 \times 10^{22}$ neutrons $/ \mathrm{cm}^{2}(>0.82 \mathrm{MeV})$.
All these targets performed satisfactorily. In addition, we prepared three sources containing ${ }^{252} \mathrm{Cf}$, four HFIR rabbits that contained ${ }^{253} \mathrm{Es}$, and one that contained ${ }^{257} \mathrm{Fm}$. Additionally, shipments of ${ }^{252} \mathrm{Cf}$ and ${ }^{244} \mathrm{Cm}$ were made to the Savannah River Plant during the reporting period. Work was also accomplished on a method for determination of the thermal conductivity of the individual target pellets in an effort to develop a technique that will nondestructively determine the suitability of the fabricated pellets to perform at the design heat fluxes.

\section{PART V. OTHER PROGRAM ACTIVITIES}

\section{Biomaterials}

A type $316 \mathrm{~L}$ stainless steel Jewett nail and plate that failed after only three weeks service in the femur of a 21-year-old soldier was metallographically examined. Failure initiated in a microscopic groove introduced in a critical area of stress during insertion of the nail. Stress-corrosion cracking and intergranular corrosion played an active role in the fracture of the implant.

Graphite is known to be highly compatible with the human body, and recently developed experimental graphites possess mechanical properties commensurate with living bone. Currently, graphites are being further developed with a pore texture to permit penetration by the living bone, thus providing a self-locking attachment between a prosthetic device and the bone. Preliminary tests carried out in rabbits at the University of Illinois have shown complete biological and mechanical compatibility.

\section{Graphite Fabrication Studies for Naval Ordnance Laboratory}

The program for development of a missile nose tip graphite with superior thermal shock and ablation resistance is continuing. During the past year successful techniques were developed to fabricate bulk graphites from acicular green cokes. Preliminary tests indicate the shock resistance of these materials is at least double that of currently used graphites.

\section{Metallography}

We are finding ever-increasing use of magnetic etching in the study of materials containing ferromagnetic and paramagnetic constituents in the microstructure. This reporting shows the application of this technique in the study of $16 \mathrm{Cr}-8 \mathrm{Ni}-2 \mathrm{Mo}$ welds deposited by the weave 
method. Metallography and radiography, often used as a team to better show and understand materials, are combined to show the size and distribution of voids in welds. The standards for thermocouple wires must remain high. Metallographic examinations of stainlesssteel-sheathed $\mathrm{W}-25 \% \mathrm{Re}$ and $\mathrm{W}-3 \%$ Re thermocouple wires are examples of the importance of scanning electron microscopy and standard optical microscopy to show flaws.

\section{Auger Electron Spectroscopy}

A facility for elemental analysis of surfaces has been built especially for metallurgical studies. Apparatus for exposing grain boundaries, sputter thinning, producing atomically clean surfaces, cleaving crystals, residual gas analysis, and studying gas-metal reactions is included. Examples of many applied and basic studies are referenced in the text. 


\title{
Part I. Fundamental Programs 1. Crystal Physics
}

\author{
G. W. Clark
}

The growth of crystals of high-melting refractory materials is our central theme. Frequently very specific crystals (composition, phase, purity, perfection, size, etc.) are required to characterize physical properties uniquely or are required in technical devices for their optimum operation; such suitable crystals are often difficult to obtain. Hence, we are conducting a continuing program to devise and improve methods of crystal growth, to develop increased understanding of crystal growth processes and kinetics, and to provide crystals needed in research. Crystals are grown by several methods: by internal centrifugal zone growth, by temperature-gradient zone melting, from molten-salt solvents, from supercritical aqueous systems, by edgedefined film-fed growth, and by the general Verneuil method. During this report period, our crystals were shared for investigating electron spin resonance; optical, defect, magnetic, and elastic properties; deformation; radiation damage and gas bubble migration; diffusion; field emission; and electronic oscillator quality. Also, we are investigating selected physical properties, both those related to the crystal growth process and those important for characterizing new compounds and eutectic structures.

\section{METAL OXIDE-METAL BINARY AND TERNARY EUTECTICS}

\section{G. W. Clark J.C. Wilson B. F. Oliver ${ }^{1}$}

We have searched for metal oxide-metal eutectic systems that demonstrate coupled growth of metal fibers or lamellae in one or more oxide phases by directional solidification. We discovered coupled growth in the binaries $\mathrm{CaO} \cdot \mathrm{Cr}_{2} \mathrm{O}_{3}-\mathrm{W}, \mathrm{CaO} \cdot \mathrm{Cr}_{2} \mathrm{O}_{3}-\mathrm{Mo}$, and $\mathrm{MgO} \cdot \mathrm{Cr}_{2} \mathrm{O}_{3} \cdot \mathrm{W}$. Tungsten and molybdenum did not dissolve in alumina and spinel $\left(\mathrm{MgO} \cdot \mathrm{Al}_{2} \mathrm{O}_{3}\right)$, but doping them with $\mathrm{Cr}_{2} \mathrm{O}_{3}$ produced a melt capable of dissolving these metals, and upon solidification the metal formed as fibers in a coupled fashion.

Several ternary systems were also found where one oxide phase is continuous and the other oxide and metal phases grew coupled as fibers or blades. Systems reported here are $\mathrm{CaO} \cdot \mathrm{Cr}_{2} \mathrm{O}_{3}-\mathrm{CaO}-\mathrm{W}, \mathrm{Cr}_{2} \mathrm{O}_{3}-\mathrm{ZrO}_{2}-\mathrm{W}$, $\mathrm{Cr}_{2} \mathrm{O}_{3}-\mathrm{ZrO}_{2}-\mathrm{Mo}, \mathrm{Cr}_{2} \mathrm{O}_{3}-\mathrm{HfO} 2-\mathrm{Mo}, \mathrm{MgO} \cdot \mathrm{Cr}_{2} \mathrm{O}_{3}-\mathrm{ZrO}_{2}-$ $\mathrm{Mo}$, and possibly $\mathrm{MgO}-\mathrm{ZrO}_{2}-\mathrm{W}$. For an example of the physical structure, let us consider the $\mathrm{Cr}_{2} \mathrm{O}_{3}-\mathrm{ZrO}_{2}-\mathrm{W}$ system. The continuous phase is $\mathrm{Cr}_{2} \mathrm{O}_{3}$, with $\mathrm{ZrO}_{2}$ and tungsten appearing predominantly as rods. Tungsten fibers as small as $0.2 \mu \mathrm{m}$ in diameter (giving a fiber density of about $10^{8}$ fibers $/ \mathrm{cm}^{2}$ ) were produced. In general each tungsten fiber grows in contact with a $\mathrm{ZrO}_{2}$ fiber, but in certain circumstances it appears possible for $\mathrm{ZrO}_{2}$ and tungsten fibers to grow simultaneously in different directions in the $\mathrm{Cr}_{2} \mathrm{O}_{3}$ crystal matrix. Thus, already we have learned that coupled. growth occurs in a number of ternary systems. If is also important to note that the addition of constituents that form solid solutions with one or more components (such as $\mathrm{Cr}_{2} \mathrm{O}_{3}$ in $\mathrm{Al}_{2} \mathrm{O}_{3}$ ) and the influence of a third solid phase in the ternaries now allow us greater freedom to develop desirable structures other than those dictated by the simple binary metal oxide-metal systems.

1. Consultant from the University of Tennessee. 


\section{GROWTH OF TERNARY METAL-METAL OXIDE EUTECTICS ${ }^{2}$}

\author{
G. W. Clark J.C. Wilson
}

B. F. Oliver ${ }^{1}$

A technique developed at the Oak Ridge National Laboratory for directionally solidifying very highmelting-temperature eutectics is described. We then discuss the selection of the ternary system, $\mathrm{UO}_{2}-\mathrm{MgO}-\mathrm{W}$ (assuming the oxygen content fixed), to demonstrate: (1) the growth of a binary eutectic structure, $\mathrm{UO}_{2}-\mathrm{W}$, below its eutectic temperature by the migration of a liquid zone, driven by a thermal gradient, through a solid; and (2) the growth of the ternary eutectic, $\mathrm{UO}_{2}-\mathrm{MgO}-\mathrm{W}$. The experimental procedures used to achieve these objectives will be illustrated. Steady-state eutectic solidification was observed for: (1) the binary $\mathrm{UO}_{2}-\mathrm{W}$; (2) the binary $\mathrm{UO}_{2}-\mathrm{MgO}$; (3) the binary $\mathrm{UO}_{2}-\mathrm{W}$, below its binary eutectic temperature $(2640 \pm$ $20^{\circ} \mathrm{C}$ ) by the addition of a third component, $\mathrm{MgO}$; and (4) the ternary $\mathrm{UO}_{2}-\mathrm{MgO}-\mathrm{W}$. The effect of adding the third solidifying phase to both the $\mathrm{UO}_{2}-\mathrm{W}$ and the $\mathrm{UO}_{2}-\mathrm{MgO}$ eutectic morphologies is most striking. Photomicrographs of these various morphologies are presented along with those of other ternary metalmetal oxide eutectics.

\section{EUTECTIC SOLIDIFICATION IN BINARY AND TERNARY METAL-METAL OXIDE SYSTEMS ${ }^{3}$}

\section{G. W. Clark}

Coupled eutectic growth in high-temperature binary and ternary metal-metal oxide systems will be described. Also to be discussed is the solidification of a binary eutectic at a temperature below its melting point by addition of a third component. The resulting morphologies will be illustrated photographically.

\section{CRYSTAL GROWTH OF OXIDES BY CZOCHRALSKI AND EDGE-DEFINED FILM-FED METHODS}

\section{G. W. Clark C. B. Finch}

We recently assembled a crystal pulling apparatus capable of growing crystals by the standard Czochralski technique and by a new method called edge-defined

2. Abstract of invited paper presented at the 5th Annual Spring Meeting of the Metallurgical Society of AIME at University of Pennsylvania, Philadelphia, May 29-June 1, 1973.

3. Abstract of invited paper presented at the American Association for Crystal Growth, Second National Conference, Princeton University, Princeton, N.J., July 30-August 3, 1972. film-fed growth (EFG). ${ }^{4}$ For the EFG method, the crystal is pulled from a melt film on the hot surface of a die. The melt film is fed by capillary action from a melt reservoir below. To establish the capability of this apparatus, we pulled (Czochralski) single-crystal boules of the ferroelectric $\mathrm{LiNbO}_{3}$ (thombohedral, $\mathrm{mp}=$ $1210^{\circ} \mathrm{C}$ ) from the melt. The growth of $\mathrm{LiNbO}_{3}$ was reported earlier in some detail, ${ }^{5}$ and our results were similar. Our efforts have now turned to gaining experience with the EFG method.

Single-crystal boules of ackermanite $(2 \mathrm{CaO} \cdot \mathrm{MgO}$. $2 \mathrm{SiO}_{2}$, tetragonal, $\mathrm{mp}=1450^{\circ} \mathrm{C}$ ) were grown up to 0.8 $\mathrm{cm}$ in diameter $\times 3 \mathrm{~cm}$ and are here reported for the first time. The crystals were pulled in air from platinum crucibles by the Czochralski method. The pull rate for transparent, optically homogeneous growth was found to be less than $4 \mathrm{~mm} / \mathrm{hr}$, with a high thermal gradient at the growth interface. Oriented growth was accomplished with a pull direction collinear with the [001] crystal axis. The boules have a blue color, the nature of which has not yet been ascertained.

\section{BRIDGMAN-STOCKBARGER GROWTH OF SINGLE-CRYSTAL BaF AND BaF $_{2}$ DOPED WITH 1 at. \% La}

\section{B. Finch}

As a preliminary step to synthesis of $\mathrm{BaF}_{2}$ doped with transuranics, single-crystal $\mathrm{BaF}_{2}$ (fluorite type, $\mathrm{mp}$ $=1380^{\circ} \mathrm{C}$ ) was prepared (1) in the pure, undoped state and (2) doped with about 1 at. $\% \mathrm{La}^{3+}$. The crystals were grown by lowering $(4 \mathrm{~mm} / \mathrm{hr})$ a $\mathrm{BaF}_{2}$ or doped melt (contained in a conical-bottom, platinum-lined graphite ampul) through a $30^{\circ} / \mathrm{cm}$ gradient at about $1380^{\circ} \mathrm{C}$ in argon atmosphere. The resulting crystals were colorless, of high optical quality, and about $8 \mathrm{~mm}$ in diameter $X 1 \mathrm{~cm}$.

\section{$\mathrm{SrCl}_{2}$ CRYSTALS CONTAINING ${ }^{251}$ Es}

\section{B. Finch M. M. Abraham}

Single crystals of $\mathrm{SrCl}_{2}(\sim 4 \times 4 \times 4 \mathrm{~mm})$ were grown doped with ${ }^{251}$ Es $\left(300 \mu \mathrm{g}\right.$ Es: $\left.1 \mathrm{~g} \mathrm{SrCl}_{2}\right)$ by a described Bridgman technique. The resulting crystals exhibited an intense, blue self-luminescence and gave an EPR spectrum due to ${ }^{251} \mathrm{Es}^{2+}$.

4. H. E. LaBelle, Jr., Mater. Res. Bull. 6, 581 (1971).

5. K. Nassau et al., J. Phys. Chem. Solids 27, 983 (1966).

6. M. M. Abraham, L. A. Boatner, C. B. Finch, R. W. Reynolds, and H. Zeldes, Phys. Rev. B 1, 3555-60 (1970). 


\section{ELECTRON PARAMAGNETIC RESONANCE OF ${ }^{249} \mathrm{Bk}^{4+}$ IN $\mathrm{ThO}_{2}$ SINGLE CRYSTALS ${ }^{7}$}
L. A. Boatner ${ }^{8}$
R. W. Reynolds 8
C. B. Finch
M. M. Abraham ${ }^{9}$

$\bar{x}$

The EPR spectrum of $\mathrm{Bk}^{4+}$ has been obtained for the first time. For a $\mathrm{ThO}_{2}$ host, a $\Gamma_{6}$ doublet lies lowest. The nuclear spin of ${ }^{249} \mathrm{Bk}$ is confirmed as $7 / 2$, and the estimated nuclear moment is $2.2 \mu_{\mathrm{N}}$.

\section{ZERO-FIELD SPLITTINGS OF Gd ${ }^{3+}$ AND $\mathrm{Cm}^{3+}$ IN $\mathrm{CeO}_{2} \mathrm{AND} \mathrm{ThO}_{2}$ (ref. 10)}
W. Kolbe ${ }^{11}$
N. Edelstein ${ }^{11}$
C. B. Finch
M. M. Abraham?

In previous investigations of $\mathrm{Gd}^{3+}$ cubic EPR spectra in the fluorite-type crystals $\mathrm{CeO}_{2}$ and $\mathrm{ThO}_{2}$, it was pointed out that although the cubic crystal field in $\mathrm{CeO}_{2}\left(a_{0}=5.4 \AA\right)$ was expected to be larger on the basis of a simple point-charge model, the actual splitting

7. Abstracted from Phys. Lett. A 42,93-94 (1972).

8. Advanced Technology Center, Inc.

9. Solid State Division.

10. Abstracted from J. Chem. Phys. 58, 820 (1973).

11. Lawrence Berkeley Laboratory, University of California, Berkeley. observed for $\mathrm{Gd}^{3+}$ in $\mathrm{CeO}_{2}$ was smaller than that observed for the more expanded $\mathrm{ThO}_{2}$ lattice $\left(a_{0}=5.6\right.$ $\AA$ ). The various mechanisms by which the eightfold degeneracy of the $S$ ground state for this $4 f^{7}$ ion $\left({ }^{8} S_{7 / 2}\right)$ is lowered are not understood. Hence, it is not certain why the splitting of the $\mathrm{Gd}^{3+}$ ground state in $\mathrm{CeO}_{2}$ is smaller than in $\mathrm{ThO}_{2}$. In this investigation we report the $\Gamma_{8}-\Gamma_{6}$ splitting of $\mathrm{Cm}^{3+}$ (the $5 \mathrm{f}^{7}$ actinide analog of $\mathrm{Gd}^{3+}$ ) in $\mathrm{CeO}_{2}$. By comparison with earlier data on $\mathrm{Cm}^{3+}$ and $\mathrm{Gd}^{3+}$ in other fluorite-type hosts, we point out that the cubic splittings of the $5 \mathrm{f}^{7}$ ion, unlike the $4 \mathrm{f}^{7}$ case, do follow qualitatively the predictions of the point-charge model.

\section{HYDROTHERMAL STUDIES OF QUARTZ}

$$
\text { O.C. Kopp }{ }^{1} \text { G. W. Clark }
$$

Our efforts have been directed toward determining which impurities affect the electronic quality of quartz. Our RbOH.grown quartz appears to be comparable in electronic quality (by indirect measurements) with the very best reported in the literature. Larger crystals have been grown so that adequately sized test samples may be fabricated for direct measurements of the oscillator quality, $Q$, and the temperature dependence of the oscillator frequency. We are seeking to get these critical measurements done at an outside laboratory, since we do not have the in-house capability. 


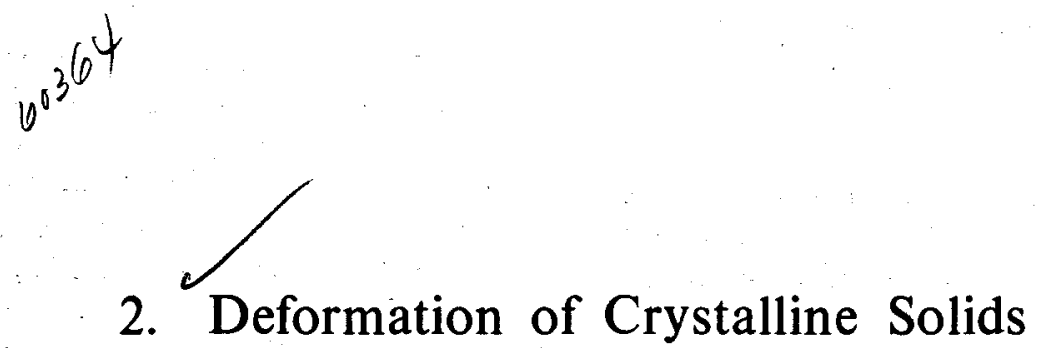

R. O. Williams

The capacity of mixtures of metals to form extensive solid solutions or compounds materially contributes to their utility. In many applications one uses an alloy that consists of a solution, a mixture of two solutions, or a solution containing a compound. The primary benefit is superior mechanical properties, and these may be further enhanced by cold work or by controlling the dispersion through precipitation. The areas of study in which we have participated include structures of solid solutions, equilibria between solutions, and precipitation from such solutions.

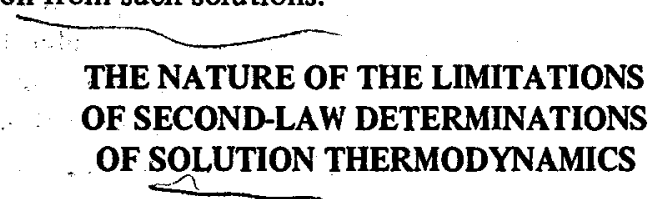

$$
\text { R. O. Williams }
$$

The unreliability of the entropy and heat of mixing of solutions deduced solely from free energy measurements results from systematic errors in the data and the lack of information on the temperature dependence of the heat of mixing. If one could predict the entropy in the high-temperature limit, then one needs to solve only one of these problems. The temperature dependence of the heat of mixing cannot be satisfactorily deduced from the free energy and must be measured calorimetrically. The finite sensitivity of the free energy measurements, which has previously been blamed as the origin of this problem, is not necessarily an important factor.

\section{A COMPUTER PROGRAM FOR THE REDUCTION OF DIFFUSE X-RAY DATA FROM SOLID SOLUTIONS}

\section{R. O. Williams}

A program has been written to allow one to obtain the short-range order parameters and the linear and quadratic displacement parameters from the diffuse $\mathrm{x}$-ray scattering from substitutional alloys by means of a multiple regression analysis. ${ }^{1}$. The advantages of this method are that one has greater freedom in the manner in which the observations are made, the observations are weighted to represent their varying precision, fewer approximations are required, and a complete error analysis is obtained. Powerful supplementary conditions that control the local structure of each series can be included to materially improve the solution. ${ }^{2}$

\section{FRACTURE MECHANISM IN PRECIPITATION-HARDENED BCC ALLOYS ${ }^{3}$.}

$$
\begin{array}{ll}
\text { R. W. Carpenter } & \text { C. T. Liu }
\end{array}
$$

A classical problem associated with the deformation of high-strength precipitation-hardened alloys at low temperatures (i.e., temperatures low enough that diffusion plays no significant role in the flow process) is the origin and microscopic mechanism of the so-called "brittle grain boundary fracture" mode. This fracture mode is often observed when a precipitation-hardenable alloy is aged to near maximum strength and then strained to fracture in tension at room temperature. Under these conditions, the stress-strain curve will generally show that fracture occurs before or shortly after general yielding, and little or no reduction in area will be observed. The fracture path follows the matrix grain boundaries almost entirely, and the fracture surface will, at low magnification, appear brightly faceted like a collection of cleavage surfaces.

1. R. O. Williams, $A$ Computer Program for the Reduction of Diffuse X-Ray Data from Solid Solutions, ORNL-4828 (October 1972).

2. R. O. Williams, "Short-Range Order Structure in a Copper-16 Atomic \% Aluminum Alloy," in preparation.

3. A portion of the results are reported by R.W. Carpenter and C. T. Liu, "Intercrystalline Fracture in an Internally Oxidized BCC Alloy," to be presented at the Third International Conference on Strength of Metals and Alloys, Cambridge University (England), August 1973. 
This phenomenon has been investigated in the bccmatrix niobium-hafnium binary system. In that case the precipitate was a transition variant of ductile hcp hafnium, and the "brittle grain boundary fracture" is actually a highly localized ductile fracture mode, resulting from relatively weak, ductile grain boundary precipitate and/or precipitate-free zones (PFZ) adjacent to the grain boundaries. ${ }^{4}$ The investigation of this fracture mode was extended to a similar bcc alloy, $\mathrm{Ta}-8 \% \mathrm{~W}-2 \% \mathrm{Hf}$, that was isothermally aged after a suitable oxidation treatment to produce a homogeneous dispersion of $\mathrm{HfO}_{2}$ precipitate particles in the matrix. There were precipitates and PFZ at the grain boundaries. Note that in the latter case the precipitate in both the matrix and grain boundaries is hard, brittle (in the fundamental sense) $\mathrm{HfO}_{2}$. This is distinctly the reverse of the former case, where the precipitate was hafnium. Engineering stress-strain curves for the tantalum-base oxygen-containing alloy after isothermal aging at $1400^{\circ} \mathrm{C}$ are compared with the unoxidized alloy (no precipitate) in Fig. 2.1. The oxide precipitation evidently caused a marked increase in matrix yield stress, but of most interest is the apparent brittle behavior of the oxidized specimens aged at $1400^{\circ} \mathrm{C}$. The predominant mode of fracture of the precipitation-hardened specimens was grain boundary separation, but the single-phase (recrystallized) specimen failed entirely by transgranular ductile shear. The steep drop in stress just before fracture for the single-phase specimen indicates a large reduction in area, but no such general ductility was observed for the precipitation-hardened specimens. Examples of the microscopic grain boundary fracture morphology of the precipitation-hardened specimens are shown in Fig. 2.2. Note that (1) all grain boundary fracture facets are covered with a fine dispersion of microdimples, which are clear evidence of localized ductile fracture in the grain boundary regions, and (2) the size of the microdimples is an increasing function of aging time. The latter observation can be directly related to the scale of the internal precipitate microstructure, examined by other experimental means (see ref. 3). The microdimple dispersion in the present case is similar to that obtained earlier in the study of

4. R. W. Carpenter, Metals and Ceramics Div. Annu. Progr. Rop. June 30, 1972, ORNL-4820, pp. 6-7.

5. R. W. Carpenter and C. T. Liu, "Internal Oxidation Mechanism in Ta-8W-2Hf Alloys," to be submitted.

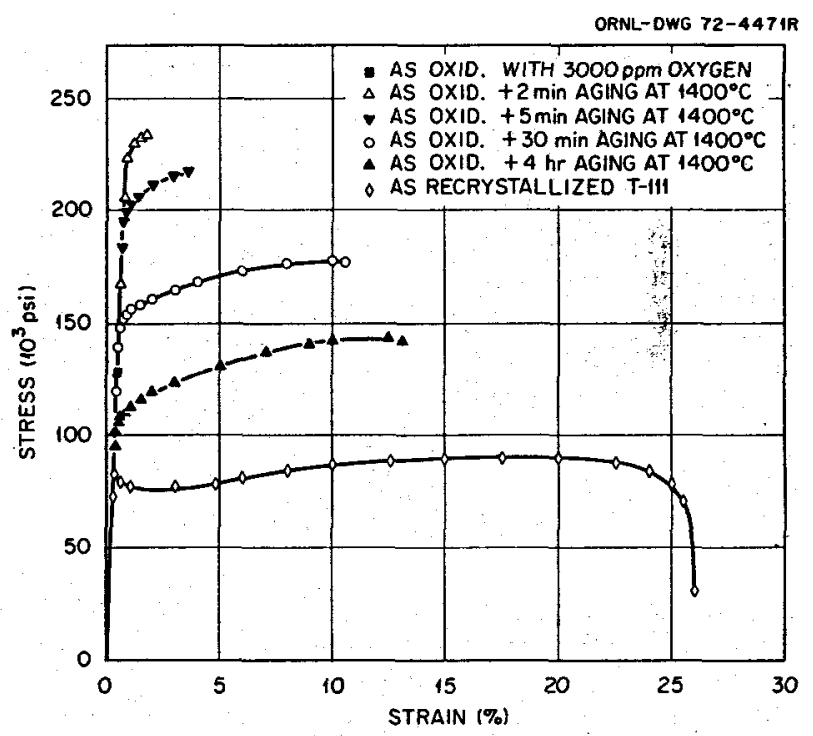

Fig. 2.1. Engineering stress-strain curves for single-phase and precipitation-hardened $\mathrm{Ta}-8 \% \mathrm{~W}-2 \% \mathrm{Hf}$ alloy.

niobium-hafnium alloys noted above. The principal difference in the microdimple dispersions observed on grain boundary fracture facets (other than one of scale) is that precipitate particles are observable in the bottom of the microdimples in the $\mathrm{HfO}_{2}$ precipitate case (see Fig. 2.2). They were not, however, observable in the hafnium precipitate case.

Localized ductile fracture occurred in the grain boundary regions of both alloys, independent of the mechanical properties of the precipitate. The fracture occurred in the grain boundary regions because a relatively weak PFZ existed there in both alloys; however, the details of microdimple nucleation may be different, depending on the mechanical properties of the precipitate. A further important conclusion that can be made by comparing Figs. 2.1 and 2.2 is that while the precipitation-hardened alloys may appear to be brittle on the basis of an engineering stress-strain curve, they are in reality ductile. The specimens fractured at short elongation because a plastic heterogeneity in the form of a PFZ existed at the grain boundaries. Both the matrix and PFZ are ductile, not brittle, materials. If the PFZ is either eliminated or strengthened to the level of the matrix by suitable treatments, the alloys can be used at high strength levels without catastrophic fracture due to grain boundary separation. 


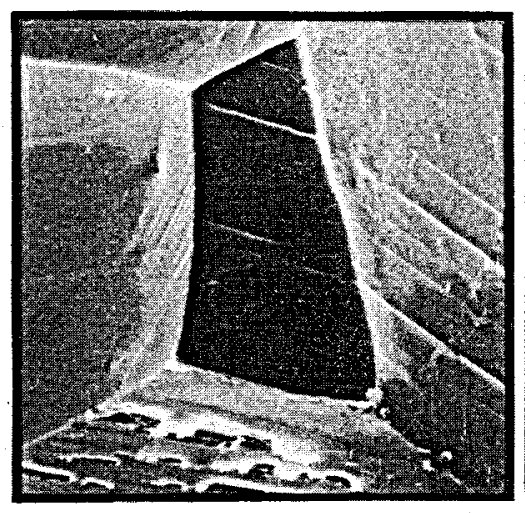

no oge

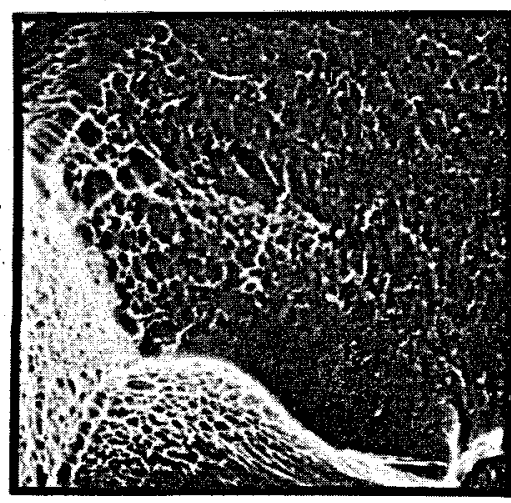

$30 \mathrm{~min}$ age

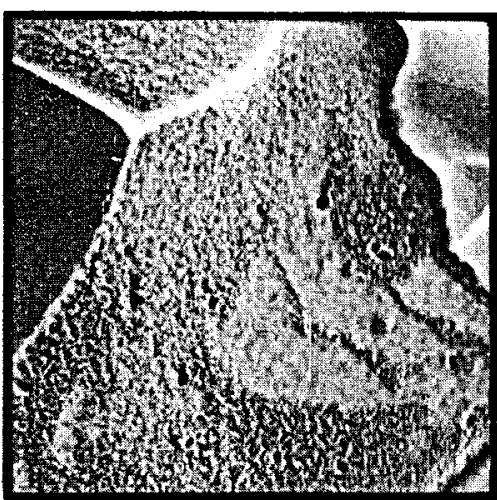

2 min oge

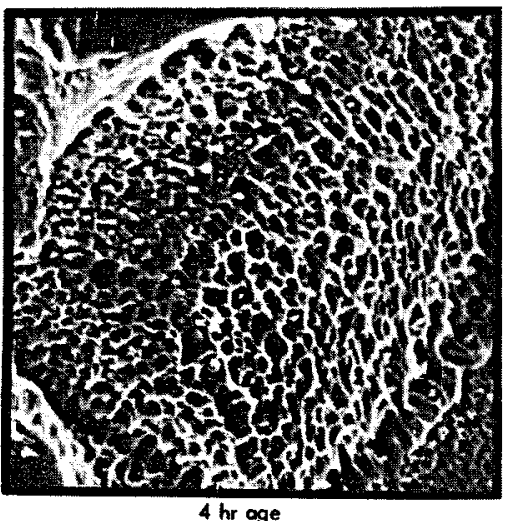

$Y-117786$
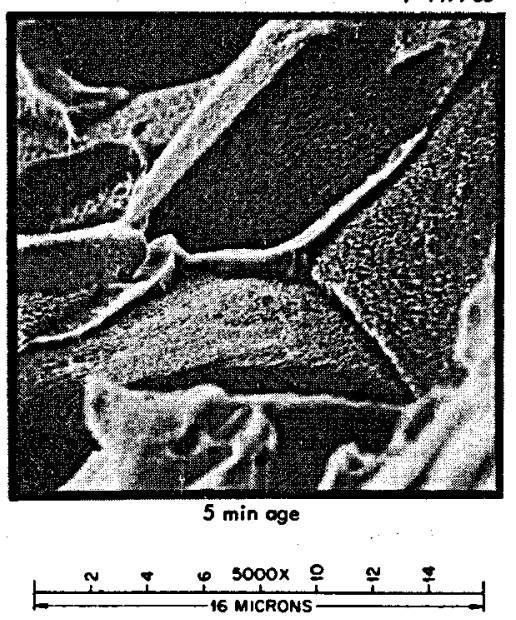

ROOM TEMPERATURE TENSILE GRAIN BOUNDARY FRACTURE MORPHOLOGY:

To-8 W-2 Hf Internally Oxidized at

$1000^{\circ} \mathrm{C}$, then Aged for Increasing Times at $1400^{\circ} \mathrm{C}$ Prior to Frocture

Fig. 2.2. Grain boundary fracture morphology for precipitation-hardened Ta-8\% W-2\% Hf alloy fractured in tension at room temperature. 


\title{
3. Diffusion in Solids
}

\author{
T.S. Lundy P. T. Carlson
}

We are concerned with all aspects of atomic migration phenomena in crystalline solids. Our principal research activities have concentrated on measurement of diffusion properties through the use of radioactive tracers for materials of potential use in the nuclear power industry. Such materials include the various ceramics, especially oxides, and a variety of metals and alloys. Lattice and short-circuiting phenomena, effects of large temperature and concentration gradients, stoichiometry, vacancy concentrations, and high pressure are all under active consideration.

\section{RELEVANCE OF TRACER DIFFUSION EXPERIMENTS TO PROBLEMS IN NUCLEAR SYSTEMS ${ }^{1}$}

\section{T.S. Lundy R. E. Pawel}

Our experience in the measurement of atomic transport parameters in a wide variety of materials systems has emphasized the importance of the identification and consideration of the various competing diffusion mechanisms. At low temperatures where engineering applications generally occur, short-circuiting phenomena, including grain boundary and dislocation pipe diffusion, dominate for the motion of substitutional atoms; at high temperatures mass transport is primarily controlled by a lattice diffusion mechanism. We will discuss this overall situation relative to the experimental assessment of mass transport characteristics and include examples relevant to problems encountered in nuclear systems.

\section{CATION SELF-DIFFUSION IN RUTILE ${ }^{2}$}

\section{T. S. Lundy W. A. Coghlan}

Diffusion in rutile $\left(\mathrm{TiO}_{2}\right)$ is characterized by extreme anisotropy, with very large diffusion rates along the $c$ direction in the body-centered tetragonal structure for interstitial elements such as lithium and boron. In marked contrast, substitutional elements appear to diffuse in the $a$ and $c$ directions at similar rates.

We have examined cation self-diffusion in $\mathrm{TiO}_{2}$ both theoretically and experimentally and find that the relative diffusion coefficients in the two directions can be used along with their partial correlation functions to aid in identification of the jumps taking place in the bct cation sublattice. We considered three types of possible jumps - $a$ direction, $c$ direction, and along the body diagonal. The information obtained shows that the diagonal jump cannot be unique for this system but must be accompanied by a significant fraction of $c$-direction jumps.

Concepts developed in this research may be extended to other anisotropic systems to assist in identification of jump mechanisms for the atomic transport processes.

\section{EFFECT OF DISLOCATIONS ON SELF-DIFFUSION OF URANIUM IN $\mathrm{UO}_{2}$ SINGLE CRYSTALS}

$$
\text { H. J. Hedger }{ }^{3}
$$

The alpha spectra obtained from deformed $\mathrm{UO}_{2}$ single crystals that had been diffusion annealed after surface application of a trace quantity of ${ }^{233} \mathrm{UO}_{2}$ suggested that the presence of dislocations could significantly influence the self-diffusion of uranium. Analysis of such spectra is very difficult since the shape is affected by all of the following factors:

1. concentration as a function of depth,

2. counter broadening,

1. Abstract of a paper presented at the 1972 Fall Meeting of the Metallurgical Society of AIME, Cleveland, Ohio.

2. Abstract of a paper to be presented at the conference on "Lattice Defects in Ionic Crystals," Marseille-Luminy, France, July 1973 .

3. On exchange assignment from UK-AERE, Harwell, England. 
3. rate of energy loss of alpha particles (a quantity dependent on particle energy),

4. number and distribution of alpha energy peaks in the isotope spectrum,

5. statistics of particle scattering, and

6. surface roughness.

Calculations of typical spectra showed that for the short diffusion distances likely to be achieved the skewness of the energy distribution is significant, considerably complicating those calculations. We developed a computer program to generate spectra for a range of values of penetration at varying rates of energy loss, counter resolutions, and energy straggling with a Gaussian distribution. Inclusion of straggling according to other distributions is being attempted but may require excessive computing times.

\section{DIFFUSION UNDER HIGH PRESSURES}

\section{T. S. Lundy}

Fire at the fabricator's plant has resulted in significant delays in delivery of the high-pressure, high-temperature equipment: In addition, redesign and rebuilding of the ORNL high-pressure facility wil take at least several more months for completign. Therefore, we have not yet been able to initiafe our experiments on the influence of pressure (in the range up to 14 kilobars) on tracer diffusion in the refractory metals $\mathrm{Nb}, \mathrm{Ta}$, and $\mathrm{W}$.

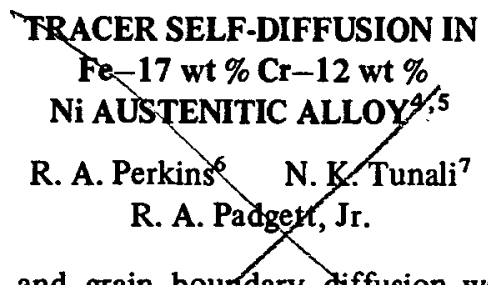

Volume and grain boyndary diffusion were investigated in the ternary austenitic alloy $\mathrm{Fe}-17 \mathrm{wt} \% \mathrm{Cr}-12$ wt \% Ni for the radioactive tracers $59 \mathrm{Fe},{ }^{51} \mathrm{Cr}$, and ${ }^{63} \mathrm{Ni}$ over the rarge 600 to $1300^{\circ} \mathrm{C}$. Conventional lathe and grinding (sectioning techniques have been used

4. R. A. Perkins, "Tracer Diffusion of ${ }^{63} \mathrm{Ni}$ in $\mathrm{Fe}-17 \mathrm{wt} \%$ $\mathrm{Cr}-12 \mathrm{wt} \% \mathrm{Ni}$," Metallurgtcal Transactions, in press.

5. R. A. Perkins, R. A. Padgett, Jr., and N. K. Tunali, "Tracer Pfiffusion of ${ }^{59} \mathrm{Fe}$ and ${ }^{51} \mathrm{Cr}$ in $\mathrm{Fe}-17$ wt $\% \mathrm{Cr}-12$ wt \% Ni Austenitic Alloy," accepted for publication in. Metallurgical Trentsactions.

6. Formerly Presidential Intern with Metals and Ceramics Division, currently with Globe-Union, Inc., Milwaukee, Wis.

7. Formerly at ORNL on leave from Middle East Technical University, Ankara, Turkey. together with a radiofrequency sputtering sectioning technique to determine diffusion coefficients over a wide range of temperatures and penetrations. Results for diffusion in this alloy, as obtained from the appropriate Arrhenius plots, are:

$$
\begin{aligned}
& D_{V}^{\mathrm{Fe}}=0.37 \exp (-66,800 / R T) \mathrm{cm}^{2} / \mathrm{sec}, \\
& \delta D_{g b}^{\mathrm{Fe}}=5.3 \times 10^{-7} \exp (-42,400 / R T) \mathrm{cm}^{3} / \mathrm{sec} \\
& D_{V}^{\mathrm{Cr}}=0.13 \exp (-63,100 / R T) \mathrm{cm}^{2} / \mathrm{sec}, \\
& \delta D_{g b}^{\mathrm{Cr}}=3.5 \times 10^{-8} \exp (-36,000 / R T) \mathrm{cm}^{3} / \mathrm{sec}, \\
& D_{V}^{\mathrm{Ni}}=8.8 \times 10^{-3} \exp (-60,000 / R T) \mathrm{cm}^{2} / \mathrm{sec}, \\
& \delta D_{g b}^{\mathrm{Ni}}=3.7 \times 10^{-9} \exp (-32,000 / R T) \mathrm{cm}^{3} / \mathrm{sec}
\end{aligned}
$$

In the above expressions, $\delta$ is the grain boundary width. For volume diffusion at any particular temperature, chromium is the most rapid while nickel is the least. All three tracers diffuse slower in this alloy at a given temperature than they do in pure iron or in other austenitic stainless steels. For grain boundary diffusion, iron is most rapid above $850^{\circ} \mathrm{C}$ and nickel below that temperature.

\section{THE VOLUME DIFFUSION OF CARBON IN $\mathrm{Fe}-17$ wt \% $\mathrm{Cr}-12$ wt \% Ni AUSTENITIC ALLO}

\section{$\begin{array}{ll}\text { R. A. Perkins } & \text { P. T. Carlson }\end{array}$}

The volume diffusion of carbon in the austenitic alloy $\mathrm{Fe}-17$ wt \% $\mathrm{Cr}-12 \mathrm{wt} \% \mathrm{Ni}$ was-lnvestigated with the radioactive tracer ${ }^{14} \mathrm{C}$ over the range 500 to $1000^{\circ} \mathrm{C}$. Residual activity tèchnigues were used in conjunction with a partially depleted surface barrier detector to determine the postdiffusion eoncentration profile of the ${ }^{14} \mathrm{C}$ that had been deposited on the surface by the decomposition of radioactive methane gas. The temperature dependence of the measured diffusion coefficient is expressed by

$$
D_{V}^{\mathrm{C}}=0.96 \exp (-41,000 / R T) \mathrm{cm}^{2} / \mathrm{sec}
$$

8. R. A. Perkins and P. T. Carlson, "The Volume Diffusion of Carbon in $\mathrm{Fe}-17$ wt \% $\mathrm{Cr}-12$ wt \% Ni," accepted for publication in Metallurgical Transactions. 
The results compare well with those published for type 316 stainless steel but are appreciably lower than those for pure iron. The activation energy for ${ }^{14} \mathrm{C}$ diffusion is approximately $.4 \mathrm{kcal} / \mathrm{mole}$ greater than that in type 316 stainless steel and about $9 \mathrm{kcal} / \mathrm{mole}$ greater than that in pure iron.

\section{THERMOTRANSPORT OF CADMIUM AND THALLIUM IN SODIUM AND POTASSIUM CHLORIDES 2 -}

\section{P. T. Carlson D. Heitkamp ${ }^{10}$}

The thermotransport of ${ }^{115 \mathrm{~m}} \mathrm{Cd}$ and ${ }^{204} \mathrm{Tl}$ radioactive tracers in single crystals of sodium and potassium chlorides, respectively, is under investigation to seek a better understanding of the heat of transport in ionic systems. An adequate understanding of this quantity would permit quantitative predictions regarding the amount of segregation that should occur in materials systems under the influence of temperature gradients.

Thin disks of $\mathrm{KCl}$ and $\mathrm{NaCl}$ doped with tracers were annealed in controlled thermal gradients of about $1000^{\circ} \mathrm{C} / \mathrm{cm}$. Then they were sectioned with a rotary microtome, and the sections were counted with suitable detectors in conjunction with a multichannel analyzer to yield activity profiles. Results for ${ }^{204} \mathrm{Tl}$ in $\mathrm{KCl}$ indicate preferential migration toward lower temperatures, with a heat of transport of approximately $+15,000 \mathrm{cal} / \mathrm{mole}$. The cadmium tracer in $\mathrm{NaCl}$ had a heat of transport of about $-7500 \mathrm{cal} / \mathrm{mole}$, where the negative sign indicates migration toward higher temperatures. Experimental difficulties are being overcome by suitable isolation of the sample to establish equilibrium between the vapor and solid phases and thereby preserve the desired boundary condition. In addition, a computer program has been developed to enable determination of the heat of transport from concentration profiles for non-steady-state distributions. This analysis is based on the exact solution to the differential equation describing thermotransport and is important

9. P. T. Carlson and D. Heitkamp, "Thermotransport of Cadmium and Thallium in Sodium and Potassium Chlorides," oral presentation at the 1972 Fall Meeting of the Metallurgical Society of AIME (1972 Materials Engineering Congress Abstracts, 14-19 October, Cleveland, Ohio).

10. Now at Kernforschungsanlage, Institut für Physikalische Chemie, Jülich, West Germany. in the present study because of the relatively small isothermal diffusion coefficients at the temperatures of interest.

\section{BINARY INTRINSIC DIFFUSION AND INTERDIFFUSION IN VANADIUM-TITANIUM SOLID SOLUTIONS}

\section{P. T. Carlson L C Manley, Jr.}

Concentration-dependent diffusion processes are currently under investigation in binary vanadium-titanium solid solutions. We are measuring interdiffusion and intrinsic diffusion coefficients across the entire composition range of the vanadium-titanium solid solution phase field at temperatures from 900 to above $1600^{\circ} \mathrm{C}$. Solid-solid couples with seven different combinations of composition are being employed with overlap of concentration ranges so as to obtain a complete set of coefficients. Intensity-penetration profiles of vanadium and titanium are measured on an electron microprobe by simultaneously monitoring the $\mathrm{Ti} K \alpha$ and $\mathrm{V} \mathrm{K} \beta_{1}$ radiations with conversion to concentration-penetration profiles accomplished through an established microprobe correction procedure. Motion of inert markers, indicative of the Kirkendall effect, is determined for each diffusion couple. Interdiffusion and intrinsic diffusion coefficients are calculated from the concentration profiles by the methods of Matano and Darken. A computer program was developed to convert the x-ray intensities obtained from the electron microprobe to concentrations and then fit the resultant concentration to an analytical function of penetration by means of a set of three complementary error functions. The program then uses Simpson's rule to locate the BoltzmannMatano interface and integrates and differentiates the resultant curve at selected points to compute the interdiffusion coefficients as functions of composition.

Initial experiments performed at $1350^{\circ} \mathrm{C}$ with both pure metal and incremental alloy couples have yielded diffusion zones about $1000 \mu \mathrm{m}$ wide with interdiffusion coefficients of the order of $10^{-9} \mathrm{~cm}^{2} / \mathrm{sec}$. Appreciable Kirkendall motion was evident in all cases, even though the results of previous tracer diffusion studies suggest the possibility that such motion is absent at certain temperatures and compositions. The marker motion phenomenon coupled with strong indications of appreciable vacancy wind effects allows the study of vacancy and porosity migration mechanisms. 


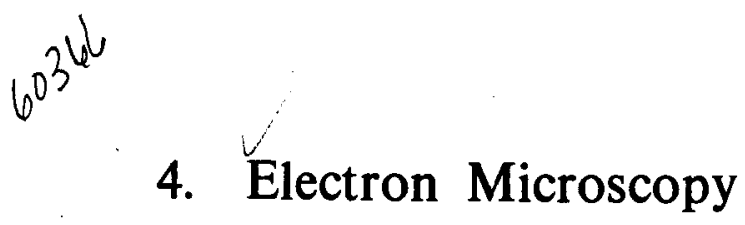

\author{
J. O. Stiegler
}

Since engineering materials are frequently placed in service under conditions where their microstructures are unstable, their mechanical and physical properties often change during use. We are using electron microscopy and related techniques to characterize microstructural changes that occur in several technologically important areas and to relate these changes to corresponding variations in properties. Our effort is focused on the changes that occur during neutron irradiation at elevated temperatures, but we are also examining elevatedtemperature deformation and fracture processes. Work supported by the USAEC Division of Physical Research is summarized in this chapter. Contributions by members of the Electron Microscopy Group in support of other programs in the Division appear in Chapters 20, 22 , and 23 of this report.

\section{RADIATION-INDUCED STRENGTHENING AND EMBRITTLEMENT IN ALUMINUM ${ }^{1}$}

\section{$\begin{array}{ll}\text { K. Farrell } & \text { R. T. King }\end{array}$}

Commercially pure aluminum (1100 grade) in the annealed condition was irradiated to fast fluences in the range 1 to $3 \times 10^{26}$ neutrons $/ \mathrm{m}^{2}(>0.1 \mathrm{MeV})$ and to similar thermal fluences at temperatures of 318 to 328 $\mathrm{K}$. It was then tensile tested at temperatures between 298 and $643 \mathrm{~K}$. This irradiation doubled the ultimate tensile strength and more than tripled the flow stress at all test temperatures. The work hardening exponent was severely reduced, and there was a large loss in ductility. Strengthening was due to a fine precipitate of transmutation-produced silicon and an associated dislocation structure.

At test temperatures below about $423 \mathrm{~K}$ the fracture mode was transgranular. Above $473 \mathrm{~K}$ grain boundary cavities were observed; the fracture mode became predominantly intergranular, and ductility was further reduced. Unirradiated specimens containing cyclotroninjected helium showed no change in strength but displayed a loss in ductility at elevated temperatures. Concurrently, holes were formed on the grain boundaries. Embrittlement in the neutron-irradiated specimens arose from two sources. One is through the defect structure, which reduces the work hardening exponent. The other is an additional effect at elevated temperatures involving grain boundary failure by cavity growth and coalescence. Helium encourages cavity nucleation; the degree of cavitation increases with increasing tensile strength.

\section{REPLY TO "COMMENTS ON 'ON THE QUESTION OF VOID FORMATION IN NEUTRON IRRADIATED ZIRCONIUM' "'2}

$$
\text { A. Wolfenden }{ }^{3} \quad \text { K. Farrell }
$$

Ferguson ${ }^{4}$ raises a moot point concerning the presence of highly soluble gases (hydrogen, nitrogen, and oxygen) in zirconium and their possible effects on void formation during neutron irradiation. It is by no means established that such impurities must be precipitated in order for them to act as nuclei for the aggregation of radiation-induced point defects. Indeed, some experiments indicate that gases in solution promote void formation. For example, when the sum of the carbon, nitrogen, and oxygen contents of vanadium is raised from 200 to $1250 / \mathrm{ppm}$ (still below the solubility limits), the void concentration is increased. ${ }^{5}$ Voids can

1. Abstracted from Met. Trans. 4, 1223-31 (1973).

2. Summary of Scripta Met. 7, 41 (1973).

3. Present address, Physics and Engineering Laboratory, Department of Scientific and Industrial Research, Private Bag, Lower Hutt, New Zealand.

4. I. F. Ferguson, Scripta Met. 7, 39 (1973).

5. F. W. Wiffen, "The Effect of Alloying and Purity on the Formation and Ordering of Voids in BCC Metals," pp. 386-96 in Radiation-Induced Voids in Metals (Proc. Int. Conf., Albany, N.Y., June 9-11, 1971), ed. by J. W. Corbett and L. C. Ianniello, AEC Symp. Ser. 26, CONF-710601 (April 1972). 
be produced ${ }^{6}$ in molybdenum by neutron irradiation at low temperature $\left(60^{\circ} \mathrm{C}\right)$ followed by postirradiation annealing at $900^{\circ} \mathrm{C}$, leading to the suggestion that a critical step in void formation, in this case, is the simultaneous migration and association of vacancies and gaseous impurity atoms (possibly $\mathrm{O}$ and $\mathrm{N}$ ). Experiments on void formation have not yet established whether impurities affect void development directly or whether there is an indirect effect via the dislocation structure. ${ }^{7}$ Also, under appropriate conditions coupled diffusion of gases and point defects might reduce the migration rates of point defects and thereby promote their recombination, thus minimizing the development of damage structure. The role of gases seems likely to be much more complex than Ferguson indicates. Studies of cobalt in both the hexagonal and cubic states $^{8}$ has, however, reemphasized the potency of helium in void formation.

\section{EFFECT OF SILICON ON VOID
FORMATION IN ALUMINUM}

$$
\text { K. Farrell A. Jostsons }{ }^{10}
$$

In this critique of Mayer and Morris [Nature; Phys. Sci. 241, 132 (1973)], who claim that the presence of 100 at. ppm Si in aluminum suppresses void formation during neutron irradiation, it is pointed out that substantial quantities of silicon are produced by transmutation in aluminum. Yet the silicon produced this way does not inhibit void formation. Also, commercially pure aluminum, which contains more than 100 ppm $\mathrm{Si}$, is not immune to voids. It is postulated that some of the effects reported by Mayer and Morris may be a result of inadequate observation and/or poor control of the irradiation temperature.

6. J. H. Evans, S. Mahajan, and B. L. Eyre, Phil. Mag. 26, 813 (1972).

7. M. J. Makin, Phil. Mag. 25, 761 (1972).

8. S. A. Manthorpe and S. N. Buckley, "The Production of Voids in Cobalt During Ion Bombardment and Electron Irradiation," pp. 239-46 in Voids Formed by Irradiation of Reactor Materials (Proc. Brit. Nucl. Energy Soc. European Conf., Reading, March 24-25, 1971), A.E.R.E., Harwell, England.

9. Summary of a paper submitted to Nature, Physical Science.

10. On attachment from Australian Atomic Energy Commission Research Establishment, Lucas Heights, N.S.W.

\section{EFFECTS OF SOLUTE INTERSTITIAL ELEMENTS ON SWELLING OF STAINLESS STEEL ${ }^{11}$, \\ J. O. Stiegler J. M. Leitnaker

\author{
E. E. Bloom
}

High-purity stainless steel (HPS), equivalent to type 316 stainless steel in major alloy elements but with greatly reduced interstitial element and manganese contents, was irradiated in the range 725 to $875 \mathrm{~K}$ to fluences ranging from 1.0 to $3.5 \times 10^{26}$ neutrons $/ \mathrm{m}^{2}$ $(>0.1 \mathrm{MeV})$. The HPS swelled 20 to 50 times more than commercial grade type 316 stainless steel ( $316 \mathrm{SS}$ ) and about the same as commercially pure nickel, which has about the same interstitial content as HPS. A finegrained $316 \mathrm{SS}$ in which interstitial elements but not manganese were precipitated by thermomechanical treatments also showed exaggerated swelling, approaching that of HPS. This behavior suggests that swelling in commercial stainless steels is retarded by small amounts of interstitial elements normally present in them and not by the major alloying elements. Interstitials tend to precipitate from solution during irradiation, and bulk extractions of precipitate particles were made to find the extent of the precipitation reactions. At both 650 and $850 \mathrm{~K}$ precipitation was clearly enhanced by irradiation significantly enough to alter the matrix composition. This enhancement suggests that swelling may be increased at high fluences over that predicted by extrapolation of lower fluence data. These observations are discussed in terms of potential behavior of fuel cladding materials and of the validity and interpretation of accelerated schemes for simulating neutron damage.

\section{A HIGH-VOLTAGE ELECTRON MICROSCOPE STUDY OF THE EFFECTS OF PREINJECTED HELIUM ON ELECTRON DAMAGE IN ALUMINUM ${ }^{12}$.}

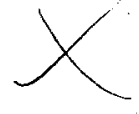

$$
\text { A. Wolfenden }{ }^{3}
$$

Defect clusters were formed and observed simultaneously in electron-irradiated foils of aluminum, both uninjected and preinjected with about 8 at. ppm $\mathrm{He}$, in a high-voltage electron microscope operating at $650 \mathrm{kV}$.

11. Abstract of a paper to be presented at the International Conference on Physical Metallurgy of Reactor Fuel Elements to be held at Berkeley Castle, Berkeley, Gloucestershire, England, September 2-7, 1973 (to be published in the Proceedings).

12. Abstract of a paper submitted to Micron. 
The nominal irradiation temperatures of the specimens were room temperature, 150 , and $200^{\circ} \mathrm{C}$. The defect clusters, in the form of dislocation loops, formed in greater concentrations and persisted to longer times in the preinjected specimens than they did in the uninjected metal. At $200^{\circ} \mathrm{C}$, no beam-induced loops were observed in the uninjected aluminum foil of usual thickness, but they were seen in the helium-injected material. Faulted dislocation loops were more prevalent in the preinjected specimens. Under certain conditions the irradiated microstructure evolved to one resembling an unirradiated structure. It is concluded that the preinjected helium itself (rather than the associated alpha-particle damage) causes the enhanced dislocation loop formation in the electron-bombarded foils.

\section{ELECTRON IRRADIATION DAMAGE IN TITANIUM ${ }^{13}$}

\section{A. Wolfenden ${ }^{3} \quad$ M. H. Yoo}

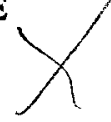

Defect clusters formed in titanium during electron bombardment at $450^{\circ} \mathrm{C}$ in the high-voltage electron microscope operating at $635 \mathrm{kV}$. The damage was due to the direct displacement of atoms by the electron beam flux of $2.8 \times 10^{18} \mathrm{~cm}^{-2} \mathrm{sec}^{-1}$ and resulted in the nucleation of interstitial clusters, which grew to form perfect (unfaulted) prismatic loops of concentration at approximately $2 \times 10^{13} / \mathrm{cm}^{3}$. The growth kinetics obeyed $d \propto t^{n}$, where $d$ is the maximum loop width, $t$ is time, and $n$ varies in the range 0.5 to 1.2 . First-order kinetics $(n \approx 1.0)$ is obeyed by those loops within the effective foil thickness, and the dependency on square root of time $(n \approx 0.5)$ by those that grew beyond the effective thickness, suggesting that the foil surfaces dominated all other sinks for interstitials.

\section{EFFECT OF PURITY ON LOOP FORMATION IN ALUMINUM AND NICKEL ${ }^{14}$

$$
\text { J. O. Stiegler K. Farrell }
$$

Impurities influence the nature and degree of damage in neutron-irradiated metals. Impurities also affect the formation of loops and the evolution of dislocation structure in aluminum and nickel during bombardment with $650-\mathrm{kV}$ electrons in a HVEM. In aluminum,

13. Based on the abstract of paper presented at 1973 Spring TMS-AIME Meeting at Philadelphia, May 29-June 1.

14. Abstract of a paper to be presented at the Third International Cónference on High Voltage Electron Microscopy to be held in Oxford, England, August 27-30, 1973, to be published in the Proceedings. decreasing purity reduces the growth rate of loops, increases the time to reach a steady-state dislocation structure, and reduces the cutoff temperatures for loop formation, suggesting that impurities reduce the migration rate of point defects and promote recombination. However, annealing and reirradiation experiments just below the cutoff temperature show that a large fraction of loops are reinitiated at their original sites, demonstrating an effect of impurities on the nucleation process. Increasing the electron flux increases the growth rate of loops but seemingly not the nucleation rate. The growth rate increases with increasing irradiation temperature. In nickel foils, impurities reduce the cutoff temperature, and suitable aging can completely suppress loop formation.

\section{DEFECT STRUCTURE OF NEUTRON-IRRADIATED BORON CARBIDE ${ }^{15}$

$$
\begin{gathered}
\text { A. Jostsons }{ }^{10} \text { C.K.H. DuBose } \\
\text { G. L. Copeland }
\end{gathered}
$$

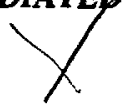

Boron carbide irradiated in thermal and fast reactor neutron spectra at 500 to $840^{\circ} \mathrm{C}$ up to $81 \%^{10} \mathrm{~B}$ burnup was examined by transmission electron microscopy. Helium bubbles formed by agglomeration of helium from the ${ }^{10} \mathrm{~B}(n, \alpha)$ reaction constitute the only form of irradiation-induced damage. The helium bubbles tend to have a disk-like morphology, with the plane of the disk parallel to (111). Lattice strain fields around the bubbles evidenced a lack of thermal equilibrium. Bubble nucleation was influenced markedly by grownin dislocations and stacking faults. Bubble coalescence, either by impingement or enhanced by bubble stress fields, frequently gave rise to both trans- and intergranular microcracking. The significance of these observations on gas release and swelling of boron carbide are discussed briefly.

\section{NUCLEATION OF VOIDS IN SOLIDS CONTAINING EXCESS VACANCIES, INTERSTITIALS, AND HELIUM ATOMS ${ }^{17}$}

$$
\text { B.T.M. Loh }{ }^{18}
$$

A homogeneous nucleation model is presented for void formation in solids containing excess vacancies,

15. Abstract of a paper submitted to Journal of Nuclear Materials.

16. Present address, Oak Ridge Gaseous Diffusion Plant.

17. Abstract of Acta Met. 20,1305-11 (1972).

18. Deceased. 
interstitials, and helium atoms. The reactions between void embryos and these diffusing species can be represented by pseudobinary kinetics. A steady-state nucleation rate is derived by assuming the existence of a saddle point in the energy surface of formation of embryos. The result can be reduced to Katz and Wiedersich's case in which no helium is present. A significant enhancement in nucleation rate by the presence of excess helium atoms is predicted.

\section{REPLY TO COMMENT ON SOME CALCULATIONS OF VACANCY CHARACTERISTICS IN SUBSTITUTIONAL ALLOYS ${ }^{19}$}

$$
\text { B.T.M. } \text { Loh }^{18} \quad \text { C. T. Liu }
$$

We have shown that the energy parameters for vacancy formation in substitutional alloys, derived from our pair approximation model, ${ }^{20}$ are physically sound, based on the "broken-bond" calculation. If the brokenbond calculation is corrected, the results from Kinoshita and Eguchi's model ${ }^{21}$ must be incorrect. We have found that the discrepancies in their values are the result of a poor approximation in estimating the combinatory factor of the configurational partition function.

\section{NEAREST NEIGHBOR PAIR MODELS FOR SOLUTION 22}

$$
\text { B.T.M. Loh }{ }^{18} \quad \text { C. T. Liu }
$$

Any solution model needs a physically sound estimate of the combinatory factor of the configurational partition function in order to yield consistent properties of the solutions. The pair approximation yields consistent solution properties. Therefore the pair approximation is a sound and self-consistent solution model in spite of some recent criticisms. The possible defects in the other models used by Gokcen and Chang, ${ }^{23}$ Kinoshita and Eguchi, ${ }^{21}$ and Alfrey and Mark $^{24}$ were identified, and the models were shown not to predict consistent solution properties.

19 Summary of Scripta Met. 6, 565-66 (1972).

20. B.T.M. Loh and C. T. Liu, Acta Met. 19, 617-20 (1971).

21. C. Kinoshita and T. Eguchi, Acta Met. 20, 45 (1972).

22. Summary of a paper published in Scripta Met. 7, 281-88 (1973).

23. N. A. Gokcen and E. T. Chang, J. Chem. Phys. 55, 2279 (1971).

24. T. Alfrey and H. Mark, J. Chem. Phys. 10, 303 (1942).

\section{REPLY TO COMMENTS ON "THE ENERGY STORED IN POLYCRYSTALLINE COPPER DEFORMED AT ROOM TEMPERATURE" - MORE DETAILS OF THE SINGLE-STEP ISOPERIBOL DEFORMATION CALORIMETER ${ }^{25}$

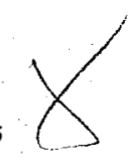

\author{
A. Wolfenden ${ }^{3}$
}

The experimental setup of the single-step isoperibol deformation calorimeter that has been used to measure the energy stored in a variety of metals and alloys is examined. Only the specific points raised by KuhlmannWilsdorf ${ }^{26}$ are pursued in detail, rather than the general outlines of the principle and operation of the calorimeter that have been given elsewhere. The items discussed are (1) occasional negative values of stored energy, (2) tests on the reliability of the method, (3) results of two tests, (4) thermo elastic cooling, and (5) the energy stored in polycrystalline copper. The difficulty of devising legitimate tests to assess the reliability of the calorimeter means that it is fair to compare the results from this calorimeter with data obtained by other authors for similar specimens and test conditions. Such a comparison was the theme of the paper on the energy stored in polycrystalline copper. ${ }^{27}$ From a calorimetric point of view, the new results and those of Williams ${ }^{28}$ agree.

\section{THE EFFICIENCY OF ENERGY STORAGE DURING PLASTIC DEFORMATION OF METALS ${ }^{2}$ \\ A. Wolfenden ${ }^{3}$}

Single-step deformation calorimeters have been used to measure the efficiency of energy storage due to defect generation in metals during tensile plastic deformation. The methods use the first law of thermodynamics to evaluate the stored energy $\left(E_{S}\right)$ as the difference between the mechanical work $\left(E_{W}\right)$ expended on the specimen by the tensile tester and the energy $\left(E_{D}\right)$ dissipated as heat in the specimen. The efficiency of energy storage is then calculated as (100 $\left.E_{S} / E_{W}\right) \%$. The instruments have been used to measure $E_{S} / E_{W}$ in copper and aluminum single crystals deformed at $78 \mathrm{~K}$ and in copper and silver single crystals strained at $300 \mathrm{~K}$. Additional measurements at $300 \mathrm{~K}$

25. Summary of a paper published in Scripta Met. 6, 903-08 (1972).

26. D. Kuhlmann-Wilsdorf, Scripta Met. 6,901 (1972).

27. A. Wolfenden, Acta Met. 19, 1373-77 (1971).

28. R. O. Williams, Acta Met. 13, 163-68 (1965).

29. Abstract of a paper presented at the 27th Annual Calorimetry Conference, Park City, Utah, July 19-22, 1972. 
have been made on polycrystalline copper and on polycrystalline gold-silver and copper-gold alloys. At the lower deformation temperature the efficiency of energy storage averaged about $60 \%$; at room temperature the single crystals and the alloys had efficiencies of about 12 and $21 \%$, respectively, while the polycrystalline copper was about $17 \%$ efficient. The results are in agreement with the prediction of Nicholas that the decreased thermal activation available during deformation at low temperatures would lead to an increased efficiency of energy storage, that is, higher values of $E_{S} / E_{W}$.

\section{CREEP PROPERTIES OF CVD TUNGSTEN ${ }^{30}$}

\section{K. Farrell}

The creep-rupture properties of sheet specimens of tungsten chemically deposited from the fluoride at
1400,1650 , and $2200^{\circ} \mathrm{C}$ in vacuum are summarized. $A$ wide scatter in the data can be rationalized by classifying it into two groups, low (2 to $9 \mathrm{ppm}$ ) fluorine and high (12 to $35 \mathrm{ppm}$ ) fluorine levels. At $1650^{\circ} \mathrm{C}$, where a clear distinction can be made, the low-fluorine materials have minimum creep rates comparable with powder metallurgy tungsten, but the rates are lower for high fluorine contents. Ductility is reduced with increasing fluorine content at all test temperatures, and intergranular cavitation and fracture are enhanced by increasing fluorine level. Ductility is increased if grain growth occurs during the test.
30. Abstract of a paper to be presented at the Fourth International Conference on Chemical Vapor Deposition to be held in Boston, October 7-12, 1973, to be published in the Proceedings. 


\title{
5. Fundamental Ceramics Research
}

\author{
G.P. Smith J. Brynestad
}

This program continues the deformation studies on $\mathrm{UO}_{2 \pm x}$ and related materials and the redox properties of molten $\mathrm{UO}_{2 \pm x}$. The research of this group is also directed at the preparation and characterization of unusual materials, such as transition metal cluster compounds and metal-metal oxide composites.

\section{OBSERVATION OF LATTICE AND GRAIN BOUNDARY DISLOCATIONS IN UO ${ }_{2}$
DEFORMED AT HIGH TEMPERATURES}

\section{S. Yust J.T.A. Roberts ${ }^{2}$}

The microstructure of a series of deformed polycrystalline uranium dioxide specimens was studied by transmission electron microscopy. The lattice and grain boundary dislocation structures observed correlate with three temperature regimes of deformation. Below the brittle-to-ductile transition temperature, $T_{c}$, the specimen is completely brittle, and all grains are essentially free of dislocations. The grain boundary structures observed in these brittle specimens are very regular in appearance. Between the high-temperature transition, $T_{t}$, and $T_{c}$, where small degrees of plastic deformation are recorded before fracture, the first evidence of dislocation activity within the grains is noted, while the boundary structures remain regular. Above $T_{t}$, appreciable plasticity occurs before fracture, and extensive dislocation network formation occurs in the grains of the polycrystal. In addition, the structures in the grain boundaries become very irregular in appearance. A qualitative discussion of the deformation process in polycrystalline $\mathrm{UO}_{2}$ is derived from the observations of this study.

1. Abstract of paper submitted to Journal of Nuclear Materials.

2. Argonne National Laboratory.

\section{OPTICAL ABSORPTION IN DEFORMED CaF 2}
G. P. Williams ${ }^{3}$
T. J. Turner ${ }^{3}$
C.S. Yust

Single crystals of $\mathrm{CaF}_{2}$ were deformed in compression along a $\langle 111\rangle$ axis. In crystals from two sources, deformation produced optical absorption bands at 199 , $233,264,301$, and $350 \mathrm{~nm}$. The absorption coefficient of the band at $199 \mathrm{~nm}$ was greatest with the others decreasing stepwise. Deforming crystals at $200^{\circ} \mathrm{C}$ produced absorption bands whose intensity varied linearly with the amount of deformation. The extent of linearity varied with the crystal batch. A striking effect observed in all crystals was a complete anisotropy of the absorption bands. The bands were present when the crystal was viewed along one axis normal to the stress axis but absent viewed along the other axis normal to the stress axis.

\section{REDOX EQUILIBRIA IN MOLTEN URANIUM DIOXIDE}
A. T. Chapman ${ }^{4}$
J. Brynestad
J.C. Wilson
G.W. Clark

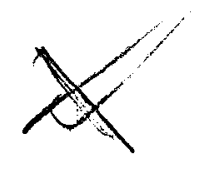

The study of the redox equilibria in molten $\mathrm{UO}_{2 \pm x}$ has continued, and the results are ready for publication. The data strongly indicate that existing literature data on the redox equilibria in solid, substoichiometric uranium dioxide are in error to a considerable degree.
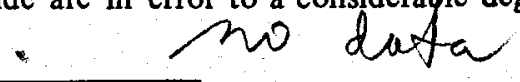

3. Wake Forest University.

4. Consultant from the Georgia Institute of Technology. 
SYNTHESIS, STRUCTURE, AND PROPERTIES

OF TITANIUM(II) TETRACHLOROALUMINATE

\section{J. Brynestad G. P. Smith \\ H. L. Yakel S. von Winbush ${ }^{6}$}

\section{A. S. Dworkin ${ }^{7}$}

Several preparative methods are given for the blue compound $\mathrm{Ti}\left(\mathrm{AlCl}_{4}\right)_{2}$, which was obtained in orthorhombic and monoclinic modifications, depending on procedural details. The orthorhombic form belongs to the space group $\mathrm{P} m a b$ or $\mathrm{P} 2_{1} a b$, with unit cell dimensions $a_{0}=13.17 \pm 0.01, b_{0}=14.94 \pm 0.01$, and $c_{0}=5.982 \pm 0.003 \AA$. The monoclinic form is of the same structural type as $\mathrm{Co}\left(\mathrm{AlCl}_{4}\right)_{2}$, with unit cell dimensions $a_{0}=13.000 \pm 0.003, b_{0}=7.711 \pm 0.002$, $c_{0}=11.772 \pm 0.003 \AA$, and $\beta=92.62 \pm 0.02^{\circ}$. Atom coordinates were determined for the latter form by three-dimensional analysis. Six chlorine atoms are coordinated to each titanium at about 2.57 . $\AA$. The monoclinic form has $\mu_{\text {eff }}=2.9 \pm 0.1$ Bohr magnetons and optical absorption maxima at 7900 and 14,800

5. To be published in Journal of Inorganic Chemistry.

6. Presently at State University of New York College at Old Westbury.

7. Chemistry Division. $\mathrm{cm}^{-1}$ assigned to ${ }^{3} \mathrm{~T}_{2}(\mathrm{~F}) \leftarrow{ }^{3} \mathrm{~T}_{1}(\mathrm{~F})$ and ${ }^{3} \mathrm{~T}_{1}(\mathrm{P})+$ ${ }^{3} \mathrm{~A}_{2}(\mathrm{~F}) \leftarrow{ }^{3} \mathrm{~T}_{1}(\mathrm{~F})$, respectively, with $D_{q}=700 \mathrm{~cm}^{-1}$.

\section{ELECTRONIC ABSORPTION SPECTRA OF PLATINUM(II) CENTERS IN LIQUID ALKALI METAL CHLORIDES $^{8}$}
G. P. Smith
G. N. Papatheodorou 9

The optical electronic absorption spectra of $\mathrm{Pt}(\mathrm{II})$ centers were measured in liquid $\mathrm{CsCl}, \mathrm{KCl}, \mathrm{LiCl}$, and $\mathrm{CsCl}-\mathrm{LiCl}$ and $\mathrm{KCl}-\mathrm{LiCl}$ mixtures over substantial temperature ranges. In $\mathrm{CsCl}$ at 650 to $700^{\circ} \mathrm{C}$ and in the eutectic mixtures below about $400^{\circ} \mathrm{C}$ the spectrum is that expected for normal square-planar $\mathrm{PtCl}_{4}{ }^{2-}$ complex anions at elevated temperatures. In $\mathrm{LiCl}$ and the mixed solvents at elevated temperatures the spectrum is modified by a drawing together of the two spin-allowed bands. This effect is attributed to the polarization of $\mathrm{PtCl}_{4}{ }^{2-}$ by the outer shell of $\mathrm{Li}^{+}$ions.

8. Abstract from J. Inorg. Nucl. Chem. 35, 799-807 (1973).

9. Presently at the James Franck Institute of the University of Chicago. 


\title{
6. Fundamental Physical Metallurgy
}

\author{
R. A. Vandermeer
}

Structure, broadly defined, plays an important role in determining physical and mechanical properties of technological materials. The extent to which structure can be controlled or altered often determines product reliability, dimensional stability, and the ultimate usefulness of engineering materials. This research seeks to provide a fundamental understanding of structural effects in metals and alloys and thus represents an essential undergirding of portions of current materials technology.

\section{PHASE TRANSFORMATIONS IN U-Nb-Zr AND U-Ti ALLOYS}

\section{R. A. Vandermeer}

Dilatometry, x-ray diffraction, and optical microscopy are being used to study phase transformations in polycrystalline uranium alloys.

In an alloy containing $7.5 \mathrm{wt} \% \mathrm{Nb}$ and $2.5 \mathrm{wt} \% \mathrm{Zr}$, quenching from the body-centered cubic $(\gamma)$ phase at $800^{\circ} \mathrm{C}$ produces a slight tetragonal distortion $\left(\gamma_{0}\right)$ of the high-temperature $\gamma$ phase. Weak, broad $x$-ray superlattice reflections are detected and can be explained by a short-range atom displacement ordering of the bcc structure. Quench rate and stress alter the character of the $x$-ray diffraction patterns of this metastable "phase," and explanations of the effects are being sought. Aging of the quenched alloy causes transformation to other structural states. The timetemperature-transformation behavior of the alloy, as determined by dilatometry measurements, shows four distinct stages. The transformation mechanisms responsible for these observations are being discovered. Additional experimental data are now being gathered to establish the composition range over which the $\gamma_{0}$ "phase" is present in quenched $\mathrm{U}-\mathrm{Nb} \cdot \mathrm{Zr}$ alloys.
A dilatometric investigation of the displacive (martensitic) shear transformations in uranium-titanium alloys is under way. The transformation start temperature $\left(M_{s}\right)$ and the volume change $(\Delta V / V)$ are being established for quenching rates between 300 and $1^{\circ} \mathrm{C} / \mathrm{sec}$ in alloys covering the composition range 0.4 to $4.0 \mathrm{wt} \% \mathrm{Ti}$. Aging studies on a U-0.75 wt \% Ti alloy quenched from $800^{\circ} \mathrm{C}$ are providing additional insight into the precipitation mechanisms of U-Ti alloys.

\section{TEXTURE INHOMOGENEITIES IN COLD-ROLLED NIOBIUM}

\section{R. A. Vandermeer J. Bernal ${ }^{1}$}

Crystal reorientation during cold rolling of polycrystalline sheet or plate material results in preferred orientation or texture. Previous work ${ }^{2}$ showed that under certain rolling conditions the nature of the texture produced in niobium depended on depth; that is, the texture was not the same from one layer to another in the thickness direction of the strip. We are seeking to understand the role that the shape of the zone of plastic deformation plays in the development of texture inhomogeneity.

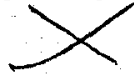

\section{DISPERSION HARDENING OF ALUMINUM}

$$
\text { R. A. Vandermeer J.C. Ogle }
$$

In the proposed underground superconducting power transmission lines, ultrahigh-purity aluminum is a candidate material for the component serving both to carry

1. On fellowship from Gerencia de Technologia, Comisión Nacional de Energia Atomica, Buenos Aires, Argentina.

2. R. A. Vandermeer and J. C. Ogle, Trans. Met. Soc. AIME 245, 1511-18 (1969). 
fault currents and to mechanically support the superconductor. High-purity aluminum, though electrically suitable, has a very low yield strength. To be acceptable, therefore, methods for producing a suitably strengthened aluminum while retaining reasonably high conductivity need to be discovered.

We are exploring the possibility of dispersion strengthening a dilute alloy whose solid solubility is extremely limited to find optimum dispersion characteristics to meet this need. Carefully characterized alloys of zone-refined aluminum containing $0.05,0.10$, and 0.20 wt $\%$ gold have been melted, cast, and homogenized. We are seeking to establish relationships between microstructure; that is, precipitate type, size, shape, concentration, and distribution; and the electrical and mechanical properties of the alloys.

\section{STRUCTURAL EFFECTS ON RADIATION}

DAMAGE

R. W. Carpenter

J. C. Ogle

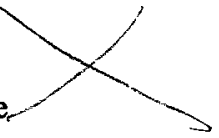

A set of alloys of the compositions $\mathrm{Al}-3.8 \% \mathrm{Cu}$, $\mathrm{Al}-1.7 \% \mathrm{Cu}, \mathrm{Al}-0.5 \% \mathrm{Si}$, and $\mathrm{Al}-3.8 \% \mathrm{Cu}-0.5 \% \mathrm{Si}$ was heat treated to produce a variety of precipitate structures spanning the morphological range from completely coherent Guinier-Preston zones through coherent $\theta^{\prime \prime}$, coherent $\theta^{\prime}$, and equilibrium incoherent $\theta$ phase. These structures were characterized by transmission electron microscopy. Specimens with these precipitate structures homogeneously distributed throughout their volume are being irradiated in the HFIR to a burnup of approximately $10^{22}$ neutrons $/ \mathrm{cm}^{2}$ (fast). 


\section{Physical Property Research<smiles></smiles>

D. L. McElroy

The physical properties of a solid are governed by mechanisms that indicate important characteristics of the solid and phenomena occurring therein. Thus, understanding the physical properties of solids can provide useful insight into solids, and application of this knowledge in materials selection may improve the performance of certain devices.

We are seeking an improved theoretical and practical understanding of the physical properties of solids by direct measurements and by critical data analyses. We accurately measure thermal conductivity, $\lambda$; electrical resistivity, $\rho$; Seebeck coefficient, $S$; specific heat capacity, $C_{p}$; coefficient of thermal expansion, $\alpha$; and total hemispherical emittance on selected solids from 4.2 to $2600 \mathrm{~K}$. Our analyses of these interrelated physical properties has tested theories, improved property estimates, suggested ways to control properties, and enhanced our measurement capacity. In addition this research provides a basis to obtain physical property information needed by other projects.

\section{APPARATUS DEVELOPMENT}

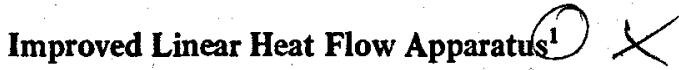
J. P. Moore
R. K. Williams
R. S. Graves

A longitudinal heat flow technique for precise measurement of $\lambda, \rho$, and $S$ for temperatures from 80 to $400 \mathrm{~K}$ is described. The basis of the technique is the use of a calibrated platinum resistance thermometer to provide in situ calibrations of specimen thermocouples. The total determinate errors at $272 \mathrm{~K}$ are $\pm 0.23 \%$ for $\rho$, $\pm 0.48 \%$ for $\lambda$, and $\pm 0.07 \mu \mathrm{V} / \mathrm{K}$ for $S$ when platinum wire is used as the reference. Experimental results on

1. Abstract of "Precision Measurements of the Thermal Conductivity, Electrical Resistivity, and Seebeck Coefficient from 80 to $400 \mathrm{~K}$ and Their Application to Pure Molybdenum," paper submitted to Review of Scientific Instruments. two high-purity molybdenum specimens with crosssectional areas differing by a factor of 4 are presented to demonstrate the system precision and low level of indeterminate errors.

\section{Electrical Resistivity Measurements}

\section{R. K. Williams $\quad$ R. S. Graves}

Many of our measurement techniques rely on a four-probe knife edge (KE) method to obtain sensor spacings. A new $\mathrm{KE}$ apparatus incorporates temperature control to $\pm 0.01^{\circ} \mathrm{C}$, improved current and low-level voltage measurements, internal resistance checks, and a KE support system to minimize KE wear. Measurements on tungsten and molybdenum were repeatable to $0.01 \%$ and were largely limited in accuracy by our ability to determine the sample cross-sectional area.

Residual resistivity ratio (RRR) measurements on high-purity samples often involve determining resistances as low as $10^{-10} \Omega$. Our RRR measurements were improved by using a turns-ratio potentiometer with a 2 $\times 10^{-9} \cdot \mathrm{V}$ detectability and by using direct currents as large as $30 \mathrm{~A}$. We believe this measuring range can be extended to $10^{-12} \Omega$ with a superconducting quantum interference device.

Equipment to measure RRR, $\rho$, and $S$ with KE was installed in a glove box. This allows high-temperature measurements of $\rho$ and $S$ on irradiated specimens, which are $\alpha$ and $\beta$ emitters.

\section{Computerized Data Acquisition}
T. G. Kollie
T. G. Godfrey
S. H. Jury ${ }^{2}$

A programmable suppression voltage supply, a digitalto-analog converter, and a binary-coded-decimal interface were added to the ORNL-designed computer-

2. Consultant, University of Tennessee. 
operated data acquisition system (CODAS). This improved system is used with various apparatuses to obtain on-line property measurements.

CODAS was interfaced with a quartz differential dilatometer to obtain $\alpha$ from 300 to $1000 \mathrm{~K}$ by automatically initiating and controlling furnace cycles and by obtaining attendant data on sample length and temperature. National Bureau of Standards (NBS) certified quartz ( 300 to $1000 \mathrm{~K}$ ) and copper ( 300 to $800 \mathrm{~K}$ ) were used to demonstrate an accuracy of $\pm 1.5 \%$ in $\alpha$ determinations.

CODAS was interfaced with a transient plane probe method to determine $\lambda$ and thermal diffusivity $(D)$ of large samples. In this technique, CODAS applies and controls the power to a planar heater mated to the sample, records the corresponding sample temperature response, and processes these data to obtain $\lambda$ and $D$, all in a matter of minutes. The accuracy of this method is being established with NBS $\lambda$ standards of rubber and pyroceram.

\section{Heat Flow Analysis}

\section{T. G. Godfrey T. G. Kollie J. P. Moore}

We applied a finite-difference heat-conduction code ${ }^{3}$ to several heat flow problems to increase our understanding of flow patterns and to suggest useful equipment modifications. Analysis of a guarded linear heat flow apparatus showed the specimen heat exchange with its insulation depended on the specimenguard temperature mismatch, which is a function of the guard cylinder material and design. The temperature response of a Nichrome-BN composite heater was modeled and compared with pulse heating experiments. This analysis showed that the $\lambda$ of the BN used was less than anticipated, and a more refractory heating element than Nichrome would be necessary to produce a high-performance heater. A similar analysis on a high- $\lambda$ and low- $\rho$ sample (aluminum) being tested in the pulse-heated calorimeter suggested ways to minimize uncertainties in $C_{p}$ measurements.

\section{TRANSPORT IN METALS}

Aluminum

\section{J. P. Moore T. G. Kollie}

The $\lambda$ and $\rho$ of four aluminum samples (RRR 950, 8500,11000 , and 17 ) were measured from 80 to $400 \mathrm{~K}$

3. W. D. Turner and M. Siman-Tov, HEATING 3 - an IBM 360 Heat Conduction Program, ORNL-TM-3208 (February 1971). in three apparatuses of different design. Within experimental scatter, there is not a minimum in $\lambda$ of any sample. A lattice contribution was calculated from

$$
\lambda_{l}=17 / T+5000 / T^{2}
$$

and the resulting electronic component of $\lambda$ as a function of temperature showed a minimum $4 \%$ below its value at a subsequent peak.

The $\rho$ of another aluminum sample (RRR 232) was measured from 300 to $900 \mathrm{~K}$ with CODAS. Data between 315 and $540 \mathrm{~K}$ fit a modified Bloch-Gruneisen equation to $\pm 0.08 \%$ :

$$
\begin{aligned}
\rho=(927 \pm 5) \times 10^{-5} T+ & (227 \pm 7) \\
& \times 10^{-8} T^{2}-(72.3 \pm 2.6) / T .
\end{aligned}
$$

From the coefficient of the $T$ term we calculated the theoretical values of the other two to be $269 \times 10^{-8}$. and 78.3. Above about $540 \mathrm{~K}$, the creation of vacancies increases $\rho$; and if this increase is proportional to the vacancy concentration, the data from 315 to $905 \mathrm{~K}$ may be fitted to

$$
\begin{aligned}
\rho=(912 & \pm 2) \times 10^{-5} T+(247 \pm 3) \times 10^{-8} T^{2} \\
& -(64.9 \pm 1.9) / T+(824 \pm 24) \exp (0.633 / k T),
\end{aligned}
$$

where the last term is due to vacancy formation in the aluminum lattice. The energy of formation of vacancies in aluminum given by this expression is $0.633 \mathrm{eV}$, which compares to the most recent literature ${ }^{5}$ value of $0.65 \mathrm{eV}$.

Because the literature values of $C_{p}$ of aluminum show a scatter of $5.1 \%$ between 400 and $933 \mathrm{~K}$, the calculated anharmonic heat capacity may be positive or negative (theory predicts negative). We are measuring $C_{p}$ of aluminum from 300 to $800 \mathrm{~K}$ in the pulse-heating calorimeter.

4. This paragraph was abstracted from J. G. Cook, J.P. Moore, T. Matsumura, añd M.P. VanderMeer, "The Thermal and Electrical Conductivity of Pure Aluminum from 80 to 400 K," paper submitted to Canadian Journal of Physics. Cook, Matsumura, and VanderMeer are with the National Research Council of Canada, Ottawa, Canada.

5. A. Seeger and H. Mehrer, "Analysis of Self-Diffusion and Equilibrium Measurements," p. 41 in Vacancies and Interstitials in Metals, ed. by A. Seeger et al., North-Holland Publishing Company, Amsterdam, 1970. 


\section{Platinum and Lead ${ }^{6}$ \\ J. P. Moore R. S. Graves

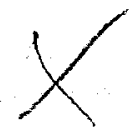

The absolute $S$ (Seebeck coefficient) of platinum was determined from 80 to $350 \mathrm{~K}$ by direct comparison with lead. Results of this comparison disagree with previous values that have been used for the calculation of absolute values for other materials. The $\lambda$ and $\rho$ of the lead standard were also determined. The $\rho$ could be described with a modified Bloch-Gruneisen equation, which allows for the effect of thermal expansion on the Debye temperature, $\theta_{D}$. The ratio $\lambda \rho / T$ was within $1 \%$ of the Sommerfeld value of $2.443 \times 10^{-8}(\mathrm{~V} / \mathrm{K})^{2}$ from 1.0 to $5.00_{D}$.

\section{Chromium \\ J. P. Moore

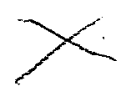

A chromium sample (Cr-A) 2 was brazed to the heater and heat sink of the high-temperature longitudinal heat flow apparatus to prevent interfacial temperature drops during $\lambda$ measurements. This should permit measurements of $\lambda, \rho$, and $S$ to high temperatures, and the $\lambda$ results should be more accurate than previous results since temperature match between specimen and guard was improved. Before any high-temperature experiments were conducted, numerous measurements were made near the Neel temperature, $T_{N}$, of $311.8 \mathrm{~K}$ using pumped ice water for a coolant and a nanovolt potentiometer for determining thermocouple outputs. These data were within $1 \%$ of our published values? over the narrow range from 285 to $340 \mathrm{~K}$ and verified the absence of a large peak in $\lambda$ near $T_{N}$.

\section{LATTICE HEAT TRANSPORT IN ALKALI HALIDES}

\section{J. P. Moore $\quad$ R. K. Williams}

In some poor thermal conductors at high reduced temperatures $\left(T / \theta_{D}\right)$, photons may transport a large part of the heat flow. To obtain phonon transport, heat

6. Abstracted from "The Absolute Seebeck Coefficient of Platinum from 80 to $340 \mathrm{~K}$ and the Thermal and Electrical Conductivities of Lead from 80 to $400 \mathrm{~K}$, " J. Appl. Phys. 44(3), 1174-78 (1973).

7. J. P. Moore, R. K. Williams, and D. L. McElroy, in Thermal Conductivity, Proceedings of the Seventh Conference, Gaithersburg, Maryland, 13-16 November 1967, edited by D. R. Flynn and B. A. Peavy, Jr., National Bureau of Standards, (U.S.) Special Publications No. 302 (U.S. Government Printing Office, Washington, D.C., 1968), pp. 297-310. flux corrections may be made by accurately calculating photon heat transfer or by measuring on samples that are opaque in the infrared. Because intemal grain boundaries scatter photons but do not significantly affect phonon transport, we prepared a dense (97-99\% of theoretical), high-purity, fine-grained sample of $\mathrm{RbI}$ to pursue the latter path. Measurements of $\lambda$ of polycrystalline $\mathrm{RbI}$ showed that previous radiation calculations for single-crystal rubidium compounds underestimated the radiant heat flow. The measurements on $\mathrm{RbI}$ were analyzed to obtain corrections for infrared transmission through $\mathrm{RbCl}$ and $\mathrm{RbBr}$.

\section{COEFFICIENT OF THERMAL EXPANSION OF NICKEL}

\section{T. G. Kollie}

Measurements of $\alpha$ for nickel from 300 to $1000 \mathrm{~K}$ were completed using the computer-operated dilatometer. Detailed data obtained near the Curie temperature $(630 \mathrm{~K})$ are being analyzed to evaluate theoretical predictions of this critical point phenomenon.

\section{APPLIED RESEARCH}

\section{L. McElroy}

We generated information for other projects, which is reported below and in other chapters of this report (16, 17,20 , and 24).

We contributed to the ORNL reassessment of lightwater-reactor Zircaloy-clad fuel pins during a loss-ofcoolant accident. We assessed the $\lambda$ of $\mathrm{UO}_{2}$ and the gap conductance between $\mathrm{UO}_{2}$ and the cladding, since both largely govern internal fuel temperatures during steadystate and transient conditions in a nuclear reactor.

We designed and constructed a calorimetric point limiter for the ORNL Thermonuclear Division (TND) to measure the energy content of the ORMAK plasma. This effort included modeling analysis of the response of the probe to an energy pulse and analog tests to define the operational limits of the probe. Analysis by the TND of the energy measured by this probe indicated that the primary electron loss mechanism in ORMAK is by nonuniform radiation.

The temperature dependences of $\alpha, C_{p}, \rho, \lambda, S$, Poisson's ratio, and the shear, Young's, and bulk moduli of two uranium alloys were measured in the range 77 to $1500 \mathrm{~K}$. The room-temperature density and hardness and the liquidus and solidus temperatures were also determined. Generally the properties of these multi- 
phased alloys were similar to $\alpha$ - or $\gamma$-uranium in their corresponding intervals of stability 8

We conducted a desk study of possible materials to line holes in a salt mine to allow double containment and retrieval of nuclear wastes. This study suggests testing of heavy-wall low-carbon steels and thin-wall steels with a thick refractory cement outer wall. The above-mentioned CODAS:plane probe method was developed to measure $\lambda$ and $D$ of core samples of strata at the salt mine.

8. T. G. Kollie, J. P. Moore, DـL.McElroy W. L. Whaley, R. K. Williams, T. G. Godfrey, W. M. Ewing, and R. S. Graves, Thermophysical Properties of Uranium Based Mo, Nb, Zr, Ti Alloys, from 77 to $1500 \mathrm{~K}$, ORNL-TM-4253 (June 1973).
The $\lambda$ of three low-density, high-temperature fibrous carbon insulations was measured from 300 to $1300 \mathrm{~K}$ in argon, nitrogen, and vacuum in the improved radial heat flow apparatus for powders: The $\lambda$ values in directions perpendicular and parallel to the fiber deposition plane increased with temperature for samples heat treated at $1300^{\circ} \mathrm{C}\left(\lambda_{\|} / \lambda_{\perp} \sim 3\right)$. However $\lambda_{\perp}$ decreased with temperature for a sample heat treated at $2500^{\circ} \mathrm{C}$, indicating incipient graphitization of the amorphous carbon fibers. In all cases radiative heat transfer became important at high temperatures.

9. T. G. Godfrey, Metals and Ceramics Div. Annu. Progr. Rep. June 30, 1972, ORNL-4820, p. 25. 


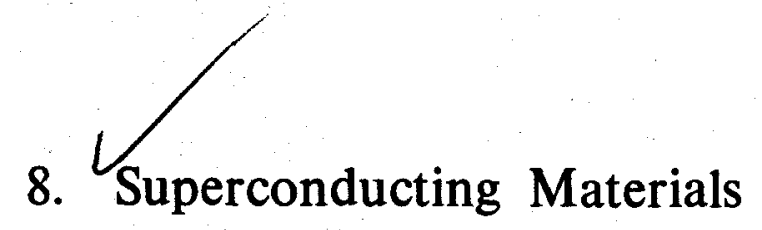

$60^{370}$

\author{
C. C. Koch
}

We are studying the effects of metallurgical variables on the properties of superconducting materials. The most highly structure-sensitive superconducting property appears to be current-carrying capacity in an applied magnetic field. It is sensitive to microstructural variables such as grain size, dislocation density and distribution, and morphology, composition, and volume fraction of second-phase particles. Meaningful correlation of structure and properties requires detailed knowledge of both. Consequently, some of our effort is devoted to obtaining basic metallurgical information on phase diagrams, transformation kinetics and products, and the microstructures that result from them in alloy systems based upon superconducting materials. We then correlate current-carrying capacity to the "model" microstructures we have prepared.

We also study the influence of metallurgy on the basic superconducting property $T_{c}$, the superconductingnormal transition temperature. This property is controlled by alloying and, in compound superconductors, by degree of long-range chemical order. In conjunction with this part of our program we measure low-temperature specific heat capacities.

\section{MEASUREMENT OF CRITICAL BULK AND SURFACE CURRENT DENSITIES IN TYPE II SUPERCONDUCTORS IN THE MIXED STATE 12}
D. M. Kroeger
C. C. Koch
W. A. Coghlan

We present an improved method for calculating from ac susceptibility measurements the critical current density $J_{c}$ and the surface shielding parameter $\Delta H$ in bulk cylindrical type II superconductors. As first developed by Bean, the method involves harmonic analysis of an expression for the voltage induced in a

1. Abstracted from a paper published in J. Appl. Phys. 44, 2391-96 (1973). pickup coil around a specimen in an axial dc magnetic field with a small ac ripple field superimposed. Values of $J_{c}$ obtained by Bean's analysis are suspect, in part because the analysis does not take account of surface shielding. Ullmaier modified Bean's calculation to remedy this defect. For simplicity he did not Fourier analyze the induced voltage, choosing instead to determine $J_{c}$ and $\Delta H$ by comparing experimental waveforms with his calculated voltage. This procedure allows one only a qualitative indication of whether the data are consistent with the model. For generality, we have modified Ullmaier's calculation by removing the approximation that the depth of penetration of the ac field is small compared to the sample radius. The resulting expression for the induced voltage, $V$, is a complicated function of $J_{c}, \Delta H$, and the amplitude of the ripple field, $h_{0}$. We developed a graphical procedure that not only extracts values of $J_{c}$ and $\Delta H$ from plots of the amplitude of the third harmonic of $V v s h_{0}$, but also provides a check for consistency of the data with the model.

\section{EFFECTS OF INTERSTITIAL OXYGEN ON THE SUPERCONDUCTIVITY OF NIOBIUM?2}
C. C. Koch
J. O. Scarbrough
D. M. Kroeger

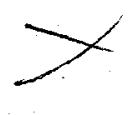

Superconductivity in niobium-oxygen bcc solidsolution alloys (oxygen content 0.024 to 3.50 at. \%) was studied by calorimetric, magnetic, and resistive measurement techniques. These measurements included low-temperature specific heat capacity, superconducting-normal transition temperature $\left(T_{c}\right)$, dc magnetization, and electrical resistivity, as well as $\mathrm{x}$-ray lattice parameter, microhardness, and optical metallography to characterize the samples. Oxygen in solid solution lowers the $T_{c}$ of niobium. In contrast to the prediction

2. Abstracted from a paper submitted for publication. 
of DeSorbo, we found that $\gamma$, the electronic coefficient of low-temperature specific heat capacity, also decreases with oxygen concentration. Our data indicated that $N_{b s}(0)$, the "band structure" electronic density of states at the Fermi level, and $\lambda$, the electron-phonon coupling constant, both decrease with oxygen content. Therefore, both the density of electronic states and the phonon spectrum may control the magnitude of $T_{c}$ in the niobium-oxygen system.

Additional superconducting parameters were calculated for the niobium-oxygen alloys from our calorimetric, magnetic, and resistive data. The GinsbergLandau parameter, $\kappa_{\mathrm{GL}}$, increased from below 1.0 for essentially pure niobium to about 10 for $\mathrm{Nb}-3.5$ at. \% O. Calculated values of $H_{C_{2}}(4.2 \mathrm{~K})$ as a function of composition exhibit a maximum at 2 at. $\% 0$, which was observed experimentally.

\section{ANNEALING, LONG-RANGE ORDER, AND SUPERCONDUCTING TRANSITION TEMPERATURE IN THE $V_{3} \mathbf{G a}$ A-15 COMPOUND ${ }^{2}$}

\section{C. Koch}

Changes in $T_{c}$ with chemical long-range-order parameter $S$ in the $V_{3}$ Ga A-15 compound were studied. Although $T_{c}$ can be increased in the $V_{3} \mathrm{Ga}$ compound by about $1.5 \mathrm{~K}$ (i.e., $10 \%$ ) by low-temperature annealing, the order parameter $S$ is independent of annealing temperature. Either the x-ray technique was too insensitive to detect subtle changes in $S$ responsible for increasing $T_{c}$, or other structural changes due to the annealing were responsible.

\section{A LOW-TEMPERATURE X-RAY INVESTIGATION OF TECHNETIUM AND THE Tc-Mo A-15 COMPOUND}

$$
\begin{array}{ll}
\text { J.A.C. Marples } & \text { C. C. Koch }
\end{array}
$$

The structural stability at low temperatures of pure technetium and the Tc-40 at. \% Mo A-15 compound was investigated by $x$-ray diffraction. Diffractometer studies between 4.2 and $298 \mathrm{~K}$ showed (1) that technetium maintains its hep structure down to $4.2 \mathrm{~K}$ with a nearly constant axial ratio, and (2) that no

3. Abstracted from a paper to be published in Journal of Physics and Chemistry of Solids.

4. Abstracted from a paper published in Phys. Letters 41A, 307-08 (1972).

5. Process Technology Division, AERE, Harwell, United Kingdom. tetragonal distortion occurs in this temperature range in a Tc-40 at. \% Mo A-15 compound with a $T_{c}$ of $13.5 \mathrm{~K}$.

\section{CRITICAL CURRENT DENSITIES IN SPUTTER-DEPOSITED Nb-Al-Ge}

\section{M. Kroeger S. Dahlgren ${ }^{6}$}

The highest known values of $T_{c}$ and $H_{C_{2}}$ occur in compounds having the approximate composition $\mathrm{Nb}_{3}\left(\mathrm{Al}_{3} \mathrm{Ge}\right)$. The upper critical field for this material $\left(H_{C_{2}} \gtrsim 400 \mathrm{kOe}\right)$ is nearly twice that of $\mathrm{Nb}_{3} \mathrm{Sn}$ and $\mathrm{V}_{3} \mathrm{Ga}$, the high field superconductors presently available commercially. Thus there is reason to hope that $\mathrm{Nb}_{3}\left(\mathrm{Al}_{3} \mathrm{Ge}\right)$, if properly prepared, would support useful current densities in significantly higher fields than would $\mathrm{Nb}_{3} \mathrm{Sn}$ and $\mathrm{V}_{3} \mathrm{Ga}$. Like $\mathrm{Nb}_{3} \mathrm{Sn}, \mathrm{V}_{3} \mathrm{Ga}$, and other very high-field materials, $\mathrm{Nb}_{3}\left(\mathrm{Al}_{3} \mathrm{Ge}\right)$ has the $\mathrm{A}-15$ crystal structure and is therefore brittle, making special fabrication procedures necessary. One method of fabrication that may be applicable to the production of large lengths of superconductor with suitable backing material (as is required for construction of high field magnets) is sputtering. In a cooperative program with Battelle Northwest Laboratories, we are investigating the current-carrying properties of sputter-deposited $\mathrm{Nb}-\mathrm{Al}-\mathrm{Ge}$ compounds. They have high sputtering-rate capabilities, which allow them to produce specimens up to several mils in thickness. Measurements on several specimens with various heat treatments have indicated critical current densities as high as $4 \times 10^{5 \mathrm{~A}} / \mathrm{cm}^{2}$ at $100 \mathrm{kOe}$. This is significantly higher than $J_{c}$ values reported by others in this material and is comparable to the values obtained in commercial materials at this field.

\section{ZIRCONIUM-CADMIUM AND CERTAIN OTHER SOLID SOLUTIONS?}

THERMODYNAMIC PROPERTIES OF

\section{$\begin{array}{lll}\text { J. H Frye, Jr. J. O. Betterton } & \text { D. S. Easton }\end{array}$}

The experimental work reported here has to do with the zirconium-rich zirconium-cadmium alloys. The phase diagram was determined up to a concentration of 20 at. \% Cd. Lattice parameters were measured for the hexagonal phase. The vapor pressure of cadmium in

6. Battelle Northwest Laboratories.

Q. Abstracted from a paper published in Acta Met. 20, 1183-95 (1972).

8. Now at Department of Physics, Louisiana State University at New Orleans, Louisiana 70100. 
equilibrium with the solid solution was measured for both the hexagonal and cubic phases as functions of temperature and concentration.

These data are considered together with earlier data on the $\mathrm{Zr}$-Ag, Zr-In, $\mathrm{Zr}$-Sn, and $\mathrm{Zr}$-Sb primary substitutional solid solutions. Empirical relations are found between the hexagonal $c / a$ ratio, the temperature of the transformation from cubic to hexagonal zirconium, and the electronic specific heat coefficient on the one hand and the concentration of principal quantum number 5 electrons on the other.

These simple relations suggest the possibility that the principal quantum number 5 electrons are entering a rigid conduction band in zirconium. To investigate this possibility, we calculated the partial molal energy of cadmium in zirconium from the vapor pressure measurements. We also did this for certain other solutions for which vapor pressure data have been published. We conclude that the rigid band model is a bad approximation and point out that this is in accord with recent quantum mechanical calculations. Furthermore, the effect of cadmium on the transformation temperature of zirconium is the resultant of two opposite and nearly balanced effects, an absolute zero energy effect that tends to stabilize the cubic form and an entropy effect that tends to stabilize the hexagonal form. Finally, we showed that, for most of the solutions considered here, the energy of a Wigner-Seitz polyhedron is independent of concentration within experimental error.

\section{SUPERCONDUCTING MATERIALS TECHNOLOGY FOR POWER TRANSMISSION}
C. C. Koch
D. M. Kroeger
D. S. Easton

The application of superconductivity to underground transmission of electricity is limited in part by the characteristics of the superconducting materials. Our goal in this program is to understand the mechanisms and the relative importance of material parameters that control ac losses so that these losses might be minimized in high $T_{c}$ materials.

We have begun our systematic investigation of ac losses with dispersions of rare earths in niobium: $\mathrm{Nb}-\mathrm{Y}$, $\mathrm{Nb}-\mathrm{Gd}$, and $\mathrm{Nb}-\mathrm{La}$. The presence of insoluble rare earth particles greatly enhances the magnetic hysteresis of niobium in both the fully cold-worked and wellannealed conditions. We have constructed levitation melting equipment to aid in the preparation of the above dispersions. We are constructing ac loss measuring equipment, which includes a sensitive wattmeter, an ac superconducting solenoid, and an ac power supply. 


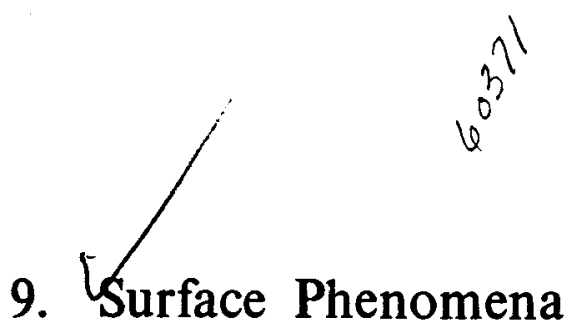

\section{J. V. Cathcart}

The major aim of the research of this group is to understand the basic mechanisms of oxidation of metals and alloys. We are concerned with the various ways alloying elements alter the oxidation properties of metals, and we are especially interested in the influence of stress on oxidation processes. We have shown for certain classes of alloys that a major effect of alloying elements on the oxidation characteristics of the base metal is related to changes they produce in the mechanical properties of the oxide scale or the base metal.

Specific research projects are divided between two areas, one involving a series of uranium-base alloys and the other several refractory metal alloys based on tantalum. Phenomena of interest in these investigations include internal oxidation, grain boundary embrittlement, oxygen solution effects, stress-generating and stress-relief mechanisms operative during oxidation, and various diffusion effects.

\section{OXIDATION OF URANIUM-BASE ALLOYS}

\section{$\begin{array}{lll}\text { J. V. Cathcart R. E. Pawel G. F. Petersen } & \text { R }\end{array}$}

The Mechanical Properties of Two Uranium Alloys and Their Role in the Oxidation of the Alloys?

$$
\text { J. V. Cathcart C. T. Liu }
$$

The creep and tensile properties of two uranium alloys (U-21 at. \% Nb and $\mathrm{U}-16.6$ at. $\% \mathrm{Nb}-5.6$ at. \% $\mathrm{Zr}$ ) were determined in the range 750 to $900^{\circ} \mathrm{C}$. The creep data were fitted to an equation of the form $\dot{\epsilon}=$ $k 0^{n} \exp (-Q / R T)$, which in turn was used to calculate stresses in oxidizing alloy specimens on the basis of elongation measurements made on the specimens during oxidation. The variation of the average stress in the

1. Abstracted from Oxidation of Metals, in press. oxide and in the substrate metal is given as a function of time. The details of the mechanism by which stresses are generated during the oxidation of the alloys are discussed. Comparisons of the relative creep and oxidation rates of the alloys with the stress levels observed during oxidation lead to the conclusion that, at least for certain specimen geometries, the differences in the mechanical properties of the oxide scales and of the parent alloys account in large measure for the differences in the oxidation characteristics of the alloys.

\section{The Oxidation of $\mathrm{U}-14$ at. \% $\mathrm{Zr}$ Between 700 and $900^{\circ} \mathrm{C} i$ \\ J. V. Cathcart G. F. Petersen}

The oxidation properties of the binary alloy $\mathrm{U}-14$ at. $\% \mathrm{Zr}$ were investigated at 700 to $900^{\circ} \mathrm{C}$ in oxygen at a pressure of 0.05 torr. Typical oxidation rate curves are presented, and the morphology of the oxide scale is discussed. The creep rate of the alloy during oxidation and a possible mechanism of stress generation are presented. The oxide morphology and the spatial redistribution of the zirconium during oxidation are discussed in terms of the relative stabilities of the oxidation products.

\section{OXIDATION OF REFRACTORY METAL ALLOYS}

$$
\text { R. E. Pawel J. J. Campbell }
$$

Certain tantalum-base alloys disintegrate into their individual grains during oxidation and "ignite" as a result of the extremely rapid oxidation that then occurs. This ignition phenomenon was studied as a function of grain size at $800^{\circ} \mathrm{C}$ for $\mathrm{Ta}-10 \mathrm{wt} \% \mathrm{~W}$. A comparison of the ignition characteristics of this alloy with those of the alloy T-222 (Ta-9 wt \% W-2.5 wt \% Hf) showed that ignition was substantially retarded in the latter alloy. We attribute this result to a delay in 
grain boundary embrittlement occasioned by the preferential reaction of the hafnium in the ternary alloy with dissolved oxygen.

\section{DIFFUSION STUDIES}

\section{R. E. Pawel}

We participated in a joint investigation sponsored by the American Society for Mass Spectrometry designed to cross-check the results of various sensitive analytical devices used in sectioning and analyzing diffusion specimens. We provided the standard specimens, which were anodic oxide films of known thicknesses, containing phosphorous in known concentrations and distributions, and formed on tantalum coupons. 


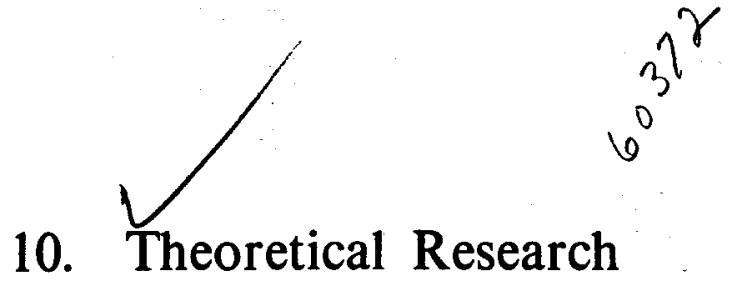

J. S. Faulkner

Our theoretical capabilities range from classical elasticity used for lattice defect theory to quantum mechanics used for studies of electrons in ordered or disordered solids. We have contributed significantly to the development of the Korringa-Kohn-Rostoker (KKR) and discrete variational method (DVM) band theory techniques, the coherent potential approximation (CPA) and its extensions for calculating electronic states in disordered systems, and the anisotropic elasticity theory of dislocations. We are using these techniques to gain an understanding of the properties of technologically interesting materials in their normal states and after radiation damage. Other contributions from this group are reported in Chapters 3 and 4.

\section{KKR BAND STRUCTURE CALCULATIONS FOR COMPLEX CRYSTALS:}

\section{J. C. Faulkner}

A formula for KKR structure constants for crystals having more than one atom per unit cell, which has the advantage that the major computational effort is spent only on calculating the relatively small number of structure constants for the associated Bravais lattice, was derived by the author from simple manipulations of the basic KKR equations. ${ }^{2}$ A new derivation of this formula on the basis of multiple scattering theory has been carried out and clarifies the meaning of the terms. This new derivation is discussed along with a comparison with recent similar work and comments on the application of the formula in practical calculations.

\section{DENSITY OF STATES EXPRESSED AS CONTINUED FRACTION OF MATRICES; APPLICATION TO DISORDERED SYSTEMS ${ }^{3}$}

\section{J. M. Lloyd ${ }^{4} \quad$ W. H. Butler}

Use of the Shur complement technique for inversion of block tri-diagonal matrices simplifies the calculation of the Green's function for disordered systems. This technique allows the consideration of systems by treating the local region exactly and approximating the more removed region.

\section{SELF-CONSISTENT CLUSTER THEORIES OF DISORDERED ALLOYS}

\author{
W. H. Butler
}

Several techniques for extending the single-site Coherent Potential Approximation to account for local clusters of atoms are evaluated. We show that attempts to define a site diagonal medium by requiring consistency between the Green's function evaluated at the center of the cluster and the external medium lead to unphysical results. If, however, one requires consistency between a site at the boundary of the cluster and the medium one can obtain (in one dimension) a site diagonal medium that reproduces the $n$-site CPA. Implications of this result for three-dimensional systems are discussed.

\section{PROBLEMS IN STRONG SCATTERING BINARY ALLOYS 5}

$$
\text { Bernie G. Nickel }{ }^{6} \quad \text { W. H. Butler }
$$

We present results of model calculations based on two different approximations, which were both intended to

1. Abstract of a talk presented at the March meeting of the American Physical Society, San Diego, California, March 19-22, 1973.

2. J. S. Faulkner, Phys. Lett. A 31, 227 (1970).

3. Abstract of a talk presented at the Southeastern Section Meeting of the American Physical Society, Birmingham, Ala., November 1972.

4. Physics Department, Auburn University, Auburn, Alabama.

5. Abstract of a paper published in Phys. Rev. Lett. 30, 373 (1973).

6. Department of Theoretical Physics, University of Oxford, Oxford, England. 
be improvements over the Coherent Potential Approximation. Both approximations yield nonphysical solutions; specifically, they predict average Green's functions that contain singularities on both upper and lower half complex energy planes. We conjecture that nonanalytic behavior will occur generally in high-order approximations to the average Green's function.

\section{CHARGED IMPURITY DRIFT AND DISPERSION IN DISCRETE MEDIA?}

\section{W. H. Butler A. T. Fromhold, $\mathrm{Jr}^{4}{ }^{4}$}

The field-modified drift rate and dispersion of a $\delta$-function distribution of charged impurities in a solid is examined by means of difference equations appropriate for discrete media. Transport is predicted to be affected markedly by the discreteness of the medium in the limit of large electric fields.

\section{AUGER CATALOG CALCULATED TRANSITION ENERGIES LISTED BY ENERGY AND ELEMENT 8 )}

\section{W. A. Coghlan R. E.Clausing}

The possible Auger transitions between 10 and 3000 $\mathrm{eV}$ for the elements from atomic number 3 through 92 have been calculated for $6000-\mathrm{eV}$ incident electrons. Use was made of the empirical expression $E_{v x y}=E_{v}$ $E_{x}-E_{y}$, where $E_{v}$ is the binding energy of the initially ejected electron, $E_{x}=\left[E_{x(z)}+E_{x(Z+1)}\right] / 2$, and $E_{y}=$ $\left[E_{y(z)}+E_{y(z+1)}\right] / 2 . E_{x(z)}$ and $E_{x(Z+1)}$ are the atomic binding energies for the $x$ electron in atoms having atomic numbers $Z$ and $Z+1$, respectively. $E_{y(Z)}$ and $E_{y(Z+1)}$ are the same for the $y$ electron. The spectra are listed in order of increasing atomic number, and the transitions for each element are identified and listed in order of increasing energy.

\section{DIFFUSION OF VACANCIES NEAR FAULTED DISLOCATION LOOPS IN ALUMINUM ${ }^{9}$}

\section{W. A. Coghlan}

Published calculations for the shrinkage rate of faulted dislocation loops in aluminum have agreed with

7. Abstract of a paper published in Solid State Communications 12, 919 (1973).

8. Abstract appearing on a catalog published as the entire number, Atomic Data 5(4), 317-469 (1973).

2. Abstract of a talk presented at the Spring meeting of the Metallurgical Society of AIME, Philadelphia, May 29-June 1, 1973. experimental observations for loops larger than about $1000 \AA$; however, smaller loops shrink much faster than predicted. We wanted to determine if this increased shrinkage rate is related to the gradient in interaction energy between the dislocation loop and the vacancy. The vacancy concentration profile and the total vacancy flux were calculated numerically for Frank loops in aluminum. The interaction energy was calculated for a finite loop by use of Eshelby's sphere-in-hole model. The resulting loop shrinkage rates were compared with published experimental data and also with rates based on analytical diffusion results that ignore the loop-vacancy interaction.

\section{ELECTRONIC STATES OF MULTILAYER GRAPHITE ${ }^{1}$}

\section{G. S. Painter}

A first-principles calculation of the electronic structure of the multilayer graphite crystal within the Hartree-Fock-Slater (HFS) energy band model was extended up to $50 \mathrm{eV}$ above the Fermi energy by use of the discrete variational method ${ }^{10}$ with a linearcombination-of-atomic-orbitals (LCAO) basis set. The density of states and optical properties derived from the bands are compared with recent thermoreflectance, photoemission, and secondary electron emission experimental data. The graphite band structure is compared with some preliminary results of a multiple-scattering HFS treatment of a cluster of carbon atoms, and the usefulness of the LCAO approach is assessed.

\section{OBSERVATION OF HIGH-ENERGY EXCITED STATES IN GRAPHITE ${ }^{1 \mathrm{~T}}$

$$
\begin{gathered}
\text { R. F. Willis }{ }^{12} \text { B. Fitton }{ }^{12} \\
\text { G. S. Painter }
\end{gathered}
$$

The resolution of weak secondary electron emission structure in the second derivative of the energy distribution spectrum of graphite is reported for kinetic energies in the range 10 to $45 \mathrm{eV}$. Intensity maxima . correlate closely with final density of states maxima located at 16.2, 19.2, 22.2, 29.2, 31.2, 36.2, and 40.7 $\mathrm{eV}$ above the Fermi energy, as determined from a first-principles energy band calculation over an $80-\mathrm{eV}$ range.

10. D. E. Ellis and G. S. Painter, Phys. Rev. B 2, 2887 (1970).

11. Abstract of a paper to appear in the Physical Review.

12. Surface Physics Division, European Space Research Organization, Noordwijk, Holland. 


\section{A COMBINED KORRINGA-KOHN-ROSTOKER- DISCRETE VARIATIONAL METHOD FOR THE ELECTRONIC STRUCTURE OF CRYSTALS AND MOLECULES WITH GENERAL POTENTIALS 13}

\section{G. S. Painter}

An increasing interest in both more adequate oneelectron model Hamiltonians and more precise calculations of eigenvalues and total energies for clusters and solids has led to renewed efforts to devise efficient computational schemes capable of treating general potentials with high accuracy. In this communication, we describe how the recently developed discrete variational method (DVM) for the energy band problem has been combined with the Korringa-Kohn-Rostoker (KKR) procedure to adapt the latter to treat general one-electron crystal potentials. Orbitals obtained from a KKR calculation for the muffin-tin average of the full Bloch Hamiltonian are used as trial variational functions for treating the complete problem within the framework of the DVM. Non-muffin-tin corrections originating from all regions of the unit cell are explicitly included by diagonalization of the relevant secular matrix in this basis set. This combination of the DVM and KKR methods to a large extent achieves the main advantages of each scheme and promises to be an efficient procedure for calculating the electronic structure of crystal compounds. With this method there is no limitation to a single type basis set; for some purposes, it may be useful to supplement the KKR orbitals with other trial functions. The high accuracy that is achieved allows definitive conclusions to be drawn concerning the effects of the non-muffin-tin corrections on electronic structure. Illustrative results given for an application of the method to paramagnetic nickel demonstrate this point. An extension of the method is described by which the non-muffin-tin potential and charge density corrections can be included in the multiple scattering approach to the electronic structure of molecules.

\section{A COMBINED MULTIPLE-SCATTERING-DISCRETE- VARIATIONAL METHOD FOR THE MOLECULAR CLUSTER PROBLEM}

\section{G. S. Painter}

Recently, multiple scattering theory has been applied with considerable success to calculating electronic states for molecular clusters in the one-electron formulation. Impressive improvement in computation time is achieved over that for the comparable LCAO treatment for the cluster. However, the great computational efficiency of the multiple-scattering approach is a consequence of the simplicity of the employed "muffin-tin" model potential. In this approximation, one reduces the Hartree-Fock exchange to the Slater statistical exchange and replaces the exact anisotropic potential and charge density by spherical averages within spheres about the nuclei and constant values in the intersphere volume. Although the potential model that is currently employed in the multiple-scattering technique is thus restricted, still solutions of arbitrary accuracy can be efficiently derived. This contrasts with the LCAO scheme, in which general potentials can be treated, but serious basis convergence problems exist.

The question poses itself then, how can we best use the mathematical and computational advantages of the multiple-scattering approach to improve variational calculations in which the muffin-tin approximation is not used. Our suggestion is that the full Hamiltonian $H$ be partitioned into a muffin-tin average $H_{0}$ and a non-muffin-tin correction, $\Delta$, and the multiplescattering method be used to find precise wave functions of $H_{0}$. Taking these orbitals as trial functions, the solutions to $H$ can then be determined variationally by considering matrix elements of $\Delta$. In this way the restrictions of the muffin-tin model can be removed without sacrificing the computational efficiency of the multiple-scattering method, and, at the same time; a trial basis set is defined which directly relates to the cluster problem (exact solutions to the muffin-tin model); such a close correspondence between trial basis and the system does not ordinarily exist for most basis sets currently used in variational calculations.

Recently the multiple-scattering technique as adapted to the energy band problem has been successfully used to generate a variational basis for treating the full crystal Hamiltonian using the discrete variational me thod. This latter technique has been programmed for cluster calculations; thus the procedures are currently available to produce a combined multiple scatteringdiscrete variational method for the cluster problem.

\section{EFFECTS OF THERMOELASTIC PROPERTIES ON VOID FORMATION IN HEXAGONAL METALSIS}

\section{H. Yoo}

The effects of anisotropic thermal expansion coefficients and elastic constants on radiation-induced void

13. Abstracted from a paper published in Phys. Rev. B 7, 3520-26 (1973) and a paper to appear in the International Journal of Quantum Chemistry.

14. Abstract of a discussion comment to appear in the proceedings of the Summer Research Conference in Theoretical Chemistry, Boulder, Colorado, June 26-30, 1972.

15. Abstract of a paper submitted to Acta Metallurgica. 
formation in hexagonal metals are analyzed. Upper bound values of thermal stress in polycrystalline metals are calculated. Cyclic temperature fluctuations at high irradiation temperature cause changes in internal stress. Those changes suppress nucleation and growth of voids by enhancing recombination of point defects at grain boundaries and by the induced self-stress field. Such effects are more pronounced in highly anisotropic zirconium than in magnesium. Effects of hydrostatic pressure on void formation are investigated. Other metallurgical variables for void formation are discussed, and an experiment to test the current concept is suggested.

\section{EQUILIBRIUM SHAPE OF A PRISMATIC DISLOCATION LOOPY? ?}

\section{H. Yoo}

A numerical method of calculating the elastic line energy and its derivatives with respect to orientation is developed based on the anisotropic elasticity theory of dislocations. The results of this calculation are used to predict equilibrium shapes of large prismatic loops (i.e., the loop radius is several hundred times its Burgers vector) in various crystal structures. Self-force acting on a loop segment is calculated by use of Brown's formulation, and the interaction energy per unit length of a loop is obtained. From the sum of line energy and interaction energy equilibrium shapes of small loops are then predicted. In some cases instability due either to the negative line tension criterion or to Gibbs-Wulff common tangent rule occurs in certain segments of pure prismatic loops. Loop segments will tend to rotate away from these unstable orientations, and thus the loop is expected to develop sharp cusps or other irregularities. 


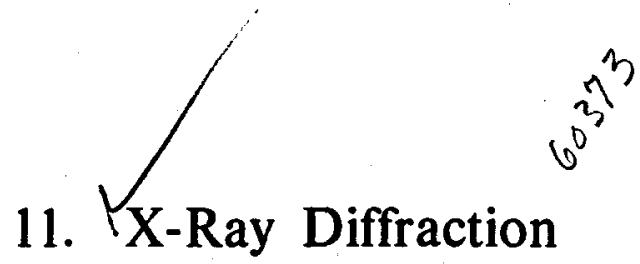

H. L. Yakel B. S. Borie

Research in our laboratory is concerned with the interaction of $x$ radiation with matter. Though the interaction of primary interest is diffraction, absorption, emission, fluorescence, and inelastic scattering are phenomena with which we must also necessarily be concerned. We report the observation of a kind of inelastic scattering, or resonance emission of $x$ rays, not previously observed. Diffraction research described includes studies of short-range structures in the omega phase and in certain uranium alloys (both of which result from rapid cooling of a bcc structure) and the crystal structure and expansion coefficients of certain boron carbides. We also report a low-angle scattering study of neutron-irradiated $\mathrm{SiO}_{2}$, a calculation concerned with optimizing collimation systems in low-angle cameras, and a method for predicting thermally excited Bragg maxima in certain simple crystals.

\section{ROUTINE ANALYSES}

\section{R.M. Steele H. L. Yakel}

X-ray diffraction experiments of a routine nature were performed on 400 samples submitted during the reporting period. Results for samples of more than casual interest are presented in other sections of this report.

\section{LATTICE EXPANSIONS OF BORON CARBIDES ${ }^{1}$}

\section{H. L. Yakel}

High-temperature $x$-ray diffraction methods were used to determine unit cell parameters of two boron

1. Synopsis of paper submitted for publication to the Journal of Applied Crystallography.

carbide compositions from 12 to about $940^{\circ} \mathrm{C}$. One composition was at the carbon-rich end of the phase field (i.e. $\mathrm{B}_{4} \mathrm{C}$ ), the second at the boron-rich end ( 5 at. $\% \mathrm{C}$ by chemical analysis). The lattice expansion of both substances was isotropic in the temperature range studied (see Fig. 11.1). Cube roots of rhombohedral cell volumes were least squares fitted to second-degree polynomials in temperature, giving the equations: ${ }^{2}$

$$
\begin{aligned}
C \text {-rich } & \sqrt[3]{V^{R}}=4.7929 \AA[0.999999(2)+5.77(5) \\
& \left.\times 10^{-6}(T-509)+1.9(2) \times 10^{-9}(T-509)^{2}\right]
\end{aligned}
$$

and

$$
\text { B-rich } \sqrt[3]{V^{R}}=4.8424 \AA[1.000001(2)+6.08(4)
$$

$$
\left.\times 10^{-6}(T-519)+2.7(1) \times 10^{-9}(T-519)^{2}\right]
$$

where $T$ is the centigrade temperature.

The mean linear thermal expansion coefficient for the carbon-rich composition is $5.65(5) \times 10^{-6} /{ }^{\circ} \mathrm{C}$, in satisfactory agreement with recently reported bulk values for a comparable temperature range [5.54 X $10^{-6} /{ }^{\circ} \mathrm{C}$ (ref. 3), $5.85 \times 10^{-6}$ (ref. 4)]. The mean coefficient for the boron-rich composition is $5.87(4) X$ $10^{-6} /{ }^{\circ} \mathrm{C}$.

2. Digits in parentheses in these equations and subsequent numerical data indicate the estimated standard deviation in the last digit of the preceding numerical quantity.

3. O. H. Krikorian, Thermal Expansion of High Temperature Materials, UCRL-6132 (1960).

4. J. C. Hedge, C. Kostenko, and J. I. Lang, Thermal Properties of Refractory Alloys, ASD-TDR-63-597 (1963). 


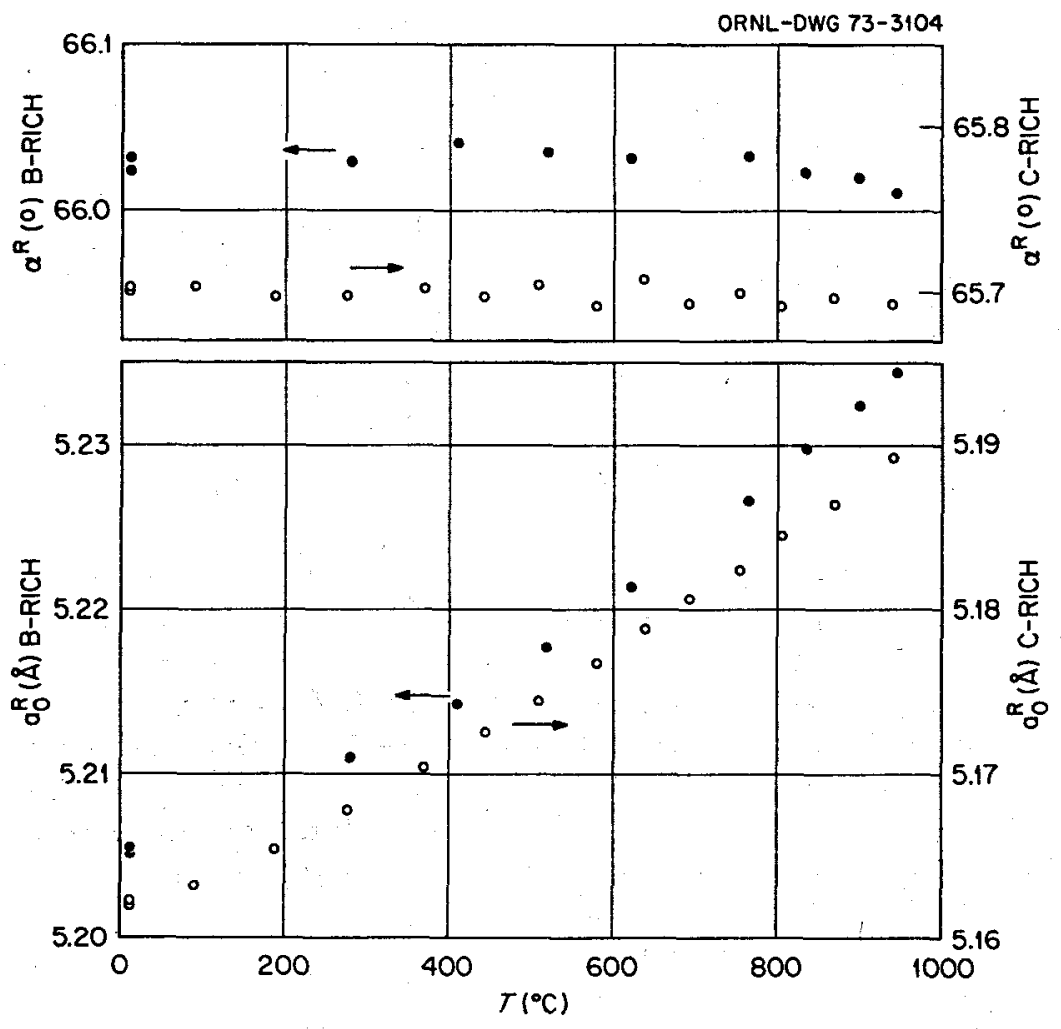

Fig. 11.1. Rhombohedral lattice parameters of carbon-rich (open circles) and boron-rich (filled circles) boron carbides as a function of temperature $(\mathrm{C})$. All temperatures are $\pm 4^{\circ} \mathrm{C}$.

\section{CRYSTAL STRUCTURE OF A HYPOSTOICHIOMETRIC BORON CARBIDE}

\section{H. L. Yakel}

In the course of the experiment to measure the lattice expansion of a boron-rich boron carbide (vide supra), a few small crystals suitable for structure analysis were gleaned from the polycrystalline aggregate. Preliminary $x$-ray diffraction data showed the largest of these to be a twinned crystal containing two rhombohedral orientations related by a (100) twin plane. The density of this crystal was measured by a flotation method to be $2.456(1) \mathrm{g} / \mathrm{cm}^{3}$. Coupled with measured rhombohedral cell parameters $a_{0}=5.2064$ (1) $\AA, \alpha=66.010(1)^{\circ}$, this density gives an average mass per thombohedral cell of 166.8(1) amu. Chemical analysis of the polycrystalline mass gave 5 at. $\% \mathrm{C}$, a value that is not compatible with the presence of $B_{12}$ icosahedra and $C B C$ chains if the experimentally determined mass is accepted. Resolution of this problem is being attempted by a complete $\mathrm{x}$-ray diffraction analysis of the structure of this crystal.

\section{MODELS OF THE $\boldsymbol{r}$ STRUCTURE IN URANIUM-BASE BCC ALLOYS}

\section{H. L. Yakel}

The $\gamma^{s}$ configuration found in many uranium-base alloys after rapid cooling from the gamma (bcc) phase field is characterized by regular displacements of atoms in specific $[100]_{\gamma}$ directions. In this it formally resembles the metastable omega phase formed in beta-quenched titanium and zirconium alloys. We have therefore attempted to model the partially transformed uranium alloy lattice along the lines successfully used by Borie in treating the omega problem. Whereas a single atom suffices as the repeat motif in the latter, a four-atom motif is the smallest from which physically sensible results can so far be deduced for $\boldsymbol{\gamma}^{s}$-Despite this drawback, a model associating four subvariants

5. H. L. Yakel, J. Nucl. Mater. 33, 286-95 (1969).

6. B. S. Borie, Metals and Ceramics Div. Annu. Progr. Rep. June 30, 1972, ORNL-4820, p. 34. 
with each of three $\gamma^{s}$ variants reproduces most of the features of the observed $x$-ray diffraction intensity distributions surprisingly well. Sharp, unshifted Bragg maxima, affected by a large Debye-Waller-like factor, are predicted at the reciprocal lattice nodes of the fundamental bcc lattice, and diffuse reflections of about the proper relative intensity and with the proper shifts along the $c^{*}$ axis of the $\gamma^{s}$ variant are also generated.

\section{THE SHORT-RANGE STRUCTURE OF TITANIUM AND ZIRCONIUM BCC SOLID SOLUTIONS}

\section{B.S. Borie H. L. Yakel}

We previously reported a model for the aperiodic atomic arrangement in some titanium- and zirconiumbase-solid solutions transformed to the mega phase. The model accounts for many of the features of the observed intensity distribution in reciprocal space. The model consists of faults in the transformed regions causing anomalous interference effects among different omega domains. It accurately predicts the relative intensities of the diffuse omega Bragg maxima and accounts quantitatively for their observed small displacements from the nodes of the reciprocal lattice. However, the model is simplistic in the sense that it treats only one variant of the system, neglecting interference effects among the variants, and it takes the entire crystal to be transformed, so that interference phenomena between omega and untransformed bcc domains are omitted. The model also fails to reproduce observed diffuse maxima that are not of thermal origin and occur under the sharp bcc Bragg reflections.

We are attempting to refine our calculation so that it will conform more nearly to a real partially transformed crystal. The theory has been recast to include both faulted omega and untransformed regions. An unanticipated consequence is that the resultant computer program generates the diffuse maxima centered on the bcc reciprocal lattice nodes. However, we have been able to find no values of the variables of the calculation that reproduce the observed relative strengths of these maxima. It appears that the quantitative details of this feature of the intensity distribution must depend not only on the volume fraction untransformed, but as well on precisely how the omega regions are dispersed in the crystal. To test this very interesting possibility we are currently reformulating the theory in sufficiently general form that the character of the distribution of the omega regions is not presumed.

Some preliminary work has been done on contributions to the intensity distribution of interference among the four variants of the system, which must ultimately be related as well to how the transformed material is dispersed in the crystal.

\section{THERMALLY EXCITED FORBIDDEN REFLECTIONS \\ B, S. Borie<smiles>CC(C)(C)C</smiles>

We have developed methods for predicting the thermal excitation of certain "forbidden" Bragg reflections in simple crystals. The excitation of these reflections is related to the anharmonicity and anisotropy of the atomic thermal motion. The best known example of this phenomenon is the forbidden 222 reflection in diamond. In fact, to our knowledge, the only systematic studies of the phenomenon have been those made with diamond and other elements having the diamond structure. However, we can show that analogous effects should be observable in other cubic crystals with simple structures. Specifically we predict the thermal excitation of certain forbidden reflections in $\mathrm{Cu}_{2} \mathrm{O}$, due to the anharmonicity of the oxygen motion and the anisotropy of the copper motion, and in $\mathrm{Nb}_{3} \mathrm{Sn}$, due to both the anharmonicity and anisotropy of the niobium motion. New extinction rules for these space-group-forbidden reflections are derived, and methods for the quantitative interpretation of the integrated intensities of these very weak Bragg maxima are described.

\section{STRUCTURAL AND DYNAMICAL PROPERTIES OF NEUTRON-IRRADIATED QUARTZ AND NONCRYSTALLINE $\mathrm{SiO}_{2}\left(\operatorname{Ref}_{3}\right)$ \\ J. B. Bates ${ }^{9}$ L. B. Shaffer ${ }^{10}$
R. W. Hendricks}

Small-angle $\mathrm{x}$-ray scattering (SAXS) was measured from samples of neutron-irradiated noncrystalline $\mathrm{SiO}_{2}$ and $\alpha$-quartz. Our objective was to determine the nature of the defect that gives rise to the previously reported ${ }^{11}$ 604- and $490-\mathrm{cm}^{-1}$ Raman bands of noncrystalline $\mathrm{SiO}_{2}$. Results show that different defect

7. Abstract of paper presented at the Storrs Meeting of the American Crystallographic Association, June 17-22, 1973.

8. Abstract of papers to be submitted for publication in the Journal of Chemical Physics.

9. Solid State Division.

10. Visiting consultant on leave from Anderson College, Anderson, Ind.

11. J. B. Bates, Chem. Div. Annu. Progr. Rep. May 20, 1972, ORNL-4791, p. 137 . 
cluster sizes are produced in the two materials by an equivalent irradiation, though the basic nature of the defects may be the same. After postirradiation annealing heat treatments, SAXS measurements again show significant structural differences between samples giving similar Raman spectra and densities.

\section{OPTIMIZATION OF THE KRATKY SMALL-ANGLE X-RAY SCATTERING COLLIMATION SYSTEM PARAMETERS 2

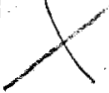
L. B. Shaffer ${ }^{10}$
R. W. Hendricks

Analýtic expressions are given to describe the power through a Kratky collimation system such as commonly used in small-angle $\mathrm{x}$-ray scattering experiments. These expressions account for any size and position of the focal spot relative to the entrance slit in the width direction. An expression for the "infinite" beam geometry is given for the length direction. Expressions are also presented for the minimum experimentally accessible angle (including parasitic scattering) and for the maximum angle to which the "infinite beam" assumption is valid. Subject to the constraint of a predetermined and fixed minimum angle the positions and widths of all slit edges are optimized to achieve maximum power through the collimation system for the cases of fully and nonfully illuminated entrance slits. Complete details of the analytic derivation are given along with a comparison of the theoretical optimization with experimental data.

\section{INELASTIC RESONANCE EMISSION OF X RAYS: ANOMALOUS SCATTERING ASSOCIATED WITH ANOMALOUS DISPERSION}

Cullie J. Sparks, Jr.

We observed a kind of inelastic x-ray scattering process that differs from those previously reported. This inelastically scattered radiation comes from a resonance emission and differs from characteristic fluorescence, Compton, and Compton-Raman inelastic scattering. The scattered radiation produced when monochromatic $\mathrm{x}$ rays impinge on elements from silicon to gold was energy-analyzed with a $\mathrm{Si}(\mathrm{Li})$ solid-state detector. Scattered $\mathbf{x}$ rays of significant intensity were observed at an energy lower than those associated with Compton scattering. Our measurements

12. Abstracted from ORNL-TM-4278 (in press). show these $x$ rays to peak in intensity at an energy lower than that of the incident photon by the binding energy of an inner shell electron, to be isotropic in distribution (independent of scattering angle), and to increase in intensity as the frequency of the incident radiation approaches an absorption edge. We interpret these scattered $x$ rays as arising from the resonance process associated with the anomalous dispersion correction to the coherent atomic scattering factor for $\mathbf{x}$ rays. We previously reported this radiation to come from Bremsstrahlung processes in which direct collisions between electrons occurred. ${ }^{13}$ Though that is a realistic physical model, the anomalous dispersion theory gives the observed cross sections as a function of frequency. Our observed intensities are fitted well by summing the square of the anomalous dispersion amplitudes for each electron that contributes. The cross sections for this anomalous scattering can be treated with second-order perturbation theory using a term previously neglected in inelastic scattering calculations.

\section{STRENGTHENING AND FRACTURE OF Ta, Nb, Mo, AND W BINARY SOLID SOLUTIONS WITH SHORT-RANGE ORDER ${ }^{14}$}

$$
\begin{gathered}
\text { R. E. Predmore } \\
\text { Cullie J. Sparks, Jr. }
\end{gathered}
$$

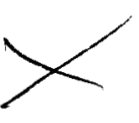

The binary substitutional solid-solution alloys of $\mathrm{Nb}$, $\mathrm{Mo}, \mathrm{Ta}$, and $\mathrm{W}$ exhibit two types of behavior. Tantalum-niobium and probably molybdenum-tungsten alloys form random solid solutions with an absence of substitutional solid-solution hardening and an absence of fracture embrittlement at high solute concentrations. Tantalum-molybdenum, and probably Ta-W, Nb-Mo, and $\mathrm{Nb}-\mathrm{W}$ alloys form short-range-ordered solid solutions. They show linear solid-solution hardening to high solute concentrations at room temperature and brittle fracture at high solute concentration. Diffuse $x$-ray scattering shows that the solution hardening of tantalum-molybdenum alloys is caused primarily by size misfit and displacement of the solute atom off the average lattice site, and secondarily by shear modulus misfit.

13. C. J. Sparks, Jr., Metals and Ceramics Div. Annu. Progr. Rep. June 30, 1971, ORNL4770, pp. 35-36.

14. Abstract of pp. 18-30 in Mechanical Behavior of Materials (Proc. Intern. Conf. Kyoto, Aug. 15-20, 1971), Vol. 1, The Society of Materials Science, Kyoto, Japan, 1972.

15. Engineering Materials Group, University of Maryland, College Park, Md. 


\section{DEVELOPMENT OF HIGH-SENSITIVITY X-RAY FLUORESCENCE FOR ANALYSIS OF TRACE ELEMENTS ${ }^{16}$}
Cullie J. Sparks, Jr.
L. A. Harris
O. B. Cavin
J. C. Ogle

Three new and different geometrical arrangements for $x$-ray fluorescent analyses (XRF) have been explored to determine their relative merits for improving the detectability of trace elements. As sensitivity improves, the number of elements detected is reduced, so only one element at a time can be detected with maximum sensitivity. The ultimate detectability of trace elements with XRF is shown to depend on the inelastic scatter of the exciting radiation by the matrix. This inelastic scatter decreases with the average atomic number of the matrix, favoring the kinds of samples of most interest to the environmentalist. However, for the lowest concentrations, the use of solid-state detectors becomes less favorable, and crystal analyzers are more satisfactory for trace element determinations. With a judicious choice of the variables, several elements can be detected at levels of a few parts per billion without concentration or any prior treatment of the sample.

Quantitative determination (without the use of standards) of a number of elements in the National Bureau of Standards reference materials was demonstrated. The method shows promise of being among the best

16. Paper given at Third Trace Metals Symposium, University of Illiñois, November 1972. Funded by National Science Foundation/RANN. analytical techniques for trace element determinations in many types of environmental specimens as well as materials of interest to the materials scientist. Rapid and less expensive elemental analysis without prior chemical treatment has many advantages over other analytical techniques.

\section{SHORT-RANGE ORDER WITH LARGE ATOMIC DISPLACEMENTS IN NIOBIUM-VANADIUM ALLOYS}

Cullie J. Sparks, Jr.

$\mathrm{X}$-ray diffuse scattering measurements on niobiumvanadium alloys showed that they form solid solutions with a preference for unlike nearest neighbors. In addition, there is a large atomic displacement effect much like that observed in the tantalum-molybdenum system. Solid-solution strengthening in bcc refractory metal alloys has been attributed to the difference in their elastic moduli and/or the stress fields from their different atomic sizes. Since there is only a small difference in the elastic moduli between niobium and vanadium $\left(\Delta E \cong 3 \times 10^{6} \mathrm{psi}\right)$, a study of the short-range order and atomic displacements in a single crystal of a $40 \% \mathrm{~V}$ alloy ${ }^{17}$ should help determine the relative roles of atom misfit and difference in elastic moduli in solution strengthening.

17. Grown by the Research Materials Section of the Solid State Division. 


\title{
Part II. Space Power Technology
}

\section{High-Temperature Alloys for Isotopic Heat Sources}

\author{
R. G. Donnelly
}

The purpose of this program is to develop highmelting, oxidation-resistant alloys for space applications of isotopic heat source capsules operating between 800 and $1400^{\circ} \mathrm{C}$. This requires alloys exhibiting superior performance under operational, abort, reentry, earth impact, and postimpact conditions. Potential applications are as fuel containment materials in ${ }^{238} \mathrm{PuO}_{2}$ - and ${ }^{244} \mathrm{Cm}_{2} \mathrm{O}_{3}$-fueled thermoelectric generators, such as the Multi-Hundred Watt (MHW) generator now under development and advanced versions of the SNAP-19 generator as used aboard the Pioneer space probe.

\section{DEVELOPMENT OF IRIDIUM-BASE ALLOYS}

\section{T. Liu H. Inouye}

Iridium alloys containing small amounts of $\mathrm{Ru}, \mathrm{Re}$, $\mathrm{W}, \mathrm{Nb}$, and Hf have been studied in an effort to develop high-melting, high-strength, oxidation-resistant materials for space power applications to $1400^{\circ} \mathrm{C}$. The iridium alloys were fabricated by cladding them in a molybdenum jacket and hot rolling between 1100 and $1300^{\circ} \mathrm{C}$, followed by cold working at room temperature with intermediate anneals. Good quality sheets 0.020 in. thick were obtained from 150-g alloy ingots containing up to 2 at. \% alloying elements.

Alloying iridium with these elements raises the recrystallization temperature. Whereas unalloyed iridium recrystallizes at about $800^{\circ} \mathrm{C}$, alloying with 2 at. $\%$ $\mathrm{Ru}, \mathrm{Re}$, and $\mathrm{W}$ increases the recrystallization temperature to 1100,1300 , and $1400^{\circ} \mathrm{C}$, respectively.

The tensile properties of the alloys to $1316^{\circ} \mathrm{C}$ $\left(2400^{\circ} \mathrm{F}\right)$ are shown in Table 12.1. Hafnium is the most effective strengthening element. Iridium -1 at. $\% \mathrm{Hf}$ has a tensile strength (TS) of 70,000 psi and a yield strength $(Y S)$ of $23,000 \mathrm{psi}$ at $1316^{\circ} \mathrm{C}, 3$ to 4 times
Table 12.1. Comparison of the tensile properties of iridium-base alloys with iridium; TZM, $\mathrm{T}-111$, and Pt-3008 ${ }^{a}$ at $1316^{\circ} \mathrm{C}\left(2400^{\circ} \mathrm{F}\right)$

\begin{tabular}{|c|c|c|c|c|}
\hline \multirow{2}{*}{$\begin{array}{l}\text { Alloy } \\
\text { (at. \%) }\end{array}$} & \multicolumn{2}{|c|}{ Strength (psi) } & \multirow{2}{*}{$\begin{array}{l}\text { Elongation } \\
(\%)\end{array}$} & \multirow{2}{*}{$\begin{array}{l}\text { Toughness } \\
\text { (in.-lb/in: }{ }^{3} \text { ) }\end{array}$} \\
\hline & Tensile & Yield & & \\
\hline Ir & 26,300 & 5,500 & 50.2 & 8,000 \\
\hline Ir -1 Hf & 70,000 & 23,000 & 37.4 & 17,400 \\
\hline Ir $-2 \mathrm{Nb}$ & 46,800 & 14,800 & 30.3 & 9,300 \\
\hline $\mathrm{Ir}-2 \mathrm{~W}$ & 45,200 & 17,000 & 36.0 & 11,200 \\
\hline $\mathrm{Ir}-2 \mathrm{Re}$ & 31,300 & 16,000 & 47.0 & 11,100 \\
\hline $\mathrm{Ir}-2 \mathrm{Ru}$ & 23,000 & 8,000 & 45.4 & 7,000 \\
\hline TZM & 20,000 & 9,900 & 40.0 & 6,100 \\
\hline$T-111$ & 37,300 & 23,500 & 36.0 & 11,000 \\
\hline Pt-3008 & 22,500 & 15,900 & 48.0 & 9,200 \\
\hline
\end{tabular}

$a_{\mathrm{Pt}-30}$ wt $\% \mathrm{Rh}-8 \mathrm{wt} \% \mathrm{~W}$.

those of unalloyed iridium. For the alloying elements studied, strengthening decreases in the order $\mathrm{Hf}, \mathrm{W}, \mathrm{Nb}$, $\mathrm{Re}$, and $\mathrm{Ru}$. The alloys $\mathrm{Ir}-1$ at. \% $\mathrm{Hf}, \mathrm{Ir}-2$ at. \% W, and Ir -2 at. $\% \mathrm{Nb}$ are all stronger than the refractory alloys TZM and T-111. In terms of toughness [defined as fracture strain $X(T S+Y S) / 2]$ at $1316^{\circ} \mathrm{C}$, the $\mathrm{Ir}-1$ at. $\%$ Hf ranks first among all the candidate alloys.

The oxidation rate of the alloys in flowing air is equal to that of pure iridium at $1000^{\circ} \mathrm{C}$ but is generally lower at 770 and $870^{\circ} \mathrm{C}$. Thus, in concentrations up to 2 at. $\%$, these alloying elements do not significantly impair the oxidation resistance of iridium.

\section{DEVELOPMENT OF PLATINUM-BASE ALLOYS}

$$
\text { H. Inouye J. H. Erwin }
$$

Recently developed platinum alloys containing 26 to $30 \% \mathrm{Rh}$ and $8 \% \mathrm{~W}$ continue to be characterized for use 
as the encapsulating material for isotopic fuels. Evaluation of alloy properties continues to show good fabricability and strength; however, in our efforts to scale up the production of these alloys, several problem areas have been identified. These include (1) compositional analyses and control; (2) melting, casting, and fabrication; and (3) inconsistency in the mechanical properties. Preliminary results suggest that difficulties in compositional analysis and control may be contributing to inconsistencies in fabricability and mechanical properties.

\section{IRIDIUM PURIFICATION AND SCRAP RECYCLE}

\section{H. Inouye}

High-purity iridium is required as the base for producing alloys to contain isotopic fuels at very high temperatures. Because of the high cost of iridium, a method of purifying and/or recycling iridium scrap was necessary. Zinc amalgamation, chlorination, and oxidation processes were investigated. ${ }^{1}$ Of these methods, the oxidation process was most suitable. In principle,

1. R. G. Donnelly and A. C. Schaffhauser, Space Power Materials Development Quart. Progr. Rep. Sept. 30, 1972, ORNL-TM-4057, pp. 4-8. impure iridium is oxidized in flowing oxygen at 1000 to $1200^{\circ} \mathrm{C}$ to produce $\mathrm{IrO}_{3}(\mathrm{~g})$, while the nonvolatile impurities remain as a residue in the furnace. The $\mathrm{IrO}_{3}(g)$ then condenses as $\mathrm{IrO}_{2}(s)$ in the cooler parts of the furnace. The acid-insoluble $\mathrm{IrO}_{2}$ is digested in $\mathrm{HF}$ and aqua regia to remove any carry-over of volatile impurities, then reduced to metal with hydrogen at $600^{\circ} \mathrm{C}$. A powder product assaying $99.98 \%$ Ir is produced.

\section{SPECIAL PROBLEMS AND CONSULTING}

\section{H. Inouye C. T. Liu}

A variety of short-term tasks and consulting services were provided to SNS in connection with the MultiHundred Watt Thermoelectric Generator Project. Among these were problems related to the development of a method for fabricating iridium sheet, a method for cleaning iridium, mass-transport studies of iridium and carbon in a temperature gradient, and vent plugging. Current activities include a study of the influence of thermomechanical treatments on the structure and mechanical properties of iridium-tungsten alloys and the development of a chemical-thermal method for processing fabricated iridium hemispheres. 


\section{Curium-244 Compatibility Testing}

R. G. Donnelly

This activity is being conducted in cooperation with the ORNL Isotopes Division in support of the overall Curium-244 Fuel Development base program and the SURVSATCOM (Survivable Satellite Communications) program being supported by the AEC's Division of Space Nuclear Systems. The purpose of this task is to determine acceptable container materials for ${ }^{244} \mathrm{Cm}_{2} \mathrm{O}_{3}$ in a variety of potential thermoelectric generator applications.

The use of ${ }^{244} \mathrm{Cm}_{2} \mathrm{O}_{3}$ in space heat-source applications requires the identification of materials that are

\section{J. R. DiStefano}

compatible with ${ }^{244} \mathrm{Cm}_{2} \mathrm{O}_{3}$ under operational, abort, and reentry conditions. A program was initiated to test the compatibility of a variety of materials for application from 900 to $1400^{\circ} \mathrm{C}$. The test system design is shown in Fig. 13.1, and test conditions are presented in Table 13.1. In each case the specimens and inner capsules are of the same material. A vent hole was provided in the top end cap of each inner capsule to expose the ${ }^{244} \mathrm{Cm}_{2} \mathrm{O}_{3}$-specimen couple to either helium or vacuum environments that simulate currently proposed systems. After test, the top specimen is

Table 13.1. Test conditions for ${ }^{244} \mathrm{Cm}_{2} \mathrm{O}_{3}$ compatibility couples ${ }^{a}$

\begin{tabular}{|c|c|c|c|}
\hline \multirow{3}{*}{ Material $^{b}$} & \multicolumn{3}{|c|}{ Conditions } \\
\hline & \multirow{2}{*}{$\begin{array}{c}\text { Static } \\
\text { helium } \\
(5000 \mathrm{hr} \\
\left.\text { at } 900^{\circ} \mathrm{C}\right)\end{array}$} & \multicolumn{2}{|c|}{$\begin{array}{l}\text { Static helium and } \\
\text { dynamic vacuum }\end{array}$} \\
\hline & & $\begin{array}{c}(2500 \mathrm{hr} \\
\left.\text { at } 1100^{\circ} \mathrm{C}\right)\end{array}$ & $\begin{array}{l}(5000 \mathrm{hr} \\
\left.\text { at } 1400^{\circ} \mathrm{C}\right)\end{array}$ \\
\hline \multirow{2}{*}{\multicolumn{4}{|c|}{$\begin{array}{l}\text { Iridium } \\
\text { Graphite }\end{array}$}} \\
\hline & $\sqrt{ }$ & $\sqrt{ }$ & $\sqrt{ }$ \\
\hline \multicolumn{4}{|l|}{ Platinum } \\
\hline \multicolumn{4}{|l|}{$\mathrm{Hf}-1 \% \mathrm{Pt}-0.5 \% \mathrm{Pd}$} \\
\hline \multicolumn{4}{|l|}{ Hastelloy C-276 } \\
\hline \multicolumn{4}{|l|}{ Haynes alloy No 25} \\
\hline \multicolumn{4}{|l|}{ Haynes alloy No. 188} \\
\hline \multicolumn{4}{|l|}{$\mathrm{ThO}_{2}$} \\
\hline \multicolumn{4}{|l|}{ Pt-20\% Rh } \\
\hline \multicolumn{4}{|l|}{$\mathrm{Pt}-26 \% \mathrm{Rh}-8 \% \mathrm{~W}$} \\
\hline \multicolumn{4}{|c|}{$\mathrm{Pt}-26 \% \mathrm{Rh}-8 \% \mathrm{~W}-0.5 \% \mathrm{Ti}$} \\
\hline \multicolumn{4}{|l|}{$\mathbf{P t}_{\mathbf{3}} \mathbf{I r}$} \\
\hline \multicolumn{4}{|l|}{ Molybdenum } \\
\hline \multirow{2}{*}{\multicolumn{4}{|c|}{ Mo-46\% Re }} \\
\hline \multirow{2}{*}{\multicolumn{4}{|c|}{ Tantalum }} \\
\hline$T-111$ & & & \\
\hline \multirow{2}{*}{\multicolumn{4}{|c|}{$\begin{array}{l}\text { Tungsten } \\
\mathrm{W}-26 \% \mathrm{Re}\end{array}$}} \\
\hline & & & $\sqrt{ }$ \\
\hline
\end{tabular}

${ }^{a}$ All couples except graphite to be tested both singly and in graphite intermediate capsule surrounding inner capsule.

$b_{\text {Inner capsule and disk specimen. }}$ 
removed for chemical analysis; the remaining inner capsule and ${ }^{244} \mathrm{Cm}_{2} \mathrm{O}_{3}$-specimen assembly is then mounted longitudinally and examined by metallographic, autoradiographic, and electron-beam microprobe techniques.

Sealed capsule tests of the following materials were examined after 1000 and 10,000 -hr exposures to ${ }^{244} \mathrm{Cm}_{2} \mathrm{O}_{3}$ at $750^{\circ} \mathrm{C}$ : $\mathrm{Ni}, \mathrm{Ni}-10 \% \mathrm{Cr}, \mathrm{Ni}-7 \% \mathrm{Cr}-16 \%$
Mo-5\% Fe (Hastelloy $\mathrm{N}$ ), $\mathrm{Ni}-20 \% \mathrm{Cr}, \mathrm{Ni}-16 \%$ $\mathrm{Cr}-16 \% \mathrm{Mo}-6 \% \mathrm{Fe}-3 \% \mathrm{~W}$ (Hastelloy C), $\mathrm{Co}-10 \% \mathrm{Cr}$, and $\mathrm{Co}-15 \% \mathrm{~W}-10 \% \mathrm{Ni}$ (Haynes alloy No. 25): The results indicated that all materials were compatible with ${ }^{244} \mathrm{Cm}_{2} \mathrm{O}_{3}$ under the test conditions. Of three commercial alloys, only Hastelloy $\mathrm{N}$ showed any attack (0.1 to $0.2 \mathrm{mil}$ ) after $10,000 \mathrm{hr}$.
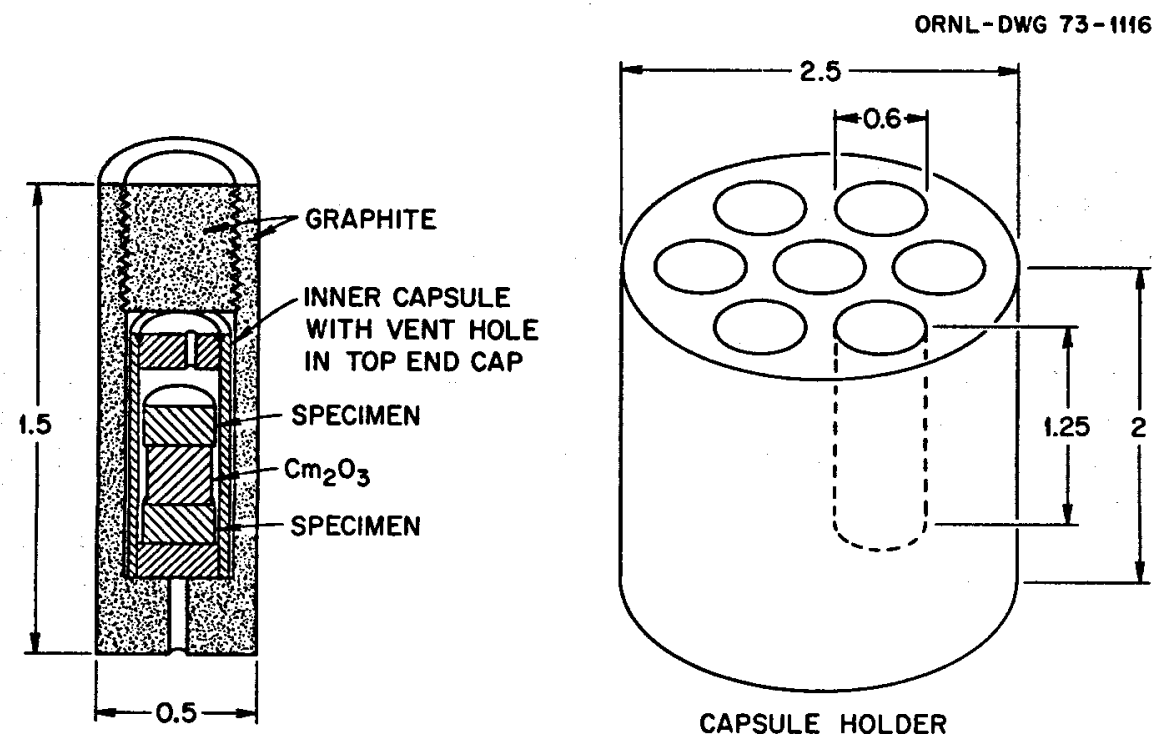

INNER CAPSULE WITH INTERMEDIATE GRAPHITE CAPSULE VACUUM SYSTEM

DIMENSIONS ARE IN INCHES

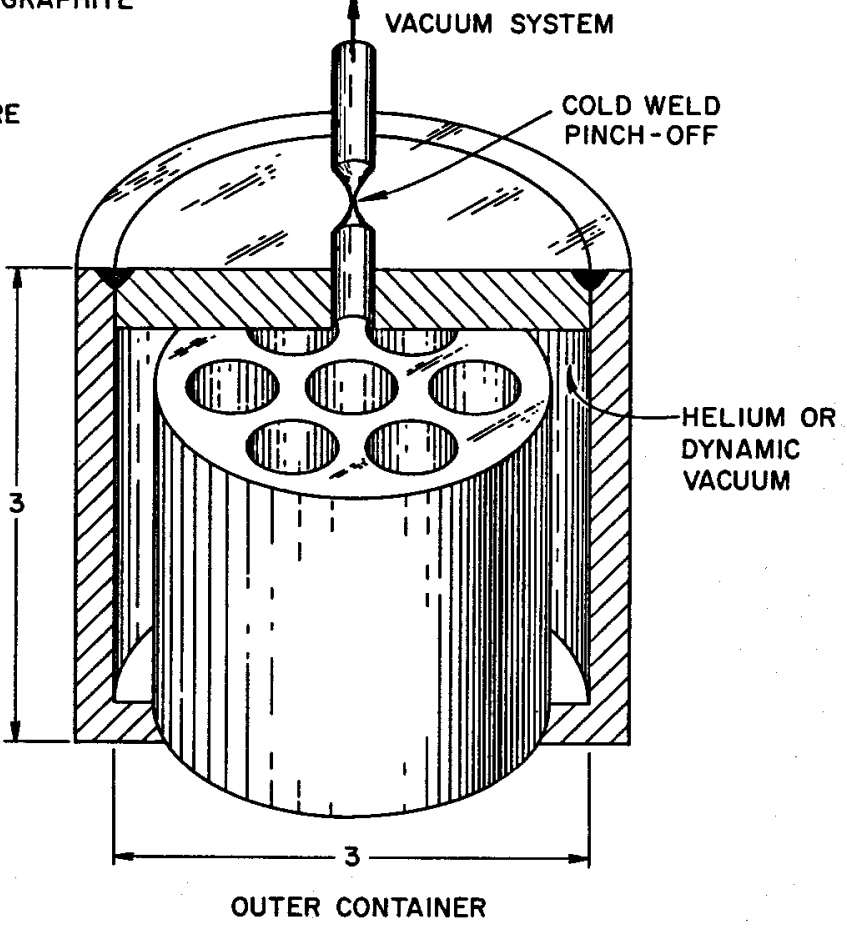

Fig. 13.1. Compatibility test system for ${ }^{244} \mathrm{Cm}_{2} \mathrm{O}_{3}$.

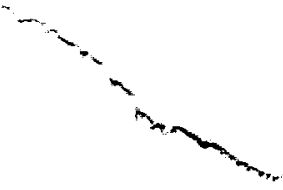




\section{Iridium Fabrication}

R. G. Donnelly

We have developed procedures for melting and fabricating high-quality iridium sheet for the Multi-Hundred Watt (MHW) Radioisotopic Thermoelectric Generator program. In a cooperative program with Mound Laboratory we supplied forming blanks machined from iridium and $\mathrm{Ir}-0.30 \% \mathrm{~W}$ sheet for warm hydroforming into hemispheres. Our melting and fabrication processes have been scaled up to meet the full production requirements of the MHW program to qualify as the backup iridium supplier for the program.

Because iridium is scarce and expensive a purification process was required to upgrade impure powder and permit recycle of scrap. This process was scaled up from the original development (see Chap. 12 of this report) and used to demonstrate the purification and rates obtainable on a variety of input products.

\section{IRIDIUM SHEET DEVELOPMENT}

\section{A. C. Schaffhauser}

\section{Preparation of Compacts for Melting}

\section{J. I. Federer}

The starting material for iridium sheet production was -325-mesh powder obtained from Matthey-Bishop, Inc. and from the Office of Emergency Preparedness (OEP). The powder from Matthey-Bishop, Inc., was about $99.98 \%$ Ir, while the OEP powder ranged from 99.85 to $99.95 \%$ Ir. Most of the OEP powder was washed with distilled water, which lowered the content of some elements, particularly $\mathrm{Al}, \mathrm{Ca}, \mathrm{K}$, and $\mathrm{Si}$, and increased the purity to about $99.96 \%$ Ir. The powder was cold pressed at 10 to 50 tsi in a $1 \times 1.8$ in. die into compacts weighing about $150 \mathrm{~g}$ each. The compacts were presintered at $1000^{\circ} \mathrm{C}$ in hydrogen, then vacuum sintered at $1500^{\circ} \mathrm{C}$ (Fig. 14.1). The presinter densified the compacts sufficiently to be handled. The vacuum sinter further densified them to 80 to $90 \%$ of theoretical and effectively reduced spatter during melting. Approximately 250 compacts have been prepared in this manner.

\section{Electron-Beam Melting and Casting}

\section{R. E. McDonald}

An electron-beam drop-casting technique, previously described, ${ }^{1}$ was upgraded for production of $1-1 \mathrm{~b}$ ingots of high-purity iridium and Ir-0.30\% W alloy. Using this process, we cast ingots $3 / 4 \times 3 / 4 \times 2 \frac{1}{8}$ in. (Fig. 14.2) that could be rolled directly to sheet with no primary breakdown by extrusion or forging required because of the relatively fine grain structure produced by drop casting. Very little ingot conditioning is required, and the process gives a very high yield of fabricable material with a small inventory.

The process consists of electron-beam melting sintered compacts and clean scrap into a $2.5 \mathrm{lb}$ button three or four times for purification and homogenization of alloying elements. The button is then electron-beam melted and drop cast into a square-cross-section mold. The head and skull from the casting is recycled directly into the next melt. We melted and cast 32 ingots of high-purity iridium and 17 ingots of iridium-tungsten alloys in the development stage of this program.

Recently we modified the melting hearth in our electron-beam furnace to more than triple our ingot casting capability. These modifications enable melting seven buttons and casting three ingots in a single furnace loading. For production qualification, we melted and cast $60 \mathrm{Ir}-0.30 \%$ W ingots during the last 30 working days of this fiscal year.

1. C. W. Dean and R. E. McDonald, High-Purity Shape Casting with an Electron-Beam Furnace, ORNL-TM-1935 (October 1967). 

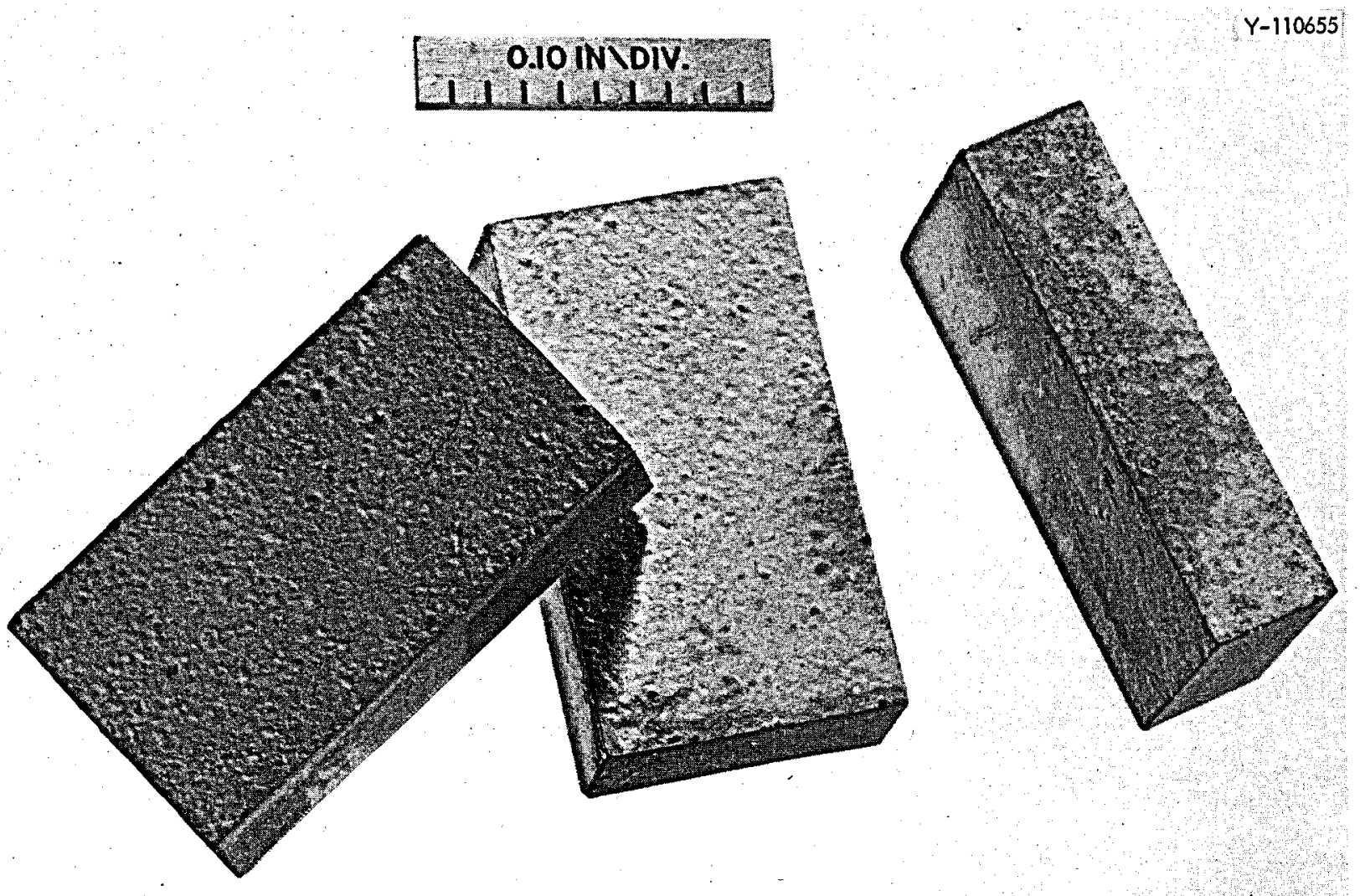

Fig. 14.1. Sintered iridium compacts.

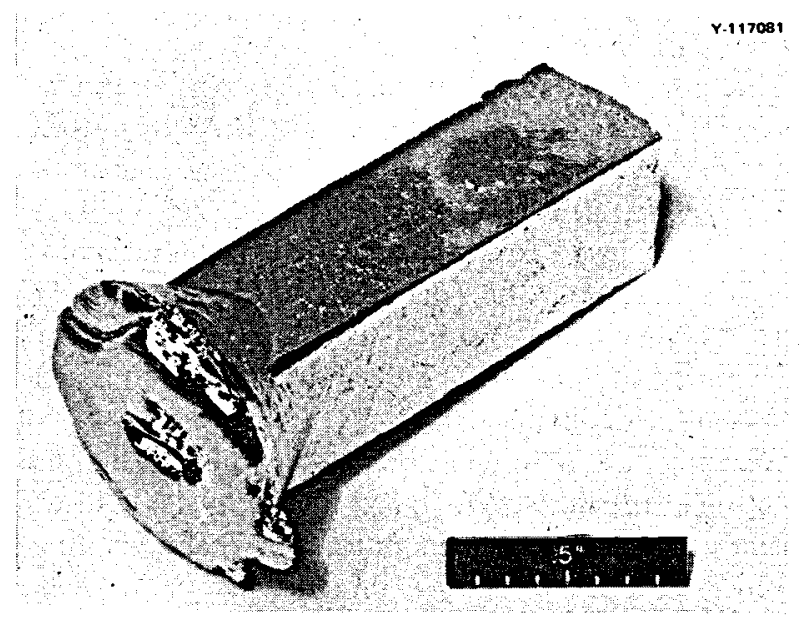

Fig. 14.2. Drop-cast iridium ingot.

\section{Sheet Rolling}
R. W. Knight
G. A. Reimann

We have developed procedures for rolling high-quality sheet of electron-beam-melted iridium-tungsten alloys.
Our objective was to determine the rolling temperature and reduction schedules necessary to produce a high yield of material having a consistent fibrous grain structure with good formability. We supplied machined blanks from the sheets to Mound Laboratory (Fig. 14.3) for determination of formability by warm hydroforming.

In the initial rolling studies we determined that breakdown rolling temperatures of 1100 to $1200^{\circ} \mathrm{C}$ are required and that cladding the ingots with molybdenum frames and cover plates minimized material losses due to surface or edge cracking. This cladding also prevents contamination during warm rolling. We determined that an intermediate recrystallization treatment of $1 \mathrm{hr}$ at $1200^{\circ} \mathrm{C}$ after about $70 \%$ reduction refined the grain size and eliminated any tendency for deformation in the final sheet. Most of the sheets were then warm rolled to $3 \times 11 \times 0.033$ to 0.031 in. ( 86 to $88 \%$ reduction). The reduction schedule had equal amounts of longitudinal and cross rolling to produce isotropic properties in the final sheet for good formability.

We found that the warm rolling and stress-relief temperatures required to produce the desired fibrous 


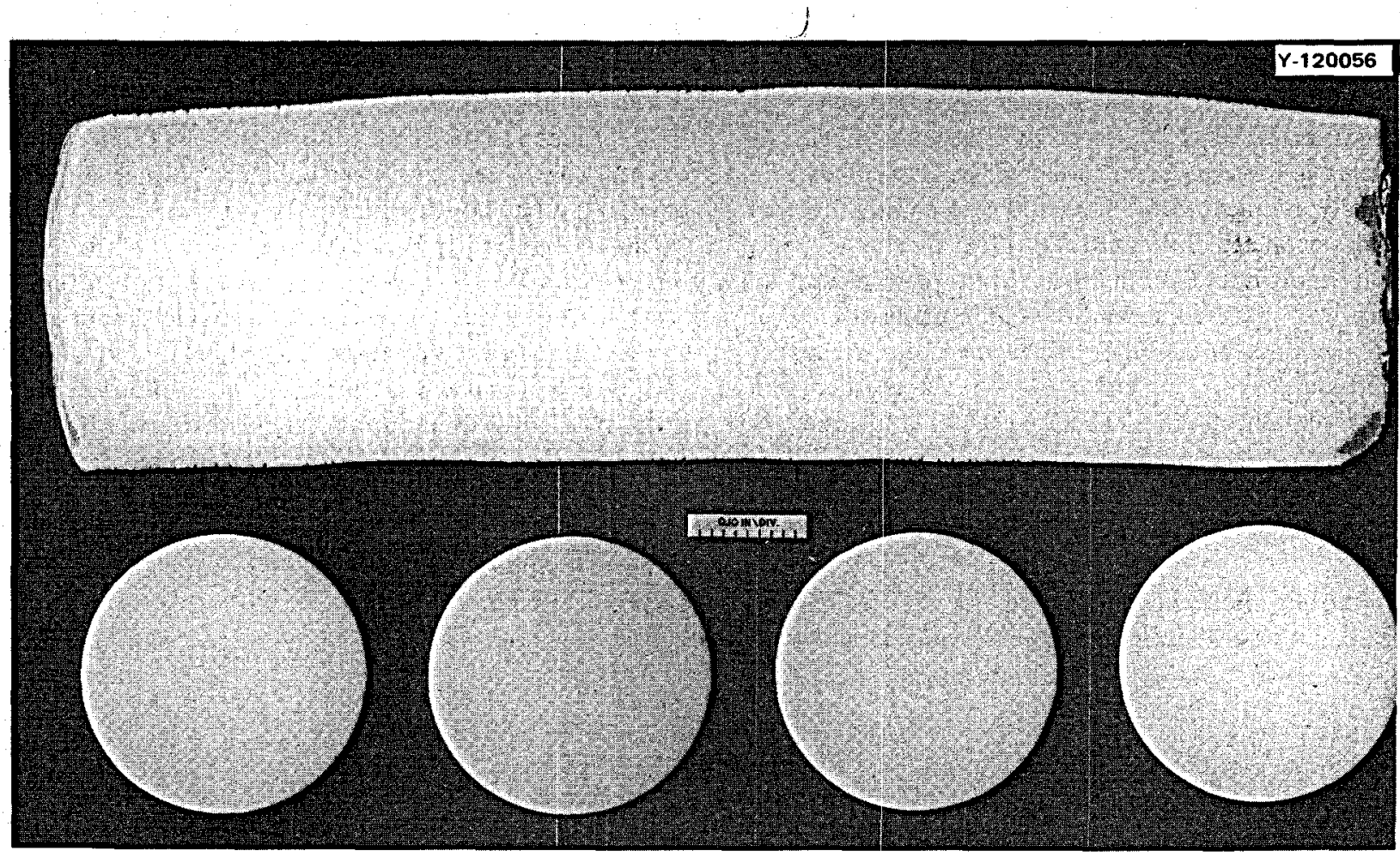

Fig. 14.3. Iridium sheet and machined blanks for forming.

grain structure associated with good formability were very dependent on the trace impurity content of the starting powder and sintered compacts. The initial development work was on Matthey-Bishop material, which contained 200 to $300 \mathrm{ppm}$ refractory metal impurity, primarily tungsten, and very small amounts of precious metal impurities. Warm rolling and stress relief at 1050 to $1100^{\circ} \mathrm{C}$ produced a fibrous grain structure with some very small recrystallized grains. The OEP material had much smaller amounts of refractory metal impurities but had a larger total impurity content, which varied within each lot of powder. Rolling and stress-relief temperatures of 800 to $900^{\circ} \mathrm{C}$ were required to obtain a fibrous grain structure in this material. However, because of variations in the impurity content and limited ductility of this material we could not obtain consistent formability.

The apparent beneficial effects of tungsten additions on the fabricability of iridium were confirmed in the OEP material with tungsten additions of 300 and 900 ppm. These additions promoted a uniformly fibrous grain structure indicative of good formability. Hightemperature impact test results on commercially available iridium also showed that iridium with tungsten additions can survive higher impact velocities.
As a result of the preceding information we developed and proceeded with prototype production of $\mathrm{Ir}-0.30 \%$ $\mathrm{W}$ alloy sheet. Fabrication schedules and quality assurance procedures have been established. We have successfully completed a production qualification schedule for supplying 90 hydroforming blanks in a 20 -working-day period.

\section{IRIDIUM PURIFICATION}

\section{J. I. Federer}

The feasibility of purifying iridium scrap and powder by an oxidation-dissolution method was demonstrated in a small production facility. The process consists of contacting oxygen with the impure material at an elevated temperature to form $\mathrm{IrO}_{3}$, which subsequently condenses as $\mathrm{IrO}_{2}$ in a cooler part of the system. Some impurities remain in the hot zone as relatively nonvolatile oxides, and some pass out of the system as gases. Impurity oxides that condense with the $\mathrm{IrO}_{2}$ can be removed by selective chemical dissolution. Finally, the $\mathrm{IrO}_{2}$ is reduced to metal powder with hydrogen. The process was proven with materials containing up to $3 \mathrm{wt} \%$ total impurities. Oxidation at 1000 and $1100^{\circ} \mathrm{C}$ 
followed by acid leaching produced a product containing about $99.98 \%$ Ir. Subsequently, 11 silica glass oxidation tubes $\left(2 \frac{1 / 8}{8}\right.$ in. ID) were constructed for purifying iridium scrap and powder. The tubes were initially charged with about $600 \mathrm{~g}$ of impure material, then operated continuously at $1100^{\circ} \mathrm{C}$ with a typical oxygen flow rate of $2000 \mathrm{~cm}^{3} / \mathrm{min}$. Periodically the $\mathrm{IrO}_{2}$ was collected and more impure material charged.

Three kinds of material have been processed: powder, approximately $1 / 4$-in. cubes of sintered powder compacts, and sheet scrap. The lowest oxidation rate was obtained with powder of several sizes between 10 and 100 mesh. The low rate was caused by partial sintering, which decreased the surface area exposed to the oxygen stream, and by channeling of the oxygen through several large holes in the sintered charge. On the other hand, lumps made from powder compacts and sheet scrap did not pack tightly together, and the oxygen passed through numerous paths in the charge. Typical $\mathrm{IrO}_{2}$ production rates at $1100^{\circ} \mathrm{C}$ and $2000 \mathrm{~cm}^{3} / \mathrm{min}$ oxygen flow were $1 \mathrm{~g} /$ day per tube for powder and 15 $\mathrm{g}$ /day per tube for either lumps or scrap.

The as-deposited $\mathrm{IrO}_{2}$ was crushed as needed to pass through a 40-mesh screen, then leached with several acid solutions to remove accompanying impurities (these impurities could not be leached before oxidation because of the chemical inertness of iridium). Very little $\mathrm{IrO}_{2}$ is dissolved during leaching. Afterwards, the $\mathrm{IrO}_{2}$ is washed with distilled water, dried, then reduced to metal powder with hydrogen at about $800^{\circ} \mathrm{C}$. The powder is then available for preparation of melting compacts. Approximately $7 \mathrm{~kg}$ of impure iridium has been processed in this way. 


\title{
/ \\ 15. Physical Metallurgy of Heat-Source Containment Materials
}

\author{
R.G. Donnelly
}

The program provides a base technology evaluation of materials for use in space applications of radioisotope thermoelectric generators (RTG's). During this period we focused attention on the compatibility of capsule materials for the ${ }^{238} \mathrm{PuO}_{2}$ fuel with the gaseous impurities present in such RTG's. These materials include the tantalum alloy $T-111$, which is the reference capsule material on the SNAP-19 RTG's used for Pioneer and planned for Viking missions. The molybdenum alloy TZM has received some consideration as a possible replacement for $T-111$ in these applications. For the Multi-Hundred Watt (MHW) generators, which operate at higher temperatures, iridium is the reference capsule material.

\section{STRUCTURE AND MECHANICAL PROPERTIES OF INTERNALLY OXIDIZED Ta-8\% W-2\% Hf (T-111) ALLOY ${ }^{1}$

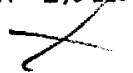

\section{T. Liu H. Inouye R. W. Carpenter}

The deformation and fracture behavior of the $\mathrm{Ta}-8 \%$ $\mathrm{W}-2 \% \mathrm{Hf}$ (T-111) alloy internally oxidized at $1273 \mathrm{~K}$ was studied at test temperatures up to $1589 \mathrm{~K}$ $\left(2400^{\circ} \mathrm{F}\right)$. The results are discussed in terms of oxygen distribution, oxygen content, and the morphology of the oxide. Thermodynamic calculations based on lattice parameter measurements indicate that the oxygen solubility in T-111 is low, about $72 \mathrm{ppm}$ at $1973 \mathrm{~K}$. Beyond the solubility limit, oxygen reacts with hafnium to form hafnium oxide, which causes a continuous decrease in lattice parameter until all the hafnium has been removed from the solid solution. A homogeneous dispersion of fine coherent hafnium-oxygen zones was

1. Abstracted from a paper accepted for publication in Metallurgical Transactions. observed in as-oxidized specimens. These zones coarsened upon annealing at or above $1673 \mathrm{~K}$ and eventually precipitated as rectangular $\mathrm{HfO}_{2}$ particles.

Alteration of the oxygen distribution and oxide morphology by heat treatment resulted in large changes in the tensile properties. For example, specimens aged $15 \mathrm{~min}$ at $1973 \mathrm{~K}$ showed little change up to $3500 \mathrm{ppm}$ 0 , but above this level the yield strength increased and ductility decreased abruptly. Ductility was completely lost at $4200 \mathrm{ppm} \mathrm{O}$, independent of test temperature. Specimens with no aging treatment other than oxygen addition lost all ductility at $800 \mathrm{ppm} 0$.

\section{LOW-PRESSURE OXIDATION AND TENSILE PROPERTIES OF OXYGEN-CONTAMINATED T-111 (Ref. 2) \\ H. Inouye C. T. Liu

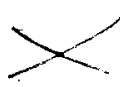

The kinetics of the oxygen contamination of T-111 by low-pressure gases was determined, and the resulting degradation of the tensile properties was measured to allow predictions of the useful life and establish the permissible limit of oxygen in the alloy when used as the capsule for containing ${ }^{238} \mathrm{PuO}_{2}$.

The reaction rate of T-111 with low-pressure oxygen, water vapor, and the gases outgassed from graphite and MIN-K insulation varied directly with the gas pressure and inversely with the alloy thickness, was constant with time, and was relatively insensitive to temperature between 825 and $1200^{\circ} \mathrm{C}$.

The ductility of T-111 decreased sharply with the oxygen content except at 760 and $825^{\circ} \mathrm{C}$ because of strain aging. The tolerance of T-111 for oxygen doubled

2. Abstract of report in preparation. 
on increasing the contaminating temperature from 825 to $1000^{\circ} \mathrm{C}$ and increased by an additional order of magnitude at $1200^{\circ} \mathrm{C}$. Service temperature between 760 and $825^{\circ} \mathrm{C}$ combined with the use of a diffusion barrier of molybdenum are considered to be the optimum condition for using T-111 in this application.

\section{MECHANICAL PROPERTIES AND INTERSTITIAL CONTAMINATION IN A MOLYBDENUM-BASE ALLOY, TZM (Ref. 3)

$$
\text { C. } T \text { : Liu H. Inouye }
$$

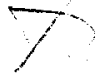

The deformation and fracture behavior of TZM (Mo-0.5\% Ti-0.08\% $\mathrm{Zr}-0.03 \% \mathrm{C}$ ) was studied at 825 and $1000^{\circ} \mathrm{C}$ after exposure to low-pressure oxygen, $\mathrm{CO}$, $\mathrm{H}_{2} \mathrm{O}$, and a simulated radioisotope thermoelectric generator environment. TZM showed an uptake of oxygen on exposure to these environments. Analysis of the results indicates that a diffusion process controls the kinetics of the oxygen absorption at $825^{\circ} \mathrm{C}$, while both diffusion and chemisorption processes affect the rate at $1000^{\circ} \mathrm{C}$. Exposed TZM also exhibited a small initial increase in carbon content followed by a decrease. Decarburization became significant only after prolonged exposure at $1000^{\circ} \mathrm{C}$.

The mechanical properties of both exposed and heat-treated specimens were determined at temperatures to $1316^{\circ} \mathrm{C}\left(2400^{\circ} \mathrm{F}\right)$. TZM specimens showed an increase in strength and a linear decrease in ductility with oxygen content. Exposed TZM lost its ductility completely at an oxygen level of $300 \mathrm{ppm}$ at room temperature, 1093 , and $1316^{\circ} \mathrm{C}$, but $500 \mathrm{ppm}$ was required at $825^{\circ} \mathrm{C}$. However, the ductility of embrittled TZM was increased significantly with heat treatment at high temperatures and was almost completely restored after annealing for $15 \mathrm{~min}$ at $1700^{\circ} \mathrm{C}$. The change in mechanical properties is discussed in terms of internal oxidation and precipitation of various forms of oxides.

3. Abstracted from ORNL-TM-4238 (in press).

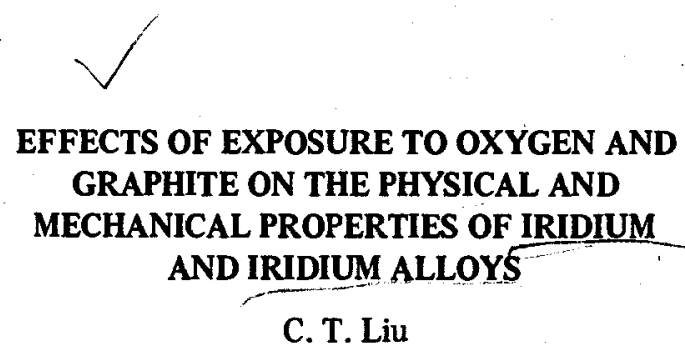

Sheet specimens of iridium and iridium alloys containing 2 at. \% W or $\mathrm{Re}$ were exposed to low-pressure oxygen and $/$ or graphite at $1300^{\circ} \mathrm{C}$ to simulate a radioisotope thermoelectric generator heat-source environment. The specimens were still bright and showed no indication of a reaction after exposure to $2000 \mathrm{hr}$. Both weight measurements and chemical analyses indicated essentially no uptake of interstitial species during exposure. The mechanical properties of the exposed specimens were determined by tensile tests in vacuum at $20,760,1093$, and $1316^{\circ} \mathrm{C}$. The results showed that exposure to these environments did not impair the ductility of iridium and iridium alloys at these temperatures. The tensile strength was not sensitive to these exposures, although the yield strength of the exposed specimens was somewhat lower than that of the unexposed ones. According to these results, iridium and the above iridium alloys appear to be compatible with low-pressure oxygen and graphite at $1300^{\circ} \mathrm{C}$.

\section{SPECIAL PROBLEMS AND CONSULTING}

$$
\begin{array}{ll}
\text { H. Inouye } & \text { C. T. Liu } \\
\begin{array}{l}
\text { E. L. Long, Jr. } \\
\text { H. E. McCoy, Jr. Donnelly }
\end{array}
\end{array}
$$

A variety of short-term tasks and consulting services were provided to SNS in connection with the Pioneer and Viking projects. Among these were problems related to the design of the helium vent, the electrical feedthrough, evaluation of the effects of environmental exposure on the properties of T-111 and TZM, and evaluation of the T-111 strength member from Pioneer test capsule PF-13. 


\section{$60^{378}$ \\ 16. Tungsten Metallurgy}

A. C. Schaffhauser

This program provided the base technology on tungsten alloys for advanced space power and general reactor applications. However, with the cancellation of all reactor space power programs early in the fiscal year much of the work being performed on this program was terminated. Only the long-term creep tests and evaluation of irradiated specimens in progress were continued.

Some of our work on creep of chemically vapordeposited tungsten is reported in Chapter 4.

\section{LOW-STRESS CREEP TESTING OF CVD TUNGSTEN}

\section{$\begin{array}{ll}\text { A. E. Richt } & \\ & \text { F. W. Wiffen }\end{array}$}

A. C. Schaffhauser

We continued creep testing different types of CVD tungsten sheet at $1000 \mathrm{psi}$ and $1650^{\circ} \mathrm{C}$ to obtain design data needed for the thermionic reactor program. ${ }^{2}$ Testing times of 7000 to $10,000 \mathrm{hr}$ have been achieved for three samples having different fluorine impurity contents.

Previous tests at $1650^{\circ} \mathrm{C}$ and stresses between 2000 and 10,000 psi showed $d^{3,4}$ that material containing 12 to $35 \mathrm{ppm} F$ had significantly higher strength than material with 2 to $9 \mathrm{ppm} F$. However, the current data at 1000 psi show that the high-fluorine material, WF-55

1. Present address, Union Carbide Corporation, South Charleston, W.Va.

2. A. C. Schaffhauser and W. L. McCollough, Metals and Ceramics Div. Annu. Progr. Rep. June 30, 1972, ORNL-4820, p. 103.

3. K. Farrell, paper to be presented at the Fourth International Conference on Chemical Vapor Deposition, October 7-12, 1973, Boston, Mass., to be published in the proceedings; see also Chap. 4 of this report.

4. H. E. McCoy, Jr., J. O. Stiegler, and A. C. Schaffhauser, ibid., pp. 102-103. containing $20 \mathrm{ppm} \mathrm{F}$, and the low-fluorine duplex material, GGA-D2 (ref. 5) containing $5 \mathrm{ppm} \mathrm{F,} \mathrm{have}$ about the same minimum creep rate of $6 \times 10^{-5} \% / \mathrm{hr}$ up to $5000 \mathrm{hr}(0.3 \%$ strain). For longer teśt times (to $10,000 \mathrm{hr}$ ) the creep rate of the low-fluorine material remains constant, whereas the high-fluorine material is unstable and has an accelerating creep rate.

\section{EFFECT OF CARBURIZATION ON THE CREEP PROPERTIES OF TUNGSTEN}

\section{H. Inouye}

The creep properties of tungsten wire and CVD tungsten tubing were determined while being gascarburized in a $10^{-4}$ to $10^{-5}$ torr partial pressure of $\mathrm{CH}_{4}$ or $\mathrm{C}_{6} \mathrm{H}_{6}$. Tests were performed at 1000 to 3000 psi and compared with control tests performed in vacuum. The creep strength of the specimens was higher tested in a carburizing atmosphere than in vacuum if a crack-free carbide layer was formed. However, at the higher stresses or under conditions where the carbide layer was cracked, the specimens tested in vacuum were stronger.

\section{EFFECT OF FAST-NEUTRON IRRADIATION ON THE PROPERTIES OF TUNGSTEN ALLOYS}

\section{F. W. Wiffen R. K. Williams}

We have partially evaluated the high-temperature fast-neutron irradiation experiment on tungsten alloys previously described. ${ }^{6}$ Resistivity and electron microscopy samples of tungsten and tungsten-rhenium alloys were irradiated at 600 to $1500^{\circ} \mathrm{C}$ to a calculated peak

5. Material supplied by Gulf Energy and Environmental Systems, San Diego, CA

6. F. W. Wiffen and R. K. Williams, Metals and Ceramics Div. Annu. Progr. Rep. June 30, 1972, ORNL-4820, p. 105. 
fluence of $7.8 \pm 2.0 \times 10^{21}$ neutrons $/ \mathrm{cm}^{2}(>0.1 \mathrm{MeV})$. All the specimens were successfully recovered during disassembly of the capsules. However, length and density measurements in the hot cells were not sufficiently accurate to determine the irradiation-induced swelling characteristics of these materials. This evaluation will have to be performed by transmission electron microscopy.

Room-temperature electrical resistivity and Seebeck coefficient data and resistance ratio measurements in liquid helium and nitrogen have been obtained on a number of the irradiated samples. Analysis of the data is incomplete, but several trends are obvious. For unalloyed tungsten samples, irradiation increased both the resistivity and absolute Seebeck coefficient. The resistivity increase amounted to about $20 \%$ for $600^{\circ} \mathrm{C}$ irradiation temperatures and decreased [approximately as $\Delta \rho \propto \exp (C / P)]$ at higher temperatures. The higher purity CVD specimens showed larger resistivity increments than arc-cast material. The low-temperature resistance ratio measurements indicate that the irradia- tion-induced resistivity deviates positively from Mattheissen's rule. Seebeck coefficient $(S)$ measurements show the same increase (about 20\%) for all irradiation temperatures.

The behavior of the tungsten-rhenium alloys $(5,7$, and $25 \% \mathrm{Re}$ ) was more complex and, as previously reported, ${ }^{6}$ indicates that irradiation induces a solidstate reaction in these alloys. For $\mathrm{W}-25 \% \mathrm{Re}$, the resistivity increased at all temperatures, but the increase was least for irradiation at $1100^{\circ} \mathrm{C}$. The Seebeck coefficients of these samples showed a constant negative increment of about $8 \%$ at all irradiation temperatures. Room-temperature measurements on arc-cast W-5\% Re and CVD W-7\% Re samples showed that the resistivity decreased by as much as $25 \%$ for $1100^{\circ} \mathrm{C}$ irradiation. The Seebeck coefficient of a W-5\% Re sample irradiated at $1100^{\circ} \mathrm{C}$ was halved. The latter result shows that the in-pile decalibration of tungsten. rhenium thermocouples (such as $\mathrm{W}-5 \% \mathrm{Re}$ vs $\mathrm{W}-25 \%$ $\mathrm{Re}$ ) is probably due to the rapid onset of a solid state reaction in the low-rhenium thermocouple leg. 


\title{
Part III. Reactor Development Support

\author{
17. Gas-Cooled Reactor Program
}

\author{
J. H. Coobs
}

Our materials effort in support of the Gas-Cooled Reactor Program is directed primarily toward the development of fuel elements for high-temperature gas-cooled converter reactors (HTGR's), such as the Fort St. Vrain Reactor and the commercial reactors that utilities have ordered from Gulf General Atomic (GGA). The reference fuel elements consist of hexagonal graphite blocks containing blended fissile and fertile particles. Reference fertile particles consist of $500-\mu \mathrm{m}$-diam $\mathrm{ThO}_{2}$ microspheres with two-layer (BISO) pyrolytic carbon coatings. Fissile particles consist of smaller $\mathrm{UO}_{2}, \mathrm{UC}_{2}$, or $(\mathrm{Th}, \mathrm{U}) \mathrm{O}_{2}$ microspheres with TRISO coatings (essentially ${ }^{\circ} \mathrm{BISO}$ with an intermediate $\mathrm{SiC}$ layer to retain $\mathrm{Ba}, \mathrm{Cs}$, and $\mathrm{Sr}$ ). Design operating conditions include fluences up to $8 \times 10^{21}$ neutrons/ $\mathrm{cm}^{2}(>0.18 \mathrm{MeV})$ and temperatures in the range 600 to $1300^{\circ} \mathrm{C}$.

Our program consists primarily of the design, fabrication, characterization, and irradiation testing of coated particles, bonded beds, and simulated fuel elements for both initial and recycle cores for the HTGR. The program is intimately connected with the Thorium Utilization Program and provides much of the base technology for it. Consequently, we emphasize fuels and fabrication processes that are amenable to remote refabrication techniques. Fissile particles of interest include (Th, $\mathrm{U}) \mathrm{O}_{2}$ made by the sol-gel process and carbon-diluted $\mathrm{UO}_{2}$ or $\mathrm{UC}_{2}$ particles made from weakacid ion exchange resins. Fuel rods, consisting of bonded beds of fuel particles, are fabricated by intruding a mixture of graphite powder and pitch into a blended bed of fissile and fertile particles and then carbonizing in argon, ultimately to $1800^{\circ} \mathrm{C}$. Sluginjection is the preferred forming operation, and carbonizing directly in the graphite block is receiving increasing attention. Fuels that meet rigid quality standards are subjected to extensive irradiation in the High Flux Isotope Reactor (HFIR) or the Oak Ridge Research Reactor (ORR). After irradiation the fuels are examined in the High Radiation Level Examination Laboratory (HRLEL). Experimental results are compared with predictions made with our mathematical models, permitting a continual improvement in both fuel particle design, fabrication techniques, and modeling capability. A small effort is directed toward the development of fuel elements for advanced, higher temperature HTGR's for direct cycle and process heat applications.

We are also participating with GGA and Argonne National Laboratory in the development of fuel elements for a Gas-Cooled Fast Breeder Reactor (GCFBR).' The ORNL phase consists of the irradiation of vented pins of type 316 stainless-steel-clad (U,Pu) $\mathrm{O}_{2}$ in the ORR followed by limited postirradiation examination. The pins are then sent to Argonne National Laboratory for final examination.

\section{COATED PARTICLES FROM ION EXCHANGE RESINS}

\section{B. Pollock ${ }^{2}$ M. D. Silverman ${ }^{3}$}

Fissile particles derived from weak-acid resins continue to be of interest. ${ }^{4}$ Studies have been limited primarily to obtaining more detailed information on the

1. R. B. Fitts, R. A. Bradley, A. W. Longest, and E. J. Manthos, Metals and Ceramics Div. Annu. Progr. Rep. June 30, 1972, ORNL-4820, pp. 111-12.

2. Now at Oak Ridge Y-12 Plant.

3. On loan from Reactor Division.

4. C. B. Pollock and M. D. Silverman, Metals and Ceramics Div. Annu. Progr. Rep. June 30, 1972, ORNL-4820, pp. 106-107. 
processing of fuel-loaded Amberlite IRC-72, manufactured by Rohm and Haas, because of its superior behavior in screening tests. Some difficulties were experienced initially in fully loading the $\mathrm{UO}_{2}{ }^{2+}$ ion on Amberlite IRC-72, but the problem was solved by use of $\mathrm{UO}_{3}$ as a buffering addition. ${ }^{5}$ Fully loaded batches of weak-acid resins are now produced routinely in a semicontinuous column-loading operation. The only resin preparation required is a wet screening operation before loading. The loaded batches are tray dried at $110^{\circ} \mathrm{C}$.

\section{Carbonization Studies}

Scouting experiments reported previously ${ }^{4}$ were extended to ascertain the temperature range in which the dried, loaded resins decomposed, lost weight, and emitted various gaseous species. Three different types of instruments were employed: the differential thermal analyzer (DTA), the thermogravimetric analyzer (TGA), and the gas chromatograph. Typical DTA and TGA curves for uranium-loaded IRC-72 heated at $3^{\circ} \mathrm{C} / \mathrm{min}$ in helium are shown in Fig. 17.1. From these and the associated gas chromatography data we concluded that the first broad endotherm, where about a $15 \%$ weight loss occurs, is associated with the release of most of the

5. P. A. Haas, HTGR Fuel Development: Use of $\mathrm{UO}_{3}$ to Load Cation Exchange Resin for Microsphere Preparation, ORNLTM-3817 (September 1972). chemically bound water. Small amounts of water that are probably trapped along with water formed by decomposition are not removed completely until about $400^{\circ} \mathrm{C}$ is attained. The second endotherm and its associated 5\% weight loss are probably due to the breakup of the polymer yielding allyl radicals, which give rise to the light unsaturated hydrocarbons, ethylene, acetylene, and propylene. The broad exotherm and $15 \%$ weight loss in the 550 to $750^{\circ} \mathrm{C}$ range probably indicate that carbonization is occurring, along with decarboxylation. Carbon monoxide and carbon dioxide are both formed in appreciable amounts. The small endotherm in the 475 to $525^{\circ} \mathrm{C}$ range may be due to the depolymerization of heavy organic fractions. Carbonization is largely completed by $600^{\circ} \mathrm{C}$, so that the heating rate may be very high above this temperature without damage to the particles.

\section{Compatibility of Carbonized Resins with Air}

Particles carbonized to temperatures in the range $\mathbf{7 5 0}$ to $1100^{\circ} \mathrm{C}$ were found to be mildly reactive with moist air. Typically, a 100-g batch would heat up and gain about $4 \%$ in weight, but no damage to the particles was observed. The reaction thought to be occurring is the oxidation of $\mathrm{UO}_{2+x}$ to form $\mathrm{U}_{3} \mathrm{O}_{8}$. X-ray analysis is of little value because of the extremely small size of the fuel crystallites. In a study to alleviate the problem, heating to $1200^{\circ} \mathrm{C}$ or higher stabilized the fueled resins, and no heating or weight gain was observed over a 24-hr

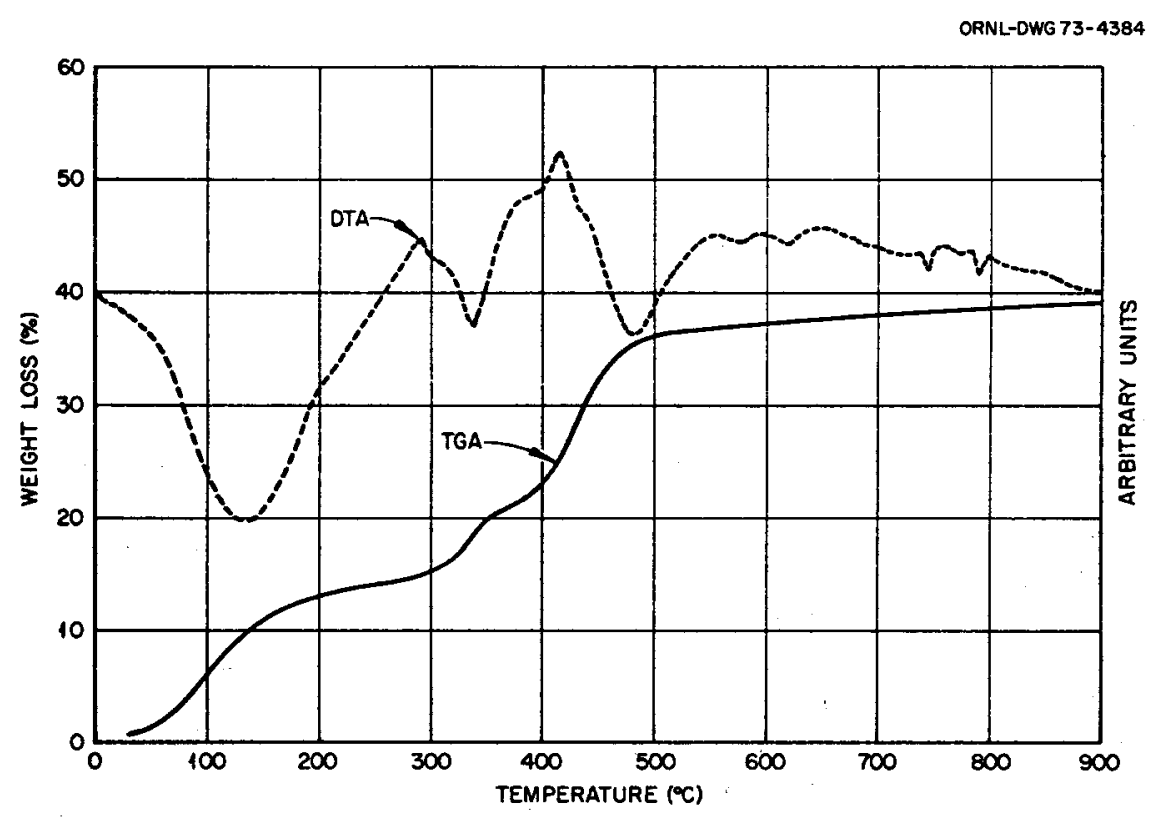

Fig. 17.1. Carbonization of uranium-loaded weak-acid resin (IRC-72). 
period. The stabilization is attributed to fuel-crystallite growth and corresponding reduction in surface area. After stabilization, good $x$-ray diffraction patterns are obtained, although we still see a considerable amount of line broadening. The overall composition after stabilizing at $1200^{\circ} \mathrm{C}$ is approximately $\mathrm{UO}_{2+x}+5 \mathrm{C}$.

\section{Adjustment of Oxygen-to-Metal Ratio}

Kernel migration up the temperature gradient has been observed in irradiated fuel rods with both dense carbide and dense oxide fuel particles. A model for the "amoeba effect" involving $\mathrm{UO}_{2}$ kernels, discussed by $\mathrm{T}$. B. Lindemer, ${ }^{6}$ is based on the $2 \mathrm{CO} \rightleftharpoons \mathrm{CO}_{2}+\mathrm{C}$ equilibrium, which provides a mechanism for carbon transport from the hot to the cold side of the fuel kernel. Lindemer suggested that the addition of about $1 \%$ carbide per $10 \%$ FIMA would be sufficient to fix the $\mathrm{CO}$ pressure at all burnups by the $\mathrm{UC}_{2}-\mathrm{UO}_{2}-\mathrm{C}$ equilibrium value.

Fuel particles derived from weak-acid resins are particularly amenable to the desired oxygen-to-heavymetal $(\mathrm{O} / \mathrm{M})$ reduction. We heated stabilized resin for various time intervals at temperatures in the range 1200 to $1800^{\circ} \mathrm{C}$ in flowing helium. The reaction $\mathrm{UO}_{2}+$ $3.86 \mathrm{C} \rightarrow \mathrm{UC}_{1.86}+2 \mathrm{CO}$ occurs above $1300^{\circ} \mathrm{C}$, the amount increasing with increasing time and helium flow rate. At $1600^{\circ} \mathrm{C}$ in $1 \mathrm{hr}$ about half conversion to $\mathrm{UC}_{1.86}: \mathrm{UO}_{2}$ is found by $\mathrm{x}$-ray analysis; in $3 \mathrm{hr}$ the reaction is essentially complete. At 1700 and $1800^{\circ} \mathrm{C}$ the reaction proceeds to completion rapidly. Thus, the $\mathrm{O} / \mathrm{M}$ may be adjusted to any desired value.

\section{FUEL ELEMENT FABRICATION STUDIES FOR HTGR FUELS}

\section{R. L. Hamner J M Robbins W. P. Eatherly}

The reference process for fabricating HTGR fuel rods is the intrusion of a blend of pitch and graphite flour into the interstices of a densely packed bed $(62 \mathrm{vol} \%)$ of coated particles. Most of the work on this process has progressed to the pilot-plant scale of production and is discussed in Chapter 21, "Thorium Utilization," of this report. Under the HTGR Base Program we are continuing a small effort to develop continuous-matrix (less than 45 vol \%) coated particles for advanced HTGR applications. The advantages of the continuousmatrix fuel rods are higher overall thermal conductivity and lower tendency for amoeba migration.

6. T. B. Lindemer, Metals and Ceramics Div. Annu. Progr. Rep. June 30, 1972, ORNL-4820, pp. 107-108.
We extruded a series of rods for testing. The matrix was modified by substituting graphitized Robinson coke for needle coke to make a more isotropic body, and more Thermax was added to maintain dimensional control and get high matrix densities. The mix was preblended with Varcum binder, coated particles were added to produce volume loadings of 30 to $45 \%$, and the mix was extruded at room temperature at'a rate of $10 \mathrm{ft} / \mathrm{min}$ to produce fuel rods about $0.5 \mathrm{in}$. in diameter. The rods were cut to length and then carbonized in argon to $1800^{\circ} \mathrm{C}$. In the cutting process it is important that particle coatings not be damaged. We found that the green rods could be cut successfully with a beveled-edge blade, which pushed the coated particles aside out of the way.

In the past we cured the rods for $16 \mathrm{hr}$ at $90^{\circ} \mathrm{C}$ and then heated the rods to $1000^{\circ} \mathrm{C}$ over a $24-\mathrm{hr}$ period. To accelerate the process we carbonized extrusions within a 3-hr period to $1000^{\circ} \mathrm{C}$ with and without curing. Some difficulties were encountered with uncured rods, but no problems were found in rods cured for $30 \mathrm{~min}$ at $90^{\circ} \mathrm{C}$ before firing.

The principal remaining question relative to extrusion fabrication is whether or not particle coatings are broken by the process. Three methods have been used to answer the question. We have dissolved green rods and examined particle coatings after screening. No evidence of damaged particles was observed. This does not preclude failure due to matrix-coating interactions during carbonizing. To evaluate breakage during heat treatment we have relied on metallography, but it is slow and not completely reliable. We recently initiated a study of ways to disintegrate fired rods. After several unsuccessful trials we found that an electrolytic disintegration technique would break up the matrix without damage to coatings on particles.

\section{THERMAL CONDUCTIVITY OF BONDED HTGR FUEL MATERIALS \\ D. L. McElroy}

Two techniques are being pursued to incorporate coated microsphere fuels in a graphite matrix for HTGR fuel elements: a slurry-blending warm-molding process and an extrusion process. Since low-temperature thermal conductivity $(\lambda)$ and electrical resistivity $(\rho)$ results are sensitive to structural changes, we completed such measurements on specimens from both processes. For equivalent microsphere concentrations the conduction properties of the extruded products are at least double those of the slurry-blended, warm-molded products. Table 17.1 contains smoothed $\lambda$ and $\rho$ values for two 
Table 17.1. Thermal conductivity and electrical resistivity of extruded fuel sticks

\begin{tabular}{|c|c|c|c|c|c|}
\hline \multirow{2}{*}{$\begin{array}{c}\text { Temperature } \\
\text { (K) }\end{array}$} & \multicolumn{2}{|c|}{$\begin{array}{c}\text { Sample JH-269-3 } \\
(0 \%)\end{array}$} & \multicolumn{2}{|c|}{$\begin{array}{l}\text { Sample JH-212 } \\
\text { (28.5\%) }\end{array}$} & \multirow{2}{*}{$\lambda_{E} / \lambda_{S B}{ }^{c}$} \\
\hline & $\rho^{a}$ & $\lambda^{b}$ & $\rho^{a}$ & $\lambda^{b}$ & \\
\hline 100 & 2155 & 0.232 & 2480 & 0.142 & 2.4 \\
\hline 200 & 1744 & 0.450 & 2130 & 0.275 & 2.2 \\
\hline 300 & 1560 & 0.522 & 1920 & 0.329 & 2.2 \\
\hline 400 & 1472 & 0.508 & 1780 & 0.340 & 2.1 \\
\hline
\end{tabular}

${ }^{a}$ Electrical resistivity in $\mu \Omega-\mathrm{cm}$.

Thermal conductivity in $W \mathrm{~cm}^{-1} \mathrm{~K}^{-1}$

${ }^{c}$ Thermal conductivity ratio: Extruded/slurry-blended (sample JH-212 and sample JH 105-1 in Table 25.1, ref. 7).

extruded specimens, one without microspheres and a matrix density of $1.8 \mathrm{~g} / \mathrm{cm}^{3}$ and one containing 28.5 vol \% inert particles in a matrix of density $1.74 \mathrm{~g} / \mathrm{cm}^{3}$, both heat treated at $1800^{\circ} \mathrm{C}$ for $30 \mathrm{~min}$ in argon. The $\lambda$ of the latter specimen is compared to that of a slurry-blended warm-molded specimen ${ }^{7}$ in this table. Further improvements in $\lambda$ might occur if the specimens could be heat treated to higher temperatures.

\section{COATED-PARTICLE PERFORMANCE MODELING}

\section{F. J. Homan R. A. Olstad}

Of the three coated-particle performance codes currently in use, one (STRETCH) is limited to BISO particles, ${ }^{8}$ a second is limited to TRISO particles, ${ }^{9}$ and the third is a general-purpose code, which can treat a wide variety of particle designs. ${ }^{10}$ The results obtained with the general-purpose code in its present form (STRESS-2) have been compared with the results of the two other codes (STRETCH and TRISO) to determine whether the codes are mathematically equivalent. In addition, we have used these codes to study the sensitivity of the predicted performance of the coated particles under irradiation to the numerous physical and mechanical properties of the kernel and coatings.

7. R. S. Graves, W. M. Ewing, and D. L. McElroy, Metals and Ceramics Div. Annu. Progr. Rep. June 30, 1972, ORNL-4820, pp. 109-10.

8. J. W. Prados and T. G. Godfrey, STRETCH, a Computer Program for Predicting Coated Particle Irradiation Behavior, Modification IV, ORNL-TM-21 27 (April 1968).

9. J. L. Kaae, “A Mathematical Model for Calculating Stresses in a Four-Layer Carbon-Silicon Carbon-Coated Fuel Particle," $J$. Nucl. Mater. 32, 322 (1969).

10. H. Walther and P. G. Novario, Stress Analysis in Coated Particle Fuels, Part I: Theory and Examples; Part II: Computer Programme Stress I, DP-Report-604 (August 1968); (Part II, July 1969).

\section{STRESS-2 and TRISO Comparison}

In comparing these two codes, we selected a TRISO particle design reported by Gulden et al. ${ }^{11}$ and materials properties derived from the literature. ${ }^{12}$ The two most important properties that affect the predicted performance under irradiation are the creep coefficient and the irradiation-induced deformation characteristics of the pyrocarbon layers. Using the same data in both codes, we obtained the predicted performances shown in Fig. 17.2, both of which essentially duplicate the calculated coating stresses reported by Gulden.

From this comparison we conclude that TRISO and STRESS-2 are mathematically equivalent, although TRISO is somewhat simpler. For example, TRISO assumes that the $\mathrm{SiC}$ layer does not creep, that it is dimensionally stable under irradiation, and that the buffer layer is weak and cannot impart loads to the other layers except through the mechanism of fuel swelling. With STRESS-2 but not TRISO one can study the effect of failure of one or more layers on the stresses developed in the remaining layers.

\section{STRESS-2 and STRETCH Comparison}

For this comparison we selected a BISO-coated fissile particle that has a $350-\mu \mathrm{m}$-diam $(\mathrm{Th}, \mathrm{U}) \mathrm{O}_{2}$ kernel coated with $100-\mu \mathrm{m}$ buffer and $100-\mu \mathrm{m}$ outer LTI (low-temperature isotropic) coating layers. The kernel has a thorium-to-uranium ratio of 4.2 , and its density was assumed to be $95 \%$ of theoretical. The buffer coating density was $50 \%$ of theoretical. The deposition temperatures of the buffer and LTI were 1470 and $1375^{\circ} \mathrm{C}$, respectively, and the irradiation temperature was assumed to be $1300^{\circ} \mathrm{C}$. Because STRESS-2 required the relationship between burnup and fluence as input, such a curve was computed with STRETCH and also used in STRESS-2.

Calculations of fission-gas pressure and LTI tangential stresses as functions of fast fluence are shown in Fig. 17.3 for both codes. Notice there is little difference in the two curves at the left of the figure below a fluence of about $60 \times 10^{20}$ neutrons $/ \mathrm{cm}^{2}$. At that point, the pressure calculated by STRESS- 2 begins to flatten compared to the pressure calculated by STRETCH. The reason for this can be demonstrated by examining the

11. T. D. Gulden et al., "The Mechanical Design of TRISOCoated Particle Fuels for the Large HTGR," Nucl. Technol. 16(1), 100-109 (October 1972).

12. J. L. Kaae, J. C. Bokros, and D. W. Stevens, "Dimensional Changes and Creep of Poorly Crystalline Isotropic Carbons and Carbon-Silicon Alloys During Irradiation," Carbon 10, 571-85 (1972). 


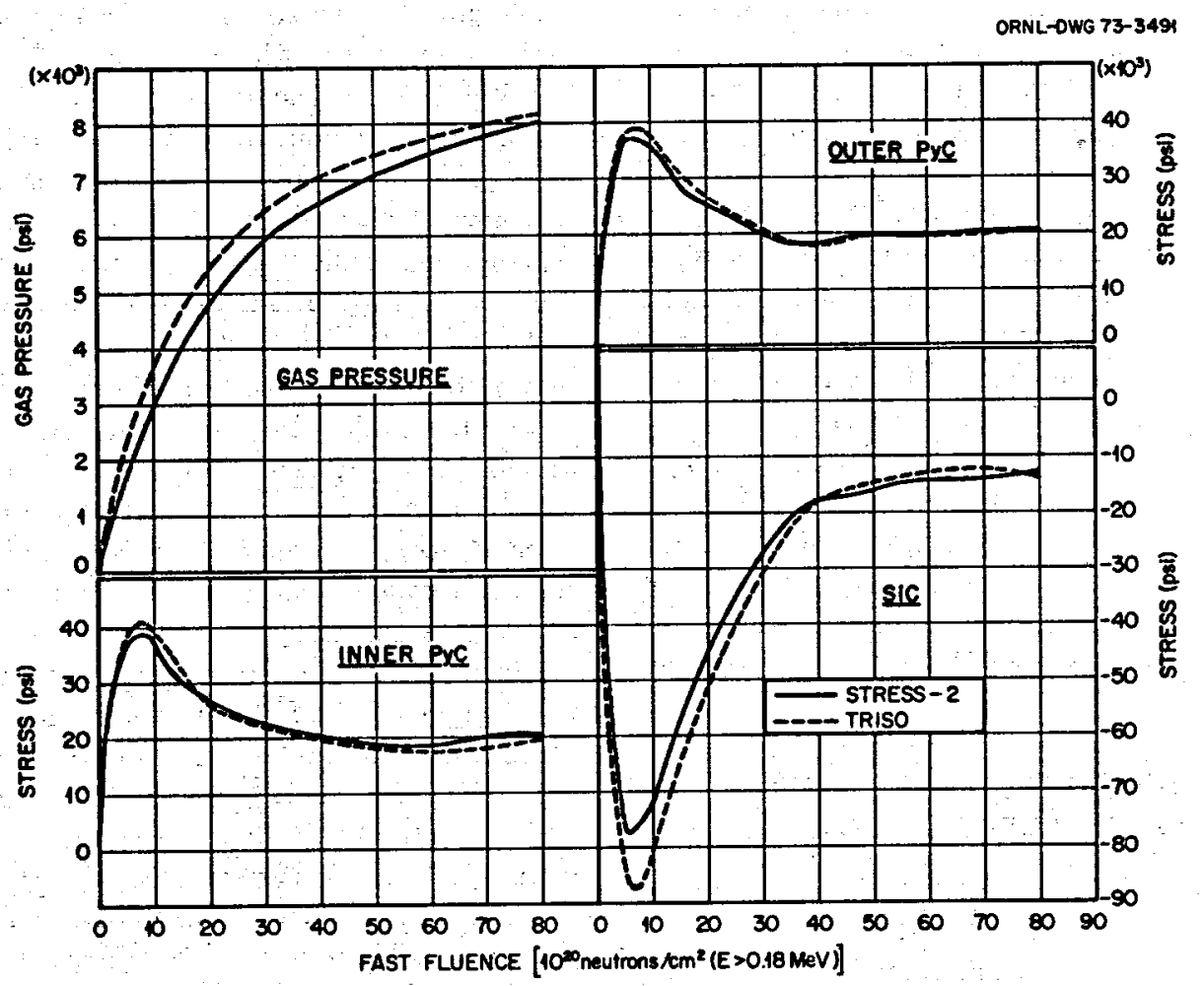

Fig. 17.2. Comparison of the analysis by TRISO and STRESS-2 codes for a GGA particle.

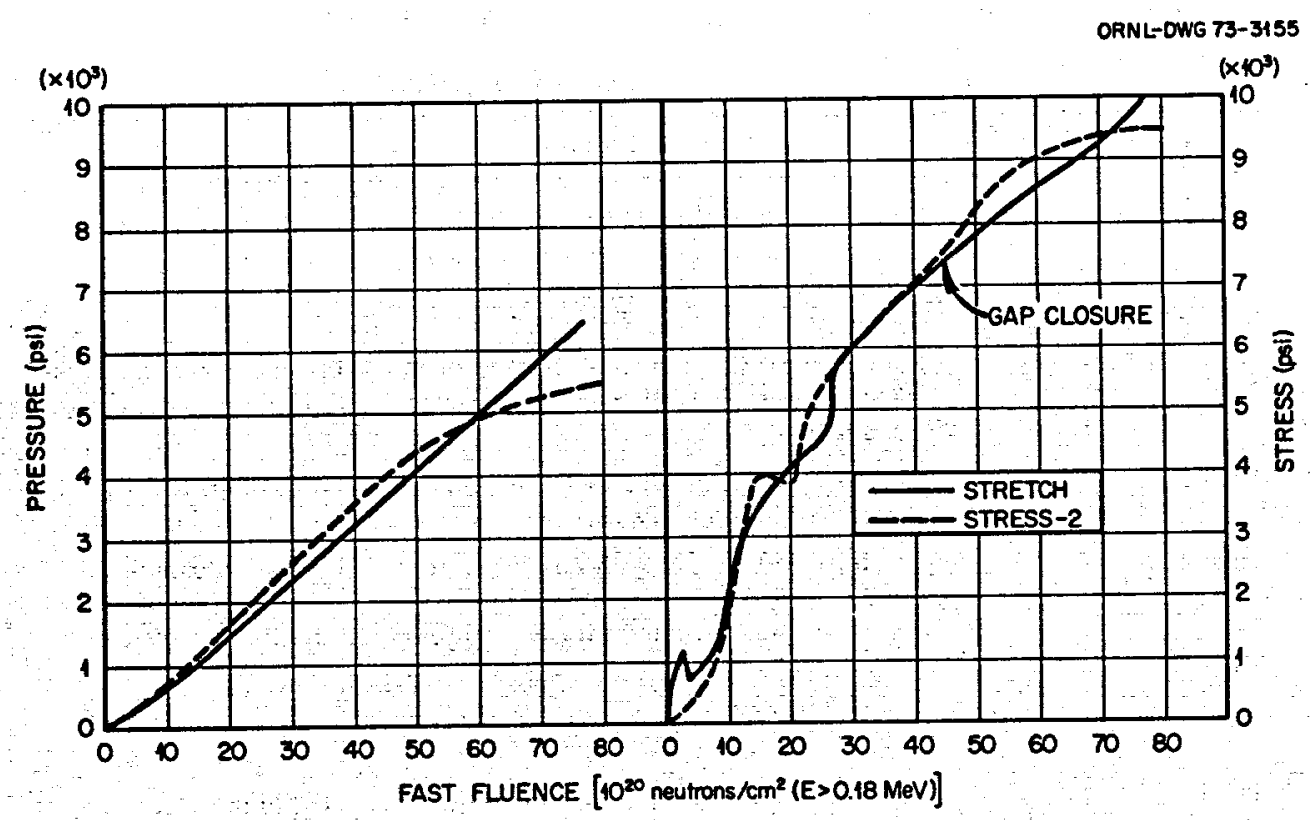

Fig. 17.3. Comparison of fission-gas pressures (left) and tangential stresses (right) calculated by STRETCH and STRESS-2. 
curves at the right of the figure, which show the tangential stresses calculated in the PyC (pyrolytic carbon). STRETCH considers the buffer layer to be very weak and incapable of supporting loads, either in tension or compression. Therefore, no loads are transmitted from the buffer to the outer $\mathrm{PyC}$ during any phase of the irradiation history. On the other hand, in STRESS- 2 the gap between the buffer and LTI layers closes at about $45 \times 10^{20}$ fast fluence, and the stresses in the PyC layer increase slightly because of the continued densification and shrinkage down upon the buffer. The presence of the buffer prevents the PyC from shrinking as much as it would if there were no restraint, and this provides more space for the fission gas. The differences noted in predicted performance of the two codes are minor, and we therefore conclude that STRESS-2 and STRETCH are mathematically equivalent.

\section{IRRADIATION TESTING OF HTGR FUELS AND FUEL ELEMENTS}
J. H. Coobs
C. B. Pollock ${ }^{2}$
D. M. Hewette II
R. B. Fitts
J M Robbins
W. P. Eatherly
J. A. Conlin ${ }^{13}$
B. H. Montgomery ${ }^{13}$
J. L. Scott
E. L. Long, Jr.

Irradiation testing of HTGR fuel and fuel element materials involved three types of experimental facilities.
Small, uninstrumented HT capsules that occupy a target position in HFIR, where the maximum fast-neutron flux is $1.2 \times 10^{15}$ neutrons $\mathrm{cm}^{-2} \mathrm{sec}^{-1}(>0.18 \mathrm{MeV})$, permit rapid attainment of the design HTGR exposure. Four of these capsules were irradiated, and final reporting of a prior series is in preparation. A second type consists of the larger instrumented and swept HRB capsules, which are located in the removable reflector region of HFIR, where the fast flux is about $40 \%$ of that in the target region. Irradiation and examination of one HRB capsule were completed, two more have been irradiated, and irradiation of another is continuing. The third type involves our cooperative program with Gulf General Atomic, whereby ORNL specimens are included in ETR irradiations in return for use of space in HFIR experiments by GGA. Irradiation of two sets of specimens containing strong- and weak-acid resin fuels was completed. The above experiments are identified and described in Table 17.2. Additional information on individual experiments is given in following sections.

The results from these experiments can be summarized as follows. Performance of BISO-coated $\mathrm{ThO}_{2}$ particles with reference design coatings was more than adequate, and the behavior of particles with less conservatively designed coatings could be correlated with a performance model. Fuel rod specimens prepared by slug-injection bonding with coal-tar pitch

13. Reactor Division.

Table 17.2. Current irradiation tests on HTGR fuels

\begin{tabular}{|c|c|c|}
\hline Experiment & Principal test variables & Status \\
\hline HT- $7,-8,-9,-10$ & $\begin{array}{l}\text { Density variations in LTI layers of TRISO } \\
\text { coatings on loose particles and in bonded } \\
\text { rods; also test of five types of resin-base } \\
\text { fissile fuels }\end{array}$ & $\begin{array}{l}\text { Final report in prep- } \\
\text { aration }\end{array}$ \\
\hline HT-12, $-13,-14,-15$ & $\begin{array}{l}\text { Reference particle design for BISO-coated } \\
\mathrm{ThO}_{2} \text {; investigate failure criteria for model } \\
\text { studies }\end{array}$ & $\begin{array}{l}\text { Initial examination com- } \\
\text { plete; analy sis in progress }\end{array}$ \\
\hline HRB-3 & $\begin{array}{l}\text { Slug-injected and molded fuel rods containing } \\
\text { strong-acid-resin fissile particles }\end{array}$ & PIE $^{a}$ complete \\
\hline HRB-4, -5 & $\begin{array}{l}\text { Slug-injected fuel rods with various matrices } \\
\text { and extruded rods with high-density } \\
\text { matrices; weak-acid-resin fissile particles }\end{array}$ & $\begin{array}{l}\text { Irradiation completed; } \\
\text { examination of } \\
\text { HRB-5 completed }\end{array}$ \\
\hline HRB-6 & $\begin{array}{l}\text { Mixed-oxide fissile particles comparing }{ }^{233} \mathrm{U} \\
\text { and }{ }^{235} \mathrm{U} \text { fuels, tested in slug-injected and } \\
\text { extruded rods }\end{array}$ & In reactor \\
\hline P-13N & $\begin{array}{l}\text { High-burnup test of strong-acid-resin fissile } \\
\text { particles in molded rods }\end{array}$ & PIE $^{a}$ in progress \\
\hline P-13P & $\begin{array}{l}\text { High-burnup test of weak-acid-resin fissile } \\
\text { particles in intrusion-bonded rods }\end{array}$ & $\begin{array}{l}\text { Irradiation complete; } \\
\text { awaiting examination } \\
\text { at GGA }\end{array}$ \\
\hline
\end{tabular}

${ }^{a}$ Postirradiation examination. 
containing natural flake graphite performed well when irradiated to the design HTGR fast neutron fluence of 8 $\times 10^{21}$ neutrons $/ \mathrm{cm}^{2}$. However, examination of polished sections revealed a potential problem in the directional migration of $\mathrm{ThO}_{2}$ kernels at the higher temperatures. Fuel rod specimens prepared by molding or extrusion have lower fuel loadings and improved physical properties, and such rods performed very well when irradiated to the same fluence and heat ratings.

\section{Performance of BISO-coated $\mathrm{ThO}_{2}$ Particles in HFIR Experiments}

Fuel elements that contain $\mathrm{ThO}_{2}$ fertile particles coated with two-layer carbon (BISO) coatings are favored for some current designs for HTGR's. Because fertile particles occupy a large fraction of the volume of the fuel rods, it is desirable to optimize the thickness ratios of coatings on these particles. We designed an experiment to define more closely the failure criteria for BISO coatings and to obtain numerical values for quantities such as the densification constant and creep coefficients used in the calculational models. Use of these data with the STRETCH code $^{8}$ would permit reliable selection of optimum designs for BISO coatings. Accordingly, we designed and prepared a set of nine particle types that had coating thickness and thickness ratios as the main variable.

We selected carefully sized and characterized samples from these nine batches for irradiation in four separate HFIR target capsules. Each capsule contained two sets of samples from all coating batches. One set was exposed at a high temperature $\left(1250^{\circ} \mathrm{C}\right.$ design) and a high flux, and the other at a lower temperature (designed for $900^{\circ} \mathrm{C}$ ) and lower flux. One batch with the reference design coating ( $85-\mu \mathrm{m}$ buffer and $75-\mu \mathrm{m}$ outer layers on $500-\mu \mathrm{m}$-diam kernel) and another batch with a less conservative design survived irradiation to an exposure of $1.6 \times 10^{22}$ neutrons $/ \mathrm{cm}^{2}(>0.18 \mathrm{MeV})$ at about $1400^{\circ} \mathrm{C}$, while other samples failed at this or at intermediate exposures. A preliminary correlation of actual and predicted survival rates of samples in the first two capsules showed ${ }^{14}$ that with few exceptions the fraction of failed coatings was large for all samples that had calculated stresses greater than 25,000 psi. Analyses of the results from all samples are in progress.

14. J. H. Coobs, W. P. Eatherly, C. B. Pollock, and J M Robbins, "Irradiation Stability of Carbon Coatings on HTGR Fuel Particles," in Extended Abstracts, Eleventh Biennial Conference on Carbon, Gatlinburg, Tennessee, June 4-8, 1973, CONF-730601.

\section{Effects of Neutron Irradiation on Loose and Bonded Inert Particles Coated with Pyrolytic Carbon and Silicon Carbide}

A final topical report ${ }^{15}$ describes the testing of TRISO-coated inert particles in capsules HT-7, $-8,-9$, and -10 . The report describes the test vehicles, the operating conditions, and the various techniques used to characterize the particles before and after irradiation. The principal test variables were the densities of the LTI coatings ( 1.7 to $2.0 \mathrm{~g} / \mathrm{cm}^{3}$ ), the test temperatures $\left(750\right.$ and $1050^{\circ} \mathrm{C}$ ), and fast fluences (up to $14 \times 10^{21}$ neutrons $/ \mathrm{cm}^{2}$ ). The results indicate that LTI coating density is not very important to the survival of TRISO-coated particles under these operating conditions, as none of the loose particles failed in the test. The principal effect of LTI coating density was its influence on shrinkage of the outer coatings, which in turn influences the dimensional change of bonded "fuel" rods made from the particles. The LTI coatings shrink because of densification under irradiation, and the shrinkage is inversely related to the starting density of the coatings. Coating densities increased with increasing fast-neutron fluence up to about $9 \times 10^{21}$ neutrons $/ \mathrm{cm}^{2}$ and at higher fluences decreased in density.

\section{The HT-8 Capsule Irradiation Test of Resin-Derived HTGR Fuels and Bonded Rods of Coated Particles}

A final topical report ${ }^{16}$ has been prepared describing this irradiation test. This report is abstracted below:

The irradiation test described in this report had two principal objectives: (1) to provide an early test of five candidate types of coated particles made from uranium-loaded ion exchange resins, and (2) to investigate the performance of intrusion-bonded rods made from TRISO-coated inert particles with various outer coating densities. The samples were irradiated in the target facility of the High Flux Isotope Reactor to a peak fast fluence $(>0.18 \mathrm{MeV})$ of $9 \times 10^{21}$ neutrons $/ \mathrm{cm}^{2}$ at 750 and $1050^{\circ} \mathrm{C}$ The resin fuel particles showed potential for adequate performance under these conditions, and bonded rods made with a $15 \mathrm{~V}$ pitch binder and natural flake graphite filler performed well. Strong-acid-resin particles coated in the as-carbonized condition performed well but displayed a weak tendency for

15. D. M. Hewette II, R. B. Fitts, C. B. Pollock, and J M Robbins, Effects of Neutron Irradiation on Loose and Bonded Inert Particles Coated with Pyrolytic Carbon and Silicon Carbide, ORNL-TM (in preparation).

16. R. B. Fitts and D. M. Hewette II, The HT-8 Capsule Irradiation Test of Resin-Derived HTGR Fuels and Bonded Rods of Coated Particles, ORNL-TM (in preparation). 
uranium and sulfur to migrate out of the kernel. Strong-acid resin particles in which the kernel had been deoxidized before coating displayed kernel instability and attack on the coating inner edge at the higher irradiation temperature. Kernels derived from weak-acid resins performed well. Experimental single-layer coatings performed marginally, and experimental coatings with layers having intermediate densities $\left(1.5 \mathrm{~g} / \mathrm{cm}^{3}\right)$ performed poorly. The dimensional stability of the bonded rods was apparently related to the dimensional stability of the outer coatings on the particles. The rods with the least dense particle coatings shrank the most.

\section{Irradiation Performance of HTGR Fuel Rod Specimens Bonded with Reference and Experimental Matrix Materials}

Experimental fuel rod specimens have been tested principally in instrumented capsules in the HFIR reflector facilities. ${ }^{17}$. Warm-molded specimens with

17. R. L. Hamner, J M Robbins, and J. H. Coobs, "Development of Continuous-Matrix Fuel Rods for Advanced HighTemperature Gas-Cooled Reactors," pp. 259-60 in Extended Abstracts, Eleventh Biennial Conference on Curbon, Gatlinburg, Tennessee, June 4-8, 1973, CONF-730601. particle volume loadings of 32 and $42 \%$ and a matrix density of $1.48 \mathrm{~g} / \mathrm{cm}^{3}$ survived irradiation to a fastneutron fluence of $7.5 \times 10^{21}$ neutrons $/ \mathrm{cm}^{2}>0.18$ $\mathrm{MeV}$ ) at an average center-line temperature of $1150^{\circ} \mathrm{C}$ Dimensional changes were anisotropic but within acceptable limits, and fuel particles in the rods performed well. Similar molded specimens irradiated in ETR capsule $\mathrm{P}-13 \mathrm{~N}$ at $1500^{\circ} \mathrm{C}$ retained their integrity; detailed examinations are in progress. Extruded fuel rod specimens containing particle volume loadings of 30 and $44 \%$ are also being tested. Three specimens with 30 vol \% particle loading and a matrix density of $1.7 \mathrm{~g} / \mathrm{cm}^{3}$ performed very well during irradiation to a fast-neutron fluence of $4 \times 10^{21}$ neutrons $/ \mathrm{cm}^{2}$ at $1250^{\circ} \mathrm{C}$ in capsule HRB-5. Other tests to higher exposures are in progress.

The first tests of slug-injected fuel rods were also completed. Three slug-injected rods irradiated in capsule HRB-3 to a fast-neutron fluence of $11 \times 10^{21}$ neutrons $/ \mathrm{cm}^{2}(>0.18 \mathrm{MeV})$ performed satisfactorily. These rods, which were fabricated with a matrix consisting of $30 \mathrm{wt} \%$ natural flake graphite in $15 \mathrm{~V}$ pitch, shrank about $1.8 \%$, and their weight loss due to

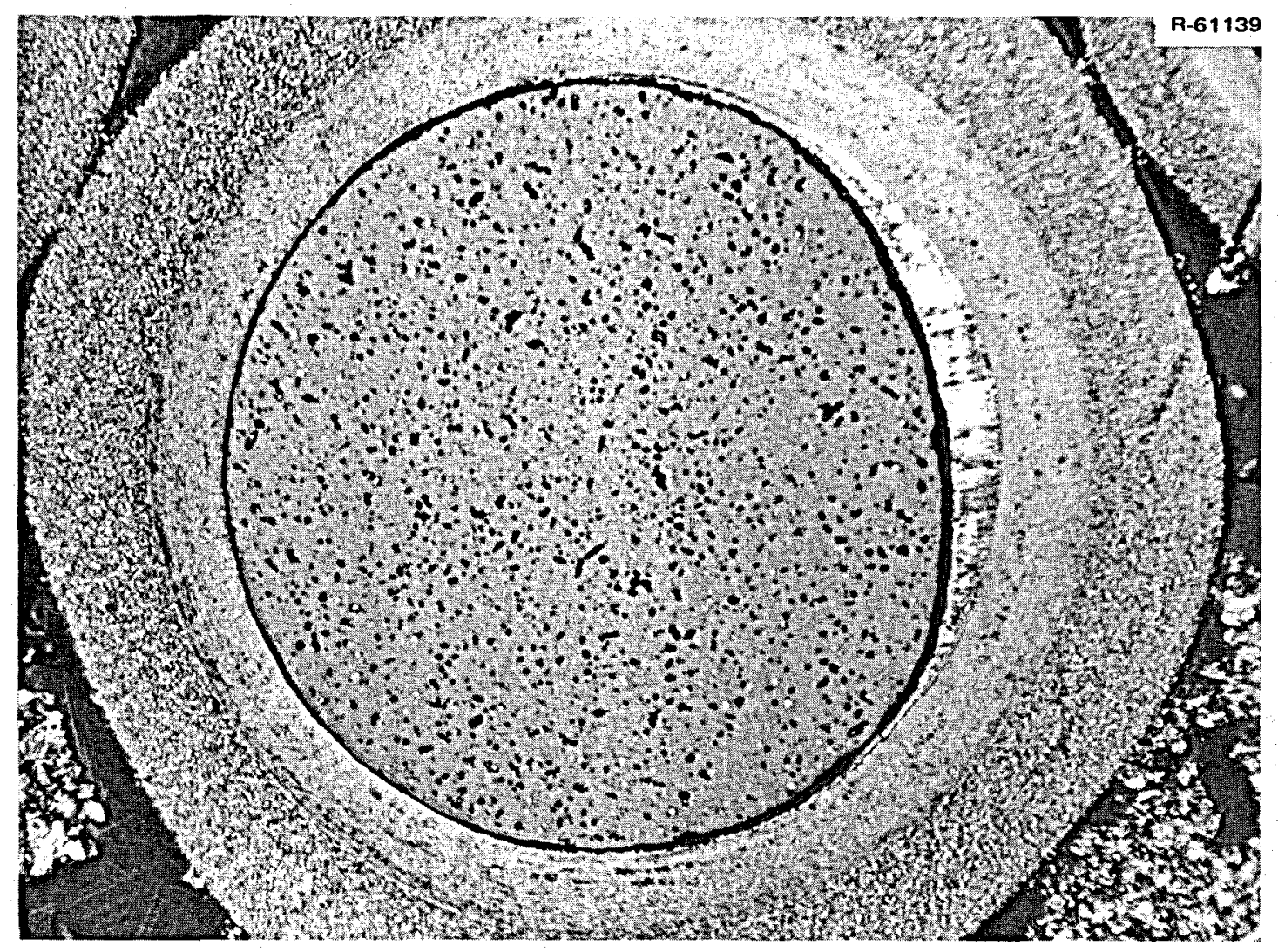

Fig. 17.4. Amoeba migration of $\mathrm{ThO}_{2}$ in $\mathrm{HTGR}$ fuel rods. This particle was exposed to a temperature of about $1500^{\circ} \mathrm{C}$ at a temperature gradient of about $400^{\circ} \mathrm{C} / \mathrm{cm}$ for 270 days in HFIR capsule HRB-3. As polished. Polarized light. 
debonding at the ends ranged up to $2.8 \%$. Metallographic examination of one rod revealed a potential problem, however, in the migration of $\mathrm{ThO}_{2}$ at the high temperature and temperature gradients. This directional migration, or amoeba effect, is illustrated in Fig. 17.4. The maximum temperatures in this position were not measured, but the calculated surface temperature of the $\operatorname{rod}\left(1130^{\circ} \mathrm{C}\right)$ is reasonably accurate because it is adjacent to an instrumented position in the graphite sleeve. If the fuel rod thermal conductivity is $0.06 \mathrm{~W}$ $\mathrm{cm}^{-1} \mathrm{~K}^{-1}$ the temperature and temperature gradient at the position of this particle would be $1400^{\circ} \mathrm{C}$ and $270^{\circ} \mathrm{C} / \mathrm{cm}$. This observed migration would be surprising in this instance, in view of the known stability of $\mathrm{ThO}_{2}$. On the other hand, if the conductivity is only $0.037 \mathrm{~W}$ $\mathrm{cm}^{-1} \mathrm{~K}^{-1}$, as suggested by some previous measurements, ${ }^{18}$ the respective values would be $1550^{\circ} \mathrm{C}$ and $440^{\circ} \mathrm{C} / \mathrm{cm}$. These results indicate that the thermal conductivity of rods may be a limiting feature at heat ratings useful for large HTGR's. Further evidence of this migration is being investigated during current testing and examination of additional slug-injected rods.

\section{GAS-COOLED FAST BREEDER REACTOR FUEL ELEMENT DEVELOPMENT}

\section{R. B. Fitts E. L. Long, Jr.}

In addition to the massive efforts on fast-breeder reactor development being applied to the sodiumcooled LMFBR, there is strong interest on the part of many utilities in the development of the gas-cooled fast breeder reactor (GCFBR) as an alternate. ${ }^{19}$ It has the potential of lower cost power production and would avoid the sodium void coefficient problem and maintenance difficulties that are peculiar to the LMFBR.

An irradiation testing program is being conducted in cooperation with Gulf General Atomic and Argonne National Laboratory (ANL) to evaluate the performance of various fuel pin designs for use at GCFBR

18. R. S. Graves and W. M. Ewing, Metals and Ceramics Div. Annu. Progr. Rep. June 30, 1971, ORNL4770, p. 144.

19. P. Fortescue, "A Reactor Strategy: FBR's and HTGR's," Nucl. News 15(4), 36-39 (April 1972). operating conditions. These tests are being conducted ${ }^{20}$ in a thermal flux environment in the Oak Ridge Research Reactor and in a fast flux in the EBR-II. The second test of a vented GCFBR-type fuel pin (GB-10) is being irradiated in the $O R R$, and the postirradiation examination of the first such capsule (GB-9) was completed at ANL after preliminary examination at ORNL.

One sample of the GB-9 fuel pin was returned from ANL for metallographic and microprobe analyses. This sample was taken from the fuel pin $4^{3 / 4} \mathrm{in}$. above the bottom of the fuel column, near the region of maximum heat generation. This sample was examined at ORNL for comparison with the earlier GCFBR experiments. The only unusual microstructural feature noted in the preliminary metallographic examination of a transverse section from the GB-9 fuel pin was the presence of large amounts of metallic deposit at the fuel-cladding interface. After regrinding and repolishing the specimen, the metallic deposit was no longer present, indicating that the locations of these deposits are spotty and unpredictable. Detailed examination of this section revealed significant attack of the inner surface regions of the $0.065-\mathrm{cm}$ (25-mil) type 316 stainless steel cladding. The attack varied in depth from about 1 to 4 mils. The attack of the cladding was intergranular, and in the regions of the most severe attack the grains were consumed and replaced by corrosion products (Fig. 17.5). The most severe attack occurred on the cooler side of the fuel rod. The cooler side was indicated by the movement of the central void in the fuel toward the hotter side of the fuel pin.

This examination enabled us to compare our metallographic results obtained by preparing a GB-9 specimen in air using aqueous polishing vehicles to those obtained by ANL on the adjacent GB-9 specimen in an inert atmosphere using nonaqueous polishing vehicles. There is no significant difference in the apparent structure of the specimens except that the specimen polished in the aqueous vehicle was somewhat superior in appearance, which is to be expected. Our experience has been that the use of nonaqueous vehicles exaggerates porosity and relief between fuel and cladding by the time the fuel has been polished sufficiently to eliminate all artifacts that had been introduced during grinding.

20. R. B. Fitts, R. A. Bradley, A. W. Longest, and E. J. Manthos, Metals and Ceramics Div. Annu. Progr. Rep. June 30, 1972, ORNL-4820, pp. 111-12. 

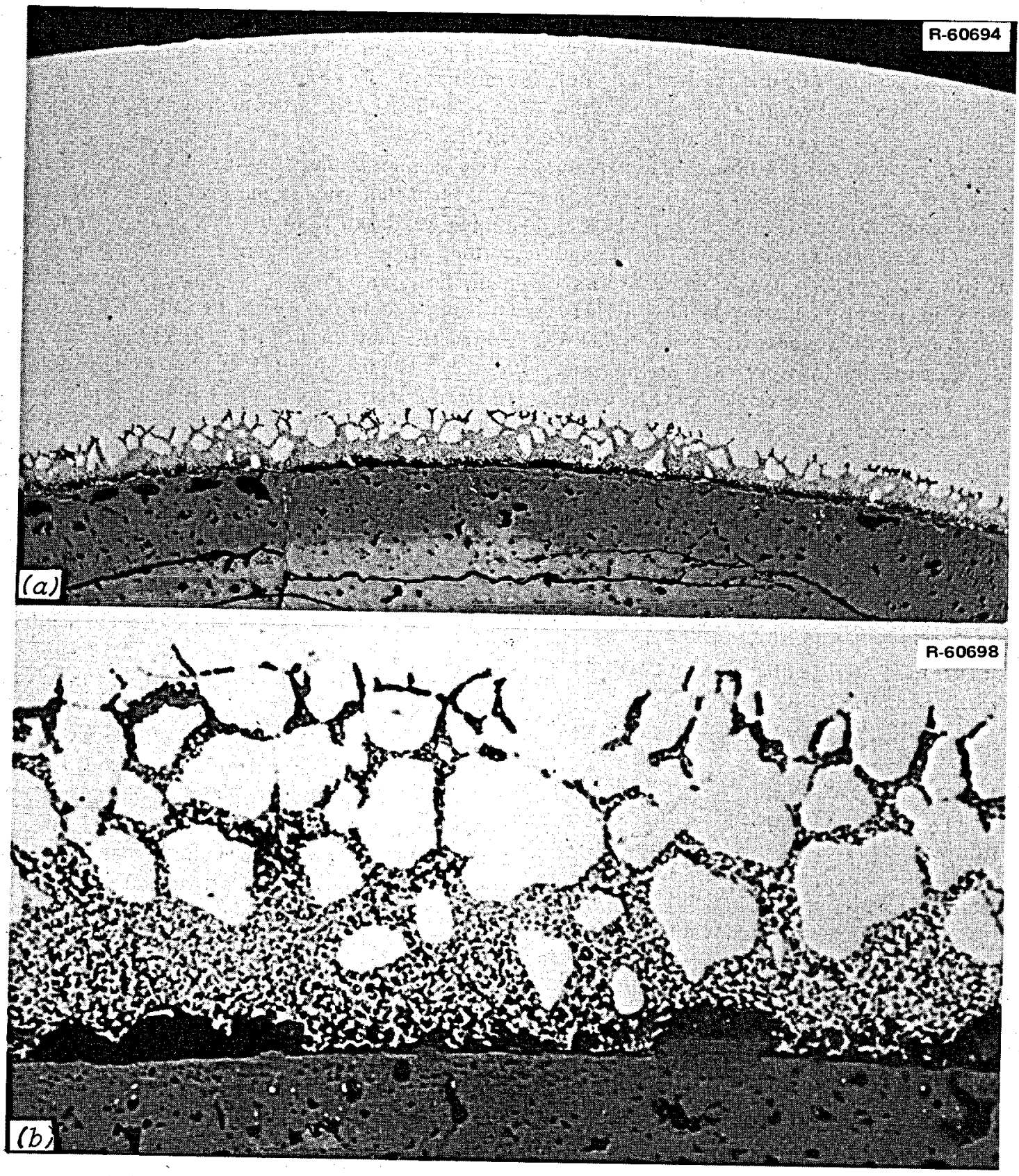

Fig. 17.5. Appearance of typical fuel-cladding interfaces from mixed oxide fuel pin GB-9. As polished. (a) 100X. (b) 500X. 


\title{
18. Heavy Section Steel Technology
}

\author{
D. A. Canonico
}

The Heavy Section Steel Technology Program is an engineering effort to determine the structural behavior of the thick plates and pressure vessels needed for large light-water nuclear reactors. The overall program emphasizes the effects of flaws, discontinuities, and inhomogeneities on the integrity of the reactor vessel during both shutdown and operation. Extensive testing programs are being conducted on weldments and plates. These include the determination of strength and classical fracture toughness properties as well as the development and application of fracture mechanics for those steels currently being used in the fabrication of light-water nuclear pressure vessels.

We participate as both consultants and experimentalists. First, we serve on the staff of the Program Office as metallurgical consultants and are expected to contribute to decisions that require metallurgical . knowledge. In addition, we are involved experimentally in those tasks that require the facilities and expertise available within the Division.

\section{CHARACTERIZATION OF HSST INTERMEDIATE TEST VESSELS}

\section{W. J.Stelzman}

The emphasis in the HSST Program has been to obtain mechanical and lower bound fracture toughness data in support of demonstrating the capability to predict failure in large, flawed, heavy-walled pressure vessels under service-type loading conditions. Under the HSST Program, a series of vessels (54-in.-long cylindrical section, 39 in. OD, and 6-in.-thick wall) that are intermediate between conventional laboratory tests and full-scale vessels are to be flawed in the base metal, welds, and nozzle junctions and then pressurized to failure. A forging steel, ASTM A508 class 2, is being used in the first six vessels. Subsequent vessels will be made from ASTM A533 grade B class 1 plate.
Material from six vessels was examined, and tensile, Charpy V impact, and drop-weight data were obtained. In addition, precracked Charpy $V$ specimens ${ }^{1,2}$ were used to provide both static and dynamic lower bound fracture toughness data. Orientation effects were investigated with specimens aligned in the axial and tangential directions. Cracks propagated in the axial or circumferential direction.

The precracked Charpy $\mathrm{V}$ specimen was used to obtain static and dynamic lower bound fracture toughness data for other ferritic steels, and their tensile properties were also determined. Two plate sections of SA516, grade 70 carbon steel were obtained from Combustion Engineering in the normalized condition and quenched-and-tempered condition. Test specimens were aligned parallel and perpendicular to the principal rolling direction. Crack propagation was perpendicular to the specimens axis. One plate section of quenchedand-tempered A533 grade B carbon steel obtained from the Marrel Frères Co., France, was similarly examined to compare the properties of a typical foreign mill practice steel with the HSST plates that were produced by mills in the U.S.

A pipe rupture program ${ }^{3}$ is being pursued at the Battelle Columbus Laboratories under the sponsorship of the HSST Program. In support of that program, pipe sections from the unnuptured portions of two ruptured $7 \frac{1}{2}$-in.-OD $\times 1 / 2$-in.-thick wall (ASTM A106, grade B) carbon steel pipes were examined. Precracked Charpy V specimens oriented axially and circumferentially were

1. W. J. Stelzman, "Characterization of Intermediate Vessel V-1," HSST Program Semiannu. Progr. Rep. Aug. 31, 1972, ORNL-4855, pp. 38-39.

2. W. J. Stelzman, "Characterization of Intermediate Test Vessels," HSST Program Semiannu. Progr. Rep. Feb. 28, 1973, ORNL report in preparation.

3. R. J. Podlasck, "Investigation of Mode III Crack Extension in Reactor Piping," HSST Program Semiannu. Progr. Rep. Aug. 31,1972 , ORNL-4855, pp. 64-72. 
examined to obtain static and dynamic lower bound fracture toughness data. Tensile data were also obtained.

\section{RADIATION STRENGTHENING AND EMBRITTLEMENT IN HEAVY SECTION STEEL PLATES AND WELDS ${ }^{4}$}

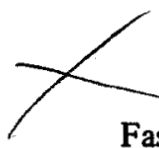

\author{
W. J.Stelzman R. G. Berggren
}

Fast-neutron-induced changes in the mechanical properties of two 12-in.-thick A533-B class 1 steel plates, a matching submerged-arc weldment, and an electroslag weld in a $6 \frac{3}{8}$-in.-thick SA302-B (Code Case 1339) steel are presented. Postirradiation increases in strength and notch-impact transition temperature and decrease in ductility were determined for several irradiation temperatures. Some observations using data obtained from an instrumented Charpy testing machine are also given.

\section{INVESTIGATION OF WELD METAL HEAT-AFFECTED ZONE}

\section{A. Canonico}

Intergranular cracking in the heat-affected zone (HAZ) of thick-section weldments representative of those employed in the fabrication of nuclear pressure vessels was reported ${ }^{5}$ at the 1972 Annual HSST Information Meeting. This information prompted the examination of submerged-arc weldments in 6-in.-thick ASTM A508 class 2 forgings and 6- and 12-in.-thick ASTM A533 grade B class 1 plates. These weldments were procured for study in the HSST program.

Longitudinal samples of the welds were prepared for metallographic examination. The samples were oriented so that the surface that was polished and viewed progressed from the base metal through the HAZ to the weld metal. Numerous samples and many hours of polishing and viewing were consumed in this project. We have not found any evidence of $\mathrm{HAZ}$ cracking. Figure 18.1 is a four-photomicrograph montage of the microstructure present at the fusion line of a submerged-arc weld in ASTM A533 grade B steel. The lower portion of the photomicrographs is weld metal; the upper portion is HAZ.

4. Abstracted from ORNL-4871 (June 1973).

5. K. Kussmaul and D. Sturm, "Research Activities at the MPA Stuttgart in the Field of Nuclear Pressure Vessel Technology: Materials - Welding - Safety," presented at the Sixth Annual Information Meeting of the Heavy-Section Steel Technology Program, Oak Ridge National Laboratory, April 25-26, 1972.

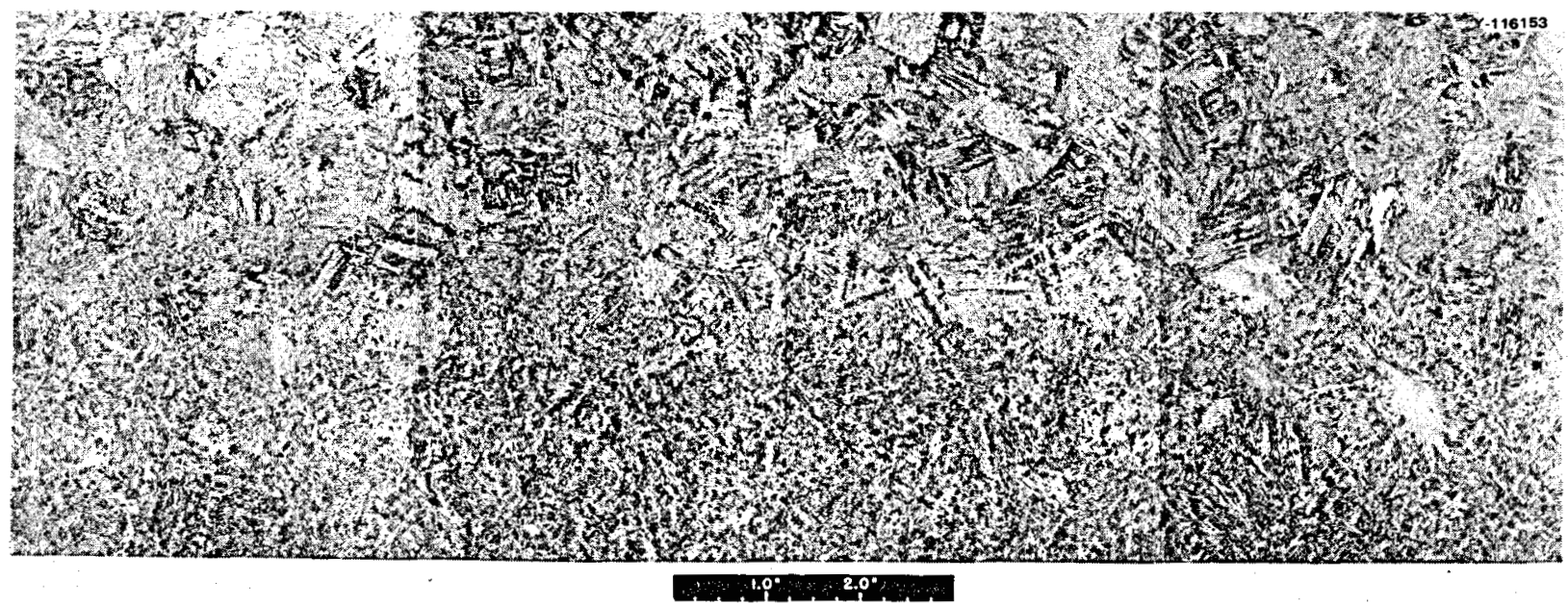

Fig. 18.1. Montage of photomicrographs representative of the tempered martensite microstructure seen at the fusion line in HSST weldments. The bottom of the montage is weld metal, and the top is the coarse-grained austenite region of the HAZ. Note the soundness and cleanliness of the weldment. No cracks were observed in any of the regions studied. 


\section{FRACTOGRAPHY STUDY OF FAILURE IN INTERMEDIATE TEST VESSEL V-1}

\section{A. Canonico}

The Intermediate Test Vessels (ITV) are fabricated from a cylindrical center section, a hemihead bottom, and a top transition piece. The material from which these pieces are made is ASTM A508 class 2 forging steel. The components are joined by circumferential submerged-arc welds. A fatigue-sharpened, semielliptical flaw approximately 8 in. long and $2 \%$ in. deep was placed at the midpoint of the center cylindrical section of this first test (ITV V-1). The flaw was oriented perpendicular to the tangent and parallel to the axis.

The first test, V-1, was internally pressurized to destruction on June 30,1972 . It was tested at $130^{\circ} \mathrm{F}$ and split longitudinally at a pressure of $28,600 \mathrm{psi}$. The vessel underwent aproximately $1 \%$ strain before failure.

The fracture propagated upward to the top head and downward around the bottom hemihead. The upward propagation of the crack ran through the circumferential weld that joined the transition piece to the cylindrical test section and terminated at the interface between the transition piece and the bolted-on cover plate. The downward propagation path was through the circumferential weld that joined the bottom hemihead to the center cylindrical test section. The crack continued around the bottom and terminated near the circumferential weld approximately $180^{\circ}$ from where it first entered the bottom hemihead.

Because of the nature of the failure, we decided to extensively study the fracture surface with our scanning electron microscope. We decided, after some deliberation, that oxy-acetylene burning and saw cutting were the most expedient techniques available for removing the fracture surface. The flame cut was made approximately 8 in. behind the fracture surface. The fracture surface is shown in Fig. 18.2 before sectioning. The original man-made flaw is quite evident. The circumferential weld that joined the bottom hemihead to the cylindrical test section is easily seen at the left side of the photograph at the change in contour. The circumferential weld at the upper end of the cylindrical test section is not evident; however, it too is located at the geometric change in section size at the right side of the photograph.

Several regions of the fracture surface shown in Fig. 18.2 were studied. One is located in the transition piece; others are located in the cylindrical test section and the hemihead. In the region adjacent to the man-made flaw the fracture surface exhibited a dimpled mode of failure.

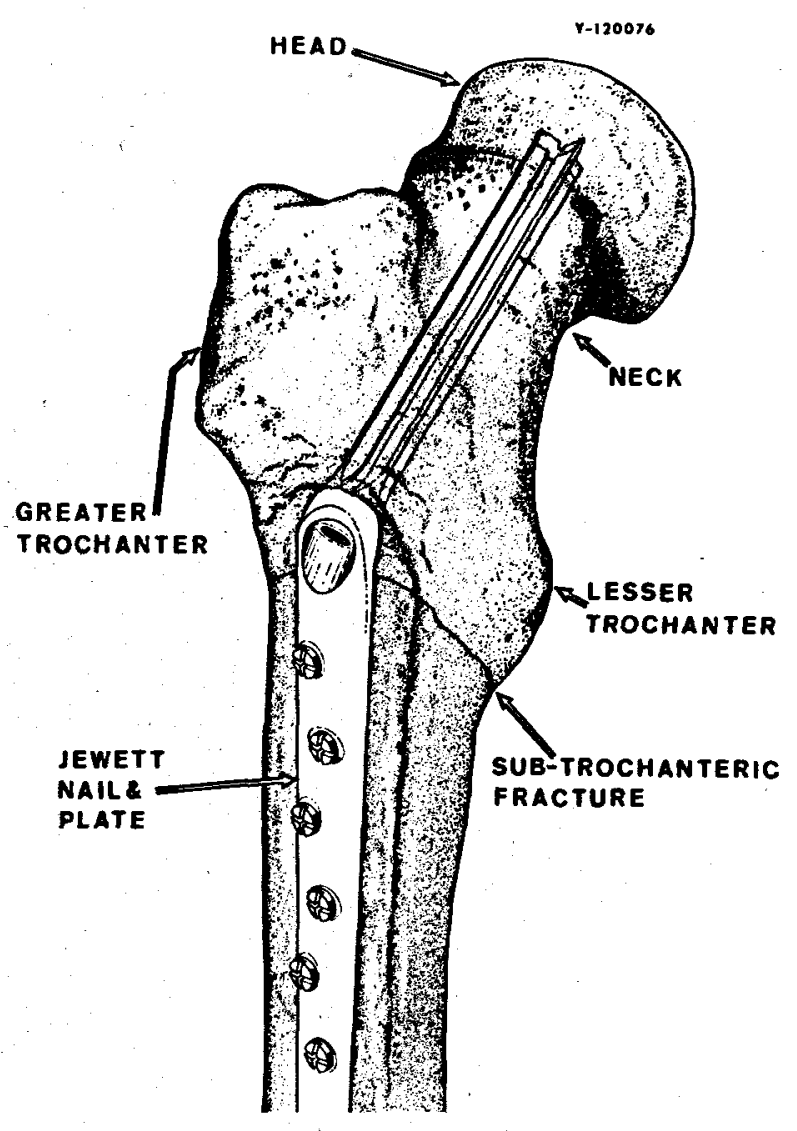

Fig. 18.2. Fracture surface from intermediate test vessel V-1.

The region just under the steel rope shown in Fig. 18.2 exhibits a change in appearance and coloration. The dark "ductile" coloration seems to terminate in a V. Chevron lines, lighter in color, appear to originate from its apex. This is usually indicative of an initiation site for fracture propagation. Figure 18.3 contains the results of the fractography study of this region. Two areas were studied. The first was close to the center of the fracture surface, within an area that appeared similar to the regions adjacent to the man-made flaw. The second area studied was outside the V-shaped area and in the lighter (shinier) area. This area exhibits a fracture surface identical to that seen in a low-energy (cleavage) failure.

Additional regions were studied. These included regions approximately 3 in. from the circumferential welds in the top transition piece and the bottom hemihead. Both exhibited cleavage fracture. Regions in the cylindrical test section approximately 3 in. from the two circumferential welds also exhibited cleavage fracture appearances. 
In summary, the fractography study revealed that the region around the man-made flaw exhibited a fracture appearance that is indicative of tough behavior (dimpled). This mode of failure continued for some distance in either direction away from the man-made flaw to a point where it underwent a transition from dimple to cleavage. This cleavage fracture continued and was found in both the bottom hemihead and the top transition piece.

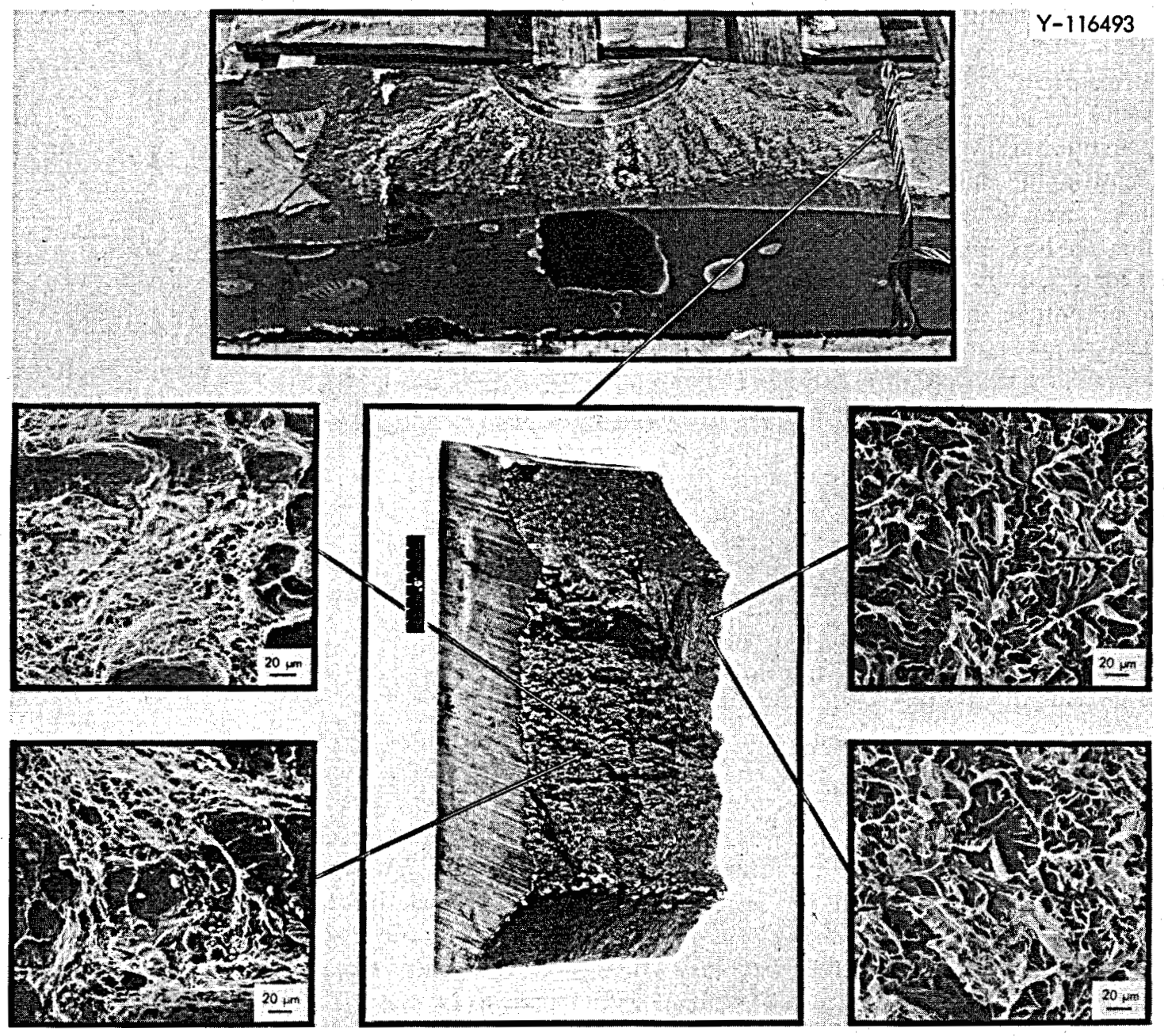

Fig. 18.3. Results of scanning electron microscopy of fracture surface near the machined flaw. The two areas shown illustrate dimple mode of failure. 


\title{
(5) \\ 19. Military Reactor Fuel Element Procurement Assistance
}

\author{
R. J. Beaver
}

This task provides technical assistance to the AEC and military services in procurement of reactor components. Included are such items as standardization of specifications, review of technical requirements for procurement packages, and participation in fuel procurement as well as quality audits of fuel fabricators.

The remainder of the 34 Type II fuel element assemblies ordered by the U.S. Army's Power Branch through the AEC Division of Reactor Research and Development, Washington, for the MH-1A power reactor on the U.S.S. Sturgis, Gatun Lake, Panama Canal Zone, were manufactured by the Kerr-McGee Corpora- tion. The last of these remaining 16 assemblies was delivered in late November, and, as with its predecessors, was accepted at the reactor site under the surveillance of an ORNL representative. During the course of this procurement, careful attention was given to these activities, including resident inspection at Kerr-McGee, assessment of qualifications at subcontractors, and an audit of Kerr-McGee. Approximately 450 documents associated with processing, inspection, and certification were reviewed and recommended to the AEC (Chicago Operations Office) for appropriate action throughout this procurement. 


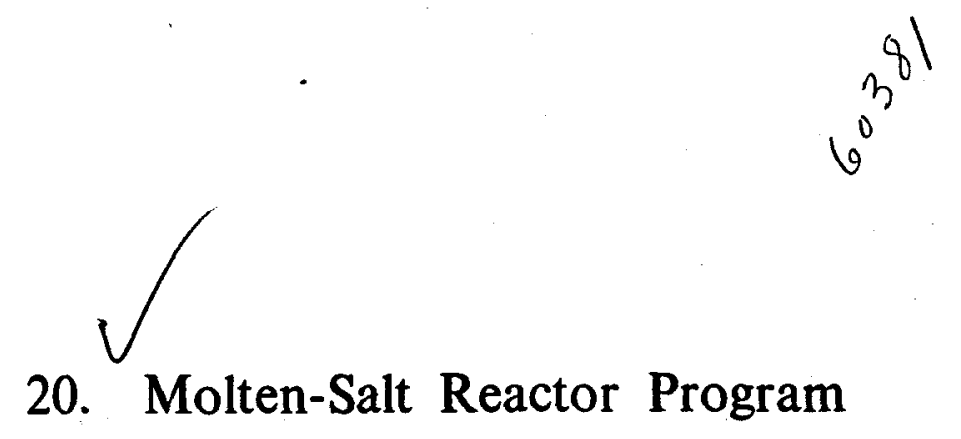

J. R. Weir, Jr. H. E. McCoy, Jr.

The molten-salt reactor concept uses a molten fluoride fuel and a critical region moderated by graphite. The fuel is circulated and the heat transferred through a secondary salt system to a steam generator. The system can be operated as a breeder with the addition of ${ }^{232} \mathrm{Th}$ to the fuel salt and a chemical processing plant for removing various fission products and protactinium. Most aspects of the concept were demonstrated in the 7.5-MW(t) Molten-Salt Reactor Experiment (MSRE), which operated from 1965 to 1969 . However, some materials problems remain to be solved before the next logical step of constructing a small experimental breeder reactor, and these problems have been the responsibility of this Division. Work was officially terminated on this program on January 26,1973 , and all work except terminating and disposing of experiments was stopped. A brief summary of the problems under study and their status will follow.

\section{STRUCTURAL ALLOYS}

$$
\begin{array}{ll}
\text { R. E. Clausing } & \text { J. W. Koger }{ }^{1} \\
\text { R. E. Gehlbach } & \text { H. E. McCoy, Jr. } \\
\text { B. McNabb, Jr. }
\end{array}
$$

Hastelloy $\mathbf{N}$ was used as the sole metallic structural material in the MSRE because of its excellent compatibility with fluoride salts. Experience with the MSRE and considerable experimental work have shown that the ductility of Hastelloy $\mathrm{N}$ is reduced by neutron irradiation to an extent that likely coutd not be tolerated in a commercial power reactor. Our work has shown that reductions in the amount of Mo and $\mathrm{Si}$ and addition of $\mathrm{Ti}, \mathrm{Hf}$, and $\mathrm{Zr}$ lead to the formation of a fine carbide precipitate that results in markedly improved resistance to embrittlement. Welding problems associated with $\mathrm{Zr}$ and Hf led to an emphasis on $\mathrm{Ti}$ and the choice of a modified alloy containing about $2 \% \mathrm{Ti}$.

1. Present address, Oak Ridge Y-12 Plant.
Five small commercial melts of this alloy were subjected to welding and postirradiation creep tests. The weldability of all alloys was excellent, and all were suitable for use at $704^{\circ} \mathrm{C}$, but only one alloy retained good ductility after irradiation at $760^{\circ} \mathrm{C}$.

Intergranular cracks up to 10 mils deep were formed in all parts of the MSRE that were exposed to fuel salt during service and deformed after irradiation.-Considerable evidence was developed ${ }^{2}$ that this cracking was due to the diffusion of the fission product tellurium into the Hastelloy N. Although the chemical behavior of the tellurides is not well established, the behavior should be qualitatively similar to that of the sulfides, and the addition of elements such as the rare earths, titanium, and chromium offers promise of reacting with the tellurium to form innocuous compounds. These elements also form stable fluorides and could increase the corrosion rate of Hastelloy $\mathbf{N}$ in fluoride salts, so additions must be made with caution. We demonstrated that several alloys were completely resistant to intergranular cracking after exposure to tellurium and that others were resistant at lower tellurium concentrations. An experiment in which the transfer rate of tellurium was comparable with that expected in a power reactor was designed and constructed but could not be run because of the termination of the program. The results offered some hope that Hastelloy $\mathrm{N}$ modified with $2 \% \mathrm{Ti}$ for improved resistance to irradiation embrittlement might also resist embrittlement by tellurium.

Hastelloy $N$ and types 304 and 316 stainless steel were subjected to several corrosion tests. Hastelloy $\mathbf{N}$ corroded at rates of about $0.01 \mathrm{mpy}$ (mil/year) in fuel salts, and the stainless steels corroded at about $1 \mathrm{mpy}$. Both natural- and forced-circulation loops of Hastelloy $\mathrm{N}$ were run with the proposed secondary coolant salt,

2. H. E. McCoy and B. McNabb, Intergranular Cracking of INOR-8 in the MSRE, ORNL-4829 (November 1972). 
sodium fluoroborate. Corrosion rates of $0.1 \mathrm{mpy}$ or less were obtained in both types of systems for long periods of time; however, impurities such as moisture increased the rate markedly.

The possible use of Hastelloy $\mathrm{N}$ in the steam generator prompted a study of its compatibility with steam. A cooperative facility for exposing stressed and unstressed samples was constructed at TVA's Bull Run Steam Plant. Unstressed Hastelloy $\mathbf{N}$ samples exposed for $15,000 \mathrm{hr}$ corroded at a metal loss rate less than 0.25 mpy. Samples stressed in steam failed to show a significant difference in stress-rupture behavior from those stressed in argon. However, the steam was very dry and pure where the test facility was located, and more deleterious conditions could exist in other parts of a plant.

\section{GRAPHITE}

$$
\begin{array}{ll}
\text { W. H. Cook } & \text { C. R. Kennedy } \\
\text { W.P. Eatherly } & \text { C. B. Pollock }
\end{array}
$$

The graphite moderator will be exposed to a high fast neutron flux and will change dimensions. A test facility in the HFIR was used to study the dimensional changes of representative samples of most commercial graphites to fluences of about $3 \times 10^{22}$ neutrons $/ \mathrm{cm}^{2}$. Two commercial graphites have adequate dimensional stability. A small fabrication program was established locally, and graphites were produced that are at least as good as the best commercial product. Some grades tested to a fluence of about $1 \times 10^{22}$ neutrons $/ \mathrm{cm}^{2}$ have better dimensional stability than the best commercial graphite at this fluence.
In the fissioning salt ${ }^{135} \mathrm{Xe}$ will be produced and will likely not be removed efficiently enough by the helium stripping gas to prevent absorption by the graphite and loss of neutrons. Pyrolytic carbon coatings were investigated as a means of reducing the surface permeability of the graphite moderator elements. Samples coated with carbon deposited from propene af 1250 and $1300^{\circ} \mathrm{C}$ were exposed to neutron fluences of $1 \times 10^{22}$ neutrons $/ \mathrm{cm}^{2}$ and remained impermeable.

\section{CHEMICAL PROCESSING PLANT MATERIALS}

$$
\begin{array}{ll}
\text { N. C. Cole } & \text { J. W. Koger1 } \\
\text { J. R. DiStefano } & \text { A. J. Moorhead }
\end{array}
$$

\section{A. C. Schaffhauser}

The chemical processing plant will require materials that can be exposed to fuel salt, bismuth, and bismuthlithium alloys. Corrosion tests showed that molybdenum and likely graphite and T-111 (Ta-8\% W-2\% $\mathrm{Hf})$ are compatible with these fluids. Each material has its own set of problems, but those associated with molybdenum were thought to be the least. The greatest problem with molybdenum is its low ductility and the associated difficulties of fabricating complex components. A test facility involving many of the shapes and types of joints that would be required for a reactor was designed and partially fabricated before the program was discontinued. ${ }^{3}$

3. J. R. DiStefano and A. J. Moorhead, Development and Construction of a Molybdenum Test Stand, ORNL-4874 (December 1972). 

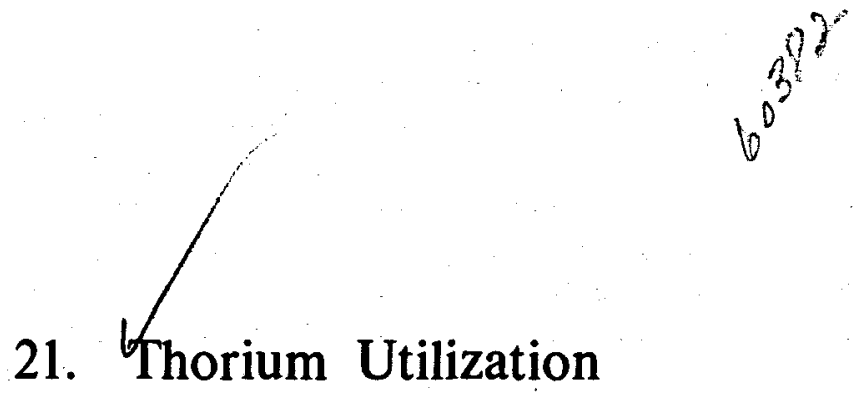

A. L. Lotts

The Thorium Utilization Program is being conducted within the context of the National HTGR Fuel Recycle Program Plan, which has recently been revised.' Our activities are being carried out in cooperation with the Chemical Technology Division of ORNL, the Idaho Chemical Processing Plant, and Gulf General Atomic. All of these are involved in the development of the head-end processes and chemical processes for HTGR fuel. Our task is to provide the necessary development for refabrication of HTGR fuel that is obtained in the use of the $\mathrm{Th}^{233} \mathrm{U}$ fuel cycle. The ultimate aim is to demonstrate economic fuel recycle techniques for this reactor in a pilot-scale facility, the Thorium-Uranium Recycle Facility at ORNL. Our program consists of refabrication process development on an engineering scale, development of remote pilot-scale equipment, and fuel cycle economic analyses. The program utilizes extensively technology developed in the Gas-Cooled Reactor Program, the progress of which is reported in Chapter 17.

Processes and equipment are being developed to fabricate $25 \mathrm{~kg} /$ day of oxide fuel into the HTGR graphite fuel blocks. The demonstration with ${ }^{233} \mathrm{U}$ is now scheduled to start in TURF in 1980.

\section{THORIUM-URANIUM RECYCLE FACILITY}

$$
\text { J. W. Anderson }{ }^{2} \quad \text { J. D. Sease }
$$

Engineering-scale development of processes and equipment in the HTGR Fuel Recycle Development Program will culminate in the demonstration of recycle technology in pilot plant operations. These operations

1. Oak Ridge National Laboratory, Gulf General Atomic, and Idaho Chemical Processing Plant, National HTGR Fuel Recycle Development Program Plan, ORNL-4702, Rev. 1, in publication.

2. General Engineering Division. for fuel refabrication will be carried out in the Refabrication Pilot Plant to be installed in TURF (ORNL Building 7930), as reported last year. Reported here are activities of the last year associated with design of this pilot plant with regard to both facilities and equipment. Conceptual design studies for the Plant were continued at a low level through the year. These design studies focused primarily on overall plant layout and capability studies, with a fair amount of work directed toward establishing criticality parameters as criteria for equipment design.

\section{Feasibility Study for Increasing Capacity in the Refabrication Pilot Plant}

\section{J. W. Anderson ${ }^{2}$}

One approach that has been considered for providing fuel recycle capability to the developing HTGR economy is to increase the capacity of the TURF pilot plant to provide production capability. This option would allow some flexibility in meeting the recycle needs of the economy if the growth rate is not such as to support a large-scale commercial recycle plant when it is economically advantageous to recycle fuel.

The maximum production capacity of the TURF Refabrication Pilot Plant was determined. The currently planned pilot plant is rated at $25 \mathrm{~kg} /$ day or about 2.5 product elements per day. Because of space limitations for process support materials, element storage and loading, and analytical and inspection facilities the 25 $\mathrm{kg} /$ day rate cannot be sustained continuously. The production capacity of the TURF could be increased to about $100 \mathrm{~kg}$ of heavy metal per day ( 10 elements/day) for sustained operation (on-line efficiency of $80 \%$ ). This would support an HTGR economy in excess of 9000 MW(e). The incremental estimated cost for converting to a $100-\mathrm{kg} /$ day production plant was estimated to be about $\$ 4.25$ million. 


\section{Design of Processing Equipment

$$
\text { F. C. Davis }{ }^{2} \text { J. D. Sease }
$$

Flowsheets were prepared for the three refabrication processing systems to be located in the pilot plant: (1) microsphere coating, (2) fuel rod fabrication, and (3) fuel element assembly. Each of these systems was arranged into subsystems and components of related equipment items. Diagrams were prepared for each system to outline the equipment components required to perform the functions presented in the process flowsheets.

\section{Design Criteria to Assure Critically Safe Equipment}

$$
\text { J.D. Sease C. F. Sanders }{ }^{3}
$$

Studies were begun to determine the influence of criticality of ${ }^{233} \mathrm{U}$ mixtures in both accident and normal conditions on the design of process equipment for HTGR fuel fabrication. Criticality limits for mixtures of ${ }^{233} \mathrm{U}$ and $\mathrm{ThO}_{2}$ with varying amounts of carbon and water were calculated.

The critical parameters established for spherical and cylindrical geometries are basic and have general applicability to all stages of fuel fabrication. Addition of thorium and carbon to the uranium generally increases the mass necessary for criticality. The addition of water to the system diminishes the dilution effect. The cursory investigation of the fluidized bed coater indicated that coaters up to $11 \mathrm{in}$. in diameter could be made critically safe without great difficulty. The results of this criticality study are reported in detail elsewhere. ${ }^{4,5}$

\section{Facility Operation}

\section{J. M. Chandler ${ }^{6}$ J. E. Van Cleve, Jr.}

The Thorium-Uranium Recycle Facility (TURF) and its equipment were operated and maintained in operational readiness in support of the heavily shielded process cell bank and the in-cell process equipment. To do this, for example, we rebuilt one of the air compressors after failure of the piston rings, installed an

3. Now at Westinghouse Electric Corporation, Columbia, S.C. 4. J. T. Thomas, Calculated Criticality of Water-Moderated Oxides of Uranium-233, Thorium-232, and Carbon Mixtures, Y-DR-107 (April 30, 1973).

5. ORNL Gas-Cooled Reactor Programs Annu. Progr. Rep. Oct. 1, 1971-Dec. 31, 1972, ORNL-4911 (in preparation).

6. Chemical Technology Division. automatic changeover system between the tower and process water used to cool the air compressors, removed and stored the model A manipulators from cell $G$, and replaced the inlet air filters in the main building air supply system.

As a portion of the cooperative effort to reduce emergency situations involving TURF and TRU a mutual compressed air supply system was designed and installed. This system automatically supplies air from either the TURF or TRU compressors to the other facility when the air pressure drops to 65 psi. Either facility can continue normal operations until the cause of the low air pressure is determined and repaired.

The main air supply system filters required changing this year. The pressure drop across the filters had reached the recommended maximum of $0.75 \mathrm{in}$. of water after service for 17 months.

The LMFBR thermocouple test work occupied Cell B for the entire year. The work has been completed except for one series of tests and the cleanup of the cell. This series will be performed when funding is available; the equipment will remain in Cell B until then.

\section{REFABRICATION DEVELOPMENT}

\section{J. D. Sease}

The objective of the HTGR refabrication development program is to develop the technology necessary for the design and operation of a pilot-scale remote fueled graphite line in the Thorium-Uranium Recycle Facility (TURF). The development is based upon technology developed under the Gas-Cooled Reactor Program, Chapter 17. The major development areas in the Metals and Ceramics Division are associated with coating of fuel particles, rod fabrication, and element assembly, only the first two having been active this year.

\section{Microsphere Coating}

\section{W. J. Lackey W. H. Pechin}

Fluidized-bed particle coating equipment and processes are being developed for remote coating of recycled HTGR fuel with carbon and perhaps silicon carbide coatings. The reference recycle fissile particle is of the BISO type and consists of a $350-\mu \mathrm{m}$-diam sol-gel (Th-20\% U) $\mathrm{O}_{2}$ kernel with buffer and isotropic carbon coatings, each about $100 \mu \mathrm{m}$ thick. For particles of this type, about $10 \mathrm{~kg}$ of heavy metal will be coated daily in the TURF pilot plant. Such particles have been produced numerous times in 1- to $3-\mathrm{kg}$ batches in the 
5-in.-diam prototype remotely operated coating furnace previously described. ${ }^{7,8}$ About $250 \mathrm{~kg}$ of such particles were coated this year.

The particle coating task includes particle inspection and particle handling in addition to coating per se. All our equipment and process development effort is focused on obtaining adequate engineering information to allow design and operation of a remote system.

Numerous improvements in the coating system were made during the year, and a listing of them is available. ${ }^{9}$

Most of our process development effort was devoted to the buffer coating process. Most of our experience has been with a 5 -in.-diam single-inlet, $30^{\circ}$-includedangle conical gas distributor. Statistically designed experiments were conducted on the buffer coating process, in which the variables of interest were acetylene flow rate, type of diluent gas, diluent gas flow rate, temperature, time, kernel size, standard deviation of kernel size, and charge weight. Responses of interest were coating thickness, particle-to-particle variation in coating thickness, coating density, efficiency of utilization of input carbon, and various system responses, such as the extent of soot formation and the influence of soot on the behavior of the soot filter. In addition to achieving a vastly improved understanding of the buffer coating process that will allow us to confidently deposit buffer coatings having the required properties in the future, we found operating conditions that reduced the within-batch coating thickness standard deviation from about $25 \%$ of the mean coating thickness to about $14 \%$. Charges as large as $3200 \mathrm{~g}$ of $\mathrm{ThO}_{2}$ kernels were successfully coated. For charge weights in the range 800 to $3200 \mathrm{~g}$ the coating efficiency was $48 \%$, independent of charge weight, and the density was rather insensitive to charge weight for the conditions used.

Phenomenological equations were developed for predicting the mass of buffer carbon deposited, the coated particle volume and density, and the standard deviation of coating thickness. The independent variables in these expressions were charge weight $(L)$, time $(t)$, acetylene

7. R. B. Pratt and S. E. Bolt, Status and Progress Report for Thorium Fuel Cycle Development for Period Ending Dec. 31, 1966, ORNL-4275, pp. 61-78.

8. W. J. Lackey, W. H. Pechin, C. F. Sanders, F. C. Davis, and F. J. Furman, Gas-Cooled Reactor and. Thorium Utilization Programs Annu. Progr. Rep. Sept. 30, 1971, ORNL-4760, pp. 45-52.

9. W. J. Lackey, W. H. Pechin, F. C. Davis, and D. D. Cannon, "Microsphere Coating," in ORNL Gas-Cooled Reactor Programs Annu. Progr. Rep. for Period Oct. 1, 1971-Dec. 31, 1972, ORNL-4911 (in preparation). flow rate $(F)$, mass ratio of diluent flow to acetylene flow $(R)$, standard deviation of kernel diameter $\left(\sigma_{k}\right)$, and kernel diameter $\left(D_{k}\right)$. An example of this work is given in Fig. 21.1. For a given buffer coating run, the coating density was greater for the thin coatings, as shown in Fig. 21.2. A virtually identical dependence was also observed for coatings deposited by use of a porous-plate gas distributor. The fact that the thinner coatings are more dense means that the average buffer coating will have to be about 5\% thicker than if thickness and density were not related.

We have constructed a new electronic particle size analyzer based on the light blockage principle previously described. 8,10 The new instrument has 1000 channels of memory as opposed to ten in the old one. The new instrument is also capable of direct interfacing with our PDP-8E computer for the statistical analysis and printout of the data. As the particles pass through the sensor, they partially block the flow of light falling on a photocell. The light blockage creates a pulse, which is amplified and sent to the multichannel analyzer, where the pulse height is converted to digital information and assigned as a count to the appropriate

10. F. J. Furman and R. A. Bowman, Status and Progress Report for Thorium Fuel Cycle Development Jan. 1, 1969 through Mar. 31, 1970, ORNL-4629, p. 80.

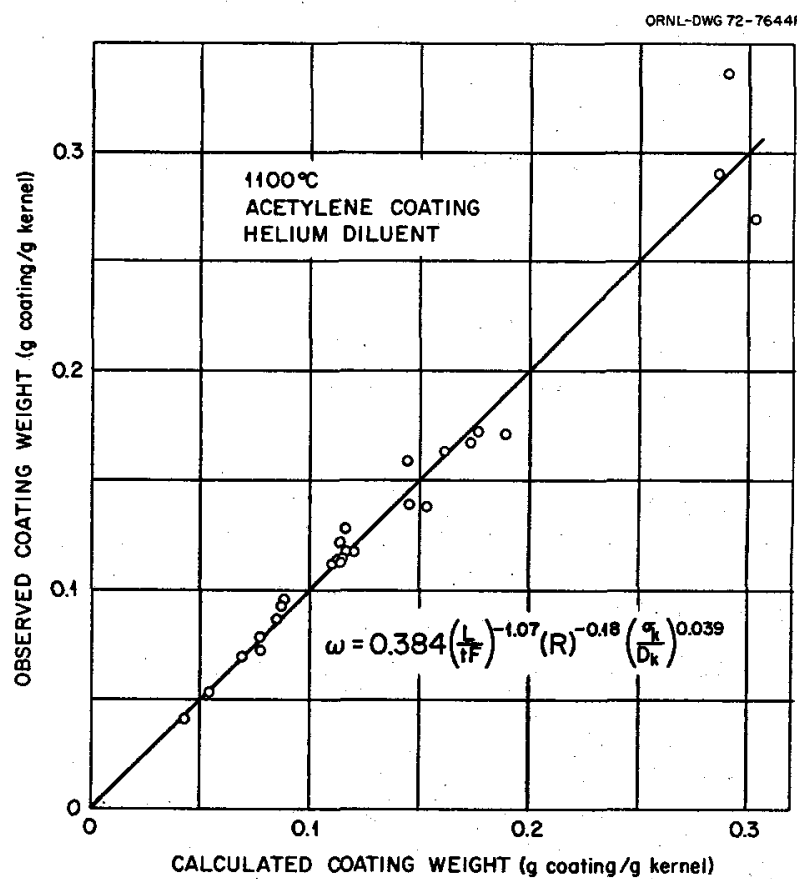

Fig. 21.1. Comparison of observed coating weights with calculated values. 


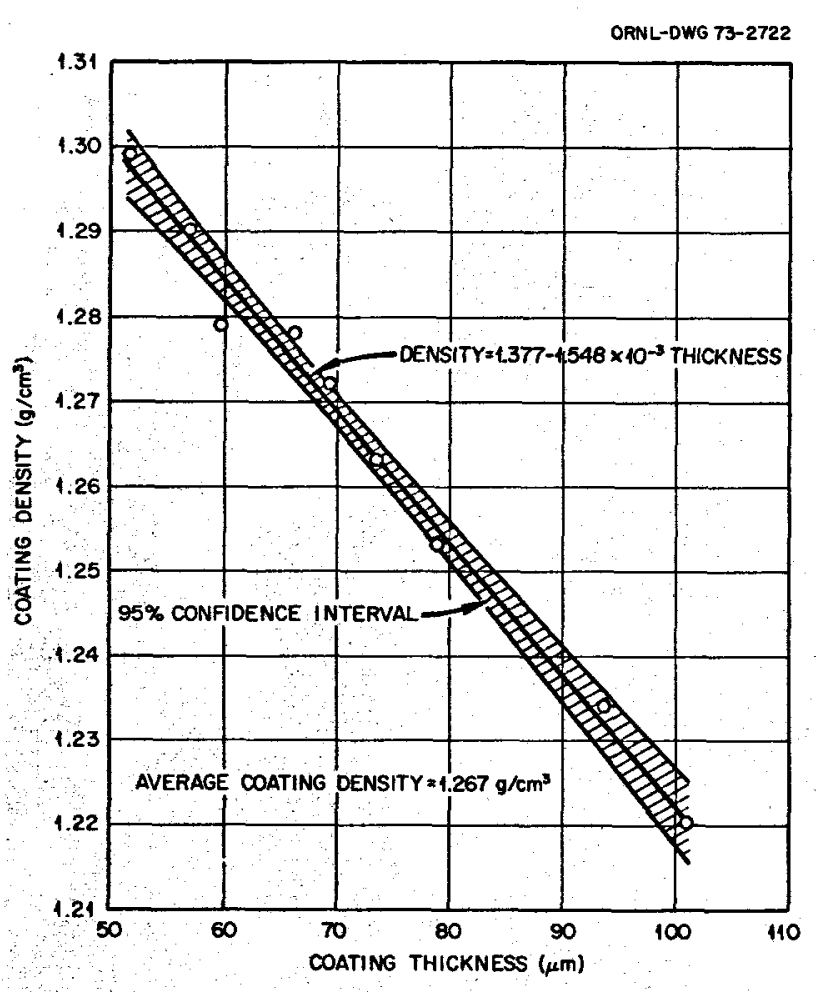

Fig. 21.2. Variation of coating density with coating thickness for a single buffer coating run.

channel. The number of counts in each channel is then transferred electronically to the computer, which applies the calibration factor and prints the particle size distribution. The machine is complete except for the data link with the computer, which is awaiting delivery of a circuit board. Our preliminary work indicates that the mean particle size for a batch reproduces to less than $1 \mu \mathrm{m}$.

We have about one year's experience now with the system for reading microradiographs, in which the digital output from a split-image eyepiece is immediately processed and printed by a small computer. With this equipment, the diameters and coating thicknesses of 50 particles can be determined in $10 \mathrm{~min}$, compared with the 2 to $3 \mathrm{hr}$ previously required.

A more complete description of the particle coating task is available. ${ }^{11}$

\section{Fuel Rod Fabrication}

$$
\begin{aligned}
& \text { R. A. Bradley C. R. Reese }{ }^{12} \\
& \text { C. F. Sanders }
\end{aligned}
$$

The purpose of our work is to develop processes and equipment suitable for fabricating about 8000 fuel rods per day at the TURF. The fuel rods are about $0.5 \mathrm{in}$. in diameter $X 2$ in. long and contain mixtures of fissile and fertile coated particles bonded by a matrix of pitch binder and graphite filler.

The principal activities in fuel rod fabrication are dispensing and blending particles and loading them into molds, injecting the matrix into a bed of particles to form a rod, carbonizing and annealing the rod, and inspecting and assaying the rod.

Particle dispensing, blending, and loading. The particle dispensing, blending, and loading system must be capable of rapidly dispensing precisely controlled quantities of fissile and fertile particles and blending and distributing them uniformly throughout the fuel rod. It should also be capable of blending graphite shim particles with the fissile and fertile particles since some of the fuel rods may require shim particles to reduce the fuel loading. Our target specification is under $5 \%$ variation in heavy metal content per inch of fuel rod.

Pinch valves can volumetrically dispense the fissile particles with sufficient reproducibility that we can say with $99 \%$ confidence that $99 \%$ of the samples dispensed will be within $\pm 0.66 \%$ of the mean sample weight.

Two approaches to blending the fissile and fertile particles were investigated, batch blending and individual rod blending. Batch blending was investigated in a pneumatic blender consisting of a 5-in.diam $X$ 5-ft-tall cylindrical mixing chamber with a conical bottom. Low-pressure air ( 1 to 11 psig) introduced through the cone at the bottom of the chamber fluidized the particle bed, and blending was accomplished by the relative motion between particles in the fluidized bed.

We tested this pneumatic blender with the extreme particle system that might be encountered in HTGR fuel fabrication (i.e., Th: $U$ ratio of 10 , fissile particle size range of $420-500 \mu \mathrm{m}$, and fertile particles size range of 707-833 $\mu \mathrm{m}$ ). Even with this extreme particle system, the pneumatic blender mixed the fissile and fertile particles in about $90 \%$ of the length of the bed adequately. ${ }^{13}$ However, in the first and last 3 to $5 \%$ of the bed the samples were always rich in the smaller fissile particles. The pneumatic blender is also promising

11. W. J. Lackey, W. H. Pechin, and J. D. Sease, "Remote Coating of HTGR Fuel Particles," IIth Biennial Conference on Carbon - Extended Abstracts and Program, June 4-8, 1973,Gatlinburg, Tennessee, CONF-730601, pp. 254-56.

12. Now at Harvard University.

13. R. A. Bradley, D. D. Cannon, F. C. Davis, C. R. Reese, and J. D. Sease, "Fuel Rod Fabrication," in ORNL Gas-Cooled Reactor Programs Annu. Progr. Rep. for Period Oct. 1, 1973-Dec. 31, 1972, ORNL-4911 (in preparation). 


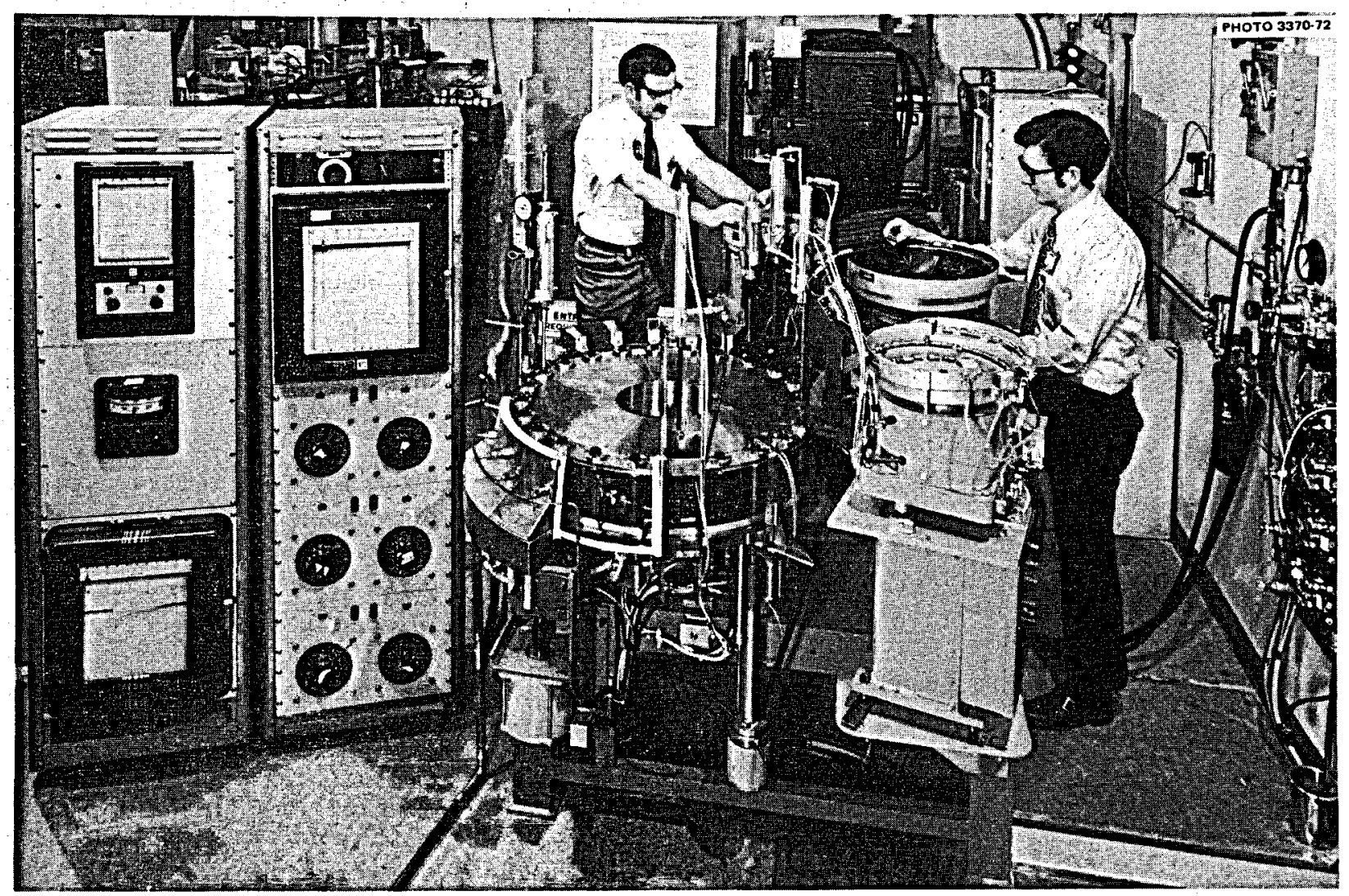

Fig. 21.3. Automatic fuel rod machine.

for cross blending particles of nominally the same size and density, but from different coating runs.

Individual rod blending involves splitting the charge required for one fuel rod into ten approximately equal increments and sequentially loading each increment into the fuel rod mold. For a 2-in. fuel rod each increment would be $0.2 \mathrm{in}$. high. Although the fissile and fertile particles within any one increment may not be perfectly blended, the ratio of fissile to fertile in any increment will be about the same as in any other increment. This splitting technique was selected because it is the most positive way of assuring that the fissile and fertile particles are distributed along the entire length of the fuel rod.

The laboratory device, termed a decade splitter, used to test this technique consists of a splitting cone fitted into the bottom of a cylindrical sleeve containing an orifice, which is centered over the apex of the cone. Around the base of the cone are ten knife edges forming ten gates leading into separate cups. A slide valve serves as the bottom of the cups and provides a means of emptying each cup sequentially into the funnel leading to the mold. The decade splitter and slide valve could uniformly distribute fissile, fertile, and shim particles along the fuel rod.

Fuel rod molding. We continued the development of the slug injection process ${ }^{14}$ for molding fuel rods. The feasibility of this process for making acceptable fuel rods was demonstrated previously, and the concept for an automatic fuel rod machine was described. ${ }^{15,16} \mathrm{We}$ completed the design, fabrication, and installation of this laboratory automatic rod machine and have operated it at a production rate of 4000 fuel rods per 20 -hr day.

This machine, shown in Fig. 21.3, is basically a rotary index table to which 24 cylindrical molds are attached.

14. J. D. Sease, W. H. Pechin, F. J. Furman, J. G. Stradley, and C. F. Sanders, Metals and Ceramics Div. Annu. Progr. Rep. June 30, 1971, ORNL-4770, pp. 172-74.

15. R. A. Bradley and C. F. Sanders, Metals and Ceramics Div. Annu. Progr. Rep. June 30, 1972, ORNL-4820, pp. 133-36.

16. R. A. Bradley, C. F. Sanders, and D. D. Cannon, Gas-Cooled Reactor and Thorium Utilization Programs Annu. Progr. Rep. Sept. 30, 1971, ORNL-4760, pp. 52-55. 
As the table indexes, the mold travels through the operating situations required to load the mold, heat it to melt the matrix, inject the molten matrix into the particle bed, then cool the mold and eject the fuel rod. This machine and its operation are described in detail. ${ }^{17}$ Also reported are detailed results of a series of experiments to determine the effect of temperature, pressure, particle size, pitch type, and filler type and amount on the intrusion rate of matrix into a bed of particles.

Carbonization and annealing. The molded fuel rod must be heated to 700 to $1000^{\circ} \mathrm{C}$ to carbonize the pitch and then to $1800^{\circ} \mathrm{C}$ to remove residual volatiles and stabilize the dimensions of the rod. The rod must be supported during carbonization to prevent distortion as the pitch melts and decomposes. In the past rods have been supported by packing them in graphite or $\mathrm{Al}_{2} \mathrm{O}_{3}$ powder.

We installed a carbonization furnace with a capacity of about 1000 rods per week. Using vertical packing in $\mathrm{Al}_{2} \mathrm{O}_{3}$ powder, we carbonized several thousand fuel rods for use in the whole block burner tests by the Chemical Technology Division. After annealing at $1800^{\circ} \mathrm{C}$ the rods were within dimensional tolerances.

Packing the rods in $\mathrm{Al}_{2} \mathrm{O}_{3}$ powder would be very difficult to accomplish remotely; therefore, we intend to load the green fuel rods directly into the graphite fuel element and carbonize and anneal them in the graphite block. Laboratory-scale experiments have been performed to establish the feasibility of in-block carbonization, and a few rods carbonized in graphite tubes to simulate in-block carbonization were included in the HRB-4 and HRB-5 irradiation tests described in Chapter 17 of this report. Experiments are under way to determine carbonization conditions that will be suitable for full-scale in-block carbonization.

Fuel stick inspection and assay. Fuel stick characterization consists of inspections to determine the filler distribution, the fission gas release due to surface contamination and/or broken particles, the fuel distribution, the variation in fuel content from rod to rod, and the amount of fuel in a given rod or a batch of rods.

We have developed and evaluated techniques for determining the filler distribution and the particle distribution. The axial distribution of graphite filler in slug-injected fuel rods is determined by breaking the

17. J. D. Sease, C. F. Sanders, W. P. Eatherly, D. P. Harman, and W. J. Scheffl, "Fabrication of Plutonium Fuels for HTGR," paper presented at ANS meeting in Las Vegas, Nevada, June $19-22,1972$. green fuel rods into three approximately equal sections, dissolving the matrix in pyridine, and separating the insoluble graphite. The fissile and fertile particle axial distribution is determined by gamma scanning the fuel rod.

The combined rod contamination and fuel particle breakage is determined by fission gas released. We irradiate the rods in a thermal neutron flux (ORR) to approximately $10^{14}$ fissions, heat the sample to $1100^{\circ} \mathrm{C}$, collect the gases, and determine the amount of ${ }^{85 \mathrm{~m}} \mathrm{Kr}$ in the gas sample by gamma spectrometry. This technique was used successfully on several plutoniumbearing samples. ${ }^{17}$ Another technique developed for determination of broken particles comprises electrochemical disintegration of a carbonized fuel rod and acid leaching of the coated particles. The amount of uranium or thorium in the leach solution measures the number of broken particles.

The major problem in characterizing fuel rods is determining the amount of fissionable material in each rod to the precision needed for this program. In a cooperative program Los Alamos Scientific Laboratory is performing scoping experiments on HTGR fuel rods. The technique that looks the best at this time is a multispectra neutron irradiation. With this technique we will induce fission in the material using different energy neutrons and count the prompt or delayed fission neutrons.

\section{HTGR RECYCLE FUELS IRRADIATION}

$$
\begin{array}{ll}
\text { F. J. Homan } & \text { R. A. Olstad } \\
\text { R. B. Fitts } & \text { E. L. Long, Jr. }
\end{array}
$$

The irradiation testing portion of the HTGR recycle fuels program has two main objectives: (1) to provide irradiated fuel for head-end reprocessing studies, and (2) to provide irradiation proof testing of the products of coated particle process development. The accomplishment of these two objectives requires irradiation experiments beginning with accelerated testing of fuel in capsule irradiations in the ORR and HFIR. These tests are assembled and conducted jointly with those that are a part of the basic Gas-Cooled Reactor Program, which are discussed in Chapter 17. Prototype irradiation of fuel elements is being carried out in the Peach Bottom Reactor. Eventually full-sized fuel elements will be tested in the FSVR, including both fresh fuel and previously irradiated fuel refabricated by the remote equipment and technology being developed under other phases of the Thorium Utilization Program. The capsule irradiations and prototype testing in the Peach Bottom Reactor are currently under way. 


\section{Large-Scale Irradiations}

$$
\text { R. B. Fitts E. L. Long, Jr. }
$$

This cooperative irradiation program with Gulf General Atomic consists of seven Recycle Test Elements (RTE's) being irradiated ${ }^{18}$ in the Peach Bottom Reactor. The design of the elements and the fuels being tested has been reported. ${ }^{19}$ The overall purposes of these tests are: (1) to provide 'gram quantities of irradiated HTGR fuel for reprocessing studies, (2) to provide irradiated fuel blocks for testing engineeringscale reprocessing equipment, and (3) to test recycle fuels made in prototype equipment, using the processes to be used in the Thorium-Uranium Recycle Facility.

Six of the seven RTE's were inserted in the Peach Bottom Reactor on July 14, 1970 and the seventh on April 24, 1971. They have operated without incident, and one was withdrawn in 1971 and another (RTE-4) removed in 1972. A third element (RTE-2) is scheduled for withdrawal in late 1973 , and the remainder will be removed in late 1974 when the final shutdown of the Peach Bottom Reactor is expected. The two elements that have been removed had achieved relatively low fast-fluence exposures $\left(<2 \times 10^{21}\right.$ neutrons $\left./ \mathrm{cm}^{2}\right)$. The remaining elements will receive up to $4 \times 10^{22}$ neutrons $/ \mathrm{cm}^{2}$ fast fluence $(>0.18 \mathrm{MeV})$.

The fuels have been examined, 20,21 and samples have been, and are presently being, used in the analysis of fission product distribution 22 and head-end reprocessing studies. ${ }^{23}$ The fuel performance has been excellent, as would be expected at this low exposure.

\section{Capsule Irradiation Tests}
R. A. Olstad
R. B. Fitts
A. R. Olsen
E. L. Long, Jr.

The $\mathrm{H}-1$ and $\mathrm{H}-2$ capsules ${ }^{24-26}$ were irradiated in the ETR between May 1971 and May 1972. The capsules were unintentionally irradiated in an inverted position during the last of the four irradiation cycles, causing about half the samples to operate much above design temperatures. We saw ${ }^{27}$ that the fuel rods that operated at very high temperatures during the inversion were severely damaged and contained a central region of reddish powder, with no recognizable particles remaining. Some of the rods that operated at normal temperatures during the inversion were largely fragmented or debonded, possibly because of the high initial heating rates ( 7 to $12 \mathrm{~kW} / \mathrm{ft}$ ) or because of chemical attack by the fission products and oxidants released from the severely damaged rods.
The operating temperatures, burnups, and fast fluences have been calculated for the various samples. The total fast fluence $(>0.18 \mathrm{MeV})$ values are estimated to vary from 2.3 to $6.5 \times 10^{21}$ neutrons $/ \mathrm{cm}^{2}$, subject to confirmation from flux monitor analysis. The burnup calculated for $\mathrm{UO}_{2}, \mathrm{UC}_{2}$, and $\mathrm{UOS}$ resin-derived particles varies from 30 to 55\% FIMA (fissions per initial metal atom). The burnup calculated for the $\mathrm{Th}_{0.67} \mathrm{U}_{0.33} \mathrm{O}_{2}, \mathrm{Th}_{0.81} \mathrm{U}_{0.19} \mathrm{O}_{2}$, and $\mathrm{ThO}_{2}$ particles is approximately 14,10 , and $1 \%$ FIMA, respectively. The calculated center-line temperatures on the bonded rods vary from 900 to $1700^{\circ} \mathrm{C}$ at the beginning of the test (assuming an initial rod thermal conductivity of $0.069 \mathrm{~W} \mathrm{~cm}^{-1}{ }^{\circ} \mathrm{C}^{-1}$ ) and from 600 to $2500^{\circ} \mathrm{C}$ at the time of the inversion (assuming an irradiated rod thermal conductivity of $\left.0.052 \mathrm{~W} \mathrm{~cm}^{-1}{ }^{\circ} \mathrm{C}^{-1}\right)$. The calculated radial average temperature gradients in the rods vary from 400 to $850^{\circ} \mathrm{C} / \mathrm{cm}$ at the beginning of the test and from 250 to $1150^{\circ} \mathrm{C} / \mathrm{cm}$ at the time of the inversion. Therefore, some of the rods operated at much higher temperatures and temperature gradients than the nominal maximum 1100-MW(e) HTGR design conditions of $1350^{\circ} \mathrm{C}$ with a thermal gradient of $650^{\circ} \mathrm{C} / \mathrm{cm}$.

Metallography has been completed on 6 of the 26 samples that were irradiated. These six samples contain BISO-coated $\mathrm{UO}_{2}, \quad \mathrm{ThO}_{2}, \quad \mathrm{Th}_{0.81} \mathrm{U}_{0.19} \mathrm{O}_{2}$, and $\mathrm{Th}_{0.67} \mathrm{U}_{0.33} \mathrm{O}_{2}$ particles. $A$ rod that operated under normal conditions is shown in Fig. 21.4. All the particle coatings are intact, and there is no apparent adverse

18. R. B. Fitts, Metals and Ceramics Div. Annu. Progr. Rep. June 30, 1971, ORNL-4770, pp. 174-75.

19. R. B. Fitts, Metals and Ceramics Div. Annu. Progr. Rep. June 30, 1970, ORNL-4570, pp. 199-200.

20. R. B. 'Fitts, Metals and Ceramics Div. Annu. Progr. Rep. June 30, 1972, ORNL-4820, pp. 138-39.

21. R. B. Fitts, "Test Elements in Peach Bottom Reactor," in ORNL Gas-Cooled Reactor Programs Annu. Progr. Rep. for Period Oct. 1, 1971-Dec. 31, 1972, ORNL-4911 (in preparation).

22. M. T. Morgan and R. L. Towns, ORNL Nuclear Safety Research and Development Progr. Bimonthly Rep. for MarchApril 1972, ORNL-TM-3831, pp. 79-83.

23. R. S. Lowrie, Chemical Technology Div. Annu. Progr. Rep. Mar. 31, 1972, ORNL-4794, pp. 27-29.

24. A. R. Olsen, Metals and Ceramics Div. Annu. Progr. Rep. June 30, 1970, ORNL-4570, pp. 198-99.

25. A. R. Olsen, Metals and Ceramics Div. Annu. Progr. Rep. June 30, 1971, ORNL-4770, p. 174.

26. A. R. Olsen, Metals and Ceramics Div. Annu. Progr. Rep. June 30, 1972, ORNL-4820, p. 139.

27. A. R. Olsen and R. B. Fitts, "ETR Capsules," in $O R N L$ Gas-Cooled Reactor Programs Annu. Progr. Rep. for Period Oct. 1,1971-Dec. 31,1972, ORNL-4911 (in preparation). 


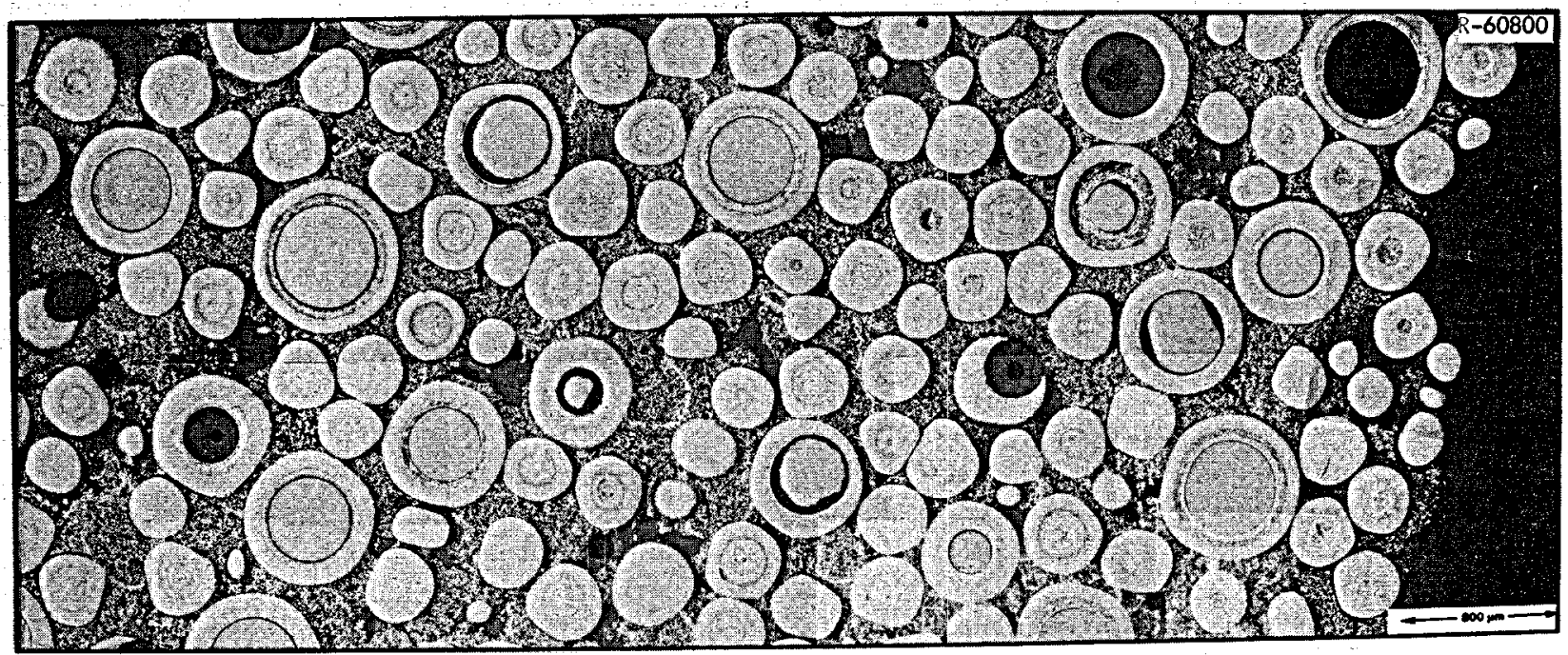

Fig. 21.4. Radial section of fuel rod H-1-2 containing BISO $\mathrm{UO}_{2}$ and $\mathrm{ThO}_{2}$ particles that operated at normal conditions: maximum temperature at center (near upper left corner) $\sim 1250^{\circ} \mathrm{C}$, average temperature gradient $\sim 600^{\circ} \mathrm{C} / \mathrm{cm}, \mathrm{UO} \mathrm{O}_{2} \mathrm{burnup} \sim 40 \%$ FIMA, $\mathrm{ThO}_{2}$ burnup <1\% FIMA, fast fluence $(>0.18 \mathrm{Mev}) \sim 5 \times 10^{21}$ neutrons $/ \mathrm{cm}^{2}$.

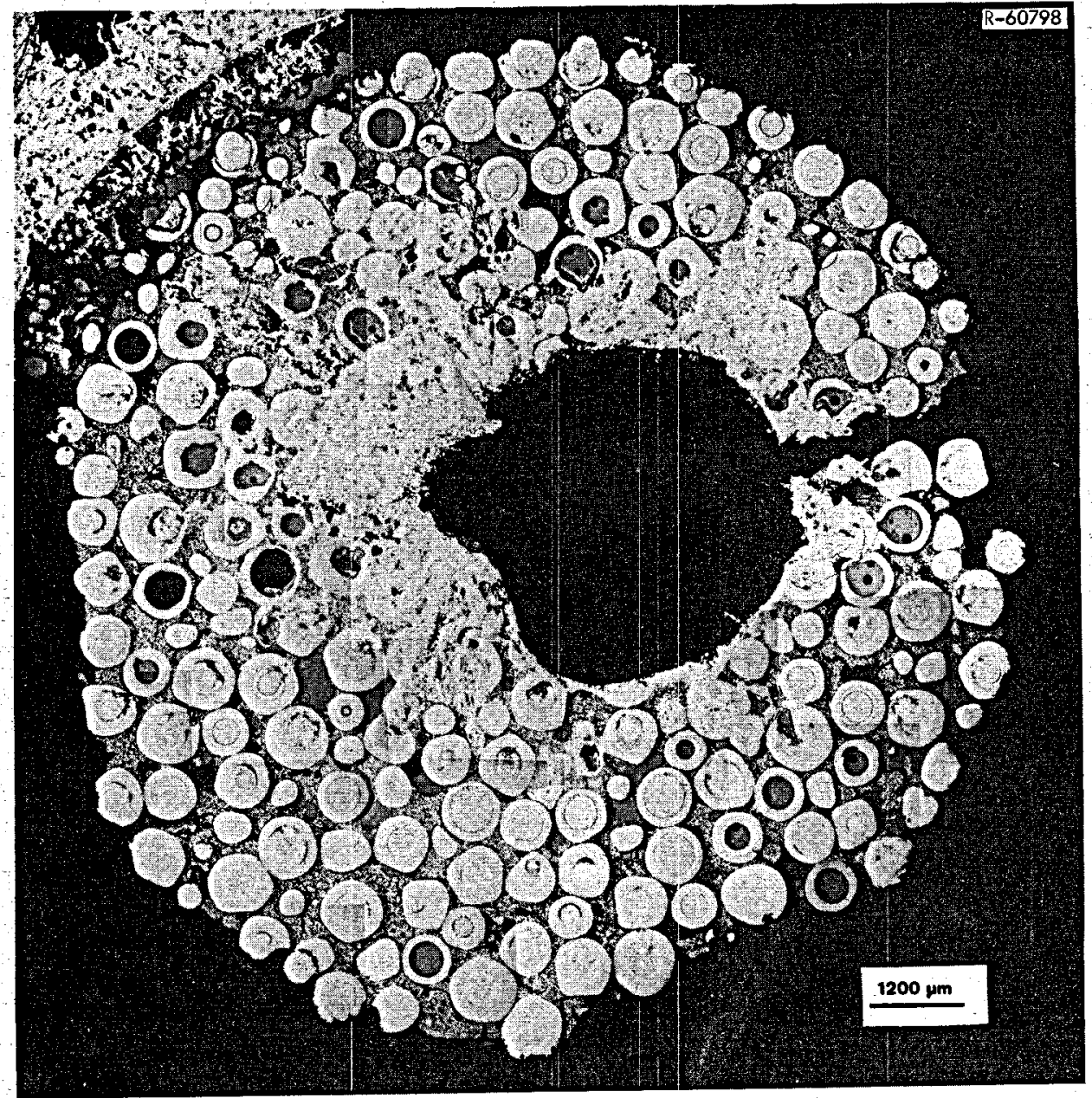

Fig. 21.5. Cross section of fuel rod H-1-10 containing BISO $\mathrm{Th}_{0.81} \mathrm{U}_{0.19} \mathrm{O}_{2}$ and $\mathrm{ThO}_{2}$ particles, which operated at very high temperatures during the inversion: maximum center-line temperature $\sim 2200^{\circ} \mathrm{C}$, maximum surface temperature $\sim 1550^{\circ} \mathrm{C}$, average temperature gradient $\sim 1100^{\circ} \mathrm{C} / \mathrm{cm}$, (Th, $\mathrm{U}_{2} \mathrm{O}_{2}$ burnup $\sim 12 \%$ FIMA, ThO $\mathrm{O}_{2}$ burnup $\sim 1 \%$ FIMA, fast fluence $\left(>0.18 \mathrm{MeV} \sim 5 \times 10^{21}\right.$ neutrons/ $\mathbf{c m}_{2}$. 
matrix-coating interaction. Some of the $\mathrm{UO}_{2}$ kernels have migrated up the temperature gradient (the socalled amoeba effect) into the buffer layer. No amoeba effect was apparent in any of the $\mathrm{ThO}_{2}$ particles.

A rod that operated at very high temperatures during the inversion is shown in Fig. 21.5. The central powdery region was lost during sample preparation, leaving a hole. Surrounding the hole is an extensively damaged region in which individual particles are not recognizable. Beyond this region, some of the particle coatings have failed and the $\mathrm{Th}_{0.81} \mathrm{U}_{0.19} \mathrm{O}_{2}$ kernels have migrated well into the outer pyrolytic carbon coatings. A small amount of amoeba effect was also observed in the $\mathrm{ThO}_{2}$ particles. These results on amoeba effect in both $\mathrm{UO}_{2}$ and $\mathrm{ThO}_{2}$ particles confirm the results reported in Chapter 17.

- Further analysis of these capsules is under way to correlate the observed effects (kernel migration, particle failure, rod debonding) with the calculated irradiation conditions (temperatures, temperature gradients, burnups, and fast fluences).

\section{FUEL CYCLE SYSTEMS ANALYSIS}

$$
\begin{gathered}
\text { J. W. Anderson }{ }^{28} \text { F. J. Homan } \\
\text { J. D. Sease }
\end{gathered}
$$

To adequately direct the fuel recycle development program, we need to understand the economic and technical problems and considerations of the commercial fuel cycle. We are conducting design and economic studies of commercial-size plants to provide input to the development efforts. At present, emphasis is on the technical and economic evaluation of various fuel recycle processing options.

\section{Evaluation of HTGR Fuel Recycle Processes}

$$
\begin{aligned}
& \text { J. W. Anderson } 28 \text { T. W. Pickel }{ }^{28} \\
& \text { J. W. Snider } 29 \text { J. L. Scott }
\end{aligned}
$$$$
\text { J. D. Sease }
$$

These studies are concerned with the developments in fuel design, performance, reprocessing, and refabrication and their impact on the timing, operability, maintainability, and economics of a commercial recycle plant. The objective of these evaluations is to help guide development work and to provide the basis for assigning priority for the development effort required to establish the base technology required for commercial recycle operations. The project is also intended to yield

28. General Engineering Division.

29. Chemical Technology Division. methods of analysis that can be used by others to assess fuel cycle cost as affected by changes in processes or methods or selection of alternatives in processing.

To carry out this study, several basic ground rules were established for recycle operations. We assumed that four basic functions would take place in an HTGR fuel recycle plant in the commercial industry: (1) spent fuel handling at the processing site; (2) processing of ${ }^{233} \mathrm{U}$ and ${ }^{235} \mathrm{U}$ recycle fuels, Type IM fuel $\left({ }^{235} \mathrm{U}\right.$ for either initial or makeup fueling), and thoria; (3) the disposal of waste as well as the recovery of by-products; and (4) the handling and shipment of fresh fuel from the processing plant.

In general, the recycle process lines are expected to require heavy shielding and to be operated remotely or semiremotely, while the thoria preparation and the IM fuel lines are expected to be handled unshielded and in glove-box facilities.

Processing analysis methods. To perform process trade-off studies, a computer program has been written to yield overall material balance data for the processing plant. With one of the project goals to determine relative economics between process alternatives, another program has been prepared to determine capital and operating cost. To date, only the capital cost portion of the program is in operation. The program estimates the capital cost that is associated with any given process as an incremental cost of the total commercial plant. A third program is planned to take the material balance and cost data and summarize processing costs, given a set of fuel specifications, a set of processes, and a plant production rate.

Conceptual design of plant. A set of general criteria for a commercial recycle plant was prepared. These criteria generally describe the baseline requirements for the commercial plant design, based upon a set of reference processes that have been chosen from various alternatives. To assist in economic evaluation of process options, basic cost factors have been developed for the different kinds of direct processing areas that would be required to meet the plant criteria. In general, this included hot cell areas with heavy shielding $(6 \mathrm{ft}$ normal concrete), medium shielding ( $4 \mathrm{ft}$ normal concrete), and light shielding ( $2 \mathrm{ft}$ normal concrete) as well as alpha-contained cells (no shielding). These cost factors also reflect whether remote, contact, or direct maintenance would be used in the various processing areas of the plant.

A very rough layout for the concept of a 1.5-metric ton/day plant was prepared to verify the estimating procedures and cost factors for different kinds of space required. 
Fuel preparation. A comparative economic assessment is being made of methods for preparing HTGR fuel kernels. The study includes several types of HTGR fuel kernels, e.g., fresh uranium and thorium plus recycled ${ }^{233} \mathrm{U}$, thorium, and ${ }^{235} \mathrm{U}$. The study to date has been limited to processes for ${ }^{233} \mathrm{U}$.

The Solex Process for oxide fuel kernels with a thorium-to-uranium ratio of 4.25 and the CUSP Process for urania fuel kernels have been evaluated. The evaluation included process equipment and total increment of plant capital cost. Waste handling costs and operating costs will be evaluated later.

Fuel specifications. Within the fuel cycle of primary interest to the HTGR system, several possible fuels and fuel combinations have potential for application in a large commercial economy. To serve as a basis for process evaluation, those receiving the greatest interest at this time were identified and some very general specifications prepared for them.

The fuel element being considered is the GGA reference fuel element for the 1160-MW(e) HTGR. The fuel block is $\mathrm{H}-327$ graphite having 72 coolant holes and 132 fuel holes and dimensions as shown in the HTGR Fuel Recycle Development Program Plan. ${ }^{30}$

The fuel rods are 3 in. long $X .5 \%$ in. in diame ter. The fuel rod matrix material is $28.5 \mathrm{wt} \%$ Asbury 6253 natural flake graphite. The binder material is $15 \mathrm{~V}$ coal tar pitch.

Sixteen different fuel particles are under consideration.

Fuel fabrication. Fuel fabrication steps include microsphere coating, fuel rod fabrication, and fuel element assembly. In the microsphere coating area, two basic processes are being considered: BISO and TRISO. Of course, these vary slightly depending upon the particular fuel kernel being coated, but basically the same flowsheet is followed. Technical data for both these processes were developed. These included flowsheets, equipment and system diagrams, and equipment size and space requirement estimates. Equipment cost estimates and the total increment of total plant cost were calculated for both processes. Operating cost and cost comparisons have not yet been completed.

Five basic fuel rod fabrication processes have been considered. These are intrusion, admix, slug injection, slurry blending, extrusion, and hot intrusion.

Options of in-block carbonization and out-of-block carbonization were considered along with both thermo-

30. Oak Ridge National Laboratory, Gulf General Atomic, and Idaho Chemical Processing Plant, National HTGR Fuel Recycle Development Program Plan, ORNL-4702, Rev. 1, in publication. setting and thermoplastic binders. For each process considered, flowsheets were prepared and a preliminary evaluation made. The slug injection thermoplastic process was chosen for additional study. Technical and cost data were prepared for the process considering both carbonization options. A conceptual design study of commercial-scale equipment necessary for process application was also performed. Operating cost and detailed economic trade-off studies for the carbonization processes have not been completed yet; however, preliminary results show significant economic incentives for development of the in-block carbonization process.

\section{Economics of Timing of HTGR Fuel Recycle}

\section{F. J. Homan}

The high-temperature gas-cooled reactor (HTGR) can be operated in both the nonrecycle mode, where replacement fuel elements are fabricated from virgin uranium and spent fuel elements are stored or discarded, and the recycle mode, where spent fuel elements are reprocessed to recover bred ${ }^{233} \mathrm{U}$, unburned ${ }^{235} \mathrm{U}$, and plutonium. The use of recycle fuel of course decreases the requirement for uranium ore and separative work. The fuel recycle aspects of the industry are independent of fresh fuel fabrication because the HTGR system can operate indefinitely without recycle capability. This independence presents a question: When is it economically attractive to initiate commercial recycle? Clearly, optimizing the time of recycle development involves a trade-off between the costs of building and operating a recycle industry and the cost of additional fresh fuel until recycle fuel is available plus the cost of storing spent fuel. Because of the economies of large-scale operation, there is merit in waiting until sufficient spent fuel has been stored to permit building large reprocessing and refabrication plants, but the cost of additional uranium and enrichment services and storage facilities for the spent fuel will limit this delay. We have recently completed a study 31,32 based on three reasonable build schedules for the HTGR, calling for 20,41 , and 124 reactors going on line between 1979 and 1988 . The 20-reactor build schedule is somewhat pessimistic of the HTGR penetration into the nuclear market, while the 124 reactor schedule may be somewhat optimistic. Our

31. F. J. Homan, "Timing the Utilization of Recycle Fuels in High-Temperature Gas-Cooled Reactors," submitted to Nuclear Technology.

32. F. J. Homan, DELAY - A Computer Code for Calculating HTGR Fuel Costs, report in preparation. 
OANL-OWS 73-6969

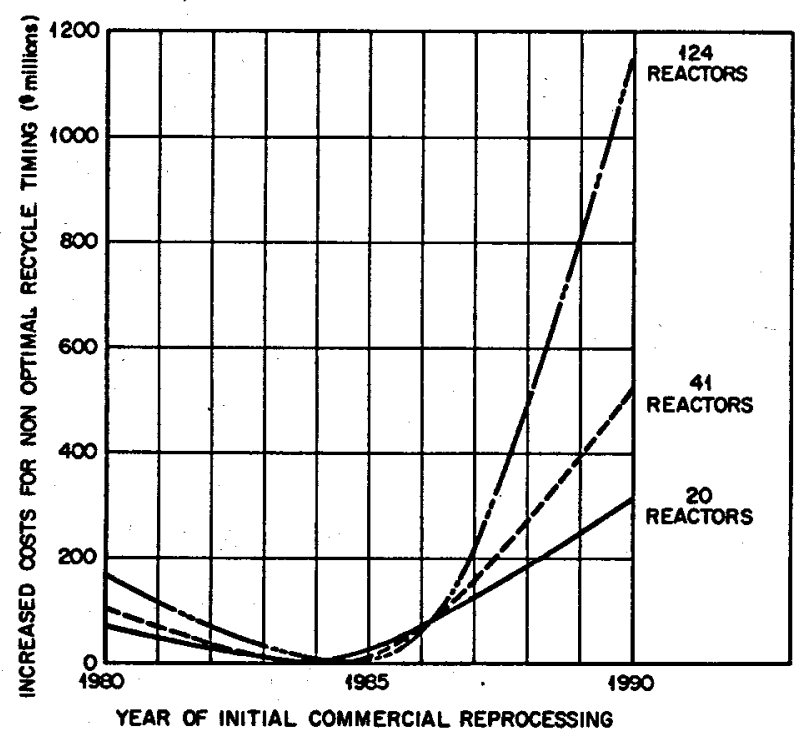

Fig. 21.6. Cost penalties for nonoptimal recycle.

analysis indicates the optimum time to begin commercial reprocessing to be 1984 or 1985 , as shown in Fig. 21.6. Present program funding schedules call for the first commercial fuel reprocessing plant to begin operating in 1987 , which will result in a penalty of $\$ 128$ to $\$ 236$ million over the cost if reprocessing were initiated sooner.

These costs are very sensitive to the assumed input. One of the most sensitive parameters is the cost of toll enrichment, because of the high enrichment (93\%) required for fresh fuel. The calculations shown in Fig. 21.6 were based on $\$ 38 / \mathrm{kg}$ separative work enrichment costs; however, there is speculation over significantly higher costs in the future. ${ }^{33}$ Therefore we determined the sensitivity of the results to enrichment costs of $\$ 50$ and $\$ 75 / \mathrm{kg}$ SWU. These results are shown in Fig. 21.7. For the 20 and 41 -reactor build schedules the optimum year to begin commercial reprocessing remained 1984 , but for the 124-reactor schedule the optimum year moved from 1985 to 1984 . In all cases the penalties for nonoptimum timing increased considerably with increased enrichment costs.

\section{THORIUM CERAMICS DATA MANUAL}

\section{Sigfred Peterson}

New portions of the Thorium Ceramics Data Manual were issued reporting compilation of properties of borides $^{34}$ and sulfides. ${ }^{35}$ Thorium forms two well-

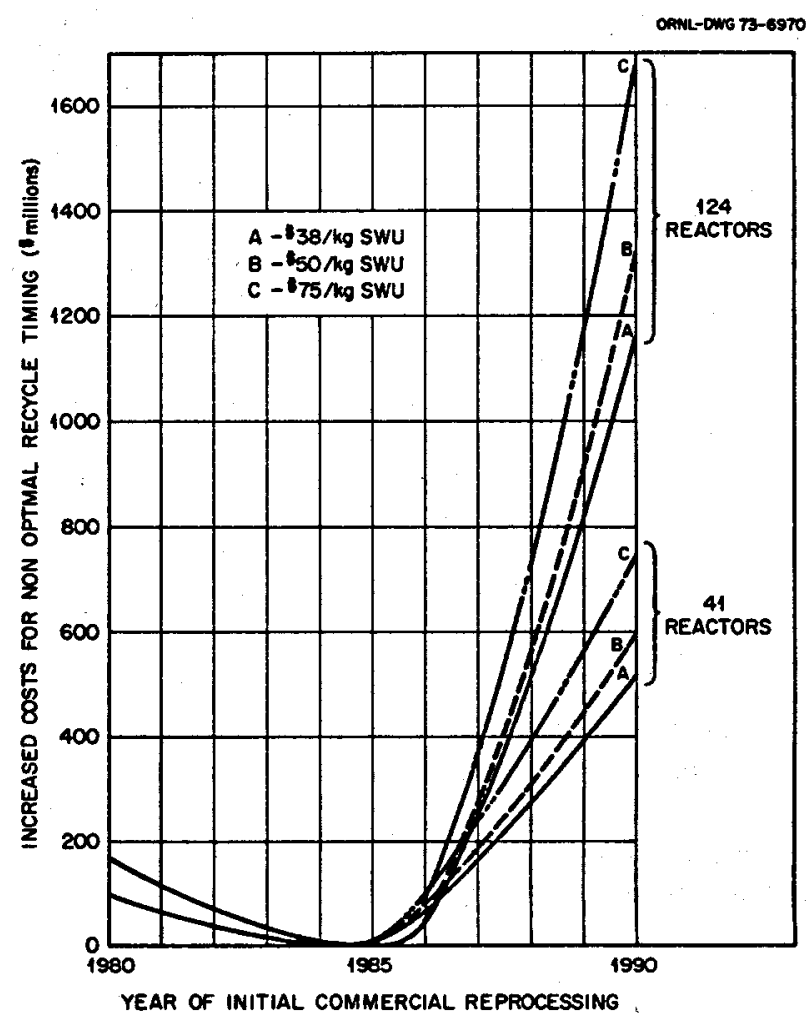

Fig. 21.7. Influence of toll enrichment charges on cost penalties.

characterized high-melting borides, $\mathrm{ThB}_{4}$ and $\mathrm{ThB}_{6}$; the former has good thermal stability and forms continuous solid solutions with $\mathrm{UB}_{4}$. Thorium forms several reasonably well-characterized refractory sulfides and the oxysulfide ThOS, although the phase equilibria are not well established. Complete miscibility exists between ThS and US.

A new section on phosphides and a revision on nitrides have been drafted. The monophosphide, ThP, although not very thoroughly studied, shows electronic conductivity, resistance to water and air, complete miscibility with UP, and the highest melting point of any actinide compound other than $\mathrm{ThO}_{2}$. New information on $\mathrm{ThN}$ has confirmed the excellent transport properties and filled many gaps in the knowledge of its properties and those of $(\mathrm{Th}, \mathrm{U}) \mathrm{N}$ solid solutions.

33. Nucleonics Week, p. 3, Dec. 21, 1972.

34. S. Peterson, Thorium Ceramics Data Manual, Vol. IV Borides, ORNL-4503, Vol. IV (November 1972).

35. S. Peterson, Thorium Ceramics Data Manual, Vol. V Sulfides, ORNL-4503, Vol. V (November 1972). 


\title{
22. Research Reactor Materials
}

\author{
K. Farrell $\quad$ R. W. Knight
}

The two major research and isotope production reactors at Oak Ridge - the Oak Ridge Research Reactor (ORR) and the High Flux Isotope Reactor (HFIR) - are water-cooled and are built largely from aluminum components. Some of the components in the high flux regions of these reactors have suffered distortion or failure in service. These components are being studied to determine the cause(s) of their behavior. In addition, a surveillance program is being undertaken in the HFIR to measure the effects of very high neutron fluences on the physical and mechanical properties of various aluminum alloys used in the construction of the ORR and the HFIR. Of particular interest in this program are radiation-induced swelling, which causes distortion, and loss of ductility, which may lead to sudden failure.

Assistance to Texas Instruments, Inc., in the manufacture of HFIR fuel elements is continuing. The examination of HFIR fuel elements $100-1$ and $100-0$ is completed.

\section{POSTIRRADIATION EXAMINATION AND
TESTING OF THE ORR NF TRAYI}
K. Farrell
R. T. King
E. L. Long, Jr.
A. Jostsons ${ }^{2}$

An Oak Ridge Research Reactor (ORR) core lattice component, and $\mathrm{N}_{\mathrm{F}}$ tray, became permanently bowed during reactor service. This tray, which had been fabricated from recrystallized 1100 aluminum, reached maximum neutron fluences of about $3.0 \times 10^{22}$ neutrons $/ \mathrm{cm}^{2}$ (thermal) and $3.2 \times 10^{22}$ neutrons $/ \mathrm{cm}^{2}$. $(>0.1 \mathrm{MeV})$ at an operating temperature of 40 to $50^{\circ} \mathrm{C}$. Microstructural examination of the tray revealed voids, many dislocations, and a fine precipitate of transmutation-produced silicon. These defects markedly

1. Abstracted from ORNL-TM-4183 (June 1973).

2. On attachment from Australian Atomic Energy Commission Research Establishment, Lucas Heights, N.S.W.

increased the hardness and strength of the 1100 aluminum and also caused a significant loss of ductility. At test temperatures above $100^{\circ} \mathrm{C}$ ductility was further degenerated by helium embrittlement, which resulted in premature intergranular fracture.

The voids made the tray swell by about $1.5 \%$ at its center. This swelling was unequal on opposite sides of the tray and thereby resulted in bowing. The degree of bowing was calculated accurately from the swelling data. We recommend that bowing can be minimized by intermittent annealing at 300 to $350^{\circ} \mathrm{C}$ whenever the first signs of bowing appear or, better still, by fabricating the $\mathrm{N}_{\mathrm{F}}$ tray from 6061 aluminum alloy in the precipitation-hardened $\mathrm{T} 6$ condition.

\section{BOWING OF AN OAK RIDGE RESEARCH REACTOR COMPONENT 3}
K. Farrell
A. Jostsons ${ }^{2}$
R. T. King
E. L. Long, Jr.

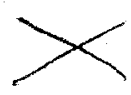

A straight, elongated tray built from recrystallized 1100 aluminum was irradiated in contact with cooling water at about $45^{\circ} \mathrm{C}$ to thermal and fast neutron fluences up to $3 \times 10^{22}$ neutrons $/ \mathrm{cm}^{2}$. It bowed to a banana-like shape. Investigation demonstrated that the fast neutron fluence profile along the tray had the same form as the measured bowing deflection, suggesting an association of bowing with displacement damage. Transmission electron microscopy revealed a nonuniform distribution of radiation-induced voids and transmutation-produced silicon precipitate along the tray, the volume of voids increasing with fast fluence and being greatest at the positions of maximum fast neutron flux and maximum curvature. Density measurements, used to determine the variation of swelling along the tray, showed that swelling was unequal across opposite

3. To be presented at the ANS-AIME Conference on Materials Performance in Operating Nuclear Systems, Ames, Iowa, August 28-30, 1973, and to be published in the Proceedings. 
sides of the tray. Calculations of length changes based on these density data showed excellent agreement with the bowing deflections, confirming that bowing was caused by the nonuniform distribution of voids created by fast neutron displacement events.

\section{EXAMINATION OF THE IRRADIATED 6061 ALUMINUM HFIR TARGET HOLDER 4}
K. Farrell
R. T. King
A. Jostsons ${ }^{2}$

A 6061 aluminum alloy target holder from the High Flux Isotope Reactor (HFIR), originally in a precipitation-hardened condition, was examined for radiation damage after exposure to a maximum fast neutron fluence of $9.2 \times 10^{22}$ neutrons $/ \mathrm{cm}^{2}(>0.1$ $\mathrm{MeV}$ ) and a thermal fluence of $1.38 \times 10^{23}$ neutrons $/ \mathrm{cm}^{2}(<0.414 \mathrm{eV})$ at about $60^{\circ} \mathrm{C}$. Voids and a precipitate of transmutation-produced silicon had caused about $1.1 \%$ internal swelling, and a surface oxide scale contributed additional dimensional change. Significant strength increases were measured at test temperatures in the range 25 to $200^{\circ} \mathrm{C}$ and are attributed to the silicon precipitate and to irradiation-induced dislocations. A corresponding loss of ductility was particularly severe at $200^{\circ} \mathrm{C}$ for testing at slow strain rate. The fracture mode appeared to remain transgranular over the range of test temperatures. Specimens tested at temperatures between 200 and $500^{\circ} \mathrm{C}$, at which the microstructure was unstable, showed considerable loss in strength but a concurrent gain in ductility. The strength and ductility of specimens containing 4043 aluminum alloy weld metal were similar to those of the 6061 aluminum alloy base metal.

\section{ASSEMBLY OF EXPERIMENTS FOR THE ALUMINUM SURVEILLANCE PROGRAM}

$$
\text { T. N. Washburn J. W. Woods }
$$

An experiment assembly consists of three aluminum housing tubes that hold the test specimens. Each of the housing tubes is joined and tack welded to a common upper and lower header for positioning in one of the peripheral target positions in the HFIR. The specimens are loaded through the bottom of each leg of the assembly, each leg holding 12 tensile specimens (0.219 in. shoulder diam $\times 1.870$ in. long). Three electron microscopy specimens in the shape of rods $(0.110 \mathrm{in}$. diam) may be substituted for a tensile specimen. A plug is riveted into the lower header to retain the specimens

4. Abstracted from ORNL-TM-4139 (May 1973). during reactor residence. Usually during irradiation coolant water flows through the tubes and over the specimens. If necessary, the tubes can be sealed off from the water and higher irradiation temperatures achieved by controlling the loss of gamma heat across a helium gas gap. Some of the experiments involve recycling specimens; that is, the use of preirradiated specimens along with new specimens to obtain high neutron fluences and to broaden the range of fluence. Such experiments are assembled remotely in a hot cell.

\section{CREEP PROPERTIES OF IRRADIATED ALUMINUM ALLOYS FROM THE HFIR SURVEILLANCE PROGRA ${ }^{3}$ ?}
R. T. King
K. Farell
A. E. Richt ${ }^{5}$

Creep specimens of $1100-0$ (annealed) aluminum, 6061-T6 (precipitation-hardened), and 6061-0 (annealed) alloy were irradiated at temperatures of about 50 to $150^{\circ} \mathrm{C}$ to fast fluences in the region of $2 \times 10^{22}$ neutrons $/ \mathrm{cm}^{2}(>0.1 \mathrm{MeV})$ and thermal fluences of about $3 \times 10^{22}$ neutrons $/ \mathrm{cm}^{2}(<0.414 \mathrm{eV})$ and were then tested at 50,100 , and $150^{\circ} \mathrm{C}$. Significant increases in creep strength were correlated qualitatively with the development of a radiation-induced dislocation structure and a precipitate of transmutation-produced silicon. Severe loss in ductility was noted especially in the $1100-0$ aluminum, but the 6061-T6 alloy had the lowest postirradiation ductility. The 6061-0 alloy had a marginally better ductility than $1100-0$ and a creep strength between that of 1100-0 and 6061-T6 alloys. The 1100-0 alloy swelled from void formation, but the 6061-T6 and the 6061-O alloys resisted void formation.

\section{SWELLING AND MECHANICAL PROPERTIES OF ALUMINUM ALLOYS IRRADIATED TO HIGH FLUENCES}

\section{A. E. Richt ${ }^{5}$}

Tensile specimens of $1100-0,5052-0,6061-0$, 6061-T6, and 8001-0 aluminum alloys were irradiated at water temperature $\left(\sim 50^{\circ} \mathrm{C}\right)$ to fast fluences up to about $7 \times 10^{22}$ neutrons $/ \mathrm{cm}^{2}(>0.1 \mathrm{MeV})$ and thermal fluences up to about $1.2 \times 10^{23}$ neutrons $/ \mathrm{cm}^{2}(<0.414$ $\mathrm{eV}$ ) in the HFIR peripheral target sites. As expected from previous findings, the $1100-0$ and $8001-0$ alloys showed significant swelling, up to 3.5 and $7.5 \%$,

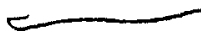

5. Now at Union Carbide Corporation, South Charleston, West Virginia. 
respectively. Most of this swelling is due to void formation, the remainder being from transmutationproduced silicon precipitate. The 5052-0, 6061-0, and 6061-T6 alloys swelled less than $0.3 \%$, in agreement with that expected from transmutation-produced silicon precipitate only.

Irradiation raised the tensile yield strength of the 6061 -T 6 alloy by $60 \%$ and the ultimate strength by $40 \%$ at a test temperature of $50^{\circ} \mathrm{C}$, and by 115 and $50 \%$, respectively, at $150^{\circ} \mathrm{C}$. The elongation was reduced from 18 to $10 \%$ at $50^{\circ} \mathrm{C}$, and from 28 to $4 \%$ at $150^{\circ} \mathrm{C}$. The yield strength of the $5052-0$ alloy was increased fourfold and the ultimate strength was doubled at $50^{\circ} \mathrm{C}$; at $150^{\circ} \mathrm{C}$ there were fourfold and threefold increases, respectively. The ductility was reduced from 28 to $10 \%$ at $50^{\circ} \mathrm{C}$, and from 33 to $2 \%$ at $150^{\circ} \mathrm{C}$. Several of the $5052-0$ specimens were cracked when removed from the irradiation assembly. This cracking is under investigation. The other alloys have not yet been tensile tested.

\section{HFIR FUEL ELEMENT PRODUCTION ASSISTANCE}

Assistance to Texas Instruments, Inc., has continued throughout the past year. To date, 138 fuel assemblies have been fabricated. The incidence of fuel plate rejections is shown in Table 22.1. The overall yield for 85,894 fuel plates is $92.8 \%$, which is an increase of $0.3 \%$ over FY 1972.
A total of 32 approval requests were processed this year: 9 for fuel plate waivers, 13 for drawing-route card and standard operating procedure revisions, 7 for purchase of equipment and materials, 2 for disposal or transfer of equipment and archive samples and data for fuel elements used in the reactor, 1 for use of a new conversion chart for burned $\mathrm{U}_{3} \mathrm{O}_{8}$ at the homogeneity scanner.

Significant changes have been made in the HFIR area at Texas Instruments, Inc., to comply with AEC safeguards regulations.

The ORNL Sciaky welder, which had been put in storage, was sent to Texas Instruments, Inc., where it was modified for HFIR use. Welding parameters for and certification of this equipment will be completed this year.

The use of unclad 6061 alloy for covers and frames is continuing on an experimental basis; to date no difference has been noted in fuel plate yield. Small differences in fuel plate curvature have been noted and corrected at the forming die. Slight differences in the fuel plate lip curvature create an undesirable channel spacing in an element assembled from both fuel plates made with unclad aluminum and fuel plates made with clad aluminum.

- X-ray attenuation curves have been established for the homogeneity scanner to be used for inspection of burned $\mathrm{U}_{3} \mathrm{O}_{8}$ fuel plates.

Texas Instruments, Inc., route cards, standard operations, and drawings have been revised to provide a more production-oriented operation.

Table 22.1. HFIR fuel plates rejected during manufacture ${ }^{a}$

\begin{tabular}{|c|c|c|c|c|c|c|}
\hline \multirow{2}{*}{ Reason for rejections } & \multicolumn{2}{|c|}{ FY 1973} & \multicolumn{2}{|c|}{ FY 1972} & \multicolumn{2}{|c|}{ All production to date } \\
\hline & $\begin{array}{l}\text { Number } \\
\text { rejected }\end{array}$ & Percent & $\begin{array}{l}\text { Number } \\
\text { rejected }\end{array}$ & Percent & $\begin{array}{l}\text { Number } \\
\text { rejected }\end{array}$ & Percent \\
\hline Compacts & 4 & 0.05 & 3 & 0.03 & 294 & 0.34 \\
\hline Surface & 37 & 0.48 & 30 & 0.31 & 2076 & 2.42 \\
\hline Bond defects & 149 & 1.95 & 100 & 1.04 & 3830 & 4.46 \\
\hline Core location & 43 & 0.56 & 17 & 0.18 & 688 & 0.80 \\
\hline Homogeneity & 212 & 2.78 & 137 & 1.42 & 1748 & 2.04 \\
\hline Dimensions & 1 & 0.01 & $\mathbf{0}$ & 0 & 143 & 0.17 \\
\hline Form & $\mathbf{0}$ & 0 & 1 & 0.01 & 37 & 0.04 \\
\hline Miscellaneous & $\underline{5}$ & 0.07 & 3 & $\underline{0.03}$ & 244 & 0.28 \\
\hline Total & 451 & 5.90 & 291 & 3.02 & 9060 & 10.55 \\
\hline Accepted on waiver & 173 & 2.27 & 109 & 1.13 & 2908 & 3.39 \\
\hline Net rejected & 278 & 3.63 & 182 & 1.89 & 6152 & 7.16 \\
\hline
\end{tabular}

${ }^{a}$ Number manufactured: 7632 in FY 1973,9624 in FY 1972 - total to date 85,894 . 


\section{POSTIRRADIATION EXAMINATION OF HFIR FUEL ELEMENTS 100-I AND 100-0}
A. E. Richt ${ }^{5}$
R. W. Knight

Hot cell examination of fuel assembly 100 has been completed. Previously reported data indicated no problems with the burned $\mathrm{U}_{3} \mathrm{O}_{8}$ fuel. ${ }^{6}$

6. A. E. Richt and R. W. Knight, Metals and Ceramics Div. Annu. Progr. Rep. June 30, 1972, ORNL-4820, pp. 147-48.
Metallographic examination of fuel plate sections showed no difference in the aluminum oxide buildup between high-fired $\mathrm{U}_{3} \mathrm{O}_{8}$ and burned $\mathrm{U}_{3} \mathrm{O}_{8}$ fuel plates. A slight increase in reaction between burned $\mathrm{U}_{3} \mathrm{O}_{8}$ and the aluminum matrix was noted; however, sufficient aluminum remains to provide a ductile core.

With all tests completed, the data show that burned $\mathrm{U}_{3} \mathrm{O}_{8}$ should perform as well in the reactor as high-fired $\mathrm{U}_{3} \mathrm{O}_{8}$, and the fuel plates will swell less and have a higher blister temperature. Use of this burned $\mathrm{U}_{3} \mathrm{O}_{8}$ should represent a substantial cost saving in manufacture of the fuel for HFIR fuel assemblies. 


\title{
Part IV. Thermonuclear and Transuranium Research
}

\author{
23. Controlled Thermonuclear Research
}

\author{
C. J. McHargue
}

Two problem areas in fusion reactor technology are being studied in the Metals and Ceramics Division, radiation damage in materials of interest for first-wall applications and the compatibility of these materials with lithium. The radiation effects program consists of both neutron irradiation and ion bombardment simulation of damage. The latter portion is being carried on jointly with members of the Solid State Division. A detailed discussion of much of this work was reported 1

\section{RADIATION DAMAGE}

\section{J. McHargue}

\section{Neutron Irradiation of Body-Centered} Cubic Materials

\section{F. W. Wiffen}

The tensile properties of fast-reactor neutronirradiated bec metals and alloys. 2 Rod tensile samples of niobium, molybdenum, tantalum, one alloy based on each of these metals, and two vanadium-base alloys have been irradiated in EBR-II at temperatures between 390 and $1140^{\circ} \mathrm{C}$ to neutron fluences in the range 1.5 to $6.1 \times 10^{22}$ neutrons $/ \mathrm{cm}^{2}(>0.1 \mathrm{MeV})$. The effect of neutron irradiation at these fluences and temperatures on the strength and ductility properties was determined

1. C. J. McHargue, compiler, Fusion Technology Studies Progress Report for Period Ending December 31, 1972, ORNLTM-4156.

2. Abstract-of a paper submitted for publication in the Proceedings of the Conference "Defects and Defect Clusters in BCC Metals and Their Alloys," sponsored by AME, NBS, and NSF, Gaithersburg, Maryland, August 14-16, 1973. in tensile tests at temperatures between 20 and $800^{\circ} \mathrm{C}$ at strain rates of $0.02 / \mathrm{min}$ or slower. The effect of irradiation is most severe in molybdenum-base systems. Irradiation near $400^{\circ} \mathrm{C}$ renders $\mathrm{Mo}-50 \% \mathrm{Re}$ brittle to at least $800^{\circ} \mathrm{C}$. Similar irradiation of molybdenum and $\mathrm{Mo}-0.5 \% \mathrm{Ti}$ produces a high concentration of small dislocation loops in the microstructure and raises the strain-rate-dependent tensile DBTT from below room temperature to the range 400 to $550^{\circ} \mathrm{C}$. Brittle failures occur with a mixed cleavage and grain boundary separation fracture mode. Specimens of tantalum, $\mathrm{T}-111$, and $\mathrm{Nb}-1 \% \mathrm{Zr}$ exhibited zero uniform elongation but had total elongations in the range 4 to $10 \%$, with ductile fractures for most test conditions. Niobium, $\mathrm{V}-10 \% \mathrm{Cr}$, and VANSTAR-7 had 5 to $17 \%$ total elongation and uniform elongations in the range 1.5 to $10 \%$. Marked strength increases over control values were found in all samples. The results are discussed in terms of the microstructures and fracture modes. It is concluded that dislocation channeling is the process responsible for the complete loss of uniform elongation where loop hardening predominates.

The effect of injected helium on the creep properties of $\mathrm{Nb}-1 \% \mathrm{Zr}$. Helium produced in metals by $(n, \alpha)$ reactions is believed to be the most important of the transmutation products of $14 \mathrm{MeV}$ neutron irradiation in a fusion reactor. One of the metals of interest to CTR that will be exposed to creep conditions is the $\mathrm{Nb}-1 \% \mathrm{Zr}$ alloy, and we are investigating the effect of helium on its creep properties. Mechanical property specimens with a gage section 0.75 in. long, 0.25 in. wide, and 0.010 in. thick were injected with helium accelerated by the ORIC. Helium is injected in the sample target by stopping an alpha beam with energy 
continuously varied by a rotating tapered aluminum degrader disk. The resulting helium concentration is constant from front to rear sample face. Creep tests at 1000,1200 , and $1400^{\circ} \mathrm{C}$ were conducted in a cold-wall vacuum furnace at pressures near $2 \times 10^{-7}$ torr.

At $1000^{\circ} \mathrm{C}$, control tests showed only a modest dependence of ductility on stress, with the ductility in a 1-hr test three-quarters that in 30 - and $800-\mathrm{hr}$ tests. Samples with 1.7 and $18 \mathrm{ppm} \mathrm{He}$ tested at $1000^{\circ} \mathrm{C}$ and $14,000 \mathrm{psi}$ had rupture lives approximately twice that of the control tests and rupture elongations approximately one-half that of the control values. All tests showed the three-stage creep behavior. The lower ductility in the helium-doped samples is reflected in a reduced third-stage creep. Creep tests at $1200^{\circ} \mathrm{C}$ showed a generally greater ductility than tests at $1000^{\circ} \mathrm{C}$, with fracture elongations approximately twice those at the lower temperatures. At this temperature tests lasted from 3 to $250 \mathrm{hr}$ at various stresses with elongations of $64 \pm 4 \%$. In tests at $1200^{\circ} \mathrm{C}$ and 6000 psi, injected samples with 1.7 and $18 \mathrm{ppm} \mathrm{He}$ had slightly shorter rupture lives and approximately threequarters of the rupture elongation of the control sample. In these tests, too, the general form of the creep curves was the same for both control and helium-doped samples, and the reduced ductility in the helium-doped samples resulted from the reduced amount of third-stage creep. Fractography on these samples did not reveal any difference in failure mode due to the helium doping. Fracture in these samples resulted from the metal necking to a chisel-point fracture edge that extended across the width of the sample. There were a few dimples on the fracture edges, corresponding to the opening of the voids that formed in the necked zone during deformation. Reduction in area for these samples was essentially $100 \%$.

Tests conducted at $1400^{\circ} \mathrm{C}$ at a stress of $5000 \mathrm{psi}$ showed $13 \%$ more elongation to rupture in the 18-ppm-He-doped specimen than in the control. However, there probably was considerable grain growth during these tests, and more detailed specimen examination is still required.

\section{Ion Simulation of Damage}

$$
\begin{array}{ll}
\text { K. Farrell } & \text { E. E. Bloom } \\
\text { J. O. Stiegler } & \text { A. Wolfenden }
\end{array}
$$

Irradiation-induced swelling in aluminum, nickel, and vanadium. It is hoped that long-term, severe radiation damage expected in the first wall of a future fusion reactor can be simulated by bombardment with ions in a particle accelerator in relatively short times. With this technique, however, the high rate of generation of defects may change the details of the damage processes and will, in essence, shift the damage to higher temperatures (i.e., damage characteristic of a given temperature in a fission or fusion reactor will occur at higher temperatures during ion bombardment; the range of temperatures for swelling will be moved upward). The first step, therefore, in our CTR damage simulation program is to determine the swelling curves and damage structures for a number of simple metals irradiated with neutrons and then to measure, at an equivalent number of displacements per atom, the appropriate temperatures required to produce similar damage during bombardment with self-ions. We will then be able to predict the temperature at which ion bombardment must be done to simulate a given temperature in a CTR wall material.

To this end we have irradiated specimens of pure $\mathrm{Al}$, $\mathrm{Ni}$, and $\mathrm{V}$ to neutron fluences of 0.5 to $1.2 \times 10^{21}$ neutrons $/ \mathrm{cm}^{2}(>0.1 \mathrm{MeV})$ in the $\mathrm{ORR}$ at 65 to $300^{\circ} \mathrm{C}$, 300 to $850^{\circ} \mathrm{C}$, and 350 to $900^{\circ} \mathrm{C}$, respectively. Voids and dislocations are produced in each of these materials. Quantitative measures of the degree of swelling are not yet complete. Qualitatively, in the aluminum the voids increase in size and decrease in concentration with increasing temperature and disappear above about $185^{\circ} \mathrm{C}$. In the nickel, cavities are present at all temperatures, and swelling is a maximum at about $600^{\circ} \mathrm{C}$; at higher temperatures some or all of the cavities may be gas bubbles. An unusual and interesting feature of nickel specimens irradiated at $300^{\circ} \mathrm{C}$ is that the dislocation loops are clustered; the small clusters seem to be ordered on a cubic lattice parallel to but much larger than the nickel host lattice. The vanadium shows many small voids and patches of dislocation loops at 300 to $450^{\circ} \mathrm{C}$. As the temperature increases the loops disappear and the voids decrease in concentration but increase in size; voids are absent above $750^{\circ} \mathrm{C}$.

Ion bombardment. A specimen chamber has been constructed and mated to the ORNL 6-MV Van de Graaff. The specimen temperature can be controlled in the range from 25 to $1000^{\circ} \mathrm{C}$ with a vacuum of $10^{-9}$ torr at the specimen surface. A multiple ion source was built by members of the Physics Division, and 5- $\mu \mathrm{A}$ currents of 5-MV $\mathrm{H}, \mathrm{He}, \mathrm{Al}$, and $\mathrm{Fe}$ have been obtained. A calorimetric technique is being used to measure the ion current.

3. Present address, Physics and Engineering Laboratory, Department of Scientific and Industrial Research, Private Bag, Lower Hutt, New Zealand. 


\section{CHEMICAL COMPATIBILITY OF POTENTIAL BLANKET AND FIRST-WALL MATERIALS}

\section{J. H. DeVan}

Because of its high tritium breeding ratio and excellent heat transfer properties, metallic lithium affords an attractive dual-purpose blanket-coolant material for fusion reactor applications. We have critically reviewed the existing corrosion data on lithium to define the scope and nature of compatibility problems that accompany the selection of prospective fusion reactor first-wall materials. Conventional alloys, such as highand low-alloy steels, pose different corrosion considerations than do refractory metals such as niobium, vanadium, and molybdenum. Problems with the former class of materials involve the mass transfer of metallic constituents, which can effect marked compositional changes along exposed surfaces and flow perturbations arising from deposited metal. On the other hand, refractory metals resist dissolution but are deoxidized in lithium. Transport of nitrogen and carbon may also occur in nonisothermal lithium-refractory metal systems.
A promising alloy for lithium containment at $500^{\circ} \mathrm{C}$ or lower has the base composition $21 / 4 \% \mathrm{Cr}-1 \%$ Mo-bal Fe. Low-alloy steels of this type require a carbide stabilizer to resist decarburization in lithium. One such steel has been developed for sodium service and contains a $1 \% \mathrm{Nb}$ addition. We are studying the mass transfer-behavior of this steel in lithium using a small thermal convection loop of the alloy. The loop has completed $8000 \mathrm{hr}$ of operation at a hot-leg temperature of $600^{\circ} \mathrm{C}$, and no flow disturbances have appeared to date.

We have also conducted capsule tests of $\mathrm{V}-20 \% \mathrm{Ti}$ in lithium to measure partitioning of oxygen at 600 to $1000^{\circ} \mathrm{C}$. Sheet specimens 0.040 in. thick containing $940 \mathrm{ppm} O$ decreased to $40 \mathrm{ppm} 0$ during $222 \mathrm{hr}$ exposure to lithium containing approximately $100 \mathrm{ppm}$ 0 . Oxygen losses also occurred in similar times at lower temperature, and the extent of these losses was controlled by the solid-state diffusion rate of oxygen in the alloy. 


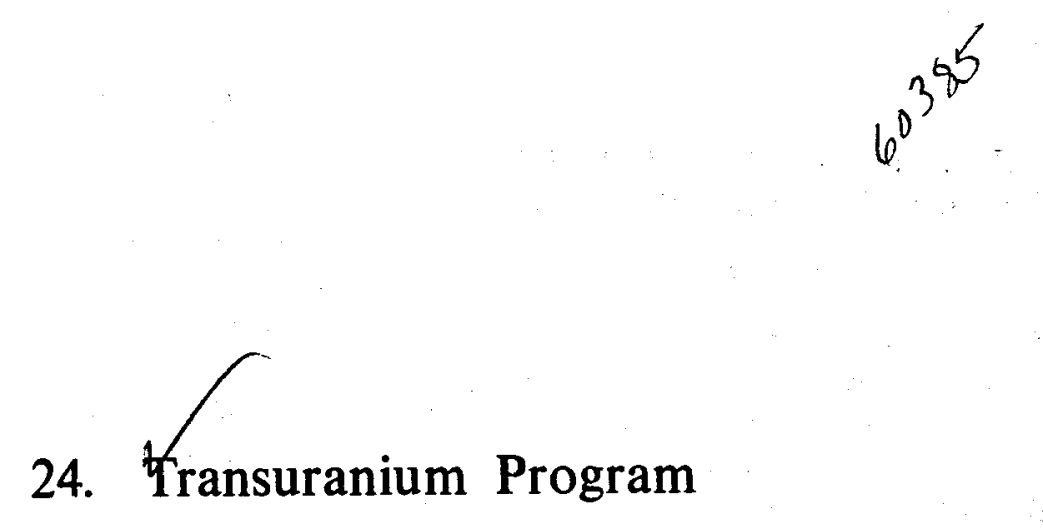

A. L. Lotts

The Transuranium Program is producing quantities of the heavier transuranium elements for research by successive neutron capture in target elements irradiated in the High Flux Isotope Reactor (HFIR). The original isotope was ${ }^{242} \mathrm{Pu}$; however, all this material has been used and ${ }^{244} \mathrm{Cm}$ is now the target material. The target elements containing the isotope are fabricated in the transuranium processing facility (TRU). The targets are periodically removed from the HFIR and chemically processed in the TRU to remove the actinides of interest to researchers. The remaining material is reconstituted and retumed as target elements to the HFIR. During the year, $204 \mathrm{~g}$ of ${ }^{244} \mathrm{Cm}$ was fabricated into targets; $594 \mathrm{~g}$ has been processed since the initiation of operations in the TRU.

The program at the TRU is carried out jointly by the Chemical Technology, Metals and Ceramics, and Analytical Chemistry divisions. Our present task in the program includes the fabrication of targets in the TRU for the HFIR, the fabrication of IFIR rabbits, fabrication of neutron sources, the evaluation of the performance of the target elements, and the improvement of the processing equipment in the TRU, as required.

\section{TARGET FABRICATION}

\section{J. E. Van Cleve, Jr. L. C. Williams}

The production line used to fabricate target rods containing $(\mathrm{Am}, \mathrm{Cm}) \mathrm{O}_{2}$ as the starting material has operated with minimum trouble as fced was available. During this reporting period, 1281 pellets were produced from curium prepared by the resin bead technique. The curium is sorbed on ion exchange resin, which is then pyrolytically decomposed. The detailed technique is described elsewhere. "We fabricated 33 targets from pellets produced during the year. To date, 25 of these targets, each containing from 5.64 to $7.25 \mathrm{~g}$ ${ }^{244} \mathrm{Cm}$ in the form of oxide microspheres, have been inserted within the HFIR core for irradiation. Since the initiation of operations in the TRU, 93 targets have been assembled, requiring $594 \mathrm{~g}$ of ${ }^{244} \mathrm{Cm}$.

\section{HFIR TARGET PERFORMANCE}

\section{J. E. Van Cleve, Jr. L. C. Williams}

During the year 22 targets were removed from the HFIR. Burnups ranged from 36.8 to $73.7 \%$ FIMA and fluences from 4.33 to $12.38 \times 10^{22}$ neutrons $/ \mathrm{cm}^{2}$ $(<0.41 \mathrm{eV})$ and 1.24 to $3.27 \times 10^{22}$ neutrons $/ \mathrm{cm}^{2}$ $(>0.82 \mathrm{MeV})$. Of these targets, 16 had been loaded with pellets pressed from oxide prepared by the resin bead technique.' After removal, each target was visually inspected before being processed to recover the contained transuranium elements. No evidence of cracks in the target cladding was found. We visually inspected these particular targets to determine if the target tube had cracked because of swelling of the pellets fabricated from the oxide microspheres. This type failure has been observed in previously irradiated targets. ${ }^{2}$

\section{NEUTRON SOURCE FABRICATION}

\section{J. E. Van Cleve, Jr. L. C. Williams}

Much of the ${ }^{252} \mathrm{Cf}$ recovered at the TRU during the processing of irradiated HFIR targets is incorporated into neutron sources, which are subsequently loaned to researchers throughout the United States. Three sources were fabricated during this report period, and the ${ }^{252} \mathrm{Cf}$ content ranged from $20 \mu \mathrm{g}$ to $6 \mathrm{mg}$. Two of

1. Chemical Technology Div. Annu. Progr. Rep. Mar. 31, 1972, ORNL-4794, p. 39.

2. R. E. Adams, Metals and Ceranics Div. Annu. Progr. Rep. June 30, 1971, ORNL-4770, pp. 179-81. 
these were doubly contained and one singly contained. ${ }^{3}$ Since these sources are intense neutron emitters, the containment closure welds, weld radiography, and containment leak detection were performed in-cell.

\section{SPECIAL PROJECTS}

\section{J. E. Van Cleve, Jr. L. C. Williams}

The primary functions of the Transuranium Processing Facility group are to fabricate targets for irradiation in the HFIR and to encapsulate ${ }^{252} \mathrm{Cf}$ neutron sources for research. However, the facilities at the TRU are also used for a variety of other purposes, such as nonroutine productions, special preparations, and special irradiations in the HFIR; in each case a unique service is provided to assist a research program at ORNL or another site.

\section{HFIR Rabbits}

Five HFIR rabbits were prepared during this report period. Four of these were loaded with ${ }^{253}$ Es and the fifth with ${ }^{257} \mathrm{Fm}$. The ${ }^{253} \mathrm{Es}$ rabbits were exposed in the HFIR to produce ${ }^{254 \mathrm{~m}} \mathrm{Es}$ and the ${ }^{257} \mathrm{Fm}$ to study the fission product yield curve.

The rabbits are assembled and sealed under a helium atmosphere, and the Heliarc closure weld is made in a new glove-box facility. The glove box is used to contain any activity that may be released should the quartz ampul containing the active isotope rupture during assembly.

\section{Savannah River Shipments}

Five shipments of ${ }^{252} \mathrm{Cf}$ totaling $175 \mathrm{mg}$ and four shipments of ${ }^{244} \mathrm{Cm}$ totaling $183 \mathrm{~g}$ were made to the Savannah River Plant during this report period. This material was separated from Savannah River Plant tubes and returned.

The isotopes are prepared for shipment by encapsulation within a stainless steel container using in-cell welding equipment. Each container is inspected and decontaminated before being loaded into the Savannah River Plant shipping carrier.

3. J. E. Van Cleve, Jr., and L. C. Williams, Metals and Ceramics Div. Annu. Progr. Rep. June 30, 1972, ORNL-4820, p. 143.

\section{THERMAL CONDUCTIVITY OF TARGET PELLETS}

\author{
J. E. Van Cleve, Jr. L. C. Williams
}

Nondestructive determination of the thermal conductivity of individual HFIR target pellets would identify the defective pellets, which operate at unacceptably high temperatures because of improper distribution of actinide oxide in the aluminum matrix. This type of test is needed in the pellet production line for better quality assurance measurements on each pellet. If an accurate measurement of the thermal conductivity can be made, the process can then be adjusted to produce a structure giving the required thermal performance.

The purpose of the program is to develop a nondestructive, remotely operated test that can be used to determine the thermal conductivity of every pellet. The approach is to develop either an eddy-current or dc technique for measuring electrical resistivity on the pressed pellet.

\section{Thermal Conductivity and DC Electrical Resistivity Measurements}

\section{R. K. Williams R. S. Graves}

Thermal conductivity $(\lambda)$ and electrical resistivity $(\rho)$ data were obtained on pellets of aluminum and dispersions in it of 5,10 , and 20 vol \% $\mathrm{Nd}_{2} \mathrm{O}_{3}$, sintered at 525,550 , and $575^{\circ} \mathrm{C}$. These results, which were obtained with the electrical and thermal currents parallel to the pellet axis, indicate that the $\rho$ changes in the pellets were considerably greater than the Eucken equation predictions, although the agreement improved with increasing sintering temperature. The $\lambda$ and $\rho$ data for samples sintered at $575^{\circ} \mathrm{C}$ could be correlated with the equation

$$
\lambda=0.9 L_{0} T / \rho+0.023 \mathrm{~W} \mathrm{~cm}^{-1} \mathrm{~K}^{-1} \text {, }
$$

where $L_{0}=2.44 \times 10^{-8} \mathrm{~V}^{2} / \mathrm{K}^{2}, \rho$ is in $\Omega$-cm, and $T$ is the Kelvin temperature. This equation could obviously be useful for predicting $\lambda$ of pellets from measured $\rho$ values.

The anisotropy of $\rho$, and presumably $\lambda$, was determined by sectioning one $\mathrm{Al}-10 \mathrm{vol} \% \mathrm{Nd}_{2} \mathrm{O}_{3}$ pellet and measuring the $\rho$ in several radial directions. These data indicated an anisotropy ratio $\left(\rho_{\text {axial }} / \rho_{\text {radial }}\right)$ of about 1.6 and thus show that an axial $\rho$ measurement will yield a pessimistic estimate of $\lambda$ in the radial direction. 
Preliminary computer calculations also showed that axial dc resistance measurements on clad target pellets could be used to infer the $\rho$ of the cermet core, and this approach is being pursued experimentally.

\section{Nondestructive Testing for Thermal Conductivity}
C. V. Dodd
W. A. Simpson

An optimized eddy-current system was designed and built for measurement of the electrical conductivity of the oxide target material in simulated HFIR target pellets. In this system, current flows perpendicular to the longitudinal axis of the pellet, and the results agreed with those obtained by dc methods within $\pm 10 \%$. A dc measurement of the longitudinal electrical conductivity indicated a large anisotropy between the radial and longitudinal conductivities, which was subsequently shown to be due to oxide segregation in thin planes perpendicular to the axis.
A theoretical study was also begun on the problem of directly determining the electrical conductivity of the target material from eddy-current measurements. The problem is complicated by the presence of several other variables (the conductivity of the cladding material, its thickness, lift-off, etc.). Two techniques are being investigated. The first uses a computer-assisted fit to the data, using matrix methods. It has the advantages of speed and ease of application, but the accuracy obtained is not controllable. The second method requires expanding the unknown variables in a Taylor series of the measured variables (i.e., magnitudes and phases). In principle, any accuracy may be obtained simply by extending the series, but the method rapidly becomes unwieldy as the number of variables increases. Both methods have been successfully used and are somewhat complementary in their application. The advantage of either method is that once the series coefficients are determined, the measured values need only be inserted in the proper series to yield the desired quantity (conductivity, thickness, etc.), a process that could easily be automated. 


\section{Part V. Other Program Activities \\ 25. Ciomaterials}

G. M. Adamson, Jr.

During the past year the Division has mounted a small effort in a new field - biomaterials. This is an effort to bring the extensive materials experience of the Division to bear on these critical problems. Exploratory studies, based upon two areas in which previous nuclear experience has been obtained, were pursued.

\section{EXAMINATION OF FAILED PROSTHESES FROM THE HUMAN BODY}

\section{R. J. Gray}

We have continued our participation in the evaluation of failed human prostheses, a neglected area of materials science and technology. ${ }^{1}$ A metallographic study of failed intramedullary bone pins from the femur and bone screws was reported. ${ }^{2,3}$

We have examined a failed Jewett nail and plate, a commonly used implant for the support of fractures of the proximal end of the femur. This implant was required for a 21 -year-old soldier wounded 18 months previously. The bone fracture had not united correctly, so the bone had to be fractured and aligned with the nail. The installation of a Jewett nail to bridge a sub-trochanteric fracture is shown schematically in Fig.

1. R. J. Gray, Metals and Ceramics Div. Annu. Progr. Rep. June 30, 1972, ORNL-4820, pp. 165-67.

2. R. J. Gray, Metallographic Examination of Retrieved Intramedullary Bone Pins and Bone Screws from the Human Body, ORNL-TM-4068 (February 1973).

3. R. J. Gray, "Metallographic Examinations of Retrieved Intramedullary Bone Pins and Bone Screws from the Human Body," The Fifth Annual Biomaterials Symposium, April $14-18,1973$. To be published in a special edition of Journal of Biomedical Materials Research.
25.1. The type 316L stainless steel appliance had been in service only three weeks before failure. The implant

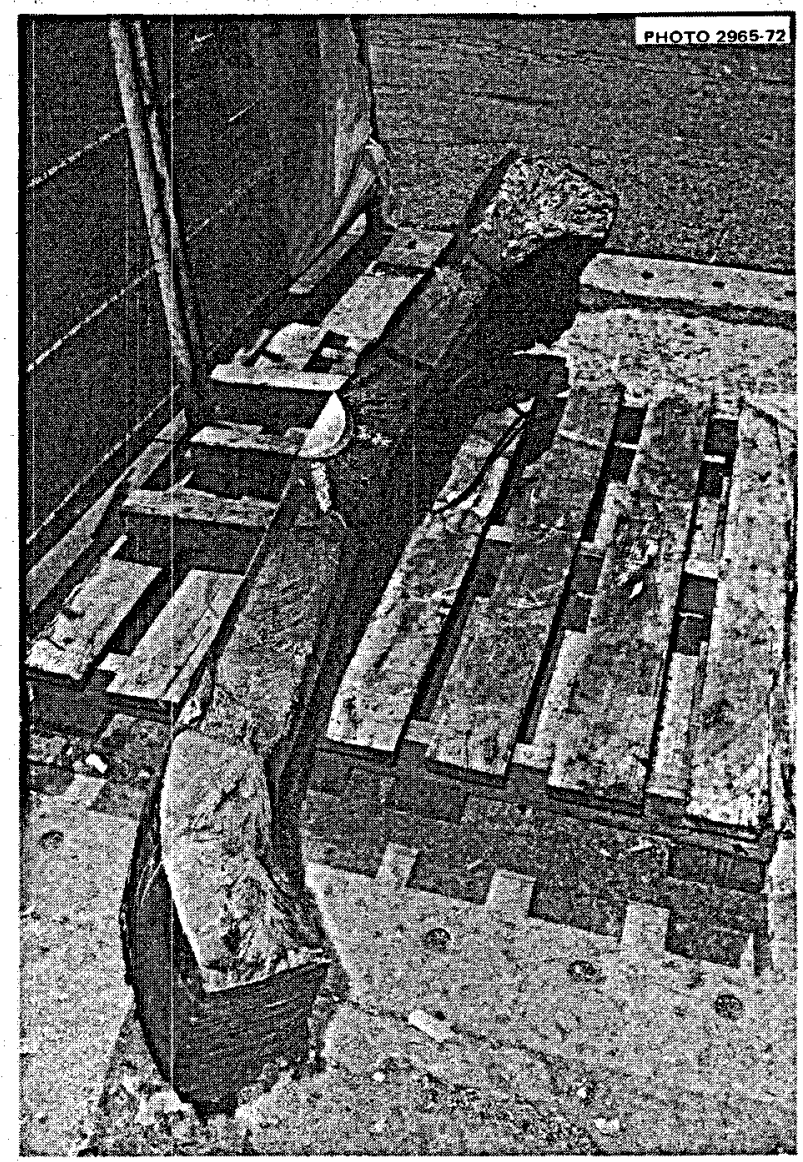

Fig. 25.1. Application of Jewett nail and plate to bridge a sub-trochanteric fracture of the femur. 


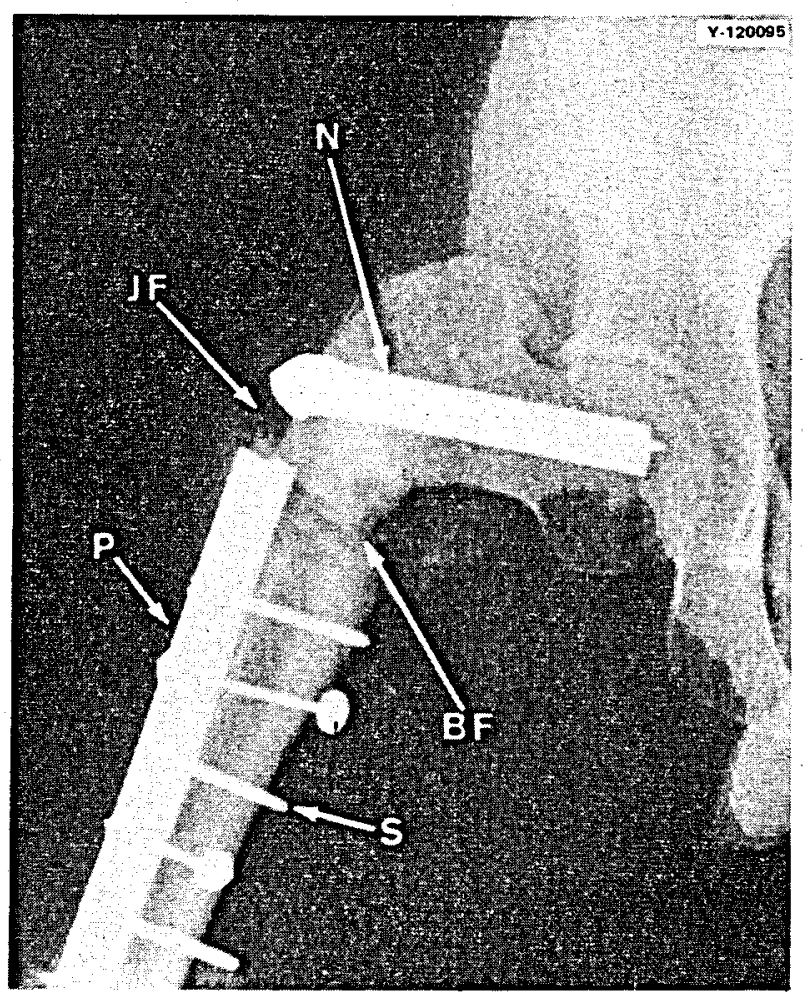

Fig. 25.2. $X$ radiograph of failed Jewett nail and plate used to bridge a sub-trochanteric fracture of the femur. $\mathrm{N}$, nail; $\mathrm{JF}$, Jewett nail fracture; $B F$, bone fracture; $P$, Jewett plate; $S$, screw.

fractured at the chamfered end of the cannula in the nail, as shown in the $x$ radiograph, Fig. 25.2. The impactor used to install the Jewett nail had broken off in it during insertion; however, the placement of the nail was complete, and the surgeon decided to leave it in place and secure the plate to the bone shaft with the required seven self-tapping screws. Fracture of the impactor was attributed to an unusual hardness of the bone caused by vascular necrosis during the intervening months following the injury. A 0.4-in. section of the fractured plate was removed, and a longitudinal median plane shown in Fig. 25.3 was examined. The major fracture and a secondary fracture show evidence of stress-corrosion cracking. Scanning electron microscopy (SEM) examinations of the ridge of the chamfer show gouges produced by the broken impactor. These gouges became stress risers where failure originated, as seen in Fig. 25.4. This normally highly stressed site, with a microscopic gouge in a critical location, was not able to withstand the stress applied to the implant by the

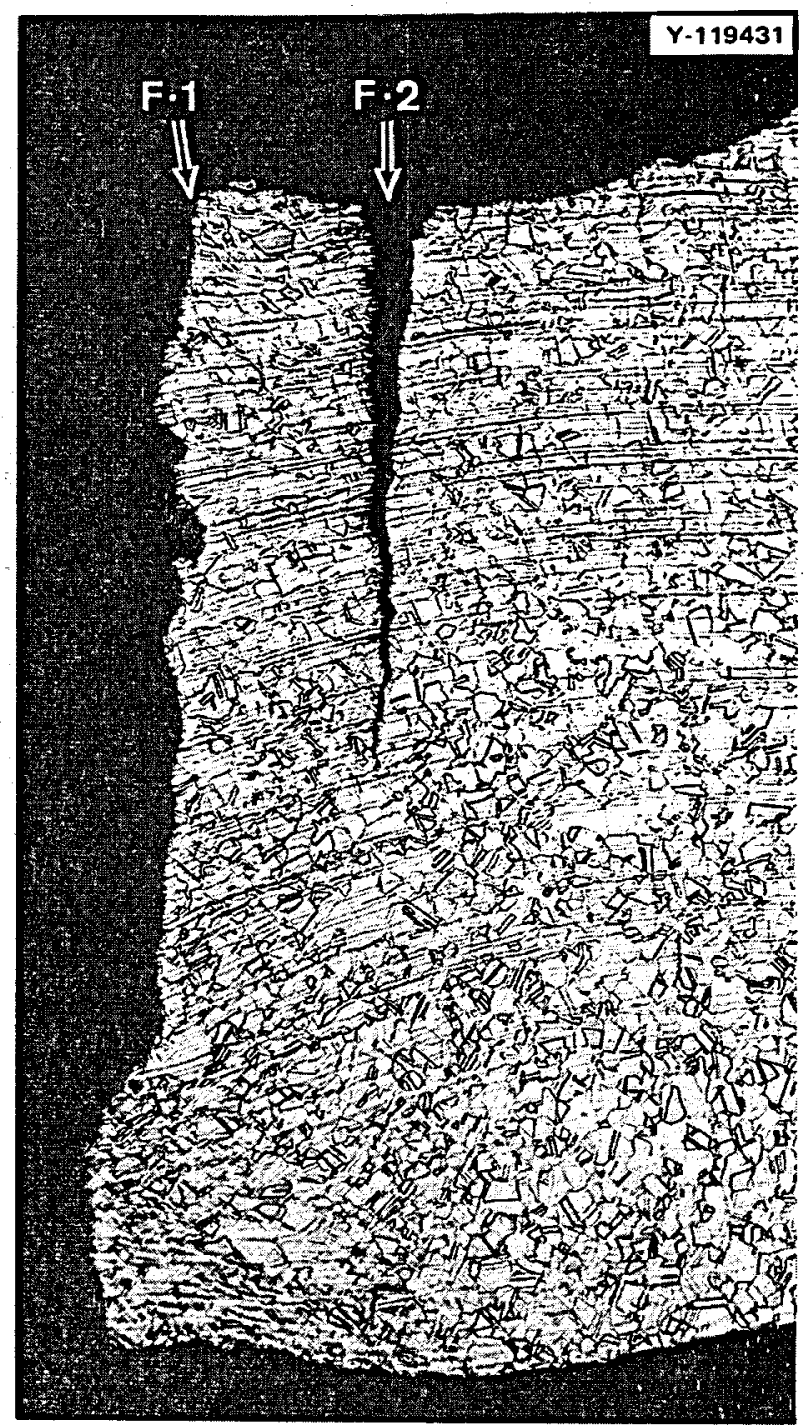

Fig. 25.3. Longitudinal median view of implant failure in the region of the chamfered nail cannula. F-1, major fracture, and F-2, secondary fracture, show evidence of stress-corrosion cracking.

patient. Additional SEM examinations of the fracture surface have several areas displaying intergranular corrosion, as shown in Fig. 25.5. This alloy normally can assume the requirements of a prosthesis and withstand the hostile environment of the body; however, a fractured surface that originates within the body does not have access to sufficient oxygen to form a protective oxide film, and corrosion can proceed quite rapidly in the saline environment. Numerous corrosion areas and fissures could be seen in examining the fractured surface. 


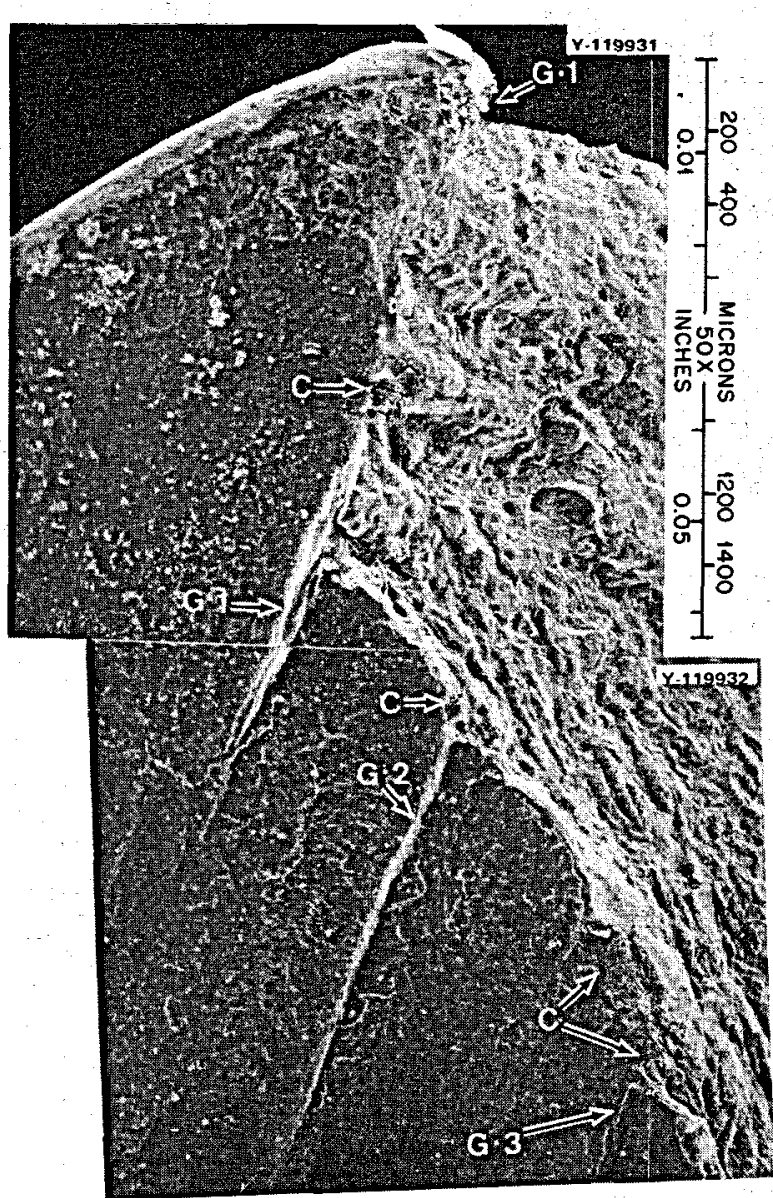

Fig. 25.4. Scanning electron micrograph of chamfered end of cannulated nail. Fracture originated at gouge (G-1) on ridge of chamfer. Other gouges (G-2, G-3) can be seen. Intergranular corrosion $(\mathrm{C})$ of the fracture surface is evident.

\section{GRAPHITE FOR SKELETAL PROSTHETICS}

\section{W. P. Eatherly J M Robbins}

In the study of radiation resistance in graphite and its relationship to microstructure, a fabrication process leading to extremely strong graphites was developed. The initial objective was to improve the plasticity of the material in order that it could withstand the microstrains introduced by the radiation distortion. Concomitant with the increased strain to failure came, however, a much improved strength for a given Young's modulus. These new graphites have mechanical properties almost perfectly matching those of human compact bone and thus become most interesting candidate materials for skeletal prosthetics. The properties are noted in Table 25.1.

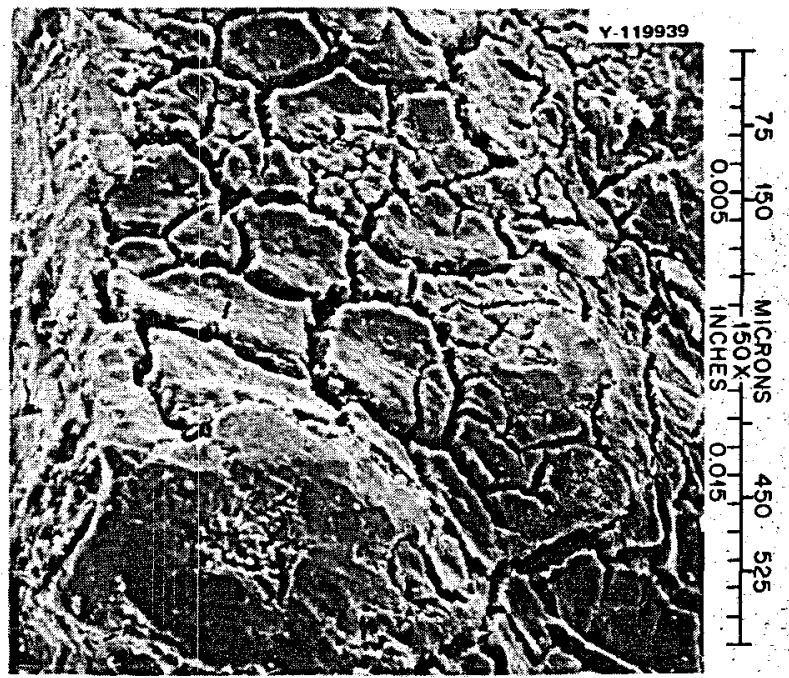

Fig. 25.5. Scanning electron micrograph of intergranular corrosion on fracture surface. Photomicrograph is typical of area indicated by $\mathrm{C}$ in Fig. 25.4 .

Table 25.1. Comparison of mechanical properties of bone and substitute materials

\begin{tabular}{lcc}
\hline Material & $\begin{array}{c}\text { Flexural } \\
\text { strength } \\
\text { (psi) }\end{array}$ & $\begin{array}{c}\text { Young's } \\
\text { modulus } \\
\text { (psi) }\end{array}$ \\
\hline Conventional graphite & 5,000 & $\times 10^{6}$ \\
ORNL graphite & 19,000 & 1.5 \\
Steel & 70,000 & 3 \\
Human femur & $14,000-28,000$ & 60 \\
\hline
\end{tabular}

It should be noted that the match between moduli is equally as important as that for strength if the prosthetic material is to be in direct contact with live bone. Otherwise the differential strains during stress cycling can kill the living tissue at the interface.

The program has recently been further broadened to develop a porous texture in the graphite to permit penetration of the Haversian system into the pores. This system is the main circulatory unit of bone, and experiments with other ceramics have indicated that it will penetrate the artificial material through pores greater than $150 \mu \mathrm{m}$ in diameter to depths of about 1 $\mathrm{mm}$. These conditions have been met, and samples are being prepared for implantation in vivo. 
Preliminary bone-plug implant experiments are being performed in conjunction with the University of Illinois Veterinary College. These experiments to date have used rabbits, and the first examinations were made one year after implantation. The live bone had grown into intimate contact with the graphite, and all tissue at the interface was perfectly normal. A second group of implants will be examined at two years.
In combination with pyrolytic graphite for bearing surfaces, every present indication is that graphite is totally compatible with the human body and mechanically can match live bone and sustain the stresses imposed at critical joints, particularly the hip. 


\title{
26. Graphite Fabrication Studies for
} Naval Ordnance Laboratory ${ }^{1}$

\author{
C. R. Kennedy $\quad$ W. P. Eatherly
}

This program is now in its second year, with the objective of developing bulk graphites with superior thermal shock and ablation resistance. Such improved materials are required for future missile nose tips.

Conventional graphites are normally produced by combining carbonized or graphitized filler materials with hydrocarbon binders derived from organic pre. cursors. During subsequent heat treatment to produce the final graphite body, the filler undergoes little or no shrinkage, whereas the binder material undergoes pronounced shrinkage as it is converted from hydrocarbon to carbon. As a result, the final product possesses a network of angular voids, which can only partially be healed by further impregnation and heat treatment. This pore morphology obviously weakens the overall structure and its ability to withstand stressing.

The effect of pore morphology becomes particularly significant when the stresses are internally generated by differential expansion of adjacent crystallites. Two cases at point are crystallite growth in the $c$ direction during radiation damage and crystallite expansion in the $c$ direction during thermal stress or shock. Both types of problem can presumably be solved by strengthening the interparticle boundaries and reducing the role of pore structures to act as stress risers. The desired structure is, then, one having a monolithic character, with the pore texture introduced by fabrication smaller or less angular than the pores inherently present in the coke structure.

An obvious approach is to employ green (i.e., raw) cokes as obtained directly from the coke drum as the filler material. Its advantages are twofold: first, the coke particle surface still retains chemical activity and will readily bond with the binder, and, second, the

1. This work was funded by the U.S. Naval Ordnance Laboratory under the REVMAT Program, P.O. 3-0139. volume shrinkage of the coke filler more closely matches the binder shrinkage during pyrolysis. We have indeed found that graphites based on green cokes do have the necessary structural characteristics and exhibit dramatic improvements in thermal shock resistance. However, conventional mixing, molding, and baking processes had to be considerably modified to realize the potential of the green coke as a starting material.

The first major alteration in processing is to slurry coat the sized coke particles with binder, followed by heat treatment to about $300^{\circ} \mathrm{C}$. This procedure further chemically activates the surface of the coke particles and also imparts an increased plasticity to the particles to improve packing. The pretreated filler particles are then resized, more binder is added, and the body is molded to as high a green density as possible.

The second major processing alteration is to heat treat the formed green body under mechanical constraint during the early stages of carbonization. This prevents any delamination of the body due to relaxation of the internal stresses introduced during the molding operation. The carbonized body is then conventionally graphitized to at least $2800^{\circ} \mathrm{C}$.

This basic processing technique was developed first to produce graphites with a high resistance to neutron damage for nuclear applications. One of the necessary properties here is isotropy, and it was readily found possible to control the pore cross section to a circular configuration essentially free of angularity. Bulk densities above $2.00 \mathrm{~g} / \mathrm{cm}^{3}$ with flexural strengths approaching 20,000 psi were obtained, but only at the expense of a high thermal expansion coefficient.

Although unimportant in a nuclear graphite, low thermal expansion and high thermal conductivity become essential for thermal shock resistance. The problem thus becomes the extent to which mechanical 
$+4$

properties had to be sacrificed to obtain better thermal properties. Toward this end, highly acicular green cokes were chosen to replace the isotropic cokes. The acicular cokes are more difficult to handle because of their large shape factor introduced by grinding and their tendency to delaminate because of their pronounced anisotropy. Clearly both factors produce a greater tendency toward pore angularity. However, careful control of particle sizing has provided the necessary end product with an acceptable compromise between mechanical and thermal properties.

As a measure of pore texture and monolithic structure, we have employed the ratio of flexural strength to modulus - an indication, if you wish, of the strain to failure. Almost all high-quality conventional graphites have essentially a constant ratio of strength to modulus, with a value of about $4 \times 10^{-3}$. This holds independent of density and of impregnation procedures, indicating that these do not basically alter the microstructure. In contrast to this, our green-coke-based graphites have strength-to-modulus ratios of $6 \times 10^{-3}$, again independent of density. Moreover, this high value has been maintained independent of the type of coke - isotropic, semiacicular, or acicular.

As a crude measure of thermal shock resistance we have used the formula

$$
F=\sigma / \alpha E \rho,
$$

where $F$ is a figure of merit, $\sigma$ the ultimate flexural strength, $\alpha$ the thermal expansion coefficient, $E$ the Young's modulus, and $\rho$ the electrical resistivity, the last being a stand-in for the thermal resistivity. As a direct indication of thermal shock resistance, we have employed a TIG welder to strike an arc at the center of a flat disk. The thermal shock resistance is then measured as the power input necessary to crack the plate at $50 \%$ probability. The results of these tests on various types of our experimental graphites and conventional materials are shown in Fig. 26.1 as a function of the calculated figure of merit. We note that the best ORNL materials cannot be broken at the maximum power rating of the equipment (about $8 \mathrm{~kW}$ ). Conversely, the best conventional graphite tested (ATJ-S from Union Carbide Corporation) failed at less than 3 $\mathrm{kW}$. More severe thermal shock tests are currently being performed.

Our initial fabrication studies were performed on $1 \frac{1}{2}$-in.-diam $\times 1 \frac{1}{2}$-in.-long specimens, including the above data. We have now successfully scaled the process up to 3-in.-long $\times 3$-in.-diam cylinders with no essential difficulty. The green-coke process has still not been extensively explored, but current results for thermal shock resistance are most encouraging and probably do not represent the ultimate capability of the process.

We are indebted to L. G. Overholser of the Y-12 Plant Development Laboratory for performing the thermal shock testing.

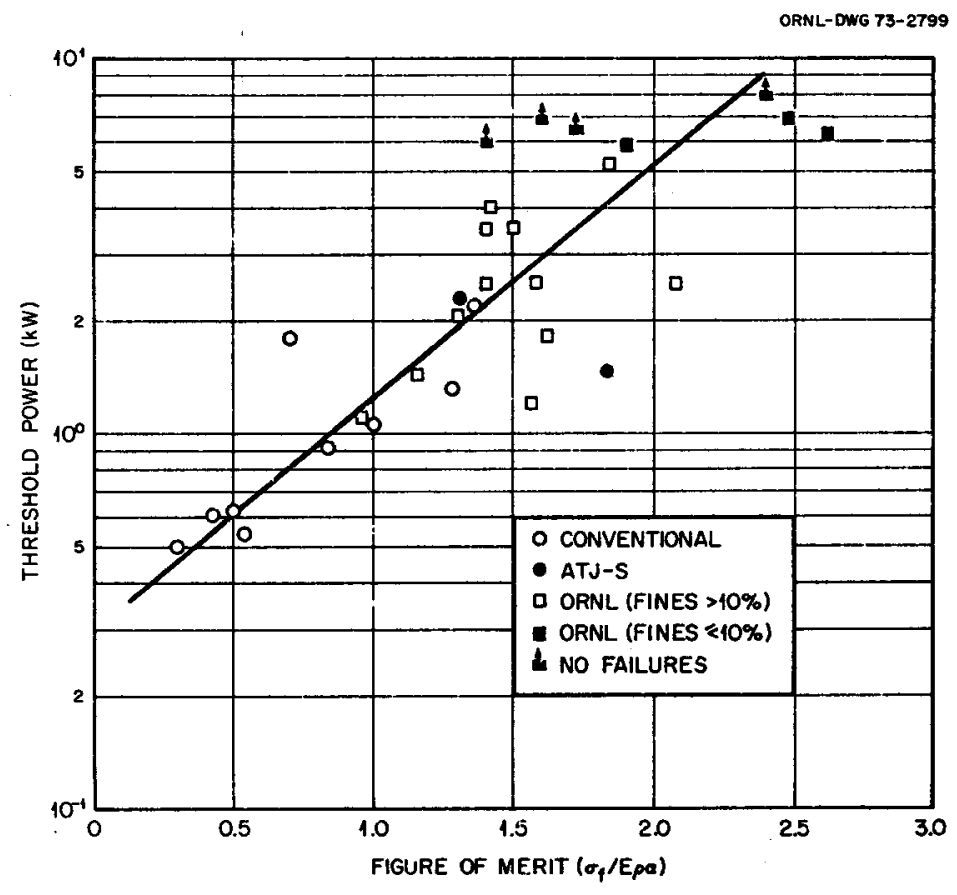

Fig. 26.1. A comparison of the thermal shock resistance for various graphites. 


\title{
27. Metallography
}

\author{
R. J. Gray
}

Metallography requirements for the Metals and Ceramics Division and other ORNL Divisions continue to be the responsibility of General, Radiation, and Electron Metallography Groups. In addition to this general metallography work, we have also continued our efforts to develop and improve metallographic techniques so as to obtain more information from a specimen.

\section{EPITAXIAL FERROMAGNETIC ETCHING}

\section{R. J. Gray}

We have extended our epitaxial ferromagnetic etching techniques $^{1,2}$ to several new systems. A very practical application involving the detection of strain-induced martensite in austenitic stainless steels has been reported. ${ }^{3}$

This technique has been very useful in the microscopic analysis of a type 316 stainless steel weld. A partial drop, about $5 \mu$ l of Ferrofluid, ${ }^{4}$ is added to an electropolshed specimen in a 11/4-in. epoxy resin specimen mount. An ultrasonically cleaned biological No. 0 glass cover slip $(1.0 \times 1.0 \times 0.003-0.004$ in. $)$ is placed on the colloid and carefully pressed against the

1. R. J. Gray, Metals and Ceramics Div. Annu. Progr. Rep. June 30, 1972, ORNL-4820, pp. 163-65.

2. R. J. Gray, "Revealing Ferromagnetic Microstructures with Ferrofluid," Proceedings Fourth Annual Technical Meeting International Microstructural Analysis Society (now the International Metallographic Society), 562 Melody Dr., Northglen, Colorado.

3. R. J.Gray, "The Detection of Strain-Induced Martensite in Types 301 and 304 Stainless Steels by Epitaxial Ferromagnetic Etching,": Advances in Microstructural Analysis, Proceedings of the 5th Annual Meeting of the International Metallographic Society, Elsevier Publishing Co., Inc., New York (to be published).

4. Ferrofluid, water base, 100 G, Ferrofluidics Corp., 144 Middlesex Turnpike, Burlington, Mass. specimen surface. The specimen is placed on the stage of a metallograph and observed in an on-off-controlled magnetic field. A schematic sketch of the mounted specimen on the metallograph stage is shown in Fig. 27.1. The specimen and the $4 \frac{1}{2}$-in.-ID coil are shown in position on the metallograph in Fig. 27.2. A crosssectional view of the chemically etched weld and related microstructures produced only by the epitaxial etching technique are shown in Fig. 27.3. The typical microstructure of the root and second passes [Fig. 27.3(b)] shows cored ferromagnetic $\delta$-ferrite in an austenitic matrix. These two passes were deposited manually, and the subsequent passes were deposited by the weave (oscillation) technique. A particular characteristic of this weave technique is the smaller number of passes required - in this case, seven passes were used in a $1 / 2$-in. plate - as compared with the stringer bead technique, which would have required three times this number of passes. The net result is a greater mass of molten metal, which results in minimum plate distortion in the weld region. The microstructures of the weave passes are shown in Fig. 27.3(c)-(f). A ferromagnetic phase presumed to be martensite is present.

The heterogeneity of the martensitic transformation is clearly defined; some austenite can be seen even in

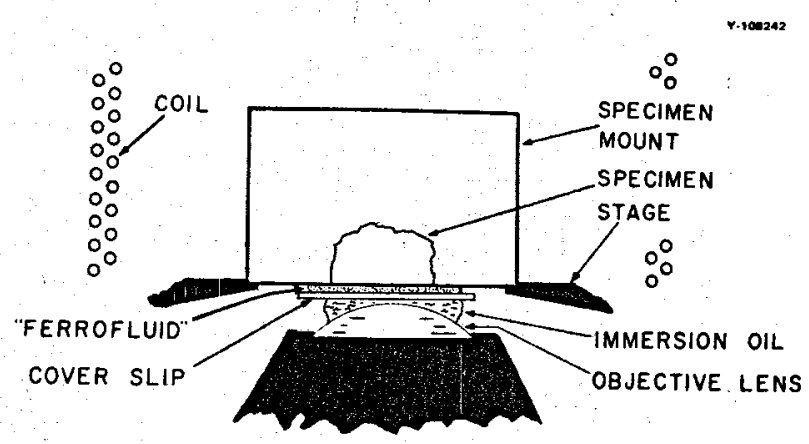

Fig. 27.1. "Magnetic etching" with Ferrofluid. 
Fig. 27.2. Specimen and coil in position on metallograph stage.

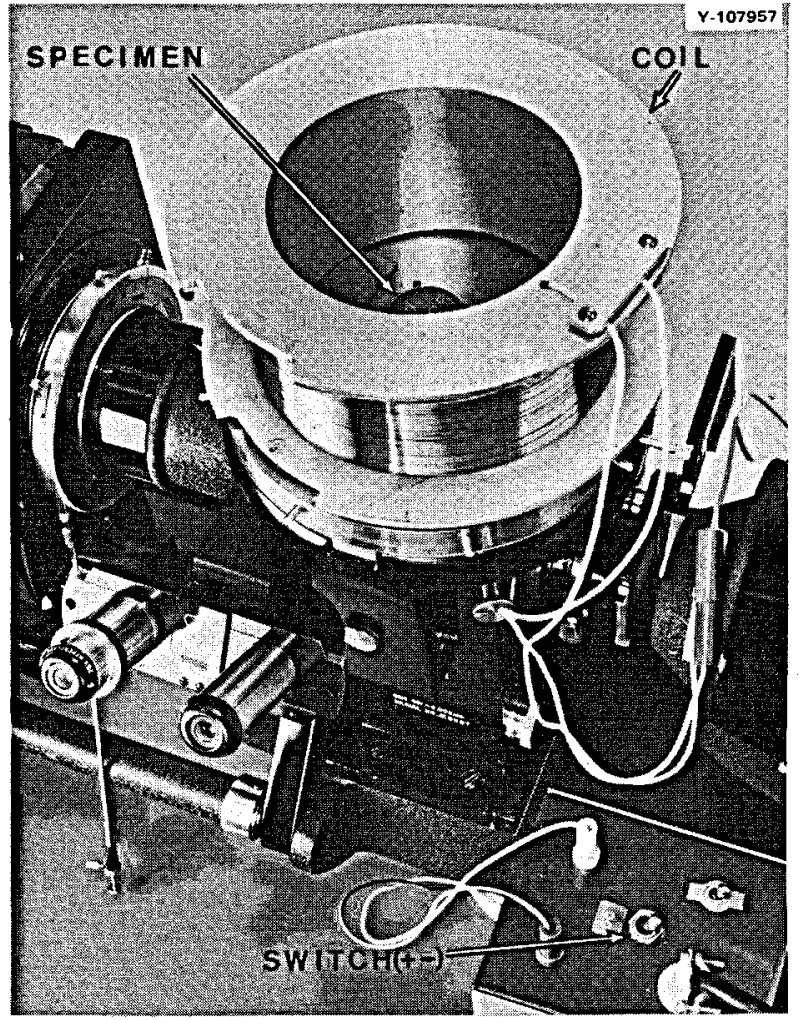

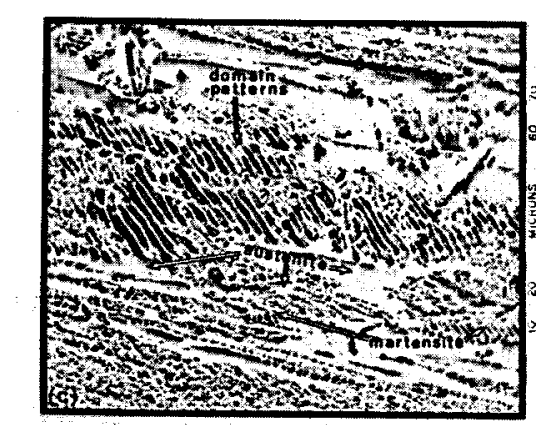
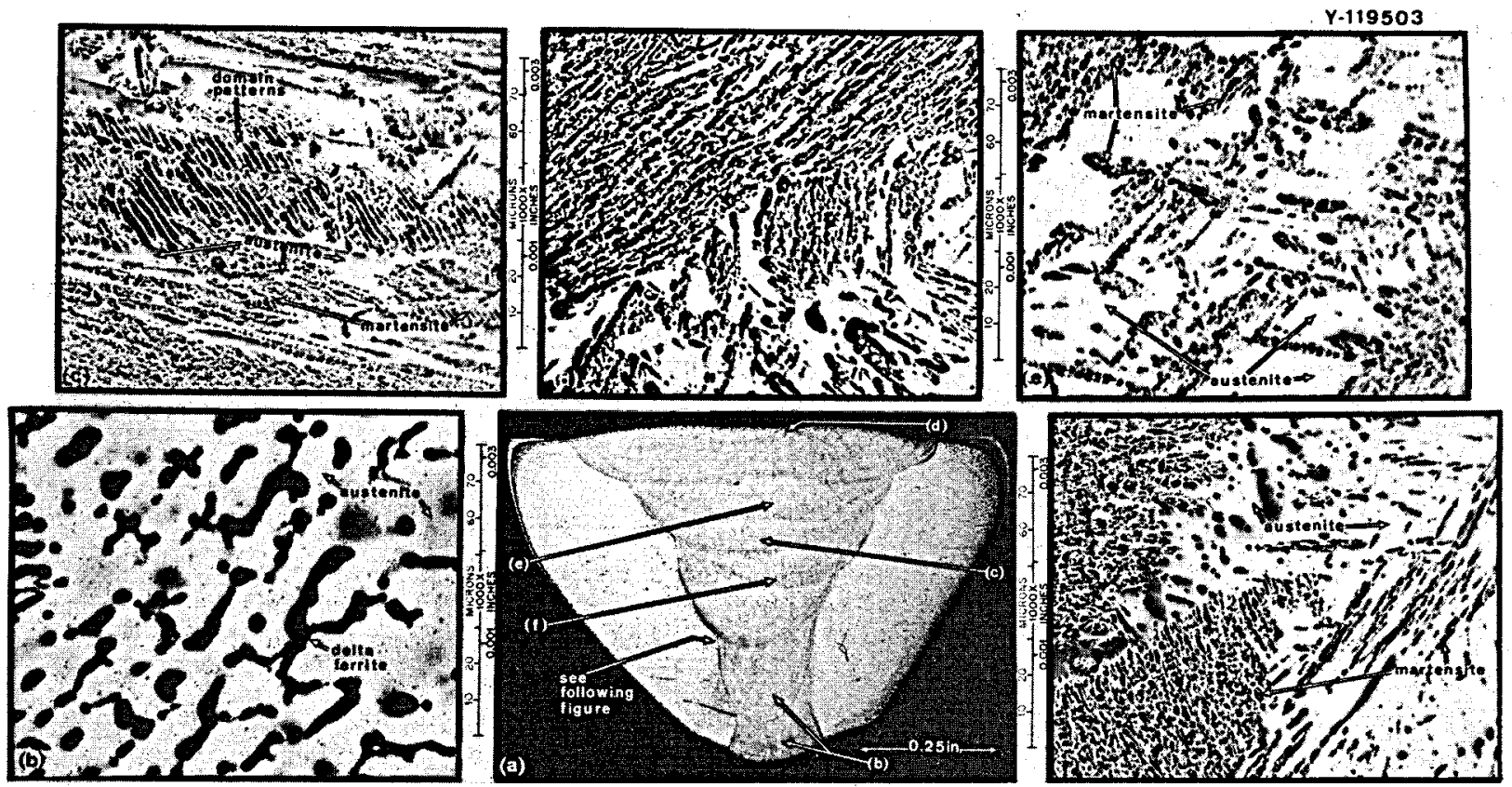

Fig. 27.3. Detection of martensite in $16 \mathrm{Cr}-8 \mathrm{Ni}-2$ Mo weldment by epitaxial ferromagnetic etching. (a) Cross section of the weldment after chemical etching. Photomicrographs $(b-f)$ show microstructures produced by colloid patterns in a magnetic field. The root pass and the second pass $(b)$ were made manually; they contain ferromagnetic $\delta$-ferrite in a paramagnetic austenitic matrix. The third through seventh passes $(c-f)$ were made by weave (oscillation) process; they contain ferromagnetic martensite in a paramagnetic austenitic matrix. Some martensitic areas in the center of the weldment exhibit tempering by the last passes to produce an ordered lattice of tempered martensite, which causes the colloid to form domain patterns $(c)$. 


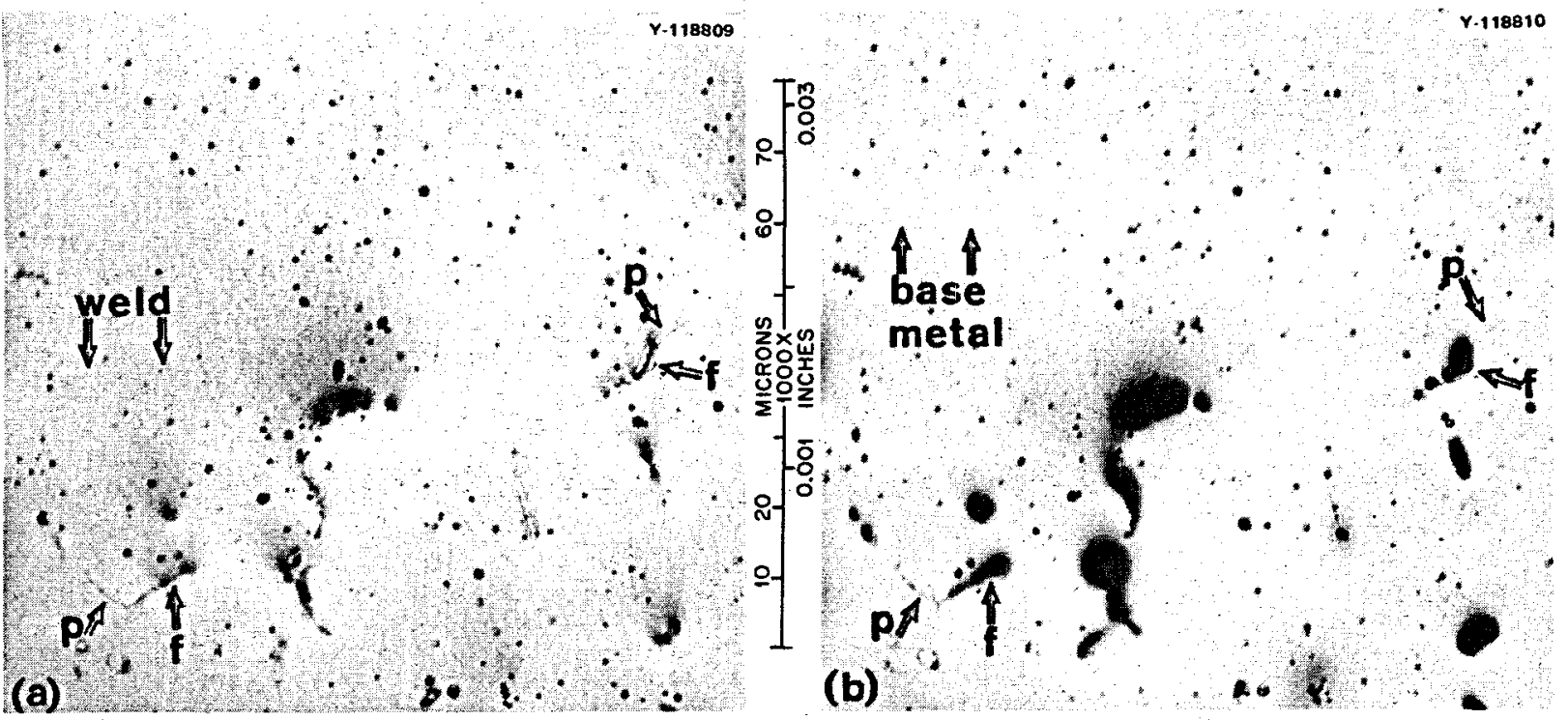

Fig. 27.4. Application of magnetic etching technique to weave-deposited type 316 stainless steel weld at base metal-weld metal interface. Arrows point out portions within the same original phase boundary that are both ferromagnetic (f) and paramagnetic (p). We can assume that the ferromagnetic portion is the original $\delta$-ferrite and the paramagnetic portion is transformed sigma. Regions at the interface displaying this phenomenon are limited. (a) Magnet off. (b) Magnet on.

high-density martensitic areas. Some high-density martensitic areas in the center of the weld show a magnetic domain pattern [Fig. 27.3(c)], seen previously in large areas of $\delta$-ferrite. ${ }^{3}$ This pattern can be attributed to a minimum of crystallographic defects, due probably to the tempering effect of the weave passes. The interface between weld and base metal shows some ferromagnetic $\delta$-ferrite partially transformed to a paramagnetic phase, which may be sigma (Fig. 27.4). This ferrite-to-sigma transformation must have occurred during the latter weave passes. Additional examinations applying the magnetic etching technique will be made of this weld material following (1) liquid nitrogen treatments in an effort to transform more austenite to martensite by cooling below the $M_{s}$ temperature and (2) tensile tests at room temperature and at elevated temperatures. Examinations of this weld material subjected to these conditions will allow us to determine if the magnetic etching technique can differentiate tempered martensite formed by the shearing mechanism directly after solidification of the weld from transformed martensite produced by deformation or a low-temperature transformation. Our etching technique is essential in bringing out the details of the complex microstructure.

\section{CORRELATION OF METALLOGRAPHY AND RADIOGRAPHY TO SHOW DEFECTS IN WELD STRUCTURES}

\section{B. C. Leslie}

We are correlating the results of metallographic and radiographic examinations of defects in aluminum welds. Welding conditions, such as speed of the arc travel and surface preparation, are being varied to produce these defects. An example of this correlation is shown in Fig. 27.5. The photographic print from $x$-ray film shows the defects as white stringers in the dark weld pass. The photograph of the as-welded plate shows outlines marked for cutting the metallographic specimens from typical defect areas found in the radiograph. The transverse and longitudinal sections show these defects as clusters of voids located near the root of the weld. These studies will be useful in the development of acceptance criteria and standards for aluminum welds. 


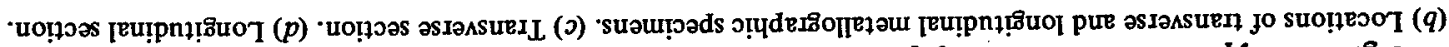

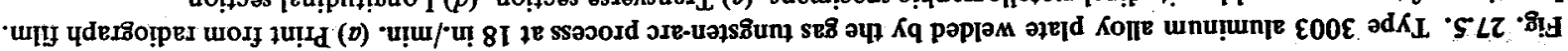
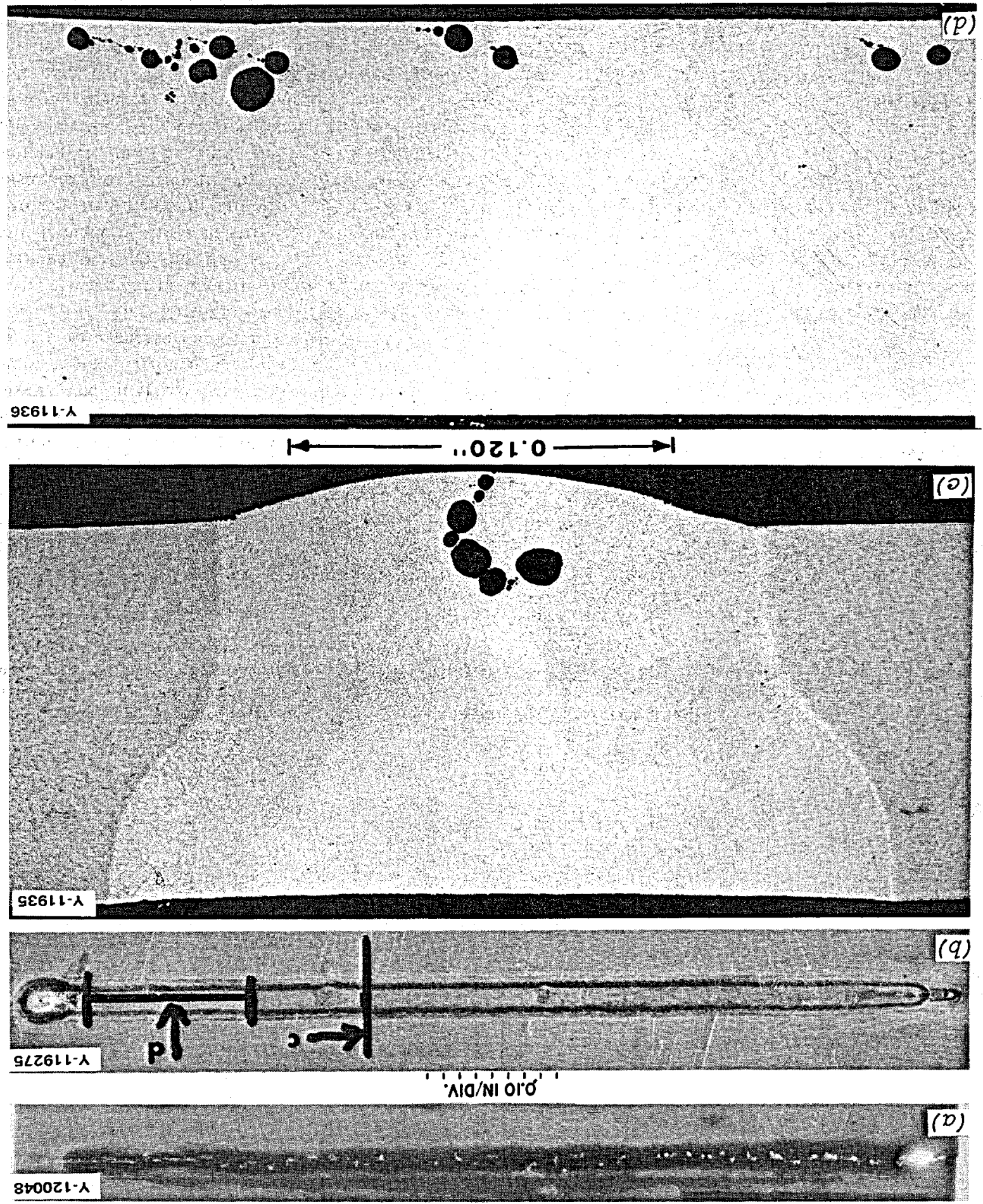


\section{EXAMINATION OF TUNGSTEN-RHENIUM THERMOCOUPLE WIRES}
B. C. Leslie
D. A. Canonico

We have examined metallographically several sections of stainless-steel-sheathed $\mathrm{W}-25 \% \mathrm{Re}$ and $\mathrm{W}-3 \% \operatorname{Re}$ thermocouple wires that failed during testing. The examined wires were of umacceptably poor quality.
Figure 27.6 shows a scanning electron micrograph of a surface flaw on the $\mathrm{W}-25 \% \mathrm{Re}$ archive sample thermocouple wire. Figure $27.6(b)$ shows that this flaw penetrated one-third of the wire diameter. A 48-in. length of archive $\mathrm{W}-25 \% \mathrm{Re}$ wire was examined, and the flaw ran the entire length of the wire. Further examinations are in progress on similar failures of these types of thermocouples. We are also examining some defective Alumel vs Chromel thermocouples.
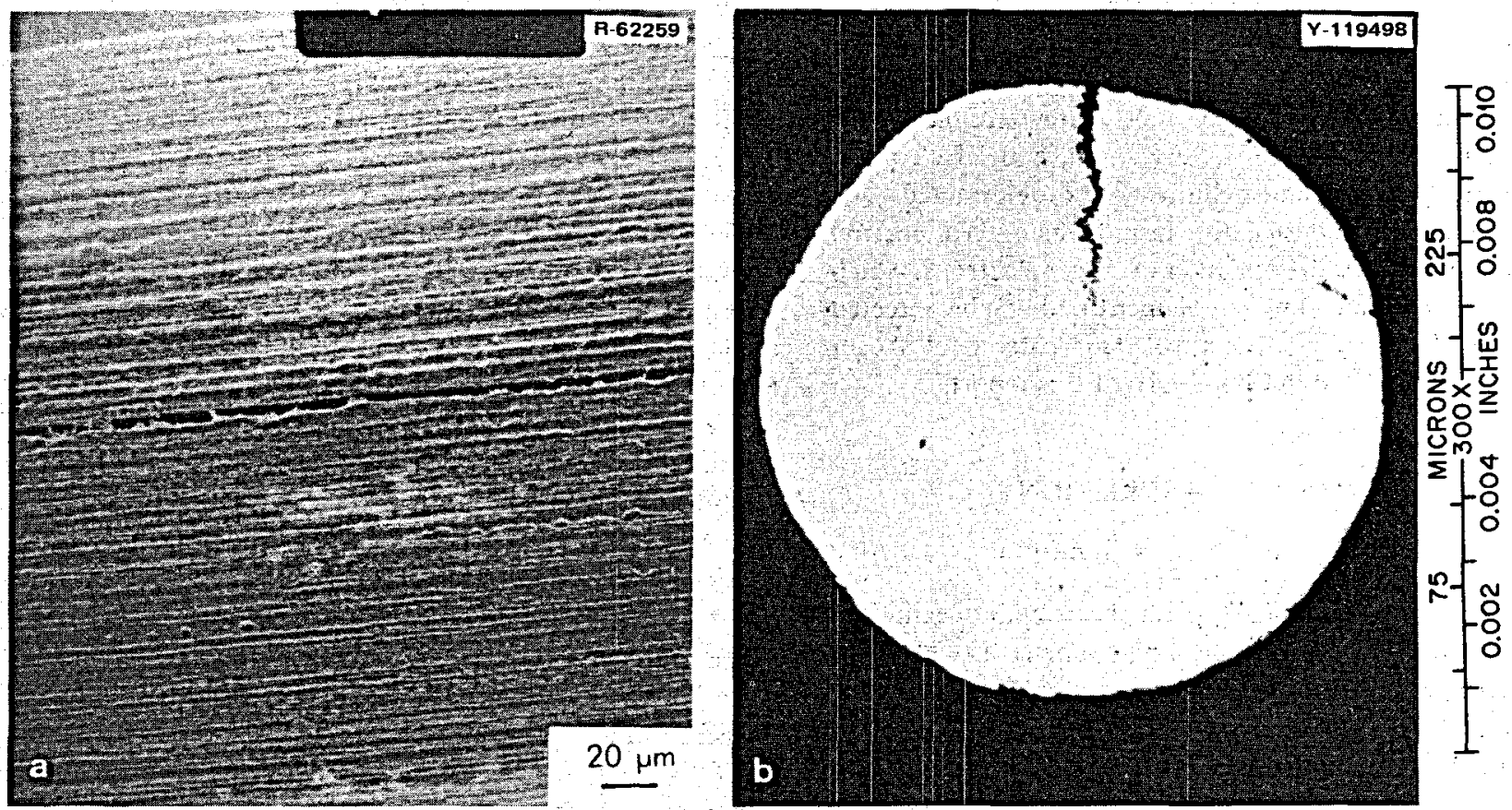

Fig. 27.6. Defect found in W-25\% Re thermocouple wire. (a) Scanning electron micrograph showing surface of wire. (b) Transverse section showing crack. 

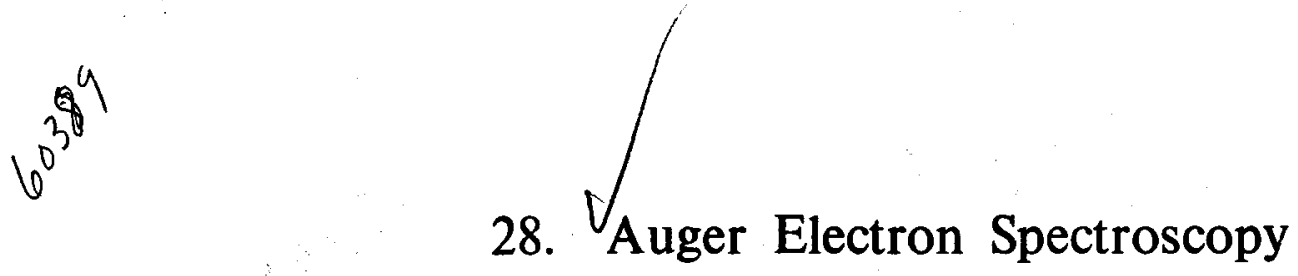

\author{
R. E. Clausing
}

Auger Electron Spectroscopy (AES) is a powerful new tool for surface analysis. The depth of the region analyzed is only one or, at most, a few atomic layers. The speed of analysis is very rapid, and all elements except hydrogen and helium can be determined. The technique is nondestructive in most cases. An electron beam stimulates the emission of Auger electrons, which are characteristic for each element and can be detected by an electron spectrometer.' Our catalog of Auger spectra is reported in Chapter 10 of this report.

\section{FACILITY DESCRIPTION}

\section{R. E. Clausing D. S. Easton}

A surface analysis facility has been built specifically for the study of metallurgical phenomena. The electron spectrometer is a double-pass cylindrical mirror with spherical retarding grids. ${ }^{2}$ The energy resolution is about $0.6 \%$ of the pass energy of the cylindrical mirror (down to about $0.06 \mathrm{eV}$ at $10 \mathrm{eV}$ pass energy). The electron beam used to stimulate Auger electron emission can be provided by either a coaxial electron gun or a grazing incidence electron gun. Electron energies up to $5000 \mathrm{eV}$ are available. The diameter of the electron beam and, therefore, the size of the spot analyzed is about 0.002 in. full width at half maximum under optimum conditions.

Information on the variation of the composition of a sample as a function of depth below the initial surface can be determined by uniform removal of surface layers by sputtering with inert gas ions. Two sputter modes have been provided. The first accommodates up to four sputter guns and can be used during the operation of the analyzer, so it is possible to continuously monitor

1. George J. Dooley III and T. W. Hass, J. Metals 22, 17-24 (November 1970).

2. Physical Electronics Industries model 15-25G. composition as a function of depth. The second sputter mode permits radioactive samples to be sputtered without contaminating other parts of the vacuum and analysis systems. Sputter rates range up to $1000 \AA / \mathrm{hr}$.

The extreme sensitivity of AES to surface composition requires that no unnecessary contamination be permitted. To this end, the system provides a vacuum base pressure below $1 \times 10^{-10}$ torr. The pumps include a liquid-nitrogen-cooled titanium sublimation pump and an Orb-Ion pump.

The sample wheel has 12 positions for samples and standards and may be loaded through an ultrahighvacuum lock without raising the analysis system pressure above $1 \times 10^{-8}$ torr. The sample transfer apparatus can be used to cleave brittle crystals or to break brittle polycrystalline materials by bending or impact. Clean surfaces may also be produced by filing or scribing, using the same motion feedthrough used to transfer samples. The lock also serves as a region where carefully prepared atomically clean surfaces may be exposed to ultrapure gases for oxidizing, nitriding, hydriding, etc. Subsequent examination by AES can be made without contamination.

Apparatus has been included to permit small creep and tensile samples to be fractured in the apparatus under ultrahigh vacuum at temperatures up to $800^{\circ} \mathrm{C}$. The freshly broken surfaces can be analyzed immediately without contamination by air or any other material external to the sample. This is especially useful when grain boundary fractures can be produced, since the exposed surface then represents grain boundary material and can be analyzed with depth resolution approaching one atomic layer. Sputtering can then be used to give composition as a function of distance from the surface initially exposed. Gases released during the rupture of a sample may be detected by a residual gas analyzer. The release of as little as one-tenth of a monolayer of helium spread over $10^{-3} \mathrm{~cm}^{2}$ of fracture surface can be detected. 


\section{APPLICATIONS}
R. E. Clausing
D. S. Easton
G. E. McGuire ${ }^{3}$

This facility has already been used for a wide variety of applied and basic studies. We have studied as short-term applied projects, for example, composite thin films of the type that may be used for solar power plants, the oxide films on tubing removed from a gas cooled reactor system, the corrosion film obtained on Monel in salt water, ${ }^{4}$ the use of AES for quantitative analysis of platinum-rhenium-tungsten alloys, and the impurity distribution of elements segregating to the grain boundaries in a platinum-rhenium-tungsten alloy.

Longer applied investigations include the use of AES to analyze special oxide films grown in a hydrogen permeation study, ${ }^{5}$ the role of tellurium in the surface cracking of Hastelloy $N$ in the MSRE, ${ }^{6}$ the grain boundary composition of type 304 stainless steel

3. Analytical Chemistry Division, Presidential Intern.

4. Report in progress.

5. R. A. Strehlow and H. C. Savage, Permeation of Hydrogen Through Structural Metals, ORNL-4881 (in press).

6. R. E. Clausing, MSR Program Semiannu. Progr. Rep. Aug. 31,1972 , ORNL-4832, pp. 86-90. irradiated in the EBR-II, ${ }^{7}$ the oxygen content and distribution in thin-wall Zircaloy tubing treated so as to simulate the exposure of fuel element cladding during a loss-of-coolant accident in a pressurized water reactor, ${ }^{8}$ and the reactions of lithium metal and lithium hydride with oxygen, hydrogen, air, and nitrogen. 9-11

More basic investigations include an identification of the major events in the Auger spectra from lithium metal, ${ }^{12}$ the role of titanium in altering mechanical and fracture properties of type 316 stainless steel, ${ }^{13}$ and the role of residual elements in weld metal deposits with regard to creep-rupture properties. ${ }^{13}$

7. E. E. Bloom, R. E. Clausing, and G. E. McGuire, Trans. Amer. Nucl. Soc. 16, 96 (1973).

8. Letter reports to J. M. Hendrie from D. B. Trauger, Jan. 30, 1973 and June 27, 1973.

9. C. E. Holcombe, Jr., G. L. Powell, and R. E. Clausing, Surface Sci. 30, 561-72, (1972).

10. R. E. Clausing, D. S. Easton, and G. L. Powell, Surface Sci. 36, 377-79 (1973).

11. Additional reports in preparation.

12. David M. Zehner, R. E. Clausing, G. E. McGuire, and Leslie H. Jenkins, Solid State Communications, in press.

13. Work presently in progress. 


\title{
Presentations at Technical Meetings
}

\author{
Compiled by Brenda J. Johnson
}

27th Annual Calorimetry Conference, Park City, Utah, July 19-22, 1972

J. M. Leitnaker,* "Nuclear Reactor Materials Problems"

Alan Wolfenden,* "The Efficiency of Energy Storage During Plastic Deformation of Metals"

American Association of Crystal Growth-II Meeting, Princeton, N.J., July 30-Aug. 3, 1972

G. W. Clark,* "Eutectic Solidification in Binary and Ternary Metal-Metal Oxide Systems" (invited paper)

IAEA Symposium on the Use of Nuclear Techniques in the Basic Metal Industries, Helsinki, Finland, July 31-Aug. 4,1972

J. P. Hammond,* G. M. Slaughter, and F. B. Gurtner, "Heterogeneity of Fusion Welds Determined by Use of ${ }^{63}$ Ni-Tagged Filler Metal"

III Inter-American Conference on Materials Technology, Rio de Janeiro, Brazil, Aug. 14-17, 1972

John H Frye, Jr., "Radiation Damage in Structural Materials" (presented by J. R. McGuffey, ORNL, Inspection Engineering)

The 13th International Conference on Low Temperature Physics, Boulder, Colo., Aug. 21-25, 1972

C. C. Koch,* W. E. Gardner, and M. J. Mortimer, "The Effects of Some 3d and 4d Solutes on the Superconductivity of Technetium"

D. M. Kroeger, ${ }^{*}$ C. C. Koch, and W. A. Coghlan, "Critical Surface and Bulk Current Densities in the Mixed State of Type-II Superconductors"

Ninth International Congress of Crystallography, Kyoto, Japan, Aug. 26-Sept. 7, 1972

Cullie J. Sparks, Jr.,* "Increased Diffuse X-Ray Scattering from Photoejected Electrons and Fluorescence of Impurities in the Sample"

European Congress for Electron Microscopy, Manchester, England, Sept. 5-12, 1972

K.H.G. Ashbee* and C.K.H. DuBose, "HVEM Studies of the $\mathrm{B}^{10}(\mathrm{n}, \alpha) \mathrm{Li}^{7}$ Reaction in Boron Carbide"

Fourth Annual Conference on Surface Studies, Livermore, Calif., Sept. 6-8, 1972

G. L. Powell,* C. E. Holcombe, R. E. Clausing, and D. S. Easton, "The Surface Structure of Lithium Hydride" American Nuclear Society National Topical Meeting, "Applications of Californium-252," Austin, Texas, Sept. 11-13, 1972

J. E. Van Cleve, Jr., ${ }^{*}$ L. C. Williams, J. B. Knauer, and J. E. Bigelow, "Fabrication of 252 Cf Neutron Sources at Oak Ridge National Laboratory"

*Speaker. 
12th Thermal Conductivity Conference, Birmingham, Ala., Sept. 12-15, 1972

T. G. Godfrey,* D. L. McElroy, and J. P. Moore, "Development of a Powders Radial Heat Flow Apparatus: Measurements on Sodium Chloride and Magnesium Oxide"

T. G. Godfrey,* J. P. Moore, S. H. Jury, and R. S. Graves, "End-Effects on the Transport of Heat, Mass, and Electrical Energy"

J. P. Moore,* R. S. Graves, and D. L. McElroy, "The Absolute Seebeck Coefficient of Platinum from 80 to 340 $\mathrm{K}$ and Thermal and Electrical Conductivities of Lead from 80 to $400 \mathrm{~K}$ "

J. P. Moore, * R. K. Williams, D. L. McElroy, and R. S. Graves, "Lattice Thermal Conductivity of RbBr, RbI and $\mathrm{RbCl}$ from 80 to $400 \mathrm{~K}$ "

Point Defects and Their Aggregates in Metals, Sussex, England, Sept. 18-20, 1972

R. W. Hendricks* and J. E. Epperson, "Small-Angle X-Ray Diffraction Studies of Radiation-Induced Voids in Aluminum"

Fifth International Microstructural Analysis Society, Regency Hyatt House, Chicago, Ill., Sept. 19-21, 1972

R. S. Crouse* and T. J. Henson, "Beam Scanning System Modification for a Shielded Microprobe"

R. J. Gray,* "The Detection of Strain-Induced Martensite in Types 304 and 301 Stainless Steels by Epitaxial Ferromagnetic Etching"

R. J. Gray,* "An Observation on the Position of Metallography in the Examination and Development of Prosthetic Appliances"

Joint Sectional Meeting of the Basic Science and Nuclear Division of the American Ceramic Society, Philadelphia, Pa., Sept. 24-27, 1972

C. B. Pollock* and M. D. Silverman, "Resin-Based Fuels for HTGR's. Part I - Carbonization and Heat Treatment Studies"

Fall Meeting of the Electrochemical Society, Miami Beach, Fla., Oct. 8-13, 1972

R. E. Pawel* and J. J. Campbell, "The Ignition of Ta-Base Alloys During Gaseous Oxidation"

Fall Meeting of the Metallurgical Society of AIME, Cleveland, Ohio, Oct. 16-19, 1972

P. T. Carlson* and D. Heitkamp, "Thermotransport of Cadmium and Thallium in Sodium and Potassium Chlorides"

1972 Materials Engineering Congress, Cleveland Convention Center, Cleveland, Ohio, Oct. 16-19, 1972

D. A. Canonico and F. J. Witt,* "Effect of Section Size on Fracture Behavior"

Robin Williams, "Quantitative Presentation of Sheet Textures"

National Conference of the American Society for Nondestructive Testing, Cleveland, Ohio, Oct. 16-19, 1972

K. V. Cook, R. W. McClung,* R. T. King, and G. A. Reimann, "Significance of Small Flaws in Tubing"

C. V. Dodd,* J. H. Smith, and W. A. Simpson, "Eddy Current Evaluation of Nuclear Control Rods"

T. S. Lundy* and R. E. Pawel, "Relevance of Tracer Diffusion Experiments to Problems in Nuclear Systems"

British Nuclear Energy Society European Conference on Irradiation Embrittlement and Creep in Fuel Cladding and Core Components, London, England, Nov. 9-10, 1972

E. E. Bloom, * "Correlation of Structure and Ductility of Irradiated Austenitic Stainless Steels"

D. Fahr, E. E. Bloom,* and J. O. Stiegler, "Postirradiation Tensile Properties of Annealed and Cold-Worked Type 316 Stainless Steel" 
American Nuclear Society International Conference on Nuclear Solutions to World Energy Problems, Washington, D.C., Nov. 12-17, 1972

C. R. Brooks* and J. E. Spruiell, "Microstructural Characterization of Deformed Type 316 Austenitic Stainless Steel"

G. L. Copeland* and R. G. Donnelly, "Evaluation of Fast Reactor Irradiated Boron Carbide Pellets"

D. E. Ferguson* and A. L. Lotts, "Fast Reactor Fuel Processing"

R. T. King,* G. M. Goodwin, and J. O. Steigler, "Properties of Thick Stainless-Steel-Shielded Metal-Arc Weldments"

R. L. Klueh," "The Effect of Carbon on the Mechanical Properties of $2 \frac{1}{4} \% \mathrm{Cr}-1 \%$ Mo Steel"

R. L. Kluech,* "The Effect of Oxygen on the Corrosion of Niobium and Tantalum by Liquid Lithium"

R. L. Shepard,* R. B. Fitts, H. E. Robertson, and R. F. Hyland, "Thermoelectric, Resistance, and Ultrasonic Centerline Thermometry for a (U,Pu) $\mathrm{O}_{2}$ Fuel Pin"

J. E. Spruiell* and R. E. Gehlbach, "An X-Ray Technique for Phase Analysis in Austenitic Stainless Steel"

R. D. Waddell, Jr.," and W. R. Martin, "Sensitivity of Elevated Temperature Mechanical Properties of Type 304 Stainless Steel Heat-to-Heat Variations"

18th American Welding Society Midwest Welding Conference, Madison, Wis., Nov. 14-15, 1972

D. A. Canonico, " "Brazing for High-Temperature Applications"

Third Trace Metals Symposium, University of Illinois, Urbana-Champaign, Ill., Nov. 21, 1972

C. J. Sparks, Jr., and L. A. Harris, "Development of High Sensitivity X-Ray Fluorescence for Analysis of Toxic Heavy Elements"

ASME-ASTM Committee Gas Turbine Panel Workshop Session Dealing with Trace Elements in Superalloys, New York, N.Y., Nov. 28, 1972

R. E. Gehlbach* and H. E. McCoy, "Effects of Tellurium on Cracking in Nickel-Base Alloys"

International Symposium on Applications of Quantum Mechanics, Sanibel, Fla., Jan. 24, 1973

W. H. Butler,* J. M. Lloyd, and E. Underwood, "Density of States Expressed as a Continued Fraction of Matrices: Application to Disordered Systems"

San Diego, California, Meeting of the American Physical Society, Mar. 19-22, 1973

J. S. Faulkner,* "KKR Band Structure Calculations for Complex Crystals"

G. S. Painter,* "Electronic States of Multilayer Graphite"

W. H. Butler,* "Self-Consistent Cluster Theories of Disordered Alloys"

Symposium on the Characterization of Corrosion Products, National Association of Corrosion Engineers Annual Meeting, Anaheim, Calif., Mar. 19-23, 1973

H. S. Isaacs, "Chemical and Kinetic Factors in Localized Corrosion" (presented by J. W. Koger)

J. W. Koger, * "Corrosion Product Deposition in Molten Fluoride Salt Systems"

American Nuclear Society Topical Meetıng on Light Water Reactor Safety, Salt Lake City, Utah, Mar. 26-28, 1973

D. O. Hobson,* "Ductile-Brittle Behavior of Zircaloy Fuel Cladding"

54th Annual Meeting of the American Welding Society, Chicago, Ill., Apr. 2-6, 1973

D. A. Canonico* and G. M. Slaughter, "Brazing Stainless Steels to Refractory Metals"

D. A. Canonico* and G. M. Slaughter, "Weldability of Niobium-Stabilized $2 \frac{11}{4} \mathrm{Cr}-1$ Mo Steel" 
N. C. Cole* and G. M. Slaughter, "Development of Unique Techniques for Brazing a Large Molybdenum Test Stand"

J. P. Hammond, F. B. Gurtner, and G. M. Slaughter, "Use of Radioisotopes to Study Heterogeneity of Arc Welds" (presented by A. J. Moorhead)

J. W. Koger, "Braze Alloy Compatibility with $\mathrm{NaBF}_{4}-\mathrm{NaF}$ (92-8 mole \%) at $610^{\circ} \mathrm{C}$ " (presented by N. C. Cole)

A. J. Moorhead* and G. M. Slaughter, "Recent Developments in the Welding of Molybdenum"

C. H. Wodtke* and W. A. Plunkett, "Remote Underwater Plasma-Arc Cutting"

The Fifth Annual Biomaterials Symposium, Clemson University, Clemson, S.C., Apr. 14-18, 1973

R. J. Gray,* "Metallographic Examinations of Retrieved Intramedullary Bone Pins and Bone Screws from the Human Body"

American Society for Metals, Southern Metals Conference, Atlanta, Ga., Apr. 18-20, 1973

R. S. Crouse," "Metallographic Tools and Techniques"

R. J. Gray,* "Metallographic Examinations of Implants from the Human Body"

J. W. Koger," "Alloys for Use in Molten Fluoride Salt Environments"

H. E. McCoy* and B. McNabb, "Evaluation of Alloys for Use in Molten-Salt Steam Generators"

C. B. Pollock,* J. L. Scott, W. P. Eatherly, R. L. Hamner, J M Robbins, D. M. Hewette II, and J. H. Coobs, “A Review of Ceramic Materials for High-Temperature Gas-Cooled Reactor Applications"

J. D. Sease," "High-Temperature Gas-Cooled Reactors and Their Fuel Cycle"

American Ceramic Society Spring Meeting, Cincinnati, Ohio, Apr. 29-May 3, 1973

R. A. Bradley* and J. D. Sease, "The Fabrication of HTGR Fuel Sticks"

W. J. Lackey, * W. H. Pechin, and J. D. Sease, "Remote Coating of HTGR Fuel Particles"

A. L. Lotts, , J. H. Coobs, and P. R. Kasten, "The Relationship of Fuels and Materials Development to the Economic and Environmental Impact of High-Temperature Gas-Cooled Reactors"

C. B. Pollock and M. D. Silverman, "Carbonization and Heat Treatment of Fuel Particles from Ion Exchange Resins" (presented by W. H. Cook)

American Chemical Society, Division of Polymer Chemistry, Detroit, Mich., May 1-4, 1973

M. D. Silverman* and C. B. Pollock, "Resin Fuel Particles for High-Temperature Gas-Cooled Reactors"

Spring Meeting of the American Institute of Mining, Metallurgical, and Petroleum Engineers, Philadelphia, Pa., May 29-June 1, 1973

R. W. Carpenter, "Grain Boundary Fracture in BCC Alloys at Low Temperature"

G. W. Clark" and J.C. Wilson, "Growth of Ternary Metal-Metal Oxide Eutectics"

W. A. Coghlan,* "Diffusion of Vacancies Near Faulted Dislocation Loops in Aluminum"

A. Wolfenden and M. H. Yoo,* "Electron Irradiation Damage in Titanium"

M. H. Yoo,* "Equilibrium Shape of a Prismatic Dislocation Loop"

Eleventh Biennial Conference on Carbon, Gatlinburg, Tenn., June 3-8, 1973

R. A. Bradley* and J. D. Sease, "The Slug Injection Process for Fabricating HTGR Fuel Rods"

R. L. Beatty* and D. B. Fischbach, "Graphitization Kinetics of Fluidized-Bed Pyrolytic Carbons"

E. S. Bomar* and W. P. Eatherly, "Optical Reflectivity of a Graphite Single Crystal"

J. H. Coobs," C. B. Pollock, W. P. Eatherly, and J M Robbins, "Irradiation Stability of Carbon Coatings on HTGR Fuel Particles" 
R. L. Hamner,* J M Robbins, and J. H. Coobs, "Development of Continuous-Matrix Fuel Rods for Advanced High-Temperature Gas-Cooled Reactors"

C. R. Kennedy* and W. P. Eatherly, "Development of Graphites for Resistance to Irradiation Damage"

C. R. Kennedy* and W. P. Eatherly, "The Development of Thermal Shock Resistant Graphite”

C. R. Kennedy, " "Irradiation of Graphite at $950^{\circ} \mathrm{C}$ "

G. H. Kenner, W. S. Williams, and W. P. Eatherly, "First Biocompatibility Tests of ORNL Graphite"

W. J. Lackey,* W. H. Pechin, and J. D. Sease, "Remote Coating of HTGR Fuel Particles"

C. B. Pollock and W. H. Cook,* "The Preparation and Characterization of Pyrolytic Carbon Sealants for Graphite in Power Reactors"

J M Robbins, W. P. Eatherly," and D. E. Rosson, "Fabrication of Graphite for Use as a Skeletal Prosthesis"

M. D. Silverman* and C. B. Pollock, "Resin Fuel Particles for High-Temperature Gas-Cooled Reactors"

The Seventh International Conference on Nondestructive Testing, Warsaw, Poland, June 4-8, 1973

K. V. Cook, R. W. McClung, and H. L. Whaley, "Advances in Electrodischarge Machining of Reference Flaws" (round table discussion)

C. V. Dodd, W. E. Deeds, and M. C. Mcllwain, "Eddy-Current Measurements of Thickness of High-Temperature Coatings" (rapporteur - Frederick Förster, Reutlingen, Germany)

B. E. Foster, R. W. McClung, and S. D. Snyder, "Enhanced Radiographic Viewing Via Television" (rapporteur W. Hartl)

19th Annual Meeting of the American Nuclear Society, Chicago, Ill., June 10-15, 1973

E. E. Bloom,* R. E. Clausing, and G. E. McGuire, "Auger Spectroscopy of Fracture Surfaces of Irradiated Stainless Steel"

R. W. McClung,* B. E. Foster, K. V. Cook, and C. V. Dodd, "Nondestructive Testing for Steam Generators"

International Conference on Stress Corrosion Cracking and Hydrogen Embrittlement of Iron Base Alloys, National Association of Corrosion Engineers, Firminy, France, June 10-16, 1973

H. S. Isaacs, " Electrochemistry of Simulated Stress-Corrosion Cracks"

7th Annual Conference on Trace Substances in Environmental Health, University of Missouri, Columbia, Mo., June $12-14,1973$

C. J. Sparks, Jr.,* O. B. Cavin, L. A. Harris, and J. C. Ogle, "Simple, Quantitative X-Ray Fluorescent Analysis for Trace Elements"

The Storrs Meeting of the American Crystallographic Association, Storrs, Conn., June 17-22, 1973

Bernard Borie," "Thermally Excited Forbidden Reflections"

L. B. Shaffer," "Optimum Camera Parameters for the Kratky Small Angle X-Ray Collimation Geometry for a Non-Fully Illuminated Entrance Slit" 


\title{
Publications
}

\author{
Compiled by Meredith R. Hill
}

Ashbee, K. H. G., “Water Damage in Glass Fiber/Polyester Resin Composites," pp. 1205-22 in Electron Microscopy and Structure of Materials (Proc. 5th Int. Materials Symp., Berkeley, Sept. 13-17, 1971), ed. by Gareth Thomas, R. M. Fulrath, and R. M. Fisher, University of California Press, Berkeley, 1972.

Beatty, R. L., and D. B. Fischbach, "Graphitization Kinetics of Fluidized-Bed Pyrolytic Carbons," pp. 30-31 in IIth Bienn. Conf. Carbon, Gatlinburg, Tenn., June 4-8, 1973, CONF-730601.

Beaver, R. J., and A. E. Richt, "Boron Concentration Gradient for Improved Thermal Reactor Performance of Boron-Stainless Steel Control Rods," Nucl. Technol 16(1): 187-96 (October 1972); also ORNL-4877 (May 1973).

Bloom, E. E., J. O. Stiegler, and C. J. McHargue, "Radiation Damage in Annealed Type 304 Stainless Steel," Radiat. Eff. 14(3-4): 231-43 (July 1972); also ORNL-TM-3732 (September 1972).

Bloom, E. E., and J. O. Stiegler, Postirradiation Mechanical Properties of Types 304 and $304+0.15 \%$ Ti Stainless Steels, ORNL-TM-3733 (July 1972); also Nucl. Technol. 17(1): 24-37 (January 1973).

Bloom, E. E., and J. R. Weir, Jr., "Effect of Neutron Irradiation on the Ductility of Austenitic Stainless Steel," Nucl. Technol. 16(1): 45-54 (October 1972).

Bloom, E. E., R. E. Clausing, and G. E. McGuire, “Auger Spectroscopy of Fracture Surfaces of Irradiated Stainless Steel," (Summary) Trans. Amer. Nucl. Soc. 16(TANSAO 16): 96 (June 1973).

Boatner, L. A., R. W. Reynolds, C. B. Finch, and M. M. Abraham, "Electron Paramagnetic Resonance of ${ }^{249} \mathrm{Bk}^{4+}$ in $\mathrm{ThO}_{2}$ Single Crystals," Phys. Lett. A 42(1): 93-94 (Nov. 6, 1972).

Bomar, E. S., and W. P. Eatherly, "Optical Reflectivity of a Graphite Single Crystal," pp. 163-64 in 11th Bienn. Conf. Carbon, Gatlinburg, Tenn. June 4-8, 1973, CONF-730601.

Bourgette, D. T., Effect of Aging Time and Temperature on the Impact and Tensile Behavior of L-605 - A Cobalt-Base Alloy, ORNL-TM-3734 (April 1973).

Bradley, R. A., and J. D. Sease, "The Slug Injection Process for Fabricating HTGR Fuel Rods," pp. 239-40 in 11th Bienn. Conf. Carbon, Gatlinburg, Tenn., June 4-8, 1973, CONF-730601.

Braunstein, J., G. Mamantov, and G. P. Smith, eds., Advances in Molten Salt Chemistry,, Vol. 2, Plenum Press, New York, 1973.

Brooks, C. R., and J. E. Spruiell, "Microstructural Characterization of Deformed Type 316 Austenitic Stainless Steel," (Summary) Trans. Amer. Nucl. Soc. 15(2): 771 (November 1972).

Brunton, G. D., L. A. Harris, and O. C. Kopp, "Crystal Structure of a Rubidium Iron Feldspar," Amer. Mineral. 57(11-12): 1720-28 (November-December 1972).

Butler, W. H., and A. T. Fromhold, Jr., "Charged Impurity Drift and Dispersion in Discrete Media," Solid State Commun. 12(9): 919-22 (May 1973).

Chandler, J. M., The Peach Bottom Spent Fuel Element Shipping Cask Accident December 8, 1971, ORNL-TM-3844 (July 1972). 
Chandler, T. L., and C.K.H. DuBose, "Electron Microscopy Specimen Preparation in a Hot Cell," pp. 128-31 in Proc. 19th Conf. Remote Systems Technol., American Nuclear Society, Hinsdale, Illinois, 1971.

Clark, G. W., C. B. Finch, L. A. Harris, and H. L. Yakel, "Epitaxial Growth of $\mathrm{LiLnMo}_{2} \mathrm{O}_{8}$ on Single Crystals of $\mathrm{Ln}_{2} \mathrm{GeMoO}_{8}, " J$. Cryst. Growth 16(2): 110-14 (November 1972).

Claudson, T. T., E. E. Sinclair, B.R.T. Frost, A. Boltax, H. Pearlman, C. N. Spalaris, and J. R. Weir, Jr., "Fundamental Behavior of Structural Materials in Fast Reactor Environments," pp. 459-77 in Peaceful Uses At. Energy, Proc. Int. Conf., 4th, 1971, Vol. 10, United Nations, New York, and International Atomic Energy Agency, Vienna, 1972.

Clausing, R. E., D. S. Easton, and G. L. Powell, “Auger Spectra of Lithium Metal and Lithium Oxide," Surface Sci. 36(1): 377-79 (April 1973).

Coghlan, W. A., and R. E. Clausing, "A Description of a Catalog of Calculated Auger Transitions for the Elements," Surface Sci. 33(2): 411-13 (November 1972).

Coghlan, W. A., and R. E. Clausing, "A Catalog of Calculated Auger Transitions for the Elements," J. Vac. Sci. Technol. 10(1): 325 (January-February 1973).

Coghlan, W. A., and R. E. Clausing, "Auger Catalog. Calculated Transition Energies Listed by Energy and Element," At. Data 5(4): 317-469 (June 1973).

Coobs, J. H., W. P. Eatherly, C. B. Pollock, and J M Robbins, "Irradiation Stability of Carbon Coatings on HTGR Fuel Particles," pp. 249-51 in 11th Bienn. Conf. Carbon, Gatlinburg, Tenn. June 4-8, 1973, CONF-730601.

Coobs, J. H., J. L. Scott, B. H. Montgomery, J M Robbins, C. B. Pollock, and J. A. Conlin, Irradiation Performance in HFIR Experiment HRB-2 of HTGR Fuel Sticks Bonded with Reference and Advanced Matrix Materials, ORNL-TM-3988 (January 1973).

Copeland, G. L., and R. G. Donnelly, "Evaluation of Fast-Reactor-Irradiated Boron Carbide Pellets," (Summary) Trans. Amer. Nucl. Soc. 15(2): 740-42 (November 1972).

Copeland, G. L., R. G. Donnelly, and W. R. Martin, "Irradiation Behavior of Boron Carbide," Nucl. Technol. 16(1): 226-37 (October 1972).

Copeland, G. L., and R. G. Donnelly, Postirradiation Evaluation of Boron Carbide from EBR-II Higher Worth Control Rod, ORNL-TM-4182 (June 1973).

Cuneo, D. R., E. L. Long, Jr., A. Jostsons, and T. N. Washburn, Examination of Irradiated Uranium Nitride Fuel Clad with Tungsten-Rhenium or T-111 Alloy, ORNL-TM-3895 (October 1972).

De Luca, J. P., and J. M. Leitnaker, "Review of Thermodynamic Properties of the Cr-N System," J. Amer. Ceram. Soc. 56(3): 126-33 (March 1973).

DeVan, J. H., T. M. Kegley, Jr., and A. R. Irvine, Investigation of the Causes of Failure of Tubes in a Simulated LMFBR Fuel Subassembly, ORNL-TM-3981 (October 1972).

DiStefano, J. R., and A. J. Moorehead, Development and Construction of a Molybdenum Test Stand, ORNL-4874 (December 1972).

DiStefano, J. R., "Compatibility of Strontium Compounds with Superalloys at 900 and $1100^{\circ} \mathrm{C}$," Nucl. Technol. 17(2): 127-42 (February 1973).

Dodd, C. V., and W. A. Simpson, Jr., "Thickness Measurements Using Eddy-Current Techniques," Mater. Eval. 31(5): 73-79 (May 1973).

Dodd, C. V., and C. C. Lu, "Nondestructive Test for Measuring the State of Heat Treatment in Closure Welds," Mater. Eval. 30(8): 142-45 and 147-48 (July 1972).

Dodd, C. V., C. C. Cheng, J. H. Smith, and W. A. Simpson, The Analysis of Reflection Type Coils for Eddy-Current Testing, ORNL-TM-4107 (April 1973).

Dodd, C. V., C. C. Cheng, C. W. Nestor, Jr., and R. B. Hofstra, Design of Induction Probes for Measurement of Level of Liquid Metals, ORNL-TM-4175 (May 1973). 
Donnelly, R. G., and A. C. Schaffhauser, Space Power Materials Development Quart. Progr. Rep. Sept. 30, 1972, ORNL-TM-4057.

Donnelly, R. G., Isotopic Power Materials Development Progress Report for September 1972, ORNL-TM-4008.

Donnelly, R. G., Space Power Materials Development Quart. Prog. Rep. Dec. 31, 1972, ORNL-TM-4165.

Donnelly, R. G., Isotopic Power Materials Development Progress Report for October 1972, ORNL-TM-4044.

Donnelly, R. G., Isotopic Power Materials Development Progress Report for November 1972, ORNL-TM-4070.

Donnelly, R. G., Isotopic Power Materials Development Progress Report for December 1972, ORNL-TM-4092.

Donnelly, R. G., Isotopic Power Materials Development Progress Report for January 1973, ORNL-TM-41 26.

Donnelly, R. G., Isotopic Power Materials Development Progress Report for February 1973, ORNL-TM-4192.

Donnelly, R. G., Isotopic Power Materials Development Progress Report for March 1973, ORNL-TM-4237.

Donnelly, R. G., Isotopic Power Materials Development Progress Report for April 1973, ORNL-TM-4263.

Engle, G. B., and W. P. Eatherly, "Irradiation Behavior of Graphite at High Temperature (A Review)," High Temperatures - High Pressures 4(2): 119-58 (1972).

Evans, E. A., E. E. Kintner, E. L. Zebroski, L. A. Neimark, and C. M. Cox, "The Status of Engineering Design and Irradiation Testing of the Stainless Clad-Mixed Oxide Fuel System for Fast Breeder Reactors," pp. 53-67 in Peaceful Uses At. Energy, Proc. Int. Conf., 4th, 1971, Vol. 10, United Nations, New York, and International Atomic Energy Agency, Vienna, 1972.

Farrell, K., and R. T. King, "Radiation-Induced Strengthening and Intergranular Fracture in Aluminum," Met. Trans. 4(5): 1223-31 (May 1973).

Farrell, K., R. T. King, and A. Jostsons, Examination of the Irradiated 6061 Aluminum HFIR Target Holder, ORNL-TM-4139 (May 1973).

Farrell, K., E. L. Long, Jr., R. T. King, and A. Jostsons, Postirradiation Examination and Testing of the ORR $N_{F}$ Tray, ORNL-TM-4183 (June 1973).

Ferguson, D. E., and A. L. Lotts, "Fast Reactor Fuel Processing," (Summary) Trans. Amer. Nucl. Soc. 15(2): 597-98 (November 1972); complete article pp. 148-66 in Proc. 1972 Int. Conf. Nuclear Solutions to World Energy Problems (Washington, D.C., Nov. 13-17, 1972), American Nuclear Society, Hinsdale, Illinois, 1973.

Ferguson, D. E., and A. L. Lotts, "Fuel Cycle - Discussion," pp. 172-73 in Proc. 1972 Int. Conf. Nuclear Solutions to World Energy Problems (Washington, D.C., Nov. 13-17, 1972), American Nuclear Society, Hinsdale, Illinois, 1973.

Finch, C. B., and G. W. Clark, "Several Optical Properties of Single-Crystal CaWO 4 Doped with 0.1 to 1.8 Atom Per Cent $\mathrm{Am}^{3+}$,"J. Phys. Chem. Solids 34(5): 922-24 (May 1973).

Fitts, R. B., J. L. Miller, Jr., and E. L. Long, Jr., "Observations on Tungsten-Rhenium Thermocouples Used In-Reactor in (U,Pu) ${ }_{2}$ Fuel Pins," pp. 1951-58 in Temperature, Its Measurement and Control in Science and Industry, Vol. 4, H. A. Plumb, Editor in Chief, Part 3, “Thermocouples, Biology and Medicine, Geophysics and Space," ed. by D. 1. Finch, G. W. Burns, R. L. Berger, and T. E. Vanzandb, Instrument Society of America, Pittsburg, 1972.

Fitts, R. B., B. Fleischer, and R. L. Senn, Fuel-Cladding Interaction and Gas Pressure Buildup in a Shortened FTR Type Fuel Pin, ORNL-4875 (June 1973).

Foster, B. E., S. D. Snyder, and R. W. McClung, Radiographic Examination of Stressed Rock Specimens, ORNL-TM-4005 (January 1973).

Frye, J. H, Jr., J. E. Cunningham, and staff, Metals and Cermamics Div. Annu. Progr. Rep. June 30, 1972, ORNL-4820.

Frye, J. H, Jr., J. O. Betterton, Jr., and D. S. Easton, "Thermodynamic Properties of Zirconium-Cadmium and Certain Other Solid Solutions," Acta Met. 20(10): 1183-95 (October 1972). 
Frye, J. H, Jr., and C. J. McHargue, "Radiation Damage in Structural Materials," pp. 211-20 in III Interamer. Conf. Materials Technology, (August 14-17, 1972, Rio de Janeiro, Brasil), Centro Regional de Ayuda Tecnica, Mexico/Buenos Aires, 1972.

Goodwin, G. M., N. C. Cole, and G. M. Slaughter, "A Study of Ferrite Morphology in Austenitic Stainless Steel Weldments," Weld. J. (Miami) 51(9): 425-s-429-s (September 1972).

Gray, R. J., "Revealing Ferromagnetic Microstructures with Ferrofluid," pp. 141-60 in Proc. Annu. Tech. Meet. Int. Microstruct. Anal. Soc. 4th, 1971, International Microstructural Analysis Society, Inc., Northglenn, Colorado, 1972.

Gray, R. J., Metallographic Examinations of Retrieved Intramedullary Bone Pins and Bone Screws from the Human Body, ORNL-TM-4068 (February 1973).

Guthrie, P. V., Jr., An X-Ray Diffraction and Transmission Electron Microscopy Study of Recovery and Recrystallization in Columbium and Columbium-40 Vanadium, ORNL-TM-3882 (August 1972). Ph.D. Thesis, University of Cincinnati, June 1971.

Hammond, J. P., G. M. Slaughter, and F. B. Gurtner, "Heterogeneity of Fusion Welds Determined by Use of ${ }^{63}$ Ni-Tagged Filler Metal," pp. 369-403 in Nuclear Techniques in the Basic Metal Industries (Proc. Symp. Helsinki, 31 July-4 August 1972), International Atomic Energy Agency, Vienna, March 1973.

Hammond, J. P., P. Patriarca, G. M. Slaughter, and W. A. Maxwell, "Corrosion of Incoloy 800 and Nickel Base Alloy Weldments in Steam," Weld. J. (Miami) 52(6): 268-s-280-s (June 1973).

Hamner, R. L., J M Robbins, and J. H. Coobs, "Development of Continuous-Matrix Fuel Rods for Advanced High-Temperature Gas-Cooled Reactors," pp. 259-60 in 11th Bienn. Conf. Carbon, Gatlinburg, Tenn, June 4-8, 1973, CONF-730601.

Harris, L. A., and C. B. Finch, "Phase Stability in the $\mathrm{ThGeO}_{4}$ System in the Range $750-1450^{\circ} \mathrm{C}$ at $1 \mathrm{~atm}$," Amer. Mineral. 57(11-12): 1894-98 (November-December 1972).

Harris, L. A., H. L. Yakel, and C. S. Yust, "Formation of an Fe-Pt Carbide from Fe Carbonyl in CO Gas," J. Amer. Ceram Soc. 56(4): 220 (April 1973).

Hendricks, J. W., N. C. Cole, and G. M. Slaughter, "Compatibility of Brazed Joints with Potassium and Vacuum," Weld. J. (Miami) 51(7): 329-s-336-s (July 1972).

Hendricks, R. W., "The Role of Soller Slits in Small-Angle Scattering Collimation Systems," J. Appl. Cryst. 5(Pt. 4): 302-4 (July 1972).

Hendricks, R. W., "The Gas Amplification Factor in Xenon Filled Proportional Counters," Nucl. Instrum. Methods 102(2): 309-12 (July 15, 1972).

Hendricks, R. W., "A Unified Theory of Absolute Intensity Measurements in Small-Angle X-Ray Scattering," $J$. Appl. Cryst. 5(Pt. 5): 315-24 (October 1972).

Hendricks, R. W., and P. W. Schmidt, "Comments on "Calculation of Weighting Functions for Collimation Corrections in Small-Angle X-Ray Scattering," " Acta Phys. Austr. 37(1-2): 20-30 (January 1973).

Hendricks, R. W., "A Pulse-Matching Method for Estimating the Gas Amplification Factor in Proportional Counters," Nucl. Instrum. Methods 106(3): 579-88 (March 1973).

Hendricks, R. W., J. T. De Lorenzo, F. M. Glass, and R. E. Zedler, "An Incident-Beam Ionization Chamber and Charge Integration System for Stabilization of X-Ray Diffraction Experiments," J. Appl. Cryst. 6(Pt. 2): 129-32 (April 1973).

Hobson, D. O., "Ductile-Brittle Behavior of Zircaloy Fuel Cladding," pp. 274-88 in Topical Meeting on Water-Reactor Safety March 26-28, 1973, CONF-730304.

Holcombe, C. E., Jr., G. L. Powell, and R. E. Clausing, "Low-Energy Electron Diffraction and Auger Emission Spectroscopy Studies of Lithium Hydride (100) Surface," Surface Sci. 30(3): 561-72 (May 1972).

Homan, F. J., "Performance Modeling of Neutron Absorbers," Nucl. Technol. 16(1): 216-25 (October 1972). 
Homan, F. J., W. J. Lackey, and C. M. Cox, FMODEL - A FORTRAN IV Computer Code to Predict In-Reactor Behavior in LMFBR Fuel Pins, ORNL-4825 (January 1973).

Homan, F. J., "A Parametric Analysis' of Fuel-Cladding Mechanical Interactions," pp. 209-22 in Proc. First Int. Conf. Structural Mechanics in Reactor Technology, Berlin, Germany, 20-24 September 1971, Vol. 2, Part C, Commission of the European Communities, Center for Information and Documentation, Luxembourg, 1972.

Inouye, H., C. T. Liu, and R. G. Donnelly, New Platinum-Rhodium-Tungsten Alloys for Space Isotopic Heat Sources, ORNL-4813 (September 1972).

Inouye, H., and R. L. Wagner, "Effect of Low-Pressure Oxygen on the Creep Properties of W-25 Pct Re," Met. Trans. 3(7): 1743-48 (July 1972).

Jostsons, A., and C.K.H. DuBose, "Microstructure of Boron Carbide after Fast Neutron Irradiation," J. Nucl. Mater. 44(1): 91-95 (July 1972).

Jostsons, A., and K. Farrell, "Structural Damage and Its Annealing Response in Neutron Irradiated Magnesium," Radiat. Eff. 15(3-4): 217-25 (August 1972).

Jostsons, A., and E. L. Long, Jr., "Radiation Damage and the Effects of Postirradiation Annealing in 1100 Grade Aluminum," Radiat. Eff. 16(1-2): 83-94 (September 1972).

Kennedy, C. R., and W. P. Eatherly, "The Development of Thermal Shock Resistant Graphite," pp. 131-32 in 11th Bienn. Conf. Carbon, Gatlinburg, Tenn., June 4-8, 1973, CONF-730601.

Kennedy, C. R., and W. P. Eatherly, "Development of Graphites for Resistance to Irradiation Damage," pp. 304-5 in 11th Bienn. Conf., Carbon, Gatlinburg, Tenn., June 4-8, 1973, CONF-730601.

Kennedy, C. R., "Irradiation of Graphite," pp. 312-13 in 11th Bienn. Conf. Carbon, Gatlinburg, Tenn., June 4-8, 1973, CONF-730601.

King, R. T., G. M. Goodwin, and J. O. Stiegler, "Properties of Thick Stainless-Steel-Shielded Metal-Arc Weldments," (Summary) Trans. Amer. Nucl. Soc. 15(2): 775-76 (November 1972).

King, R. T., G. M. Goodwin, and J. O. Stiegler, Creep Properties of a Type 308 Stainless Steel Pressure Vessel Weld with Controlled Residual Elements, ORNL-TM-4131 (May 1973).

Klint, K. K., and D. A. Canonico, Evaluation of Discontinuities in HSST Twelve-Inch-Thick Plate, ORNL-TM-4155 (June 1973).

Klueh, R. L., "The Effect of Oxygen on Tantalum-Sodium Compatibility," Met. Trans. 3(8): 2145-50 (August 1972).

Klueh, R. L., "Effect of Oxygen on the Compatibility of Tantalum and Potassium," Corrosion 28(10): 360-67 (October 1972).

Klueh, R. L., "The Effect of Oxygen on the Corrosion of Niobium and Tantalum by Liquid Lithium," (Summary) Trans. Amer. Nuch Soc. 15(2): 746-47 (November 1972); complete report in ORNL-TM-4069 (March 1973).

Klueh, R. L., "The Effect of Carbon on the Mechanical Properties of $2 \frac{11 / 4}{\%} \mathrm{Cr}-1 \%$ Mo Steel," (Summary) Trans. Amer. Nucl. Soc. 15(2): 769 (November 1972).

Klueh, R. L., and J. H. DeVan, "The Effect of Oxygen in Static Sodium on Vanadium and Vanadium Alloys: I. Unalloyed Vanadium, Vanadium-Chromium, and Vanadium-Molybdenum Alloys," J. Less-Common Metals 30(1): 9-24 (January 1973).

Klueh, R. L., and J. H. DeVan, "The Effect of Oxygen in Static Sodium on Vanadium and Vanadium Alloys: II. Alloys Containing Titanium and Zirconium,"J. Less-Common Metals 30(1): 25-37 (January 1973).

Knight, R. W., and A. E. Richt, "Evaluation of Absorber Materials Performance in HFIR Control Cylinders," Nucl. Technol. 15(3): 384-90 (September 1972):

Koger, J. W., Valve Failure in the ORNL Fuel Failure Mockup Liquid Metal Facility, ORNL-TM-3725 (August 1972). 
Koger, J. W., Corrosion and Mass Transfer Characteristics of $\mathrm{NaBF}_{4}-\mathrm{NaF}$ (92-8 mole \%) in Hastelloy $\mathrm{N}$, ORNL-TM-3866 (October 1972).

Koger, J. W., Corrosion of Type 304L Stainless Steel and Hastelloy $N$ by Mixtures of Boron Trifluoride, Air, and Argon, ORNL-TM-4172 (December 1972).

Koger, J. W., Effect of $\mathrm{FeF}_{2}$ Addition on Mass Transfer in a Hastelloy $\mathrm{N}-\mathrm{LiF}_{-} \mathrm{BeF} \mathrm{F}_{2}-\mathrm{UF}_{4}$ Thermal Convection Loop, ORNL-TM-4188 (December 1972).

Koger, J. W., Evaluation of Hastelloy $N$ Alloys After Nine Years Exposure to Both a Molten Fluoride Salt and Air at Temperatures from 700 to $560^{\circ} \mathrm{C}$, ORNL-TM-4189 (December 1972).

Koger, J. W., A Forced-Circulation Loop for Corrosion Studies: Hastelloy N Compatibility with $\mathrm{NaBF}_{4}-\mathrm{NaF}$ (92-8 mole \%), ORNL-TM-4221 (December 1972).

Koger, J. W., Compatibility of Brazing Alloys and the Molten Salt $\mathrm{NaBF}_{4}-8$ mole $\% \mathrm{NaF}$ at $610^{\circ} \mathrm{C}$, ORNL-TM-4272 (December 1972).

Koger, J. W., Alloy Compatibility with $\mathrm{LiF}_{-\mathrm{BeF}}$ Salts Containing $\mathrm{ThF}_{4}$ and $U F_{4}$, ORNL-TM-4286 (December 1972).

Koger, J. W., "Fluoride Salt Corrosion and Mass Transfer in High-Temperature Dynamic Systems," Corrosion 29(3): 115-22 (March 1973).

Kolbe, W., N. Edelstein, C. B. Finch, and M. M. Abraham, "Zero-Field Splittings in $\mathrm{Cm}^{3+}$ and $\mathrm{Am}^{2+}$ in Fluorite Type Crystals," J. Chem. Phys. 56(11): 5432-33 (June 1972).

Kolbe, W., N. Edelstein, C. B. Finch, and M. M. Abraham, "Zero-Field Splittings of $\mathrm{Gd}^{3+}$ and $\mathrm{Cm}^{3+}$ in $\mathrm{CeO}_{2}$ and $\mathrm{ThO}_{2}$, , J. Chem. Phys. 58(2): 820-21 (15 January 1973).

Kollie, T. G., D. L. McElroy, R. K. Adams, and J. M. Jansen, "Measurement Accuracy of a Computer-Operated Data-Acquisition System," pp. 1457-66 in Temperature, Its Measurement and Control in Science and Industry, Vol. 4, H. A. Plumb, Editor in Chief, Part 2, "Resistance, Electronic and Magnetic Thermometry, Controls and Calibration Bridges," ed. by L. G. Robin, A. C. Anderson, J. E. Janssen, and R. D. Curkosky, Instrument Society of America, Pittsburg, 1972.

Kollie, T. G., J. P. Moore, D. L. McElroy, H. L. Whaley, R. K. Williams, T. G. Godfrey, W. M. Ewing, and R. S. Graves, Thermophysical Properties of Uranium Based Mo, Nb, Zr, Ti Alloys from 77 to $1500 \mathrm{~K}$, ORNL-TM-4253 (June 1973).

Kroeger, D. M., C. C. Koch, and W. A. Coghlan, "Measurement of Critical Bulk and Surface Current Densities in Type-II Superconductors in Mixed State,"J. Appl. Phys. 44(5): 2391-96 (May 1973).

Lackey, W. J., F. J. Homan, and A. R. Olsen, Porosity and Actinide Redistribution During Irradiation of $(U, P u) O_{2}$, ORNL-TM-3762 (August 1972); also Nucl. Technol. 16(1): 120-42 (October 1972).

Lackey, W. J., W. H. Pechin, and J. D. Sease, "Remote Coating of HTGR Fuel Particles," pp. 254-56 in 11th Bienn. Conf. Carbon, Gatlinburg, Tenn., June 4-6, 1973, CONF-730601.

Leitnaker, J. M., and K. E. Spear, "Elimination of $\mathrm{CO}_{2}$ and $\mathrm{H}_{2} \mathrm{O}$ as Oxygen Transport Species in Mixed Oxide Fuel Pins," J. Nucl. Mater. 45: 195-200 (1972/73).

Lindemer, T. B., "Kinetics of the $\mathrm{UO}_{2}-\mathrm{C}-\mathrm{N}_{2}$ Reaction at $1700^{\circ} \mathrm{C}$," J. Amer. Ceram. Soc. 55(12): 601-5 (December 1972).

Liu, C. T., H. Inouye, and R. W. Carpenter, Mechanical Properties and Structure of Oxygen-Doped Tantalum-Base Alloys, ORNL-4839 (December 1972).

Loh, B.T.M., and C. T. Liu, "Reply to Comment on Some Calculations of Vacancy Characteristics in Substitutional Alloys," Scripta Met. 6(7): 565-66 (July 1972).

Loh, B.T.M., "Nucleation of Voids in Solids Containing Excess Vacancies, Interstitials, and Helium Atoms," Acta Met. 20(11): 1305-11 (November 1972).

Loh, B.T.M., and C. T. Liu, "Nearest Neighbor Pair Models for Solutions,” Scripta Met. 7(3): 281-88 (March 1973). 
Lotts, A. L., T. N. Washburn, L. Geller, H. H. Klepfer, and W. H. Layman, "Status of Thermal Reactor Fuel Manufacture in the United States," pp. 201-14 in Peaceful Uses At. Energy, Proc. Int. Conf., 4th, 1971, Vol. 8, United Nations, New York, and International Atomic Energy Agency, Vienna, 1972.

Lubinsky, A. R., D. E. Ellis, and G. S. Painter, "First Principles Calculation of the Optical Absorption in Diamond," Phys. Rev. B 6(10): 3950-56 (November 1972).

Lundy, T. S., R. A. Padgett, and M. D. Banus, "Cation Self Diffusion in Titanium Monoxide," Met. Trans. 4(4): 1179-80 (April 1973).

March, N. H., P. Gibbs, G. M. Stocks, and J. S. Faulkner, "Copper-Zinc Alloys as Treated by Virtual Crystal and Related Approximations," J. Phys. (Paris) Colloq. 33: C3-259-C3-267 (May-June 1972).

Marples, J.A.C., and C. C. Koch, "A Low Temperature X-Ray Investigation of Technetium and the Tc-Mo A-15 Compound," Phys. Lett. 41A(4): 307-8 (Oct. 9, 1972).

Martin, M. M., A. E. Richt, and W. R. Martin, Irradiation Behavior of Aluminum-Base Fuel Dispersions, ORNL-4856 (May 1973).

McClung, R. W., "Use of Nondestructive Testing in the U.S.A. During Fabrication and Surveillance of Pressure Tubes," pp. 79-86; "Nondestructive Testing of Irradiated Fuel Elements in the U.S.A.," pp. 155-67; "On Nondestructive Examination of Nuclear Fuel Pellets in the U.S.A.," pp. 427-31; and "On Nondestructive Testing in the U.S.A. of Prestressed Concrete Pressure Vessels for Nuclear Reactors," pp. 527-40 in Non-Destructive Testing for Reactor Core Components and Pressure Vessels (Report of an IAEA Panel, Vienna, 29 November-3 December 1971), IAEA-145, International Atomic Energy Agency, Vienna, 1972.

McClung, R. W., B. E. Foster, K. V. Cook, and C. V. Dodd, "Nondestructive Testing for Steam Generators," (Summary) Trans. Amer. Nucl. Soc. 16(TANSAO 16): 84 (June 1973).

McCoy, H. E., and B. McNabb, Intergranular Cracking of INOR-8 in the MSRE, ORNL-4829 (November 1972).

McCoy, H. E., Influence of Various Alloying Additions on the Strength of Nickel-Base Alloys, ORNL-TM-4173 (December 1972).

McCoy, H. E., and B. McNabb, Postirradiation Examination of Materials from the MSRE, ORNL-TM-4174 (December 1972).

McHargue, C. J., Fusion Technology Studies Progr. Rep. Dec. 31, 1972, ORNL-TM-4156.

Moore, J. P., and R. S. Graves, "The Absolute Seebeck Coefficient of Platinum from 80 to $340 \mathrm{~K}$ and Thermal and Electrical Conductivities of Lead from 80 to 400 K," J. Appl. Phys. 44(3): 1174-78 (March 1973).

Morgan, C. S., "Material Transport by Dislocation Motion in Sintering," Phys. Sintering 5(1): 31-40 (January 1973).

Morgan, C. S., K. H. McCorkle, and G. L. Powell, "Sintering and Desintering of Thoria," pp. 293-99 in Materials Science Research (3rd Int. Conf. Sintering and Related Phenomena), Vol. 6, ed. by G. C. Kuczynski, Plenum, New York, 1973.

Nickel, B. G., and W. H. Butler, "Problems in Strong-Scattering Binary Alloys," Phys. Rev. Lett. 30(9): 373-77 (February 1973).

Painter, G. S., "A Combined Korringa-Kohn-Rostaker-Discrete Variational Method for the Electronic Structure of Crystals and Molecules with General Potentials," Phys. Rev. B 7(8): 3520-26 (April 1973).

Paptheodorou, G. N., and G. P. Smith, "Electronic Absorption Spectra of Platinum(II) Centers in Liquid Alkali Metal Chlorides," J. Inorg. Nucl. Chem 35(3): 799-807 (March 1973).

Patriarca, P., Fuels and Materials Development Program Quart. Progr. Rep. June 30, 1972, ORNL-TM-3969.

Patriarca, P., Fuels and Materials Development Program Quart. Progr. Rep. Sept. 30, 1972, ORNL-TM-4055.

Patriarca, P., Fuels and Materials Development Program Quart. Progr. Rep. Dec. 31, 1972, ORNL-TM-4105.

Patriarca, P., Fuels and Materials Development Program Quart. Progr. Rep. Mar. 31, 1973, ORNL-TM-4250. 
Pechin, W. H., R. A. Bradley, W. J. Lackey, and J. D. Sease, "Analysis of $(\mathrm{U}, \mathrm{Pu}) \mathrm{O}_{2}$ Fuels at Oak Ridge National Laboratory," pp. 279-94 in Analytical Methods in the Nuclear Fuel Cycle (Symp. in Vienna 29 November-3 December 1971), International Atomic Energy Agency, Vienna, 1972.

Peterson, S., Thorium Ceramics Data Manual, Volume IV - Borides; Volume V - Sulfides, ORNL-4503 (November 1972).

Pollock, C. B., and W. H. Cook, "The Preparation and Characterization of Pyrolytic Carbon Sealants for Graphite in Power Reactors," pp. 286-87 in 11th Bienn. Conf. Carbon, Gatlinburg, Tenn., June 4-6, 1973, CONF-730601.

Prados, J. W., and H. C. Roland, "Analysis of Spherical Coatings on Nuclear Fuel Particles," pp. 317-28 in Proc. Conf. Continuum Aspects of Graphite Design, Nov. 9-12, 1970, Gatlinburg, Tennessee, CONF-701105 (February 1972).

Predmore, R. E., R. J. Arsenault, and C. J. Sparks, Jr., "Local Atomic Arrangements in Ta-Mo and Ta-Nb B.C.C. Alloys," pp. 155-67 in X-Ray Study on Strength and Deformation of Metals (Proc. Semin. X-Ray Study on Strength and Deformation of Metals, Tokyo, Aug. 23-24, 1971), The Society of Materials Science, Tokyo, Japan, 1971.

Predmore, R. E., R. J. Arsenault, and C. J. Sparks, Jr., "Strengthening and Fracture of Ta, Nb, Mo and W Binary Solid Solutions with Short Range Order," pp. 18-30 in Mechanical Behavior of Materials (Proc. Int. Conf. Mechanical Behavior of Materials, Kyoto, Aug. 15-20, 1971), Vol. 1, The Society of Materials Science, Kyoto, Japan, 1972.

Roake, W. E., C. E. Weber, D. H. Wiese, C. S. Caldwell, I. D. Thomas, J. L. Scott, and A. B. Shuck, "The United States Program for Developing the Manufacture of High-Quality Fast Reactor Fuels," pp. 311-25 in Peaceful Uses At. Energy, Proc. Int. Conf., 4th, 1971, Vol. 8, United Nations, New York, and International Atomic Energy Agency, Vienna, 1972.

Robbins, J M, W. P. Eatherly, and D. E. Rosson, "Fabrication of Graphite for Use as a Skeletal Prosthesis," p. 123 in 11th Bienn. Conf. Carbon, Gatlinburg, Tenn., June 4-6, 1973, CONF-730601.

Rosenthal, M. W., E. S. Bettis, R. B. Briggs, W. R. Grimes, P. N. Haubenreich, H. E. McCoy, and L. E. McNeese, "Advances in the Development of Molten-Salt Breeder Reactors," pp. 225-37 in Peaceful Uses At. Energy. Proc. Int. Conf., 4th, 1971, Vol. 5, United Nations, New York, and International Atomic Energy Agency, Vienna, 1972.

Salmon, R., J. T. Roberts, A. L. Lotts, T. N. Washburn, and W. H. McVey, "Price Forecasting and Resource Utilization for the Fuel-Cycle Industry of the United States of America," pp. 255-65 in Peaceful Uses At. Energy, Proc. Int. Conf., 4th, 1971, Vol. 4, United Nations, New York, and International Atomic Energy Agency, Vienna, 1972.

Sass, S. L., and Bernard Borie, "The Symmetry of the Structure of the Omega Phase in $\mathrm{Zr}$ and Alloys," J. Appl. Cryst. 5(Part 3): 236-38 (June 1972).

Shepard, R. L., R. B. Fitts, H. E. Robertson, and R. F. Hyland, "Thermoelectric, Resistance, and Ultrasonic Centerline Thermometry for a (U,Pu)O $\mathrm{O}_{2}$ Fuel Pin," (Summary) Trans. Amer. Nucl. Soc. 15(2): 766-67 (November 1972).

Shewmon, P. G., G. W. Cunningham, C. E. Dickerman, D. P. Hines, F. J. Homan, G. A. Last, and P. Murray, "Analytical Methods to Design and Predict Performance of Fast Reactor Fuel Elements," pp. 123-39 in Peaceful Uses At. Energy, Proc. Int. Conf., 4th, 1971, Vol. 10, United Nations, New York, and International Atomic Energy Agency, Vienna, 1972.

Silverman, M. D., and C. B. Pollock, "Resin Fuel Particles for High-Temperature Gas-Cooled Reactors," pp. 245-46 in 11th Bienn. Conf. Carbon, Gatlinburg, Tenn., June 4-6, 1973, CONF-730601.

Sinha, K. K., and J. P. Hammond, "Dispersion Hardening in Molybdenum and Its Evaluation by Hot-Hardness Test," pp. 445-59 in Symposium on Materials Science Research (High Temperature Materials), (Hyderabad, India, Feb. 21-23, 1972), CONF-720223. 
Slaughter, G. M., D. A. Canonico, and R. G. Donnelly, "Welding and Brazing of Advanced Refractory Alloys," SAMPE Quart. 3(4): 17-21 (July 1972).

Sparks, C. J., Jr., and D. A. Gedcke, "Rapid Recording of Powder Diffraction Patterns with Si(Li) X-Ray Energy Analysis System: W and Cu Targets and Error Analysis," pp. 240-53 in Advances in X-Ray Analysis, Vol. 15, ed. by K. F. Heinrich, C. S. Barrett, J. B. Newkirk, and C. O. Ruud, Plenum, New York, 1972.

Spruiell, J. E., and R. E. Gehlbach, "An X-Ray Technique for Phase Analysis in Austenitic Stainless Steel," (Summary) Trans. Amer. Nucl. Soc. 15(2): 769-70 (November 1972).

Stelzman, W. J., and R. G. Berggren, Radiation Strengthening and Embrittlement in Heavy-Section Steel Plates and Welds, ORNL-4871 (June 1973).

Stephenson, R. L., "Creep-Rupture Properties of SU-16 and Their Response to Heat Treatment," SAMPE J. 8(6): 21-23 (October-November 1972).

Stewart, H. B., R. C. Dahlbert, W. V. Goeddel, D. B. Trauger, P. R. Kasten, and A. L. Lotts, "Utilization of the Thorium Cycle in the HTGR," pp. 433-47 in Peaceful Uses At. Energy, Proc. Int. Conf., 4th, 1971, Vol. 4, United Nations, New York, and International Atomic Energy Agency, Vienna, 1972.

Stocks, G. M., G. D. Gaspari, and B. L. Gyorffy, "Pressure Induced Superconductivity in Cesium," J. Phys. F: Metal Phys. 2: L123-28 (November 1972).

Tennery, V. J., and T. G. Godfrey, "Oxidation Properties of $(\mathrm{U}, \mathrm{Pu}) \mathrm{O}_{2}$ Solid Solutions," J. Amer. Ceram. Soc. 56(3): 129-33 (March 1973).

Vandermeer, R. A., "The Behavior of Grain Boundaries During Recrystallization of Dilute Aluminum-Gold Alloys," pp. 285-327 in Nature and Behavior of Grain Boundaries (Fall Meet. AIME, Detroit, Oct. 18-21, 1971), ed. by Hsun Hu, Plenum, New York, 1972.

Waddell, R. D., Jr., and W. R. Martin, "Sensitivity of Elevated-Temperature Mechanical Properties of Type 304 Stainless Steel to Heat-to-Heat Variations," (Summary) Trans. Amer. Nucl. Soc. 15(2): 737 (November 1972).

Wiffen, F. W., "The Tensile Properties of Fast Reactor Neutron Irradiated BCC Metals and Alloys," pp. 176-97 in Defects and Defect Clusters in B.C.C. Metals and Their Alloys, Nucl. Met. 18, ed. by R. J. Arsenault, National Bureau of Standards, Gaithersburg, Maryland, 1973.

Williams, R. O., A Computer Program for the Reduction of Diffuse X-Ray Data from Solid Solutions, ORNL-4828 (October 1972).

Williams, R. O., "The Application of Atomic Potentials to the Heat of Mixing, the Lattice Parameter and the Compressibility of Random Cubic Solutions," Acta Met. 20(12): 1381-85 (December 1972).

Williams, R. O., "Deformation of Nonrandom Solid Solutions and the Calculations of Magnetic Anisotropy," Scripta Met. 7(1): 121-22 (January 1973).

Wolfenden, A., "Electron Radiation Damage Near the Threshold Energy in Aluminum," Radiat. Eff. 14(3-4): 225-29 (June 1972).

Wolfenden, A., "High Fluence Neutron Irradiation Damage in Copper-10 wt \% Aluminum and Copper," Radiat. Eff. 15(3-4): 255-58 (August 1972).

Wolfenden. A.. "Reply to Comments on "The Energy Stored in Polycrystalline Copper Deformed at Room Temperature' - More Details of the Single-Step Isoperibol Deformation Calorimeter," Scripta Met. 6(10): 903-8 (October 1972).

Wolfenden, A., and K. Farrell, "Reply to "Comments on "On the Question of Void Formation in Neutron Irradiated Zirconium," " Scripta Met. 7(1): 41 (January 1973).

Yoo, M. H., and S. M. Ohr, "Elastic Interaction of a Point Defect with a Prismatic Dislocation Loop in Hexagonal Crystals," J. Appl Phys. 43(11): 4477-82 (November 1972).

Yust, C. S., and C. J. McHargue, "Model for the Deformation of Hyperstoichiometric $\mathrm{UO}_{2}$,"J. Amer. Ceram. Soc. 56(3): 161-64 (March 1973). 


\section{PATENTS}

Beatty, R. L., and D. V. Kiplinger, Pulsed Method for Impregnation of Graphite (to U.S. Atomic Energy Commision) U.S. Patent 3,664,859. May 23, 1972.

Binkley, N. C., and J. P. Hammond, Bonding Tungsten with a Fugitive Alloy Binder (to U.S. Atomic Energy Commission) U.S. Patent 3,707,763. Jan. 2, 1973.

Cannon, D. D., F. J. Furman, Jr., and F. C. Davis, Fabrication of Bonded-Particle Nuclear Fuel Sticks (to U.S. Atomic Energy Commission) U.S. Patent 3,714,305. Jan. 30, 1973.

Canonico, D. A., N. C. Cole, and C. W. Houck, Method for Brazing Graphite and Other Refractory Materials (to U.S. Atomic Energy Commission) U.S. Patent 3,673,038. June 27, 1972.

Hammond, J. P., Method for Diffusion Bonding Refractory Metals and Alloys (to U.S. Atomic Energy Commission) U.S. Patent 3,714,702. Feb. 6, 1973.

Knight, R. W., M. M. Martin, and W. R. Martin, Gradient-Type Nuclear Fuel Plate (to U.S. Atomic Energy Commission) U.S. Patent 3,697,374. Oct. 10, 1972.

Leitnaker, J. M., and K. E. Spear, Stabilized Uranium or Uranium-Plutonium Nitride Fuel (to U.S. Atomic Energy Commission) U.S. Patent 3,708,433. Jan. 2, 1973.

Lindemer, T. B., and R. A. Bradley, Method for Reducing the Oxygen in Certain Actinide Oxides to Less than Stoichiometric Level (to U.S. Atomic Energy Commission) U.S. Patent 3,717,582. Feb. 20, 1973.

Liu, C. T., and H. Inouye, Novel Platinum-Rhodium-Tungsten Alloy (to U.S. Atomic Energy Commission) U.S. Patent 3,737,309. June 5, 1973.

Pechin, W. H., R. A. Bradley, and J. D. Sease, Nuclear Fuel Having Minimum-Gas-Release Properties (to U.S. Atomic Energy Commission) U.S. Patent 3,689,428. Sept. 5, 1972.

Reimann, G. A., and W. R. Martin, Process for Producing a Fine-Grained 316 Stainless Steel Tubing Containing a Uniformly Distributed Intergranular Carbide Phase (to U.S. Atomic Energy Commission) U.S. Patent 3,723, 193. Mar. 27, 1973.

Sease, J. D., and F. E. Harrington, Method of Vibratory Loading Nuclear Fuel Elements (to U.S. Atomic Energy Commission) U.S. Patent 3,683,975. Aug. 15, 1972.

Werner, W. J., Fluxless Aluminum Brazing Composition (to U.S. Atomic Energy Commission) U.S. Patent 3,697,259. Oct. 10, 1972.

Whaley, H. L., and Laszlo Adler, Ultrasonic Flaw Determination by Spectral Analysis (to U.S. Atomic Energy Commission) U.S. Patent 3,662,589. May 16, 1972. 


\section{Author Index}

Abraham, M. M., 2,3

Adamson, G. M., 87

Anderson, J. W., 66, 74

Arsenault, R. J., 35

Bates, J. B., 34

Beaver, R. J., 63

Berggren, R. G., 60

Bernal, J., 17

Betterton, J. O., 24

Bloom, E. E., 11, 82

Boatner, L. A., 3

Borie, B. S., 32, 34

Bradley, R. A., 69

Brynestad, J., 15, 16

Butler, W. H., 28, 29

Campbell, J. J., 26

Canonico, D. A., 59, 60, 61, 97

Carlson, P. T., 7, 8, 9

Carpenter, R. W., 4, 18, 45

Cathcart, J. V., 26

Cavin, O. B., 36

Chandler, J. M., 67

Chapman, A. T., 15

Clark, G. W., 1, 2, 3, 15

Clausing, R. E., 29, 64, 98, 99

Coghlan, W. A., 7, 23, 29

Cole, N. C., 65

Conlin, J. A., 54

Coobs, J. H., 49, 54

Cook, W. H., 65

Copeland, G. L., 12

Dahlgren, S., 24

Davis, F.C., 67

DeVan, J.H., 83

DiStefano, J. R., 39, 65

Dodd, C. V., 86

Donnelly, R. G., 37, 39, 41, 45, 46
DuBose, C.K. H., 12

Dworkin, A.S., 16

Easton, D. S., 24, 25, 98, 99

Eatherly, W. P., 51, 65, 89, 91

Edelstein, N., 3

Erwin, J. H., 37

Farrell, K., 10, 11, 12, 14, 77, 78, 82

Faulkner, J. S., 28

Federer, J. I., 41, 43

Finch, C. B., 2, 3

Fitton, B., 29

Fitts, R. B., 54, 57, 71, 72

Fromhold, A. T., Jr., 29

Frye, J. H, Jr., 24

Gehlbach, R. E., 64

Godfrey, T. G., 19, 20

Graves, R. S., 19, 21,85

Gray, R. J., 87, 93

Hamner, R. L., 51

Harris, L. A., 36

Hedger, H. J., 7

Heitkamp, D., 9

Hendricks, R. W., 34, 35

Hewette, D. M. II, 54

Hill, Meredith R., 105

Homan, F. J., 52, 71, 74, 75

Inouye, H., 37, 38, 45, 46, 47

Jeffers, Brenda S., 100

Jostsons, A., 11, 12, 77, 78

Jury, S. H., 19

Kennedy, C. R., 65, 91

King, R. T., 10, 77, 78

Knight, R. W., 42, 77, 79, 80 
Koch, C. C., 23, 24, 25

Koger, J. W., 64, 65

Kolbe, W., 3

Kollie, T. G., 19, 20, 21

Kopp, O. C., 3

Kroeger, D. M., 23, 24, 25

Lackey, W. J., 67

Leitnaker, J. M., 11

Leslie, B. C., 95, 97

Liu, C. T., 4, 13, 26, 37, 38, 45, 46

Lloyd, J. M., 28

Loh, B. T. M., 12, 13

Long, E. L., Jr., 46, 54, 57, 71, 72, 77

Lotts, A. L., 66, 84

Lundy, T. S., 7, 8

Manley, L C, Jr., 9

Marples, J. A. C., 24

McCoy, H. E., Jr., 46, 64

McDonald, R. E., 41

McElroy, D. L., 19, 21, 51

McGuire, G. E., 99

McHargue, C. J., 81

McNabb, B., Jr., 64

Montgomery, B. H., 54

Moore, J. P., 19, 20, 21

Moorhead, A. J., 65

Nickel, Bernie J., 28

Ogle, J.C., 17, 18, 36

Oliver, B. F., 1, 2

Olsen, A. R., 72

Olstad, R. A., 52, 71, 72

Padgett, R. A., Jr., 8

Painter, G. S., 29, 30

Papatheodorou, G. N., 16

Pawel, R. E., 8, 26, 27

Pechin, W. H., 67

Perkins, R. A., 8

Petersen, G. F., 26

Peterson, Sigfred, 76

Pickel, T. W., 74

Pollock, C. B., 49, 54, 65

Predmore, R. E., 35
Reese, C. R., 69

Reimann, G. A., 42

Reynolds, R. W., 3

Richt, A. E., 47, 78, 80

Robbins, J M, 51, 54, 89

Roberts, J. T. A., 15

Sanders, C. F., 67, 69

Scarbrough, J. 0., 23

Schaffhauser, A. C., 41, 46, 65

Scott, J. L., 54, 74

Sease, J. D., 66, 67, 74

Shaffer, L. B., 34, 35

Silverman, M. D., 49

Simpson, W. A., Jr., 86

Smith, G. P., 15, 16

Snider, J. W., 74

Sparks, C. J., Jr., 35, 36

Steele, R. M., 32

Stelzman, W. J., 59, 60

Stiegler, J. O., 10, 11, 82

Tunali, N. K., 8

Turner, T. J., 15

Van Cleve, J. E., Jr., 67, 84, 85

Vandermeer, R. A., 17, 18

von Winbush, S., 16

Washburn, T. N., 78

Weir, J. R., Jr., 64

Wiffen, F. W., 46, 81

Williams, G. P., 15

Williams, L. C., 84, 85

Williams, R. K., 19, 21, 46, 85

Williams, R. O., 4

Willis, R. F., 29

Wilson, J. C., 1, 2, 15

Wolfenden, A., 10, 11, 12, 13, 82

Woods, J. W., 78

Yakel, H. L., 16, 32, 33, 34

Yoo, M. H., 12, 30, 31

Yust, C. S., 15 


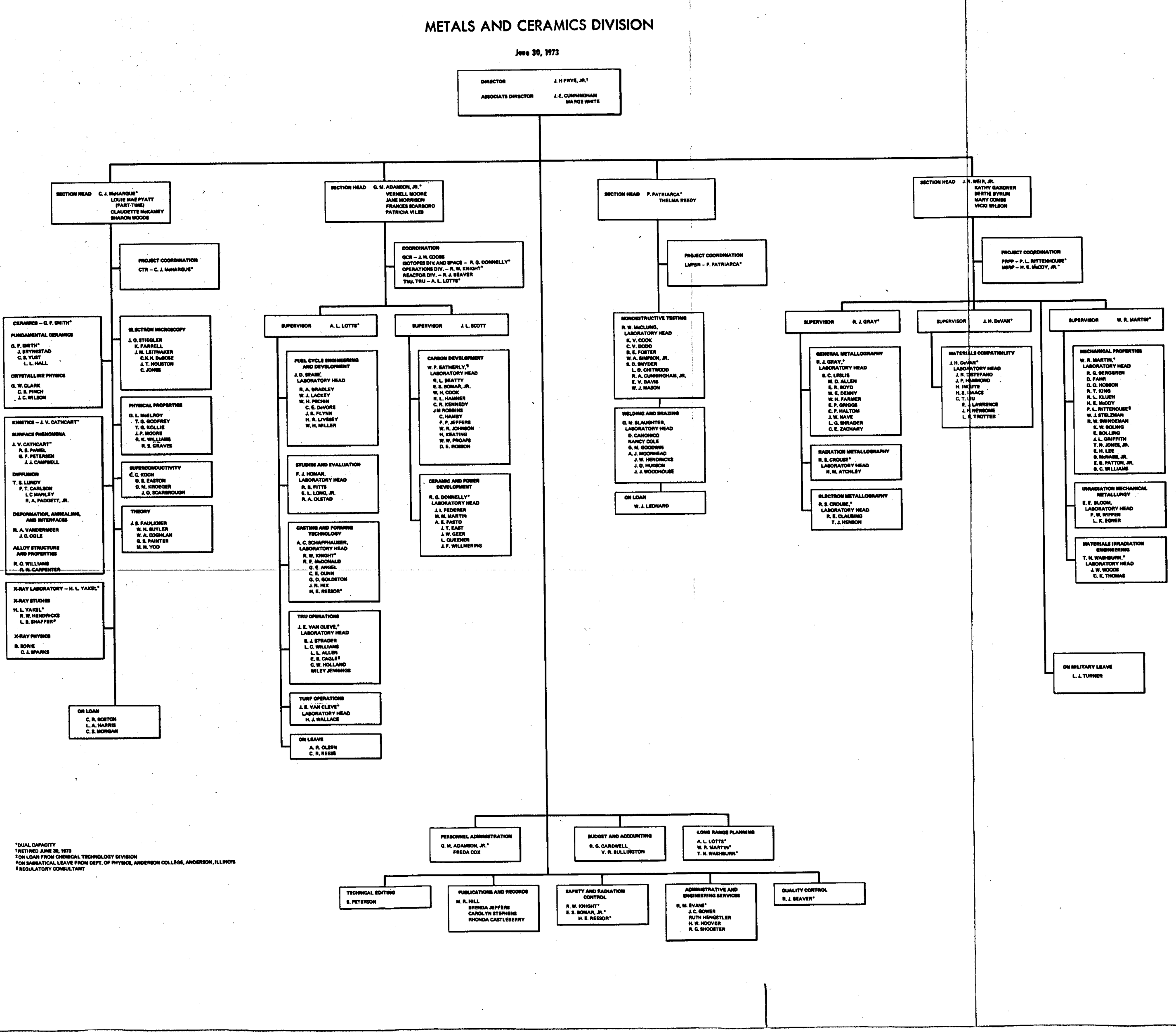



(3) Central Research Library ORNL - Y-12 Technical Library Document Reference Section

(55) Laboratory Records Department Laboratory Records, ORNL R.C. MIT Practice School ORNL Patent Office Laboratory Shift Supervisor M. M. Abraham

G. M. Adamson, Jr. J. W. Anderson H. I. Adler

S. I. Auerbach J. B. Bates

R. L. Beatty

S. E. Beall

R. J. Beaver

M. Bender

L. L. Bennett

R. G. Berggren

D. S. Billington

E. E. Bloom

E. S. Bomar

A. L. Boch

B. S. Borie

C. J. Borkowski

C. R. Boston

R. A. Bradley

R. B. Briggs

W. E. Browning, Jr.

J. Brynestad

F. R. Bruce

W. H. Butler

D. A. Canonico

P. T. Carlson

R. W. Carpenter

J. M. Case (Y-12)

J. V. Cathcart

G. W. Clark

R. E. Clausing

W. A. Coghlan

N. C. Cole

W. C. Colwell

J. A. Conlin
J. H. Coobs

K. V. Cook

W. H. Cook

G. L. Copeland (K-25)

L. T. Corbin

W. B. Cottrell

J. A. Cox

R. S. Crouse

F. L. Culler

J. E. Cunningham

F. C. Davis

J. H. DeVan

J. R. DiStefano

C. V. Dodd

R. G. Donnelly

D. S. Easton

W. P. Eatherly

E. C. Evans (K-25)

K. Farrell

J. S. Faulkner

J. I. Federer

D. E. Ferguson

C. B. Finch

R. B. Fitts

B. E. Foster

A. P. Fraas

J. H. Gillette

T. G. Godfrey

G. M. Goodwin

R. J. Gray

W. L. Greenstreet

J. P. Hammond

R. L. Hamner

W. O. Harms

L. A. Harris

H. J. Hedger

R. F. Hibbs

(25) M. R. Hill

R. W. Hendricks

D. O. Hobson

F. J. Homan

A. P. Huber (K-25)

H. Inouye

H. S. Isaacs 
R. G. Jordan (K-25)

P. R. Kasten

S. I. Kaplan

C. R. Kennedy

E. M. King

R. T. King

R. L. Klueh

R. W. Knight

C. C. Koch

J. W. Koger (Y-12)

T. G. Kollie

D. M. Kroeger

W. J. Lackey

J. M. Leitnaker

W. J. Leonard

B. C. Leslie

C. T. Liu

R. S. Livingston

E. L. Long, Jr.

A. L. Lotts

T. S. Lundy

M. M. Martin

W. R. Martin

C. L. Matthews

R. W. McClung

H. E. McCoy

H. C. McCurdy

R. E. McDonald

H. F. McDuffie

D. L. McElroy

C. J. McHargue

R. A. McNees

B. H. Montgomery

J. P. Moore

A. J. Moorhead

C. S. Morgan

F. H. Neill

L. C. Oakes

J. C. Ogle

R. A. Olstad

G. S. Painter

(2) R. B. Parker
A. E. Pasto
P. Patriarca
R. E. Pawel
W. H. Pechin
G. F. Petersen
S. Peterson
T. W. Pickel

C. B. Pollock (Y-12)

H. Postma

P. L. Rittenhouse

J M Robbins

M. W. Rosenthal

A. C. Schaffhauser

J. L. Scott

H. E. Seagren

J. D. Sease

S. Siegel

W. A. Simpson, Jr.

G. M. Slaughter

G. P. Smith, Jr.

J. W. Snider

S. D. Snyder

C. J. Sparks, Jr.

D. Steiner

W. J. Stelzman

R. L. Stephenson

J. O. Stiegler

D. A. Sundberg

R.W. Swindeman

J. R. Totter

D. B. Trauger

J. E. Van Cleve, Jr.

R. A. Vandermeer

P. R. Vanstrum (Y-12)

T. N. Washburn

A. M. Weinberg

J. R. Weir, Jr.

J. C. White

G. D. Whitman

F. W. Wiffen

W. J. Wilcox, Jr.

M. K. Wilkinson

R. K. Williams

R. O. Williams

J. W. Woods

R. G. Wymer

W. J. Yaggi (Y-12)

H. L. Yakel, Jr.

M. H. Yoo

F. W. Young, Jr.

C. S. Yust

A. Zucker

Leo Brewer (consultant)

Walter Kohn (consultant)

G. V. Smith (consultant)

W. S. Williams (consultant) 
EXTERNAL DISTRIBUTION

(326 copies)

J. J. Flaherty, Assistant General Manager, AEC, Washington, DC 20545

(5) Executive Secretary, Advisory Committee on Reactor Safeguards, AEC, Washington, DC 20545

Division of Applied Technology, AEC, Washington, DC 20545

G. W. Johnson, Director

E. E. Fowler

J. C. Bresee

Division of Controlled Thermonuclear Research, AEC, Washington, DC 20545

R. L. Hirsch, Director

W. C. Gough

Division of Military Applications, AEC, Washington, DC 20545

Major General Frank A. Camm (USAF), Director

Division of Naval Reactors, AEC, Washington, DC 20545

R. H. Steele

Division of Physical Research, AEC, Washington, DC 20545

J. M. Teem, Director

L. C. Ianniello

D. K. Stevens

Division of Reactor Research and Technology, AEC, Washington, DC 20545

T. A. Nemzek, Director

G. M. Anderson

LTC H. L. Arnold

J. W. Crawford, Jr.

G. W. Cunningham

R. P. Denise

N. Grossman

P. A. Halpine

W. H. Hannum

P. L. Havenstein

K. E. Horton

J. R. Hunter

E. E. Kintner

R. E. Kosiba

E. C. Kovacic

W. H. Layman

J. E. McEwen

T. W. McIntosh

W. H. McVey

J. J. Morabito

R. E. Pahler

D. E. Pollock

A. J. Pressesky

D. R. Riley

M. A. Rosen

F. A. Ross

(4) J.M. Simmons

E. E. Sinclair

J. F. Smith, Jr.

S. A. Szawlewicz 

A. N. Tardiff
C. E. Weber
G. W. Wensch
M. J. Whitman
W. A. Williams, Jr.
J. G. Yevick

Division of Reactor Safety Research, AEC, Washington, DC 20545

H. J. C. Kouts, Director

Division of Space Nuclear Systems, AEC, Washington, DC 20545

D. S. Gabriel, Director

G. P. Dix

N. Goldenberg

H. Jaffe

C. E. Johnson, Jr.

A. P. Litman

J. J. Lombardo

G. A. Newby

F. C. Schwenk

C. O. Tarr

Division of Waste Management and Transportation, AEC, Washington, DC 20545

F. K. Pittman

National Aeronautics and Space Administration, 1520 H Street, Washington, DC 20546

R. R. Nash

NASA, Lewis Research Center, 21000 Brookpark Road, Cleveland, OH 44135

G. M. Ault

National Science Foundation, 1800 G Street, NW, Washington, DC 20550

E. C. Creutz

P. G. Shewmon

R. J. Reynik

Office of Regulation, AEC, Washington, DC 20545

L. Manning Muntzing, Director

J. M. Chandler

Richard Cunningham

A. Giambusso

S. H. Hanauer

J. M. Hendrie

A. R. Olsen

J. A. Powers

L. R. Rogers

Lazlo Adler, 4206 Taliluna Ave., Knoxville, TN 27919

Lida K. Barrett, 7100 Downing Drive, Knoxville, TN 37919

J. O. Betterton, Dept. of Physics, Louisiana State University, New Orleans, LA 70100

H. M. Burte, Chief, Metals and Ceramics Div., Air Force Materials Laboratory, Wright-Patterson AFB, OH 45433

W. T. Case, Mound Laboratory, P. O. Box 32, Miamisburg, OH 45342

A. T. Chapman, School of Ceramics Engineering, Georgia Institute of Technology, Atlanta, GA 30332

William Cooper, Teledyne Materials Research Corp., 303 Bare Hill Road, Waltham, MA 02154

D. F. Cope, RDT, SSR, AEC, Oak Ridge National Laboratory

S. Dahlgren, Pacific Northwest Laboratory, P. O. Box 999, Richland, WA 99352

N. Edelstein, Lawrence Livermore Laboratory, P. O. Box 808, Livermore, CA 94550

J. H Frye, Jr., Dept. of Chemical and Metallurgical Engineering, College of Engineering, University of Alabama,

P. O. Box 1968, University, AL 35486

R. M. Goldhoff, Metallurgy Applied Research, General Electric Company, One River Road, Schenectady, NY 12305 
Claude Good, U.S. Bureau of Mines, Pittsburgh Mining and Safety Research Center, 4800 Forbes Ave., Pittsburgh, PA 15213

F. B. Gurtner, U.S. Army Edgewood Arsenal, Edgewood Arsenal, MD 21010

-

A. Jostsons, Materials Division, AAEC Research Establishment, Private Mail Bag, Sutherland, NSW 2232, Australia

J. H. Jury, Dept. of Chemical and Metallurgical Engineering, University of Tennessee, Knoxville, TN 37916

W. Kolbe, Lawrence Livermore Laboratory, P. O. Box 808, Livermore, CA 94550

O. C. Kopp, Dept. of Geology and Geography, University of Tennessee, Knoxville, TN 37916

Jan Korringa, Dept. of Physics, Ohio State University, 174 West 18 th Ave., Columbus, OH 43210

J. R. Lane, National Materials Advisory Board, National Research Council, 2101 Constitution Ave., Washington, DC 20418

W. D. Manly, Stellite Division, Cabot Corp., 1020 Park Ave., Kokomo, IN 46901

J. A. C. Marples, Process Technology Division, Atomic Energy Research Establishment, Harwell, Bldg. 220, Didcot, Berkshire, UK

Col. W. A. Martin, Air Force Office of Scientific Research, 1400 Wilson Boulevard, Arlington, VA 22209

W. J. O’Donnell, President, O'Donnell and Associates, Inc., 5100 Centre Ave., Pittsburgh, PA 15232

B. F. Oliver, 4211 Holston Hills Road, Knoxville, TN 37914

R. A. Perkins, Globe-Union, Inc., 5757 North Green Bay Ave., Milwaukee, WI 53201

N. E. Promisel, National Materials Advisory Board, National Research Council, 2101 Constitution Ave., Washington, DC 20418

G. A. Reimann, Aerojet Nuclear Company, P. O. Box 1845, Idaho Falls, ID 83401

A. E. Richt, Union Carbide Corp., South Charleston, WV 25303

David Roberts, Gulf General Atomic, Inc., P. O. Box 81608, San Diego, CA 92138

J. T. A. Roberts, Argonne National Laboratory, 9700 South Cass Ave., Argonne, IL 60439

Chester Sims, Materials Processing Laboratory, General Electric Company, One River Road, Schenectady, NY 12305

Richard Slember, Advanced Reactors Division, Westinghouse Electric Corp., P. O. Box 158, Madison, PA 15663

J. E. Spruiell, Dept. of Chemical and Metallurgical Engineering, University of Tennessee, Knoxville, TN 37916

E. E. Stansbury, Dept. of Chemical and Metallurgical Engineering, University of Tennessee, Knoxville, TN 37916

Alan Wolfenden, Physics and Engineering Laboratory, Private Bag, Lower Hutt, New Zealand

Ling Yang, Gulf General Atomic, P. O. Box 81608, San Diego, CA 92138

Research and Technical Support Division, AEC, ORO

Patent Office, AEC, ORO

(203) Given distribution as shown in TID-4500 under Materials category (25 copies - NTIS) 